\title{
Effects of Ingredients on Cigarette Smoke Composition and Biological Activity: A Literature Overview*
}

by

\author{
Thilo Paschke ${ }^{1,2}$, Gerhard Scherer ${ }^{3}$ and Wolf-Dieter Heller ${ }^{I}$ \\ ${ }^{I}$ Verband der Cigarettenindustrie, Scientific Department, Berlin, Germany \\ ${ }^{2}$ Present address: Japan Tobacco International, Geneva, Switzerland \\ ${ }^{3}$ Analytisch Biologisches Forschungslabor GmbH, ABF, München, Germany
}

\section{CONTENTS}

Summary . . . . . . . . . . . . . . . . . . . . . 107

Introduction . . . . . . . . . . . . . . . . . . . . . 108

Function of Ingredients . . . . . . . . . . . . . . 109

Materials and Methods . . . . . . . . . . . . . . . . . . . 109

Results ... . . . . . . . . . . . . . . . . . . . . . . 109

Concluding Remarks . . . . . . . . . . . . 111

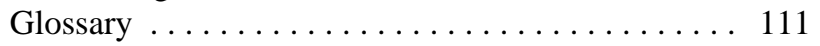

References ................... 112

Appendix. Tables 2 to 7: Evaluation of ingredients . 119

Table 2. Overview of ingredients mentioned

in the literature . . . . . . . . . . . . . . . . . 119

Table 3. Influence of ingredients on the chemical composition of cigarette mainstream smoke: single substances . . . . . . . . . . . . . . . . . . . 144

Table 4. Influence of ingredients on the chemical composition of cigarette mainstream smoke: mixtures

Table 5. Pyrolysis experiments with tobacco ingredients . ................ 226

Table 6. Biological activity of ingredients used on cigarette tobacco . . . . . . . . . . . . . . . . . . 242

Table 7. Biological activity of experimental ingredients

\section{SUMMARY}

This paper presents a literature review of published scientific studies of the effects of tobacco product ingredients and various experimental additives on cigarette smoke composition and its biological activity. The format of this work is that of an uncommented reference paper rather than a critical scientific review. Therefore, the mention of an ingredient in this survey does not imply that it is used by the tobacco industry or that it is covered by any existing na- tional regulations. A broad range of scientific papers and patents on tobacco ingredients is included as well as studies on experimental ingredients.

This review may provide public health officials as well as scientists in government agencies and in the tobacco industry with a helpful overview of published information on tobacco product ingredients, their transfer into mainstream cigarette smoke, pyrolysis products, and influence on the biological activity of mainstream cigarette smoke. [Beitr. Tabakforsch. Int. 20 (2002) 107-247]

\section{ZUSAMMENFASSUNG}

Bei der vorliegenden Publikation handelt es sich um eine Literaturübersicht über publizierte wissenschaftliche Studien, die die Auswirkungen von gebräuchlichen Zusatzstoffen und auch von verschiedenen experimentellen Additiven zu Cigaretten auf die chemische Zusammensetzung oder auf die biologische Aktivität des Rauches untersucht haben. Da das Format dieser Arbeit eher das einer unkommentierten Zusammenstellung publizierter Daten als das eines kritischen Übersichtsartikels ist, soll an dieser Stelle darauf hingewiesen werden, dass die Erwähnung eines Zusatzstoffes nicht bedeutet, dass er von der Tabakindustrie verwendet oder dass er durch irgendeine nationale Regulierung erfasst wird. Neben einer Vielzahl von wissenschaftlichen Publikationen und Patenten über verwendete Zusatzstoffe wurden auch Daten aus zahlreichen Studien über experimentelle Zusatzstoffe aufgenommen.

Das Ziel dieses Reviews ist, sowohl den Gesundheitsbehörden als auch Wissenschaftlern in Regierungseinrichtungen und in der Tabakindustrie einen schnellen Überblick über publizierte Informationen zu Additiven, ihren Übergang in den Hauptstromrauch, ihre Pyrolyse und auch ihren Einfluss auf die biologische Aktivität des Hauptstromrauches zu geben. [Beitr. Tabakforsch. Int. 20 (2002) 107-247] 


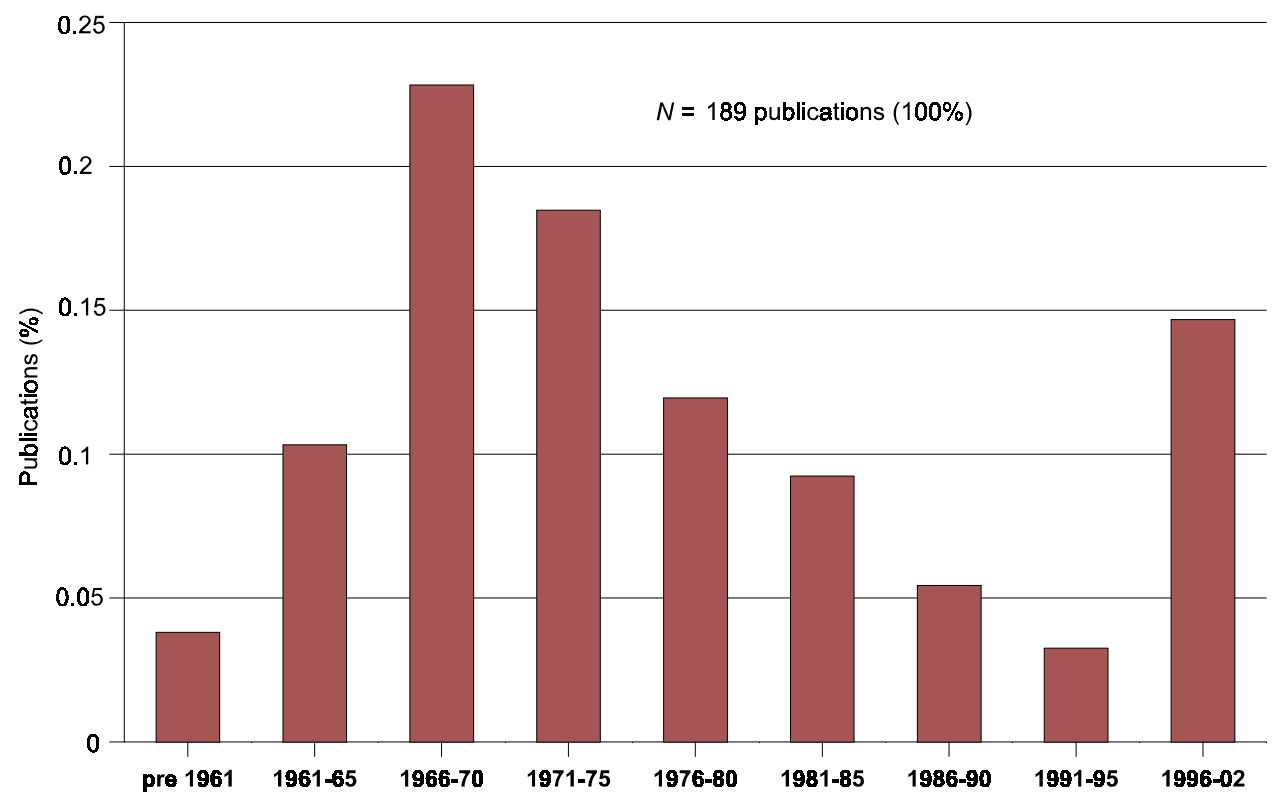

Figure 1. Temporal distribution of publications dealing with additives

\section{RESUME}

Cette étude est une revue de la littérature scientifique sur les effets des composants des produits du tabac et de divers additifs expérimentaux sur la composition de la fumée du tabac et de son activité biologique. Cette étude est présentée sous forme d'une liste de références non commentées plutôt que d'une revue scientifique critique. Pour cette raison, la mention dans cette revue d'un composant ne signifie pas qu'il est apporté au tabac ou qu'il fait l'objet d'une réglementation nationale. Cette revue examine une vaste gamme de publications scientifiques et brevets sur les composants des produits du tabac et des études sur les additifs expérimentaux.

Cette revue peut donc fournir aux autorités de la santé publique, ainsi qu'aux chercheurs des institutions gouvernementales et de l'industrie du tabac, un bref aperçu des informations publiées sur les composants des produits du tabac, leur transfert dans la fumée du courant principal, leurs produits de pyrolyse et leur influence sur l'activité biologique de la fumée du courant principal. [Beitr. Tabakforsch. Int. 20 (2002) 107-247]

\section{INTRODUCTION}

The use of certain additives, in particular the use of those claimed to enhance nicotine delivery to smokers, has been subject to extensive debate (Action on Smoking and Health [ASH] 1999, Müller and Röper 2000). Although most substances employed as additives in cigarette manufacture are "generally recognised as safe" (GRAS) for use in foods and/or listed on the Flavour and Extract Manufactures Association's (FEMA) GRAS list, they may yield unknown pyrolysis products on combustion if used in to- bacco products. The fact that an ingredient is GRAS does not mean that it is safe, or has been approved for use, in tobacco products.

Nowadays, different forms of regulations and disclosures exist in several countries of the European Union (e.g., France, the United Kingdom and Germany) as well as in the United States (list of 599 ingredients [TR Staff Report, 1994]), which control the use of ingredients for the manufacture of tobacco products.

In a directive of the European Parliament and of the Council concerning the manufacture, presentation and sale of tobacco products, an ingredient is defined as "any substance except for tobacco leaf and other natural or unprocessed tobacco plant parts used in the manufacture and preparation of a tobacco product and still present in the finished product, even if in altered form, including paper, filter, inks and adhesives" (EU-Directive 2001/37/EC, Article 2 (5)).

This literature review was compiled to provide an overview of the published data concerning the effects of ingredients on smoke composition and its biological activity. More than 10,000 literature search hits were evaluated for their relevance for inclusion in this review according to the criteria defined in the section "Materials and Methods". The 189 reports thus selected form the basis for the evaluation of the ingredients in Tables 2 to 7 (see Appendix). This literature can be divided into two categories: The major part of the published literature is concerned with the chemical identification and detection of the pyrolysis products of tobacco ingredients (Tables 3 to 5), while Tables 6 and 7 deal with studies evaluating toxicological aspects of the burned ingredients. In general, it can be seen that many papers on the topic of ingredients were published between 1965 and 1975, after which the frequency of publications gradually dropped and only increased again from 1995 onwards (see Figure 1). 
Table 1. Classification of ingredients and their functions

\begin{tabular}{|c|c|c|}
\hline Ingredient & Classification & Function \\
\hline $\begin{array}{l}\text { Flavourings, } \\
\text { casings }\end{array}$ & 1 & $\begin{array}{l}\text { Improvement of } \\
\text { organoleptic properties }\end{array}$ \\
\hline Humectants & 2 & $\begin{array}{l}\text { Improvement of moisture } \\
\text { retention and elasticity of } \\
\text { the leaf }\end{array}$ \\
\hline Burn additives & 3 & $\begin{array}{l}\text { Improvement of ash } \\
\text { appearance, whiteness and } \\
\text { burn uniformity }\end{array}$ \\
\hline Plasticisers & 4 & $\begin{array}{l}\text { For printing of colours on } \\
\text { cigarette papers, cigarette } \\
\text { filter wrappers, tips and filter } \\
\text { tips }\end{array}$ \\
\hline $\begin{array}{l}\text { Preservatives, } \\
\text { stabilisers }\end{array}$ & 5 & $\begin{array}{l}\text { Improvement of product } \\
\text { shelf life }\end{array}$ \\
\hline $\begin{array}{l}\text { Adhesives, } \\
\text { thickening } \\
\text { agents, fillers }\end{array}$ & 6 & $\begin{array}{l}\text { Needed for the seam, the } \\
\text { plug wraps, the tips and } \\
\text { filter tippings, and for } \\
\text { reconstituted tobacco sheet }\end{array}$ \\
\hline Dyes & 7 & $\begin{array}{l}\text { Needed for imprints on } \\
\text { cigarette paper or paper for } \\
\text { tips and filter tips }\end{array}$ \\
\hline $\begin{array}{l}\text { Processing aids, } \\
\text { solvents }\end{array}$ & 8 & $\begin{array}{l}\text { Auxiliary materials for the } \\
\text { manufacturing process }\end{array}$ \\
\hline $\begin{array}{l}\text { Experimental } \\
\text { additives }\end{array}$ & 9 & $\begin{array}{l}\text { Not known to be used as } \\
\text { ingredients on cigarette } \\
\text { tobacco }\end{array}$ \\
\hline
\end{tabular}

\section{FUNCTION OF INGREDIENTS}

Although the tobacco leaf is primarily responsible for the taste and flavour of tobacco smoke, certain ingredients when combined in a unique, proprietary manner, provide each brand with its own unique flavour, taste and aroma (Gutcho, 1972). About three decades ago, LEFFINGWELL et al. (1972) reviewed the use of flavouring components in smoking products.

The classification used in terms of the function of the ingredients is shown in Table 1. All ingredients dealt with in this review were assigned to one or more of these nine classes (Table 2). The approach taken is meant to be informative and pragmatic rather than authoritative.

\section{MATERIALS AND METHODS}

\section{Literature search}

A wide search algorithm was used which included the terms "flavo(u)r", "additive", "aroma", "cigarette", "smoking" or "tobacco" as well as the names of individual substances covered for example by the German Tobacco Ordinance (Tabakverordnung No. 360, German TVO) or contained in the list of 599 ingredients for use in the manufacture of cigarettes sold in the USA submitted to the US Department of Health and Human Services (TR Staff Report, 1994). This search algorithm was used to examine:

a) In-house databases

b) Medical databases such as Medline, Embase, Somed and Biotechnobase c) Toxicological databases such as Toxline and Toxcas

d) Chemical database clusters such as Analytical Chemistry and Chemical Engineering (which also contains Chemical Abstracts and patents).

Using the above search algorithm, over 10,000 hits for research papers, reports and patents were obtained. Information provided in patents and research papers has to be treated with caution since this does not necessarily imply use by the tobacco industry.

\section{Inclusion criteria}

Only those publications were considered in which the influence of the ingredients applied to tobacco on the properties and composition of the mainstream smoke was investigated. Also included were studies which investigated the pyrolysis products of ingredients or mixtures of ingredients. Papers that analysed ingredients in unpyrolysed form were not included, such as those used in quality control to determine the stability of an ingredient during cigarette storage. Studies concerned with new filter technologies or those dealing with filter materials such as cellulose acetate or non-volatile compounds and salts added in the filter were not included because these substances are not expected to appear in mainstream smoke. Publications reporting the effect of ingredients only on the burn characteristics of tobacco and changes only in the organoleptic properties of tobacco smoke were also excluded.

For studies reporting toxicological effects of ingredients, an additional selection criterion was used. Publications which analysed only the toxicological effects of ingredients (in unchanged or pyrolysed form) independently of their application to tobacco were not considered.

\section{RESULTS}

All ingredients covered in this review are listed in alphabetical order in Table 2, which can be used as an index. The entries in columns 3 to 6 of Table 2 indicate whether the ingredient was investigated as a single compound (S) or in a mixture (M 1 - M 65). Experimental additives are marked with grey shading.

For each individual ingredient, the following information is provided: Function, as classified in Table 1; data in mainstream smoke (Tables 3 and 4); pyrolysis data (Table 5 ); data of biological activity in mainstream smoke (Tables 6 and 7).

\section{Mainstream smoke}

Table 3 contains information on the influence of ingredients on the chemical composition of cigarette mainstream smoke.

More than 150 different ingredients are cited and alphabetically listed. The reported ingredients have been applied either to the tobacco filler, the finished product, to the cigarette paper, or used as components in the manufacture of reconstituted tobacco sheets. The column "Amount" contains information on the amount of ingredients in the relevant end product. The form in which the ingredients were applied differed widely, depending on the experimen- 
tal design and the materials used. It ranged from spraying ingredient solutions onto the tobacco filler, injection of ingredients into the tobacco rod of cigarettes or impregnating cigarette paper with a solution of ingredients. Whenever possible, transfer data into the smoke are listed, pyrolysis products and their concentrations are registered, or their influence on other mainstream smoke components is stated. Whenever a percentage is given for a smoke component it generally signifies an increase $(\succ)$ or decrease $(\searrow)$ compared to control cigarettes without the ingredient(s).

Based on the structure of Table 3, a further list of mixtures of ingredients is presented (Table 4). Many ingredients are incorporated into cigarettes in the form of mixtures, in many cases as components of reconstituted tobacco.

The evaluated literature revealed 61 different combinations of ingredients as listed in Table 4 and labelled as M 1 M 58, M 62, M 63 and M 64. In this Table, the published data for the combinations of ingredients are listed alphabetically by the author's name. Most of the mixtures (M1 M 59, M 65) are listed with their relevant ingredients in Tables 4, 6 and 7. The composition of mixtures M $60-$ M 64 is not given in detail. The list of ingredients for these mixtures can be found in the original literature or can be extracted from Table 2.

The column "Amount" in Table 4, in contrast to Table 3, does not always give information on the amount of ingredients in the relevant end product. In some cases data in this column refer to the portion of single ingredients within the mixture.

\section{Pyrolysis}

Table 5 summarises the results of pyrolysis experiments performed with tobacco and cigarette ingredients. Furthermore, this table contains information on the experimental pyrolysis conditions used, the percentage of unchanged material in the pyrolysate as well as qualitative and quantitative data on the pyrolysis products formed. The analytical pyrolysis experiments do not predict with certainty which materials will be produced when the ingredient is added to a cigarette and burned, but provide some insight of what may be produced. Table 5 has 161 entries, corresponding to 104 different "single" ingredients.

Since no standardised conditions exist for the investigation of ingredient pyrolysis, most experimental conditions were chosen to simulate the temperature conditions found in a burning cigarette, both during and between puffs. However, the pyrolysis conditions actually used varied widely. The temperature ranged from 50 to $900{ }^{\circ} \mathrm{C}$, with approximately $700{ }^{\circ} \mathrm{C}$ most frequently used. In most investigations, the ingredient (or mixture of ingredients) was pyrolysed without adding any carrier substances. In some studies, the ingredient was mixed with Celite as a carrier (Robb et al., 1964). The duration of pyrolysis was most frequently between 1 and $10 \mathrm{~min}$. Some pyrolysis studies were performed until the test material had disappeared.

\footnotetext{
1“Single" additive does not necessarily mean an individual substance. In many cases extracts from natural products forming complex mixtures were used as an additive.
}

Pyrolytic experiments were performed in streams of air, nitrogen or helium. The gas flows, when given, ranged from $15 \mathrm{~mL} / \mathrm{min}$ to $1.5 \mathrm{~L} / \mathrm{min}$.

It should be mentioned that the investigations of KRÖLLER, a scientist at the former German Federal Health Office (Bundesgesundheitsamt, BGA, which was responsible for the regulation of tobacco ingredients in Germany) contribute the vast majority of the pyrolysis data on tobacco ingredients in Table 5 (KRÖLLER investigated 58 different ingredients constituting about a third of all entries and more than half of all ingredients listed in Table 5).

Data on the percentage of unchanged ingredients in the pyrolysate are scarce. In the first place, data are available for ingredients which are designed to release the desired additive when heated (e.g., Robb et al., 1964; Southwick, 1992). In addition, quantitative data on unchanged ingredients in the pyrolysate (primarily for humectants) are available from the investigations of KRÖLLER (Kröller, 1964b, 1970).

Most of the results of pyrolysis experiments with tobacco ingredients deal with thermal decomposition products, primarily those which are of relevance for the toxicological and flavour properties of the ingredient. KRÖLLER was primarily interested in the assumed toxicological properties of tobacco ingredients when he analysed the pyrolysate for polycyclic aromatic hydrocarbons (PAHs), quinones, phenols and aldehydes. For some constituents, e.g. benzo[a]pyrene $(\mathrm{B}[a] \mathrm{P})$, quantitative data (expressed as $\mu \mathrm{g} / 100 \mathrm{~g}$ ingredient pyrolysed) are available. In a series of pyrolysis experiments, SCHLOTZHAUER investigated primarily monoand polysaccharides as well as amino acids and proteins for their potential to form phenols and aldehydes or $\mathrm{N}$ heterocyclic compounds and nitriles, respectively (Schmeltz et al., 1972; Schlotzhauer et al., 1982, 1986). The remaining studies shown in Table 5 also focussed their attention on the pyrolytic formation of toxic substances from ingredients.

\section{Biological activity}

The literature search identified a total of 37 publications in which the change in biological activity of cigarette smoke due to the application of ingredients was studied (Tables 6 and 7). Table 6 contains publications reporting studies on ingredients which are, or could be, used in the manufacturing process, while Table 7 presents publications on experimental ingredients.

The fact that cigarette smoke itself is biologically active means that a high level of sensitivity is required in the test systems to detect changes in toxicological endpoints. The selected publications used the assays listed in Table 8 to study the effect of ingredients on the biological activity of cigarette smoke or cigarette smoke condensate.

The majority of the ingredients listed in Tables 6 and 7 were systematically investigated for their biological activity in just a few studies (Gaworski et al., 1998, 1999b; Römer et al., 2002; Vanscheeuwijck et al., 2002). In these studies, ingredients were added to cigarettes in different mixtures at realistic concentrations and, where technically possible, also at higher levels. In none of the studies listed in Table 6 was the biological activity of cigarette smoke found to be increased due to application of the ingredient mixtures, 
Table 8. Assays used to determine biological activity of cigarette smoke

\begin{tabular}{|c|c|c|c|}
\hline Assay & Toxicological endpoint & Tested agent & References \\
\hline $\begin{array}{l}\text { Mouse skin-painting } \\
\text { assay }\end{array}$ & Tumorigenicity & $\operatorname{CSC}^{a}$ & $\begin{array}{l}\text { BoCK et al., 1974; ColLINS et al., 1981; DONTENWILL } \\
\text { et al., 1972, 1976; GARGUS et al., 1975; GAWORSKI } \\
\text { et al., 1999a; HALTER and ITO, 1972; HOFFMANN and } \\
\text { WYNDER, 1967, 1968, 1972; NCI Report No. 1, } \\
\text { 1976; No. 3, 1977; No. 4, 1980; RÖMER and } \\
\text { HACKENBERG, 1990; TSO, 1975; WYNDER and } \\
\text { HOFFMANN, 1961, } 1969\end{array}$ \\
\hline Ames assay & Mutagenicity & $\operatorname{CSC}^{a}$ & $\begin{array}{l}\text { KIER et al., 1974; MCCOY and ROSENKRANZ, 1982; } \\
\text { RöMER et al., 2002; SATO et al., 1979; BOMBICK } \\
\text { et al., } 2001\end{array}$ \\
\hline $\begin{array}{l}\text { Inhalation studies using } \\
\text { rodents }\end{array}$ & $\begin{array}{l}\text { Tumorigenicity, other } \\
\text { toxicological endpoints such } \\
\text { as decrease in weight gain, } \\
\text { changes in tissue and cell } \\
\text { properties }\end{array}$ & $\begin{array}{l}\text { Tobacco } \\
\text { smoke }\end{array}$ & $\begin{array}{l}\text { DONTENWILL, 1974; GAWORSKI et al., 1997, 1998, } \\
\text { 1999b; JONES et al., 1972, 1973; VANSCHEEUWIJCK } \\
\text { et al., 2002; MISRA et al., } 2001\end{array}$ \\
\hline $\begin{array}{l}\text { In vivo and in vitro } \\
\text { ciliatoxicity }\end{array}$ & $\begin{array}{l}\text { Ciliostasis, inhibition of } \\
\text { particle clearance }\end{array}$ & $\begin{array}{l}\text { Tobacco } \\
\text { smoke }\end{array}$ & $\begin{array}{l}\text { DALHAMN, 1969; DALHAMN and Rylander, 1971; } \\
\text { NCI Report No. 1, 1976; No. 3, 1977; No. 4, 1980; } \\
\text { RAKIETEN, 1952; RYLANDER, 1971, } 1973\end{array}$ \\
\hline $\begin{array}{l}\text { Cytotoxicity in cell } \\
\text { cultures }\end{array}$ & $\begin{array}{l}\text { Growth inhibition, cell } \\
\text { viability }\end{array}$ & $\operatorname{CSC}^{a}$ & $\begin{array}{l}\text { RÖMER et al., 2002; NCI Report No. 1, 1976; No. 3, } \\
\text { 1977; No. 4, 1980; BOMBICK et al., } 2001\end{array}$ \\
\hline $\begin{array}{l}\text { In vitro macrophage } \\
\text { inhibition assay }\end{array}$ & $\begin{array}{l}\text { Inhibition of macrophage } \\
\text { activity }\end{array}$ & $\begin{array}{l}\text { Tobacco } \\
\text { smoke }\end{array}$ & NCI Report No. 1, 1976 \\
\hline Chemical analysis & Determination of risk indices & $\begin{array}{l}\text { Tobacco } \\
\text { smoke }\end{array}$ & RUSTEMEIER et al., 2002 \\
\hline $\begin{array}{l}\text { Sister-chromatid exchange } \\
\text { in cell cultures }\end{array}$ & Cytogenetic endpoint & $\operatorname{CSC}^{a}$ & BomBick et al., 2001 \\
\hline
\end{tabular}

${ }^{a} \mathrm{CSC}=$ cigarette smoke condensate.

whereas the addition of ingredients under experimental conditions in some cases lead to an increase in biological activity (NCI Report No.1, 1976; No. 3, 1977; Wynder and Hoffmann, 1961; Hoffmann and Wynder, 1968; Kier et al., 1974; McCoy and Rosenkranz, 1982) (Table 7).

A number of ingredients such as cocoa, glycerol, menthol or sugar are used at considerably higher inclusion levels than most flavour additives and have been subject to extensive toxicological testing (NCI Report No. 3, 1977; Römer and Hackenberg, 1990; Gaworski et al., 1997, 1999b; Sato et al., 1979; Carmines, 2002; Römer et al., 2002; Van-scheeuwijck et al., 2002). Except for one study by the National Cancer Institute (NCI Report No. 3, 1977) in which the addition of $1 \%$ cocoa to test cigarettes led to an increase in tumorigenicity of mainstream smoke condensate in the mouse skin painting assay, other studies have shown no increase in biological activity of mainstream cigarette smoke condensate from test cigarettes. The findings of the NCI study could not be confirmed in another study in which addition of $1 \%$ or $3 \%$ cocoa to cigarette tobacco filler did not result in an increase in mainstream smoke condensate tumorigenicity in mouse skin painting assays (Römer and Hackenberg, 1990). The authors explained the contradictory results by the fact that a control group used in the NCI study exhibited an unusually low tumour incidence in comparison with other controls.

Although the results of the NCI study with respect to an increase in tumorigenicity due to the addition of cocoa to cigarettes were not statistically significant (NCI Report No. 3, 1977), the British Government reacted to this publication by prohibiting the addition of cocoa to tobacco products (Glantz, 1996). However, in view of new toxicological data submitted to the UK Independent Scientific Committee on Smoking and Health the prohibition was removed in 1983 and the addition of up to $5 \%$ cocoa allowed in tobacco products (Glantz, 1996).

\section{CONCLUDING REMARKS}

This compilation clearly reveals that experimental investigations on tobacco product ingredients are rather heterogeneous. The majority of ingredients have been evaluated for biological activity and most of these studies clearly indicate that ingredients do not increase the biological activity of cigarettes. It is obvious that a lot of gaps exist in our knowledge on the pyrolysis and potential transfer of tobacco product ingredients to mainstream cigarette smoke. Perhaps the most compelling conclusion from this literature survey is the need for generally accepted (standard) methods for the investigation of tobacco product ingredients and their influence on the properties of mainstream cigarette smoke.

\section{GLOSSARY (Tables 2 to 7)}

$\begin{array}{ll}\mathrm{A} & =\text { abstract } \\ \text { act. } & =\text { activity } \\ \text { aliph. hydrocarb. } & =\text { aliphatic hydrocarbons } \\ \mathrm{B}[a] \mathrm{A} & =\text { benz }[a] \text { anthracene } \\ \mathrm{B}[a] \mathrm{P} & =\text { benzo }[a] \text { pyrene } \\ \mathrm{B}[e] \mathrm{P} & =\text { benzo }[e] \text { pyrene } \\ \mathrm{CA} & =\text { cellulose acetate }\end{array}$




\begin{tabular}{|c|c|}
\hline $\mathrm{CF}$ & $=$ Cambridge filter \\
\hline $\mathrm{CH}$ & $=$ charcoal + cellulose acetate \\
\hline cig. & $=$ cigarette \\
\hline $\mathrm{CMC}$ & $=$ carboxymethyl-cellulose \\
\hline colorim. & $=$ colorimetric \\
\hline cond. & $=$ condition \\
\hline CSC & $=$ cigarette smoke condensate \\
\hline DAP & $=$ diammonium phosphate \\
\hline DNP & $=2,4$-dinitrophenol \\
\hline DPM & $=$ dry particulate matter \\
\hline FF-M & $=$ full flavour menthol \\
\hline FFLT-M & $=$ full flavour low "tar" menthol \\
\hline $\max$ & $=$ maximum \\
\hline $\min$. & $=$ minimum \\
\hline MSS & $=$ mainstream smoke \\
\hline n.d. & $=$ not determined \\
\hline n.r. & $=$ not reported \\
\hline NAB & $=N$-nitrosoanabasine \\
\hline NAT & $=N$-nitrosoanatabine \\
\hline NCI & $=$ National Cancer Institute \\
\hline NDMA & $=N$-nitroso-dimethylamine \\
\hline NFDPM & $=$ nicotine free dry particulate matter \\
\hline NNK & $\begin{aligned}= & 4-(N \text {-methyl- } N \text {-nitrosamino })-1-(3-\text { py- } \\
& \text { ridyl })-1 \text {-butanone }\end{aligned}$ \\
\hline NNN & $=N$-nitrosonornicotine \\
\hline $\mathrm{NO}_{\mathrm{x}}$ & $=$ nitrogen oxides \\
\hline NPYR & $=N$-nitrosopyrrolidine \\
\hline OLL & $=$ oleic, linoleic, linolenic acids \\
\hline $\mathrm{P}$ & $=$ patent \\
\hline PAH & $=$ polycyclic aromatic hydrocarbons \\
\hline PHB & $=$ polybetahydroxy butyric acid \\
\hline PMO & $=$ phenyl-methyl-oxadiazole \\
\hline RT & $=$ reconstituted tobacco \\
\hline SB & $=$ standard blend \\
\hline SEB & $=$ standard experimental blend \\
\hline synth. & $=$ synthetic \\
\hline tot. & $=$ total \\
\hline tot. w-acids & $=$ total weak acids \\
\hline TPM & $=$ total particulate matter \\
\hline ULT-M & $=$ ultra low "tar" menthol \\
\hline$v / v$ & $=$ volume/volume \\
\hline$w / w$ & $=$ weight $/$ weight \\
\hline
\end{tabular}

Acknowledgements: The authors wish to thank their colleagues and coworkers for making many helpful comments and suggestions on various aspects of this review during its preparation. The authors are very grateful to Karin Mauritz and Ulrike Stahlhacke for performing extensive literature searches and especially to Dr. Barbara Boenke for her help and guidance in the final preparation of this manuscript. The authors would also like to acknowledge the important contribution of Dr. Hans-Jochen Erberhardt to an earlier version of this paper.

\section{REFERENCES}

1) Action on smoking and health (ASH), Bates, C., M. Jarvis and G. Connolly: Tobacco additives. Cigarette engineering and nicotine addiction; http://www.ash. org.uk/papers/additives.html (1999)
2) Adams, J.D., S.J. Lee and D. Hoffmann: Carcinogenic agents in cigarette smoke and the influence of nitrate on their formation; Carcinogenesis 5 (1984) 221-223.

3) Aksu, S.: Einige organische Salze als Feuchthaltemittel in Cigaretten; Beitr. Tabakforsch. 5 (1969) 18-19.

4) Alvord, E.T. and S.Z. Cardon: The inhibition of formation of 3,4-benzpyrene in cigarette smoke; Brit. J. Cancer 10 (1956) 498-503.

5) An, H., Y. Shi, L. Huang, G. Feng and J. An: Manufacture of composite material for decreasing tar and filtering poison of cigarette; Chinese Patent No. A24B15/28 (May 1996).

6) Armbrust, B.F.and V.G. Carithers:Tobacco composition; U.S. Patent No. 3,410,276 (Nov. 1968).

7) Van Auken, T.V., H.J. Grubbs and W.R. Johnson, Jr.: Smoking tobacco compositions; U.S. Patent No. 4,177,339 (Dec. 1979).

8) Badgett, C.E. and J.S. Osmalov: Flavor-releasing smoking article and method of making the same; U.S. Patent No. 3,603,319 (Sept. 1971).

9) Baldry, P.J., C.F. Cullis, D. Goring and M.M. Hirschler: The combustion of cigarette paper; Fire and Materials 12 (1988) 25-33.

10) BAT- British-American Tobacco Co. Ltd.: Flavouring tobacco; Research Disclosure 16836 (Apr. 1978) p. 8 .

11) Bavley, A. and E.W. Robb: Rauchwaren und Verfahren, Rauchwaren Aroma zu verleihen; German Patent No. 1517302 (Sept. 1969).

12) Bell, J.H., A.O. Saunders and A.W. Spears: The contribution of tobacco constituents to phenol yield of cigarettes; Tob. Sci. 10 (1966)138-142.

13) Benner, J.F., H.R. Burton and D. Burdick: Temperature-yield profiles of tobacco and tobacco constituents I: Borate-treated and untreated tobacco; Beitr. Tabakforsch. 5 (1969a) 74-79.

14) Benner, J.F., H.R. Burton and D. Burdick: Temperature-yield profiles of tobacco and tobacco constituents: II. Yields of phenol and cresols from untreated and borate-treated cellulose and lignin; Beitr. Tabakforsch. 5 (1969b) 134-139.

15) Bentley, H.R. and J.G. Burgan: Polynuclear hydrocarbons in tobacco and tobacco smoke. Part III. The inhibition of the formation of 3,4-benzopyrene in cigarette smoke; Analyst 85 (1960) 727-730.

16) Biggs, P.J., R.T. Gilbert, K.G. McAdam and B. Natarajan: Smoking article and smoking material therefor; International Patent No. PCT/GB98/01586 (Dec. 1998).

17) Bilimoria, M.H. and M.A. Nisbet: The reducing property of tobacco smoke: 1 . Modified flue-cured tobacco and other smoking products; Beitr. Tabakforsch. 8 (1975) 186-192.

18) Bock, F.G., I. Michelson, I.D.J. Bross and R.L. Priore: Carcinogenic activity of smoke condensate from cigarettes with ammonium sulfamate-treated paper; Cancer 33 (1974) 1010-1016.

19) Bombick, B.R., J.T. Avalos and K.P. Putnam: Comparative studies on the genotoxic and cytotoxic potential of mainstream smoke condensate from men- 
thol and non-menthol cigarettes which burn or primarily heat tobacco; 55th Tobacco Science Research Conference, Program Booklet and Abstracts, Vol. 55, Paper No. 8, 2001, p. 25.

20) Briskin, T.S.: Smokable material and method for preparing same; U.S. Patent No. 4,133,317 (Jan. 1979).

21) Brozinski, M., U. Dölberg and G. Lipp: Untersuchungen über die Verteilung des Menthols auf Tabak, Filter und Rauch von Mentholcigaretten; Beitr. Tabakforsch. 6 (1972) 124-130.

22) Brunnemann, K.D. and L. Posset: Routine high-performance liquid chromatographic method for assessing sorbate in tobacco; J. Chromatography 202 (1980) 494-499.

23) Bryant Jr., H.G., V. Norman and T.B. Williams: Tobacco composition; U.S. Patent No. 4,177,822 (Dec. 1979).

24) Burdick, D., J.F. Benner and H.R. Burton: Thermal decomposition of tobacco IV. Apparent correlations between thermogravimetric data and certain constituents in smoke from chemically-treated tobaccos; Tob. Sci. 13 (1969) 138-141.

25) Burton, H.R.: Thermal analyses of chemically-treated tobacco; Proc. Tob. Health Workshop (1969) 33-37.

26) Burton, H.R. and J.F. Benner: Investigations on the effect of chemical modifiers on tobacco and tobacco smoke; Proceedings of the University of Kentucky, Tobacco and Health Workshop Conference, Lexington, 1972, p. 341-363.

27) Candeli, A., A.J. Lindsey and K. Persaud: Carta di sigarette al sulfammato di ammonio e idrocarburi cancerigeni; Boll. Soc. Ital. Biol. Sper. 36 (1960) 452-454.

28) Carmella, S.G., S.S. Hecht, T.C. Tso and D. Hoffmann: Roles of tobacco cellulose, sugars, and chlorogenic acid as precursors to catechol in cigarette smoke; J. Agric. Food. Chem. 32 (1984) 267-273.

29) Carmines, E.L.: Evaluation of the potential effects of ingredients added to cigarettes. Part 1: Cigarette design, testing approach, and review of results; Food Chem. Toxicol. 40 (2002) 77-91.

30) Carugno, N., S. Rossi and G. Lionetti: Gas-chromatographic determination of the trimethylsilyl derivatives of polyhydric alcohol humectants in tobacco and in tobacco smoke; Beitr. Tabakforsch. 6 (1971) 79-83.

31) Chakraborty, B.B., K.D. Kilburn and R.E. Thornton: Reduction in the concentration of aromatic polycyclic hydrocarbons in cigarette smoke; Chemistry and Industry (1971) p. 672.

32) Chan, G.W., Y. Houminer, H.J. Grubbs, K.F. Podraza and E.B. Sanders: Smoking compositions containing a vanillin-release additive; European Patent No. EP 0510817 A1 (Oct. 1992).

33) Cheng, A.L.S.: Sterol content in cigarette tobacco and smoke; Beitr. Tabakforsch. 7 (1973) 14-17.

34) Chung H.L. and J.C. Aldridge: Thermal study of licorice by online thermogravimetry/gas chromatography/mass spectrometry; 53rd Tobacco Science Research Conference Montréal, Canada, Program
Booklet and Abstracts, Vol. 53, Poster No. 7, 1999, p. 23.

35) Collins, P.F., H.G. Bryant, Jr., and J.O. Pullman: Tobacco composition including palladium; U.S. Patent No. 4,257,430 (March 1981).

36) Cook, C.J., J.H. Lauterbach, W.T. Pannell, B.F. Price and W.M. Bowser: Transfer rate studies on cigarettes of various designs; 53rd Tobacco Science Research Conference Montréal, Canada, Program Booklet and Abstracts, Vol. 53, Paper No. 90, 1999.

37) Cox, R.H., H.J. Grubbs and S.A. Haut: Smoking compositions containing a glycosylamine flavorant additive; U.S. Patent No. 4,638,816 (Jan. 1987).

38) Crosthwaite, L., S.J. Sheen and H.R. Burton: Alkylating activity in the extract and pyrolyzate of tobacco leaves varying in genotype and chemical treatment; Tob. Sci. 23 (1979) 35-37.

39) Cullis, C.F., Hirschler, M.M., Townsend, R.P. and V. Visanuvimol: The combustion of cellulose under conditions of rapid heating; Combustion Flame 49 (1983a) 249-254.

40) Cullis, C.F., Hirschler, M.M., Townsend, R.P. and V. Visanuvimol: The pyrolysis of cellulose under conditions of rapid heating; Combusition Flame 49 (1983b) 235-248.

41) Curran, J.G.: Delivery of menthol from cigarettes containing either a mentholated filter or mentholated tobacco; Tob. Sci. 16 (1972) 40-42.

42) Curran, J.G.: Effect of certain liquid filter additives on menthol delivery; Tob. Sci. 19 (1975) 69-70.

43) Cuzin, J.-L., M. Hubert-Habart, B. Muel, R. Royer and R. Latarjet: La production du benzo-3,4 pyrène dans des cigarettes à papier imprégné de sulfamate d'ammonium; Bulletin de la Société Chimique de France 5 (1960) p. 982.

44) Dalhamn, T.: The anticiliostatic effect of cigarettes treated with oxolamine citrate; Amer. Rev. Resp. Dis. 99 (1969) 447-448.

45) Dalhamn, T. and R. Rylander: Reduction of cigarette smoke ciliotoxicity by certain tobacco additives; Amer. Rev. Resp. Dis. 103 (1971) 855-857.

46) Detert, E.-R. and W. Ruchholz: Envelope for tobacco goods; U.S. Patent No. 3,826,268 (July 1974).

47) Doihara, T., U. Kobashi, S. Sugawara, and Y. Kaburaki: Studies on flavoring effect (IV). Pyrolysis of polyhydric alcohols; Scientific Papers of the Central Research Institute Japan Monopoly Corporation, 106 (1964) 129-135.

48) Dontenwill, W., H.-J. Chevalier, H.-P. Harke, H.-J. Klimisch, U. Lafrenz und G. Reckzeh: Experimentelle Untersuchungen über die tumorerzeugende Wirkung von Zigarettenrauch-Kondensaten an der Mäusehaut. IV. Einzelvergleiche von Kondensaten aus verschiedenen Tabakfolien, Einfluß eines Zusatzes von $\mathrm{NaNO}_{3}$ zum Tabak oder zu Tabakfolien, Wirkung flüchtiger Bestandteile des Rauches, Einfluß einer Initialbehandlung mit Dimethylbenzanthracen; Z. Krebsforsch. 78 (1972) 236-264.

49) Dontenwill, W.: Search for a less hazardous cigarette. Excerpta Medica International Congress Series 3 (1974) 131-137.

50) Dontenwill, W., H.-J. Chevalier, H.-P. Harke, H.-J. 
Klimisch, G. Reckzeh, B. Fleischmann and W. Keller: Experimentelle Untersuchungen über die tumorerzeugende Wirkung von Zigarettenrauch-Kondensaten an der Mäusehaut. V. Mitteilung: Einzelvergleiche von Kondensaten verschiedener modifizierter Zigaretten; Z. Krebsforsch. 85 (1976) 141-153.

51) Van Duuren, B.L., A. Sivak, L. Langseth, B.M. Goldschmidt and A. Segal: Initiators and promoters in tobacco carcinogenesis; National Cancer Institute Monograph 28 (1968) 173-180.

52) Eicher, T. and F. Müller: Rauchbare Produkte; German Patent No. 2729759 (May 1985).

53) Ellis, C., R. Cox, C. Callicutt, S. Laffoon, K. Podraza, J. Seeman, R. Kinser, D. Farthing and F. Hsu: The effect of ingredients added to tobacco in a commercial Marlboro Lights cigarette on FTC nicotine yield, "smoke $\mathrm{pH}$ ", and Cambridge filter trapping efficiency; CORESTA, Meeting of the smoke and technology study groups, 5-9th September 1999, Innsbruck, Austria.

54) EU-Directive 2001/37/EC: On the approximation of the laws, regulations and administrative provisions of the Member States concerning the manufacture, presentation and sale of tobacco products; Official Journal L 194 (18/07/2001) 26-35.

55) Frattini, C., C. Bicchi, C. Barettini, and G.M. Nano: Volatile flavor components of licorice; J. Agric. Food Chem. 25 (1977) 1238-1241.

56) Gager Jr., F.L., J.W. Nedlock and W.J. Martin: Tobacco additives and cigarette smoke. Part I. Transfer of D-glucose, sucrose, and their degradation products to the smoke; Carbohydrate Res. 17 (1971a) 327-333.

57) Gager Jr., F.L., J.W. Nedlock and W.J. Martin: Tobacco additives and cigarette smoke. Part II. Organic, gas-phase products from D-glucose and sucrose; Carbohydrate Res. 17 (1971b) 335-339.

58) Garcia Roche, M.O., A. Cabrera, A. Becquer, C. Duverger, M. Cuervo and J. Guardiola: Health risk due to the use of nitrate in the manufacture of Cuban golden cigarettes; Rev. Cubana Hig. Epidemiol. 24 (1986) 487-492.

59) Gargus, J.L., J.B. Sullivan, R.T. Habermann, J. Copeland and J. Everly: Mouse dermal study of smoke condensate from "Chemosol"-treated cigarettes; Tox. Appl. Pharm. 33 (1975) 568-574.

60) Gaworski, C.L., M.M. Dozier, J.M. Gerhart, N. Rajendran, L.H. Brennecke, C. Aranyi and J.D. Heck: 13-week inhalation toxicity study of menthol cigarette smoke; Fd. Chem. Toxic. 35 (1997) 683-692.

61) Gaworski, C.L., M.M. Dozier, J.D. Heck, J.M. Gerhart, N. Rajendran, R.M. David, L.H. Brennecke and R. Morrissey: Toxicologic evaluation of flavor ingredients added to cigarette tobacco: 13-week inhalation exposure in rats; Inhal. Toxicol. 10 (1998) 357-381.

62) Gaworski, C.L., J.D. Heck, M.B. Bennett and M.L. Wenk: Toxicologic evaluation of flavor ingredients added to cigarette tobacco: skin painting bioassay of cigarette smoke condensate in SENCAR mice; Toxicology 139 (1999a) 1-17.

63) Gaworski, C.L., J.D. Heck and N. Rajendran: Toxi- cologic evaluation of glycerine and propylene glycol added to cigarette tobacco: 13-week inhalation studies in Fisher-344 rats; 53rd Tobacco Science Research Conference Montréal, Canada, Program Booklet and Abstracts, Vol. 53, Poster No. 5, 1999b, p. 21.

64) Gilbert, J.A.S. and A.J. Lindsey: The thermal decomposition of some tobacco constituents, Br. J. Cancer, 11 (1957) 398-402.

65) Glantz, S.A., J. Slade, L.A., Bero, P. Hanauer and D.E. Barnes: The Cigarette Papers; University of California Press, Berkeley and Los Angeles, California, 1996.

66) Grant, S.J.: Catalytic and non-catalytic additives for the removal of carbon monoxide from cigarette smoke; 34th Tobacco Chemists Research Conference, Paper No. 54, 1980, p. 28.

67) Green, J.D., J. Chalmers and P.J. Kinnard: The transfer of tobacco additives to cigarette smoke: Examination of the possible contribution of pyrolysis products to mainstream smoke composition; Beitr. Tabakforsch. Int. 14 (1989) 283-288.

68) Grubbs, H.J., T.V. Van Auken and W.R. Johnson Jr.: $\alpha$-Substituted vinyl menthyl carbonates; U.S. Patent No. 4,127,601 (Nov. 1978).

69) Grubbs H.J. and Y. Houminer: Flavour-release compositions; European Patent No. 0064326 A1 (March 1982).

70) Gutcho, S.: Tobacco flavoring substances and methods; Noyes Data Corporation, Noyes Building, Park Ridge, New Jersey, USA, 1972, p. 1-161.

71) Halter, H.M. and T.I. Ito: Reconstituted tobacco smoking and health possibilities; J. Natl. Cancer Inst. 48 (1972) 1869-1883.

72) Herron, J.: Tobacco product containing side stream smoke flavorant; European Patent No. WO 88/09133 (Dec. 1988).

73) Higman, E.B., Schmeltz, I. and W.S. Schlotzhauer: Products from the thermal degradation of some naturally occurring materials, J. Agric. Food Chem., 18 (1970) 636-639.

74) Higman, H.C., E.B. Higman and O.T. Chortyk: Pyrolysis of selected tobacco flavoring additives; Tob. Sci. 18 (1974) 136-138.

75) Hoffmann, D. and E.L. Wynder: The reduction of the tumorigenicity of cigarette smoke condensate by addition of sodium nitrate to tobacco; Cancer Res. 27 (1967) 172-174.

76) Hoffmann, D. and E.L. Wynder: Selective reduction of the tumorigenicity of tobacco smoke. Experimental approaches; in: Toward a less harmful cigarette, edited by E.L. Wynder and D. Hoffmann, Natl. Cancer Inst. Monograph 28 (1968) 151-172.

77) Hoffmann, D. and E.L. Wynder: Selective reduction of tumorigenicity of tobacco smoke. II. Experimental approaches; J. Natl. Cancer Inst. 48 (1972) 1855-1868.

78) Ishiguro, S., T. Ohsumi, S. Matsushima and S. Sugawara: A rapid method for the determination of polyols in cigarettes and leaf tobacco; Kenkyo Hokoku Nippon Senbai Kosha Chuo Kenkyusho 121 (1979) 7-11.

79) Jenkins Jr., R.W., R.H. Newman, R.D. Carpenter and 
T.S. Osdene: Cigarette smoke formation studies: I. Distribution and mainstream products from added ${ }^{14} \mathrm{C}$-dotriacontane-16, 17; Beitr. Tabakforsch. 5 (1970a) 295-298.

80) Jenkins Jr., R.W., R.H. Newman and M.K. Chavis: Cigarette smoke formation studies: II. Smoke distribution and mainstream pyrolytic composition of added ${ }^{14} \mathrm{C}$-menthol (U); Beitr. Tabakforsch. 5 (1970b) 299-301.

81) Jenkins Jr., R.W., R.H. Newman, M.D. Edmonds and T.S. Osdene: Cigarette smoke formation studies: III. The contribution of dotriacontane to the benzo[a]pyrene content of smoke; Beitr. Tabakforsch. 7 (1973) $154-157$.

82) Jenkins Jr., R.W., M.K. Chavis, R.T. Bass and T.S. Osdene: Cigarette smoke formation studies: VI. The carbon contribution to total smoke from each individual component in the 1R1-type cigarette; Beitr. Tabakforsch. Int. 10 (1980) 145-148.

83) Jing, Y. and K. Xian: The effects of different levels of filter ventilation on the deliveries of flavor constituents in mainstream smoke; CORESTA, Meeting of the smoke and technology study groups, 5-9th September 1999, Innsbruck, Austria.

84) Jodl, R.: Über den Einfluß der Glimmsalze des Cigarettenpapiers auf die Abrauchergebnisse von Cigaretten; Beitr. Tabakforsch. 5 (1969) 22-24.

85) Johnson, W.R., R.W. Hale, S.C. Clough and P.H. Chen: Chemistry of the conversion of nitrate nitrogen to smoke products; Nature 243 (1973) 223-225.

86) Jones, R., P. Bolduc and L. Reid: Protection of rat bronchial epithelium against tobacco smoke; Brit. Med. J. 2 (1972) 142-144.

87) Jones, R., P. Bolduc and L. Reid: Goblet cell glycoprotein and tracheal gland hypertrophy in rat airways: The effect of tobacco smoke with or without the anti-inflammatory agent phenylmethyloxadiazole; Br. J. Exp. Path. 54 (1973) 229-239.

88) Kaburaki, Y., H. Shigematsu, Y. Mikami and H. Kusakabe: Studies on the composition of tobacco smoke (XI). Relations between vapor phase components of smoke and constituents of tobacco; Kenkyo Hokoku - Nippon Sembai Kosha Chuo Kenkyusho 111 (1969) 143-149.

89) Kagan, M.R., J.A. Cunningham and D. Hoffmann: Propylene glycol: A precursor of propylene oxide in cigarette smoke; 53rd Tobacco Science Research Conference Montréal, Canada, Program Booklet and Abstracts, Vol. 53, Paper No. 41, 1999, p. 42.

90) Kallianos, A.G., R.E. Means and J.D. Mold: Effect of nitrates in tobacco on the catechol yield in cigarette smoke; Tob. Sci. 12 (1968) 125-129.

91) Kato, K.: Pyrolysis of cellulose, Part III. Comparative studies of the volatile compounds from pyrolysates of cellulose and its related compounds; Agric. Biol. Chem. 31 (1967) 657-663.

92) Kato, K. and Y. Shibayama: The thermal decomposition products of vanillin and their transfer into cigarette smoke; Scientific Papers of the Central Research Institute Japan Monopoly Corporation 104 (1962) 115-121.

93) Keritsis, G.D.: Tobacco treatment; European Patent
No. 0034922 A1 (Sept. 1981).

94) Kier, L.D., E. Yamasaki and B.N. Ames: Detection of mutagenic activity in cigarette smoke condensate; Proc. Nat. Acad. Sci. USA 71 (1974) 4159-4163.

95) Klimisch, H.-J.: Vergleichende chemisch-analytische Untersuchungen an Kondensaten modifizierter Cigaretten. Diskussion einer Korrelation zur biologischen Wirksamkeit; Zeitschrift für Lebensmittel-Untersuchung und -Forsch. 150 (1972) 93-99.

96) Kobashi, U., T. Doihara, S. Sugawara and Y. Kaburaki: Changes in chemical composition of smoke from cigarettes imparted with several polyols; Scientific Papers of the Central Research Institute Japan Monopoly Corporation 107 (1965) 319-323.

97) Komatsu, H.: Reagent for removing harmful matter from cigarette; Japanese Patent No. JP 9238667 (Sept. 1997).

98) Kossack, C.: Verfahren zum Herabsetzen von beim Rauchen von Tabak im Verbrennungsbereich frei werdenden Schadstoffen; German Patent No. DE 3534504A1 (April 1987).

99) Kratchanova, M., A. Stoilova, I. Panchev and A. Richnev: Characteristics and application of pectin extracts in cigarette production; Food Hydrocolloids 9 (1995) 97-102.

100) Kröller, E.: Ergebnisse von Schwelversuchen an Farbstoffen zur Farbmattierung von Tabakwaren. 2. Mitteilung (Kreuzbeerenextrakt); Bundesgesundhbl. 20 (1963a) 317-318.

101) Kröller, E.: Ergebnisse von Schwelversuchen an Farbstoffen zur Farbmattierung von Tabakwaren. 3. Mitteilung (Blauholzextrakt); Bundesgesundhbl. 21 (1963b) 332-335.

102) Kröller, E.: Ergebnisse von Schwelversuchen an Farbstoffen zur Farbmattierung von Tabakwaren. 4. Mitteilung (Huminsäure); Bundesgesundhbl. 22 (1963c) 348-349.

103) Kröller, E.: Ergebnisse von Schwelversuchen an Farbstoffen zur Farbmattierung von Tabakwaren; Bundesgesundhbl. 6 (1963d) 38-40.

104) Kröller, E.: Ein Beitrag zur Beurteilung von Tabakzusatzstoffen auf Grund ihrer Pyrolyseprodukte. 1. Cellulose und ihre Derivate; Bundesgesundhbl. 24 (1964a) 375-378.

105) Kröller, E.: Ergebnisse von Schwelversuchen an $\mathrm{Zu}$ satzstoffen zu Tabakwaren. 1. Mitteilung (Glykole); Deutsche Lebensmittel-Rundschau 60 (1964b) 235-239.

106) Kröller, E.: Ergebnisse von Schwelversuchen an Zusatzstoffen zu Tabakwaren. 2. Mitteilung (Polyglykole, Glycerin); Deutsche Lebensmittel-Rundschau 60 (1965a) 16-17.

107) Kröller, E.: Ergebnisse von Schwelversuchen an Zusatzstoffen zu Tabakwaren. 3. Mitteilung (Pflanzliche Schleim- und Gummiarten); Deutsche Lebensmittel-Rundschau 61 (1965b) 150-155.

108) Kröller, E.: Ein Beitrag zur Beurteilung von Tabakzusatzstoffen auf Grund ihrer Pyrolyseprodukte. 2. Stärke und ihre Derivate; Bundesgesundhbl. 9 (1966a) 106-107.

109) Kröller, E.: Ein Beitrag zur Beurteilung von Tabakzusatzstoffen auf Grund ihrer Pyrolyseprodukte. 3. 
Weißbrand- und Flottbrandmittel; Bundesgesundhbl. 22 (1966 b) 333-334.

110) Kröller, E.: Ergebnisse von Schwelversuchen an Farbstoffen zur Farbmattierung von Tabakwaren. 5. Mitteilung (Gelbholzextrakt); Bundesgesundhbl. 12 (1966 c) 173-174.

111) Kröller, E.: Ergebnisse von Schwelversuchen an $\mathrm{Zu}$ satzstoffen zu Tabakwaren. 4. Mitteilung; Deutsche Lebensmittel-Rundschau 62 (1966 d) 208-210.

112) Kröller, E.: Ein Beitrag zur Beurteilung von Tabakzusatzstoffen auf Grund ihrer Pyrolyseprodukte. 4. Aromastoffe; Bundesgesundhbl. 18 (1967) 277-279.

113) Kröller, E.: Ergebnisse von Schwelversuchen an Zusatzstoffen zu Tabakwaren. 5. Mitteilung; Deutsche Lebensmittel-Rundschau 64 (1968) 111-113.

114) Kröller, E.: Untersuchungen zur Bestimmung des aus dem Tabak unzersetzt in den Rauch übergehenden Thiabendazols; Deutsche Lebensmittel-Rundschau 65 (1969) 85-86.

115) Kröller, E.: Ein Beitrag zur Beurteilung von Tabakzusatzstoffen auf Grund ihrer Pyrolyseprodukte. 5. Mitteilung; Bundesgesundhbl. 23 (1970) 321-323.

116) Lakritz, L., R.L. Stedman and E.D. Strange: Composition studies on tobacco XXXIX: Changes in smoke composition and filtration by artificial alteration of smoke $\mathrm{pH}$ : Formic and acetic acids and volatile phenols; Beitr. Tabakforsch. 5 (1969) 104-108.

117) Lakritz, L., E.D. Strange, D.G. Bailey and R.L. Stedman: Composition studies on tobacco: XLV. Use of cigarette additives to alter the composition and reducing properties of cigarette smoke; Beitr. Tabakforsch. 6 (1972) 120-123.

118) Laurene, A.H., R.H. Cundiff and G.H. Greene: Determination of glycerol and propylene glycol in cigarette smoke; Tob. Sci. 9 (1965) 1-4.

119) Leffingwell, J.C., H.J. Young, E. Bernasek: Tobacco flavoring for smoking products; R.J. Reynolds Tobacco Company, Winston-Salem 1972.

120) Lindsey, A.J., K. Persaud and A. Candeli: Reduction of benzpyrene in tobacco smoke; Brit. Med. J. 2 (1959) 821.

121) Lyerly, L.A.: Direct vapor chromatographic determination of menthol, propylene glycol, nicotine and triacetin in cigarette smoke; Tob. Sci. 11 (1967) 49-51.

122) Mariner, D.C., A.K. Armitage, M. Dixon, T. Higenbotham and N.M. Sinclair: The effect of inhalation volume and blend additives on nicotine retention and uptake; 2000 CORESTA Congress, Lisbon, Portugal, 15-19 October 2000, Information Bulletin, Abstract No. ST 24, p. 169.

123) Marmor, R.S. and H.J. Minnemeyer: Material balance studies on cigarettes containing 3-phenyl-5methyl-1,2,4-oxadiazole; Beitr. Tabakforsch. 8 (1975) 199-203.

124) Mathis, D.E.: Migration and delivery of filter flavors; Beitr. Tabakforsch. Int. 12 (1983) 1-8.

125) Matsushita, H. and M. Shinozaki: Flavourant composition for tobacco, method for its production and tobacco product containing said composition; European Patent No. EP 0014105 A2 (Aug. 1980).

126) McAdam, K.G.: Smokable filler material for smoking articles; International Patent No. PCT/GB97/00589 (March 1997).

127) McCoy, E.C. and H.S. Rosenkranz: Cigarette smoking may yield nitroarenes; Cancer Letters 15 (1982) 9-13.

128) Meier, W.M. and K. Siegmann: Significant reduction of carcinogenic compounds in tobacco smoke by the use of zeolite catalysts; Microporous and Mesoporous Materials 33 (1999) 307-310.

129) Miano, R.R. and C.H. Keith; Smoking materials; U.S. Patent No. 3,931,824 (Jan. 1976).

130) Michelson, I. and G. Rathkamp: Composition of cigarette smoke: Effects of ammonium sulfamate in cigarette paper; Beitr. Tabakforsch. 7 (1974) 212-216.

131) Miranda, E.J.F., A.A.S. Rodrigues, M.G.F. dos Santos and M.R. Luzia: Method to study the flavor transfer to cigarette smoke; 53rd Tobacco Science Research Conference Montréal, Canada, Program Booklet and Abstracts, Vol. 53, Paper No. 57, 1999, p. 51.

132) Misra, M., D.J. Heck and C.L. Gaworski: Toxicologic evaluation of diammonium phosphate added to cigarette tobacco and reconstituted leaf: 13-week smoke inhalation studies in rats; 55th Tobacco Science Research Conference, Program Booklet and Abstracts, Vol. 55, Paper No. 18, 2001, p. 30.

133) Mitchell, B.C., E.P. Barbee and R.M. Irby Jr.: The chromatographic determination of menthol in cigarettes and cigarette smoke; Tob. Sci. 7 (1963) 64-66.

134) Morie, G.P. and C.H. Sloan: Determination of $N$ nitrosodimethylamine in the smoke of high-nitrate tobacco cigarettes; Beitr. Tabakforsch. 7 (1973) 61-66.

135) Müller, L. and W. Röper: Commentary. It ain't necessarily so; Beitr. Tabakforsch. Int. 19 (2000) 51-54.

136) NCI, National Cancer Institute, Smoking and Health Program: Toward less hazardous cigarettes: Report No. 1. The first set of experimental cigarettes; DHEW Publication No. (NIH) 76-905 (1976).

137) NCI, National Cancer Institute, Smoking and Health Program: Toward less hazardous cigarettes: Report No. 3. The third set of experimental cigarettes; DHEW Publication No. (NIH) 77-12380 (1977).

138) NCI, National Cancer Institute, Smoking and Health Program: Toward less hazardous cigarettes: Report No. 4. The fourth set of experimental cigarettes; DHEW Publication (1980).

139) Nichols, W., R. Newsome, R. Thesing and W. Houck: Matrix entrapment of flavorings for smoking articles; European Patent No. 0223454 A2 (May 1987).

140) Norman, V. and H.G. Bryant, Jr.: Composition de Tabac; Belgian Patent No. 827431 (July 1975).

141) Norman, V., H.G. Bryant Jr. and T.B. Williams: Smoking composition; U.S. Patent No. 3,720,214 (March 1973).

142) Ogawa, S.: Modifier for smoke flavor and perfume of cigarette; Japanese Patent No. 10066557 (March 1998).

143) Ohshiro, M.: Regulator for smoking flavor of tobacco; International Patent No. PCT/JP98/04210 (April 1999). 
144) Perfetti, T.A. and H.H. Gordin: Just noticeable difference studies of mentholated cigarette products; Tob. Sci. 29 (1985) 57-67.

145) Pintaske, F.: Zusatzstoff für Rauchtabak; German Patent No. 2942544 (April 1981).

146) Prouse, R.E., A.A. West, D.A. King and R. Poulson: Smoking materials; U.S. Patent No. 4,005,718 (Feb. 1977).

147) Pyriki, C., W. Moldenhauer and T. Knappe: Zur Frage der Behandlung des Zigarettenpapiers und des Tabaks zwecks Verminderung von polycyklischen Kohlenwasserstoffen in deren Rauch; Ber. Inst. Tabakforsch. Dresden 12 (1965) 37-55.

148) Rakieten, N., M.L. Rakieten, D. Feldman and M.J. Boykin Jr.: Mammalian ciliated respiratory epithelium. Studies with particular reference to effects of menthol, nicotine, and smoke of mentholated and nonmentholated cigarettes; Arch. Otolaryngol. 56 (1952) 494-503.

149) Rathkamp, G. and D. Hoffmann: Chemical studies on tobacco smoke, XIII. Inhibition of the pyrosyntheses of several selective smoke constituents; Beitr. Tabakforsch. 5 (1970) 302-306.

150) Reif, G.: Der Nachweis von Aethylenglykol im Tabakrauch mit $\beta$-Naphthol; Pharmazie 4 (1949) 110-113.

151) Riehl, T.F., L.L. Shockley and M.L. Reynolds: Menthol distribution and transfer; Tob. Sci. 17 (1973) $10-11$.

152) Robb, E.W., J.J. Westbrook, III and A. Bavley: The use of non-volatile adducts in smoke flavor; Tob. Sci. 8 (1964) 3-7.

153) Robb, E.W., W.R. Johnson, J.J. Westbrook, and R.B. Seligman: Model pyrolysis - The study of cellulose; Fourth International Tobacco Scientific Congress Athens-Greece, September 19-26 , 1966, p. 10751085.

154) Römer, E., F.J. Tewes, T.J. Meisgen, D.J. Veltel and E.L. Carmines: Evaluation of the potential effects of ingredients added to cigarettes. Part 3: In vitro genotoxicity and cytotoxicity; Food Chem. Toxicol. 40 (2002) 105-111.

155) Römer, E. and U. Hackenberg: Mouse skin bioassay of smoke condensates from cigarettes containing different levels of cocoa; Food Add. Cont. 7(1990) 563-569.

156) Rustemeier, K., R. Stabbert, H.-J. Haussmann, E. Römer and E.L. Carmines: Evaluation of the potential effects of ingredients added to cigarettes. Part 2: Chemical composition of mainstream smoke; Food Chem. Toxicol. 40 (2002) 93-104.

157) Rylander, R.: Lung clearance of particles and bacteria. Effects of cigarette smoke exposure; Arch. Environ. Health 23 (1971) 321-326.

158) Rylander, R.: Alteration of certain pulmonary smoke exposure reactions by phenylmethyloxadiazole (PMO); Scand. J. Resp. Dis. 54 (1973) 223-230.

159) Saint-Jalm, Y., G. Duval, T. Conte and I. Bonnichon: Mechanisms of transfer of ammonia in cigarette smoke from ammonium compounds in tobacco; 2000 CORESTA Congress, 2000 CORESTA Congress, Lisbon, Portugal, 15-19 October 2000, Information
Bulletin, Abstract No. ST 9, p. 153.

160) Sakagami, H.: The behavior of glycyrrhizic acid and glycyrrhetinic acid added to tobacco on smoking. Studies on the components of licorice root used for tobacco flavouring. Part III; Nippon Nogei Kagaku Kaishi 47 (1973) 623-626.

161) Sakuma, H., S. Munakata and S. Sugawara: Volatile products of cellulose pyrolysis; Agric. Biol. Chem. 45 (1981) 443-451.

162) Sato, S., T. Ohka, M. Nagao, K. Tsuji and T. Kosuge: Reduction in mutagenicity of cigarette smoke condensate by added sugars; Mut. Res. 60 (1979) $155-161$.

163) Schlotzhauer, W.S.: Fatty acids and phenols from pyrolysis of cocoa powder, a tobacco product flavorant; Tob. Sci. 22 (1978) 1-2.

164) Schlotzhauer, W.S., I. Schmeltz and L.C. Hickey: Pyrolytic formation of phenols from some high molecular weight tobacco leaf constituents and related non-tobacco materials; Tob. Sci. 11 (1967) 31-34.

165) Schlotzhauer, W.S., R.M. Martin, M.E. Snook and R.E. Williamson: Pyrolytic studies on the contribution of tobacco leaf constituents to the formation of smoke catechols; J. Agric. Food Chem. 30 (1982) 372-374.

166) Schlotzhauer, W.S., R.F. Arrendale and O.T. Chortyk: The rapid pyrolytic characterization of tobacco leaf carbohydrate material; Beitr. Tabakforsch. Int. 13 (1985) 74-80.

167) Schlotzhauer, W.S., R.F. Severson and R.M. Martin: The contribution of sucrose esters to tobacco smoke composition; Beitr. Tabakforsch. Int. 13 (1986) 229-238.

168) Schmeltz, I. and W.S. Schlotzhauer: Benzo[a]pyrene, phenols and other products from pyrolysis of the cigarette additive, $(d, l)$-menthol; Nature 219 (1968) 371.

169) Schmeltz, I., W.S. Schlotzhauer, and E.B. Higman: Characteristic products from pyrolysis of nitrogenous organic substances; Beitr. Tabakforsch. 6 (1972) 134-138.

170) Schmeltz, I., A. Wenger, D. Hoffmann and T.C. Tso: Chemical studies on tobacco smoke. 53. Use of radioactive tobacco isolates for studying the formation of smoke components; J. Agric. Food Chem. 26 (1978) 234-239.

171) Settle, V.A., R.T. Walker, R.D. Stevens and M.A. Sudholt: A fast gas chromatography method for simultaneous analysis of menthol, propylene glycol, and glycerol using a multicapillary column; 53rd Tobacco Science Research Conference Montréal, Canada, Program Booklet and Abstracts, Vol. 53, Paper No. 67, 1999.

172) Shepherd, T.H. and F.E. Gould: Tobacco smoke filters; U.S. Patent No. 3,470,883 (Aug. 1968).

173) Sjöberg, A.M. and H. Pyysalo: Identification of food thickeners by monitoring of their pyrolytic products; J. Chromatogr. 319 (1985) 90-98.

174) Sloan, C.H. and J.E. Kiefer: Determination of NO and $\mathrm{NO}_{2}$ in cigarette smoke from kinetic data; Tob. Sci. 13 (1969) 180-182.

175) Smit, H.: Die Wirkung einiger Feuchthaltemittel auf 
die Eigenschaften eines röhrengetrockneten Tabaks; Beitr. Tabakforsch. 5 (1970) 231-238.

176) Southwick E.W.: Smoking compositions containing a vanillin-release additive; U.S. Patent No. 5,144,965 (Sep. 1992).

177) de Souza, J.E. and M. Scherbak: The effect of glycerol added to tobacco on the constituents of cigarette smoke; The Analyst 89 (1964) 735-739.

178) Stedman, R.L., L. Lakritz and E.D. Strange: Composition studies on tobacco XXXIII. Changes in smoke composition and filtration by artificial alteration of smoke $\mathrm{pH}$ : Pyridine and nicotine; Beitr. Tabakforsch. 5 (1969) 13-17.

179) Stein, Y.S. and M.J. Antal Jr.: A study of the gasphase pyrolysis of glycerol; J. Anal. Appl. Pyrolysis 4 (1983) 283-296.

180) Stoilova, A., M. Kratchanova and C. Kratchanov: Comparative investigations of the influence of polyvalent alcohols and fruit extracts on the physicochemical properties of tobacco; Beitr. Tabakforsch. Int. 16 (1994) 1-9.

181) Stotesbury, S., H. Digard, L. Willoughby and A. Couch: The pyrolysis of tobacco additives as a means of predicting their behaviour in a burning cigarette; Beitr. Tabakforsch. Int. 18 (1999) 147-163.

182) Stotesbury, S.J., L.J. Willoughby and A. Couch: Pyrolysis of cigarette ingredients labelled with stable isotopes; Beitr. Tabakforsch. Int. 19 (2000) 55-64.

183) Tabakverordnung (Verordnung über Tabakerzeugnisse) vom 20. Dezember 1977, p. 1-12; in: Meyer, A.H.: Lebensmittelrecht, Band II, Bundesgesetze und Verordnungen sowie EG-Recht über Lebensmittel, Tabakerzeugnisse, kosmetische Mittel und Bedarfsgegenstände; Stand 30.06.2000.

184) Terrell, J.H. and I. Schmeltz: Cigarettes: Chemical effects of sodium nitrate content; Science 160 (1968) 1456.

185) Terrell, J.H. and I. Schmeltz: Alteration of cigarette smoke composition, 1. Influence of certain additives; Tob. Sci. 14 (1970) 78-81.

186) Thornton, R.E. and S.R. Massey: Some effects of adding sugar to tobacco; Beitr. Tabakforsch. 8 (1975) 11-15.

187) Thornton, R.E. and C. Valentine: Determination of the balance of carbon-14 activity added to cigarettes; Beitr. Tabakforsch. 4 (1968) 287-292.

188) Tiggelbeck, D.D. and M. Manes: Mentholated cigarette filter; U.S. Patent No. 3,972,335 (Aug. 1976).

189) Tomasik, P.: The thermal decomposition of carbohydrates. Part I. The decompositon of mono-, di-, and oligo-saccharides; Advances in Carbohydrate Chemistry and Biochemistry 47 (1989) 203-278.
190) TR Staff Report: Safe - Cig flavorings not a risk says independent panel; Tobacco Reporter 121 (1994) 32-39.

191) Tso, T.C.: Process for treating tobacco; U.S. Patent No. 3,863,645 (Feb. 1975).

192) Vanscheeuwijck, P.M., A. Teredesai, P.M. Terpstra, J. Verbeeck, P. Kuhl, B. Gerstenberg, S. Gebel and E.L. Carmines: Evaluation of the potential effects of ingredients added to cigarettes. Part 4: Subchronic inhalation toxicity; Food Chem. Toxicol. 40 (2002) 113-131.

193) Wakeham, H. and H. Silberman: Effect of cellulose on taste of cigaret smoke; Beitr. Tabakforsch. 3 (1966) 605-610.

194) Wynder, E.L. and D. Hoffmann: Present status of laboratory studies on tobacco carcinogenesis; Acta Pathol. Microbiol. Scand. 52 (1961) 119-132.

195) Wynder, E.L. and D. Hoffmann: Ein experimenteller Beitrag zur Tabakrauchkanzerogenese; Dtsch. Med. Wschr. 88 (1963) 623-628.

196) Wynder, E.L. and D. Hoffmann: A study of tobacco carcinogenesis. X. Tumor promoting activity; Cancer 24 (1969) 289-301.

197) Yang, H., J. Liu, K. Li, X. Yin, X. Tan and J. Wang: Synthesis of 3-oxo- $\alpha$-ionol ethyl carbonate and its conversion of megastigmatrienones in tobacco smoke; Beitr. Tabakforsch. Int. 19 (2001) 339-343.

198) Yongkuan, C.and H. Wangyun: Pyrolysis of glycyrrhizic acid and its sodium salts; Tob. Sci. 39 (1995) 49-54.

Address for correspondence

Wolf-Dieter Heller

Verband der Cigarettenindustrie

Scientific Department

Neustädtische Kirchstraße 8

10117 Berlin

Germany 
Table 2: Overview of ingredients mentioned in the literature

\begin{tabular}{|c|c|c|c|c|c|c|}
\hline \multirow[b]{2}{*}{ Ingredients } & \multirow{2}{*}{$\begin{array}{c}\text { Classification } \\
\text { Table } 1^{\mathrm{a}}\end{array}$} & \multirow{2}{*}{$\begin{array}{c}\text { MSS } \\
\text { Tables } 3 \& 4^{\mathrm{b}} \\
\end{array}$} & \multirow{2}{*}{$\begin{array}{c}\text { Pyrolysis } \\
\text { Table }^{\text {b }} \\
\end{array}$} & \multicolumn{2}{|c|}{ Biological activity } & \multirow[b]{2}{*}{ Reference(s) } \\
\hline & & & & Table $6^{\text {b }}$ & Table $7^{b}$ & \\
\hline Acetanisole & 1 & M 62, 63 & & $\begin{array}{c}\text { M 61 } \\
\text { M 60 } \\
\text { M 62, } 63\end{array}$ & & $\begin{array}{l}\text { Gaworski et al., } 1998 \\
\text { Gaworski et al., } 1999 a \\
\text { Carmines, } 2002^{\mathrm{c}}\end{array}$ \\
\hline Acetic acid & 3 & M 62, 63 & $S$ & $\begin{array}{c}\text { M } 61 \\
\text { M } 60 \\
\text { M 62, } 63\end{array}$ & & 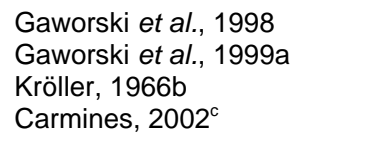 \\
\hline Acetoin & 1 & M 62, 63 & & $\begin{array}{c}\text { M 61 } \\
\text { M } 60 \\
M \text { 62, } 63\end{array}$ & & $\begin{array}{l}\text { Gaworski et al., } 1998 \\
\text { Gaworski et al., } 1999 a \\
\text { Carmines, } 2002^{\mathrm{c}}\end{array}$ \\
\hline Acetophenone & 1 & M 62, 63 & & $\begin{array}{c}\text { M } 61 \\
\text { M } 60 \\
M \text { 62, } 63\end{array}$ & & $\begin{array}{l}\text { Bavley and Robb, } 1969 \\
\text { Gaworski et al., } 1998 \\
\text { Gaworski et al., } 1999 \mathrm{a} \\
\text { Carmines, } 2002^{\mathrm{c}}\end{array}$ \\
\hline Acetylpyrazine & 1 & M 63 & & $\begin{array}{l}\text { M } 61 \\
\text { M } 60 \\
\text { M } 63\end{array}$ & & $\begin{array}{l}\text { Gaworski et al., } 1998 \\
\text { Gaworski et al., } 1999 a \\
\text { Carmines, } 2002^{\mathrm{c}}\end{array}$ \\
\hline 2-Acetylthiazole & 1 & M 63 & & M 63 & & Carmines, $2002^{c}$ \\
\hline Aconitic acid & 1 & M 63 & & M 63 & & Carmines, $2002^{\mathrm{C}}$ \\
\hline Adipic acid & 9 & M 28 & & & & Komatsu, 1997 \\
\hline Agar-agar & 6 & & $\begin{array}{l}\mathrm{S} \\
\mathrm{S}\end{array}$ & & & $\begin{array}{l}\text { Kröller, 1965b } \\
\text { Sjöberg and Pyysalo, } 1985\end{array}$ \\
\hline Alanine & 1 & $\mathrm{~S}$ & & M 61 & & $\begin{array}{l}\text { Kaburaki et al., } 1969 \\
\text { Gaworski et al., } 1998\end{array}$ \\
\hline Alfalfa extract & 1 & M 62 & & M 62 & & Carmines, $2002^{\mathrm{C}}$ \\
\hline Alginic acid & 6 & & $\begin{array}{l}S \\
S\end{array}$ & & & $\begin{array}{l}\text { Kröller, 1965b } \\
\text { Sjöberg and Pyysalo, } 1985\end{array}$ \\
\hline Allspice oil & 1 & M 62 & & M 62 & & Carmines, $2002^{c}$ \\
\hline Aluminium oxide & 3 & & & & $\begin{array}{l}S \\
S\end{array}$ & $\begin{array}{l}\text { Hoffmann and Wynder, } 1968 \\
\text { Wynder and Hoffmann, } 1961\end{array}$ \\
\hline Aluminium oxide + molybdenum $t$ & roxide & Catalyst & & & & \\
\hline Aluminium oxide hydrate & 3 & M 24, 25 & & & & Eicher and Müller, 1985 \\
\hline Aluminium oxide trihydrate & & & & & $S$ & Wynder and Hoffmann, 1961 \\
\hline Aluminium silicate & 6,8 & & & & $S$ & Wynder and Hoffmann, 1961 \\
\hline Aluminium sulfate & 3 & $S$ & & & & Baldry et al., 1988 \\
\hline Aluminium trihydrate & 3 & M 2 & & & & Armbrust and Carithers, 1968 \\
\hline Ambergris tincture & 1 & M 63 & & M 63 & & Carmines, $2002^{\mathrm{c}}$ \\
\hline Ambroxide & 1 & M 38 & & & & Miranda et al., 1999 \\
\hline $\mathrm{Y}$-Aminobutyric acid & 1 & $S$ & & & & Kaburaki et al., 1969 \\
\hline Ammonium ceric sulfate & 9 & S & & & & Bentley and Burgan, 1960 \\
\hline Ammonium chromic sulfate & 9 & S & & & & Bentley and Burgan, 1960 \\
\hline Ammonium citrate & $1,3,6$ & M 19-24 & & & & Eicher and Müller, 1985 \\
\hline Ammonium cobalt sulfate & 9 & S & & & & Bentley and Burgan, 1960 \\
\hline Ammonium compounds & $1,3,6$ & S & & & & Ellis et al., 1999 \\
\hline Ammonium ferric sulfate & 9 & S & & & & Bentley and Burgan, 1960 \\
\hline Ammonium ferrous sulfate & 9 & $\mathrm{~S}$ & & & & Bentley and Burgan, 1960 \\
\hline Ammonium hexachloropalladate & 9 & S & & & & Bryant et al., 1979 \\
\hline Ammonium hydrogen carbonate & 1,3 & $S$ & & & & Burton and Benner, 1972 \\
\hline Ammonium hydroxide & $1,3,8$ & $S$ & & & & Stedman et al., 1969 \\
\hline Ammonium iron(III) citrate & 1,3 & M 19-24 & & & & Eicher and Müller, 1985 \\
\hline Ammonium iron(III) oxalate & 9 & M 26 & & & & Eicher and Müller, 1985 \\
\hline
\end{tabular}


Table 2 (contd.)

\begin{tabular}{|c|c|c|c|c|c|c|}
\hline \multirow[b]{2}{*}{ Ingredients } & \multirow{2}{*}{$\begin{array}{c}\text { Classification } \\
\text { Table } 1^{\mathrm{a}}\end{array}$} & \multirow{2}{*}{$\begin{array}{c}\text { MSS } \\
\text { Tables } 3 \& 4^{\mathrm{b}} \\
\end{array}$} & \multirow{2}{*}{$\begin{array}{c}\text { Pyrolysis } \\
\text { Table }^{\text {b }} \\
\end{array}$} & \multicolumn{2}{|c|}{ Biological activity } & \multirow[b]{2}{*}{ Reference(s) } \\
\hline & & & & Table $6^{\mathrm{b}}$ & Table $7^{b}$ & \\
\hline Ammonium molybdate & 9 & S & & & & Bentley and Burgan, 1960 \\
\hline Ammonium nickel sulfate & 9 & $S$ & & & & Bentley and Burgan, 1960 \\
\hline Ammonium perchlorate & 9 & $S$ & & & & Bentley and Burgan, 1960 \\
\hline Ammonium phosphate & 3,8 & $\begin{array}{l}\mathrm{S} \\
\mathrm{S}\end{array}$ & & & & $\begin{array}{l}\text { Grant, } 1980 \\
\text { Halter and Ito, } 1972\end{array}$ \\
\hline Ammonium sulfamate & 9 & $\begin{array}{l}\mathrm{S} \\
\mathrm{S} \\
\mathrm{S} \\
\mathrm{S} \\
\mathrm{S} \\
\mathrm{S} \\
\mathrm{S} \\
\mathrm{S}\end{array}$ & & & $\mathrm{S}$ & $\begin{array}{l}\text { Alvord and Cardon, } 1956 \\
\text { Bentley and Burgan, } 1960 \\
\text { Bock et al., } 1974 \\
\text { Candeli et al., } 1960 \\
\text { Cuzin et al., } 1960 \\
\text { Hoffmann and Wynder, } 1968 \\
\text { Lindsey et al., } 1959 \\
\text { Michelson and Rathkamp, } 1974 \\
\text { Pyriki et al., } 1965\end{array}$ \\
\hline Ammonium tetrachloropalladate & 9 & $S$ & & & & Bryant et al., 1979 \\
\hline Ammonium vanadate & 9 & $\begin{array}{l}\mathrm{S} \\
\mathrm{S} \\
\mathrm{S}\end{array}$ & & & & $\begin{array}{l}\text { Burton and Benner, } 1972 \\
\text { Burdick et al., } 1969 \\
\text { Burton, } 1969\end{array}$ \\
\hline Amyl butyrate & 1 & M 63 & & M 63 & & Carmines, $2002^{\mathrm{C}}$ \\
\hline Amyl formate & 1 & M 63 & & M 63 & & Carmines, $2002^{\mathrm{C}}$ \\
\hline Amyl octanoate & 1 & & & $\begin{array}{l}\text { M } 61 \\
\text { M } 60\end{array}$ & & $\begin{array}{l}\text { Gaworski et al., } 1998 \\
\text { Gaworski et al., 1999a }\end{array}$ \\
\hline Amyris oil & 1 & M 63 & & M 63 & & Carmines, $2002^{c}$ \\
\hline Anethole & 1 & $\mathrm{~S}$ & S & $\begin{array}{l}\text { M } 61 \\
\text { M } 60\end{array}$ & & $\begin{array}{l}\text { Badgett and Osmalov, } 1971 \\
\text { Bavley and Robb, } 1969 \\
\text { Gaworski et al., } 1998 \\
\text { Gaworski et al., } 1999 \text { a } \\
\text { Robb et al., } 1964 \\
\text { Van Auken et al., } 1979\end{array}$ \\
\hline Angelica root oil & 1 & M 63 & & M 63 & & Carmines, $2002^{c}$ \\
\hline Aniline & 1,9 & $S$ & & & & Bentley and Burgan, 1960 \\
\hline $\begin{array}{l}\text { Anisaldehyde } \\
\text { (p-Methoxy-benzaldehyde) }\end{array}$ & 1 & $\begin{array}{c}S \\
S \\
S \\
M 62,63\end{array}$ & & $\begin{array}{c}\text { M } 61 \\
M 60 \\
M 62,63\end{array}$ & & $\begin{array}{l}\text { Green et al., } 1989 \\
\text { Stotesbury et al., } 1999 \\
\text { Stotesbury et al., } 2000 \\
\text { Gaworski et al., } 1998 \\
\text { Gaworski et al., } 1999 \text { a } \\
\text { Carmines, } 2002^{c}\end{array}$ \\
\hline Anisole & 1 & $\begin{array}{l}S \\
M 38 \\
S\end{array}$ & & & & $\begin{array}{l}\text { Green et al., } 1989 \\
\text { Miranda et al., } 1999 \\
\text { Stotesbury et al., } 1999\end{array}$ \\
\hline Anisyl acetate & 1 & M 63 & & $\begin{array}{l}\text { M } 61 \\
\text { M } 60 \\
\text { M } 63\end{array}$ & & $\begin{array}{l}\text { Gaworski et al., } 1998 \\
\text { Gaworski et al., } 1999 a \\
\text { Carmines, } 2002^{\mathrm{c}}\end{array}$ \\
\hline Anisyl alcohol & 1 & M 63 & & M 63 & & Carmines, $2002^{c}$ \\
\hline Anisyl formate & 1 & M 63 & & M 63 & & Carmines, $2002^{c}$ \\
\hline Anisyl phenylacetate & 1 & M 63 & & M 63 & & Carmines, $2002^{c}$ \\
\hline Anthracene & 9 & $S$ & & & & Thornton and Valentine, 1968 \\
\hline Apple juice & 1 & & & M 61 & & Gaworski et al., 1998 \\
\hline Apple juice concentrate & 1 & M 62 & & $\begin{array}{l}\text { M } 60 \\
\text { M } 62\end{array}$ & & $\begin{array}{l}\text { Gaworski et al., 1999a } \\
\text { Carmines, } 2002^{\circ}\end{array}$ \\
\hline Apricot extract & 1 & M 62 & & M 62 & & Carmines, $2002^{c}$ \\
\hline L-Arginine & 1 & & & M 61 & & Gaworski et al., 1998 \\
\hline Asbestos & 9 & M 2 & & & & Armbrust and Carithers, 1968 \\
\hline Ascorbic acid & 1,5 & $\begin{array}{l}\text { S } \\
\text { M } 51 \\
\text { M } 52\end{array}$ & & & & $\begin{array}{l}\text { Bentley and Burgan, } 1960 \\
\text { Ogawa, } 1998 \\
\text { Ohshiro, } 1999\end{array}$ \\
\hline Aspartic acid & 1 & $S$ & & M 61 & & $\begin{array}{l}\text { Kaburaki et al., } 1969 \\
\text { Gaworski et al., } 1998\end{array}$ \\
\hline
\end{tabular}




\begin{tabular}{|c|c|c|c|c|c|c|}
\hline \multirow[b]{2}{*}{ Ingredients } & \multirow{2}{*}{$\begin{array}{c}\text { Classification } \\
\text { Table } 1^{\mathrm{a}}\end{array}$} & \multirow{2}{*}{$\begin{array}{c}\text { MSS } \\
\text { Tables } 3 \& 4^{b}\end{array}$} & \multirow{2}{*}{$\begin{array}{l}\text { Pyrolysis } \\
\text { Table } 5^{\mathrm{b}}\end{array}$} & \multicolumn{2}{|c|}{ Biological activity } & \multirow[b]{2}{*}{ Reference(s) } \\
\hline & & & & Table $6^{\mathrm{b}}$ & Table $7^{b}$ & \\
\hline Azo-bis-isobutyrodinitrile & 9 & S & & & & Burton and Benner, 1972 \\
\hline Azo-bis-isobutyronitrile (Vazo) & 9 & S & & & & Terrell and Schmeltz, 1970 \\
\hline Balsam oil peru & 1 & M 63 & & M 63 & & Carmines, $2002^{c}$ \\
\hline Balsam peru & 1 & M 63 & & $\begin{array}{l}\text { M } 61 \\
\text { M } 60 \\
\text { M } 63\end{array}$ & & $\begin{array}{l}\text { Gaworski et al., } 1998 \\
\text { Gaworski et al., } 1999 a \\
\text { Carmines, } 2002^{\mathrm{c}}\end{array}$ \\
\hline Barium acetate & 9 & $S$ & & & & Burton and Benner, 1972 \\
\hline Beeswax & 1 & & & M 61 & & Gaworski et al., 1998 \\
\hline Beeswax white & 1 & & & M 60 & & Gaworski et al., 1999a \\
\hline Beet juice & 1 & & & M 61 & & Gaworski et al., 1998 \\
\hline Beet juice concentrate & 1 & & & M 60 & & Gaworski et al., 1999a \\
\hline Benzaldehyde & 1 & $\begin{array}{c}S \\
M 38 \\
M 62,63 \\
S\end{array}$ & & $\begin{array}{c}\text { M } 61 \\
\text { M } 60 \\
\text { M 62, } 63\end{array}$ & & $\begin{array}{l}\text { Gaworski et al., } 1998 \\
\text { Gaworski et al., } 1999 a \\
\text { Green et al., } 1989 \\
\text { Miranda et al., } 1999 \\
\text { Carmines, } 2002^{c} \\
\text { Stotesbury et al., } 1999\end{array}$ \\
\hline Benzoic acid & 1,5 & & $S$ & & & Kröller, 1970 \\
\hline Benzoin & 1 & & & M 61 & & Gaworski et al., 1998 \\
\hline Benzoin resin & 1 & & & $\begin{array}{l}\text { M } 61 \\
\text { M } 60\end{array}$ & & $\begin{array}{l}\text { Gaworski et al., } 1998 \\
\text { Gaworski et al., } 1999 a\end{array}$ \\
\hline Benzoin, resinoid & 1 & M 62, 63 & & M 62, 63 & & Carmines, $2002^{c}$ \\
\hline Benzophenone & 1 & M 63 & & M 63 & & Carmines, $2002^{c}$ \\
\hline Benzoquinone & 9 & $S$ & & & & Lakritz et al., 1972 \\
\hline Benzothiazyl disulfide & 9 & $S$ & & & & Terrell and Schmeltz, 1970 \\
\hline Benzo[a]pyrene & 9 & $S$ & & & & Thornton and Valentine, 1968 \\
\hline Benzyl alcohol & 1,8 & M 62, 63 & & $\begin{array}{c}\text { M } 61 \\
\text { M } 60 \\
M \text { 62, } 63\end{array}$ & & $\begin{array}{l}\text { Gaworski et al., } 1998 \\
\text { Gaworski et al., } 1999 a \\
\text { Carmines, 2002 }\end{array}$ \\
\hline Benzyl benzoate & 1 & M 62, 63 & & M 62, 63 & & Carmines, $2002^{c}$ \\
\hline Benzyl butyrate & 1 & M 63 & & M 63 & & Carmines, $2002^{c}$ \\
\hline Benzyl cinnamate & 1 & M 62, 63 & & M 62, 63 & & Carmines, $2002^{c}$ \\
\hline Benzyl propionate & 1 & M 63 & & M 63 & & Carmines, $2002^{c}$ \\
\hline Benzyl salicylate & 1 & M 63 & & M 63 & & Carmines, $2002^{c}$ \\
\hline Bergamot oil & 1 & M 63 & & M 63 & & Carmines, $2002^{c}$ \\
\hline Bisabolene & 1 & M 63 & & M 63 & & Carmines, $2002^{c}$ \\
\hline Bismuth oxide & 9 & $S$ & & & & Chakraborty et al., 1971 \\
\hline Bois de rose oil & 1 & M 63 & & M 63 & & Carmines, $2002^{\mathrm{C}}$ \\
\hline Borate & 5 & $\begin{array}{l}\mathrm{S} \\
\mathrm{S} \\
\mathrm{S} \\
\mathrm{S}\end{array}$ & & & & $\begin{array}{l}\text { Benner et al., 1969a, } \\
\text { Benner et al., 1969b } \\
\text { Burdick et al., } 1969 \\
\text { Burton, } 1969\end{array}$ \\
\hline Boric acid & 3,5 & $S$ & & & $S$ & $\begin{array}{l}\text { Burton and Benner, } 1972 \\
\text { Wynder and Hoffmann, } 1961\end{array}$ \\
\hline Borneol & 1 & M 63 & & M 63 & & Carmines, $2002^{c}$ \\
\hline Bornyl acetate & 1 & M 62, 63 & & M 62, 63 & & Carmines, $2002^{c}$ \\
\hline Bornyl isovalerate & 1 & M 63 & & M 63 & & Carmines, $2002^{c}$ \\
\hline Brown invert syrup & 1,2 & & & M 60 & & Gaworski et al., 1999a \\
\hline Buchu leaves oil & 1 & M 63 & & M 63 & & Carmines, $2002^{c}$ \\
\hline Buckthorne berry extract & 7 & & $S$ & & & Kröller, 1963a \\
\hline Butanediol $\Leftrightarrow$ & ycol & & & & & \\
\hline 2,3-Butanedione & 1 & & & $\begin{array}{l}\text { M } 61 \\
\text { M } 60\end{array}$ & & $\begin{array}{l}\text { Gaworski et al., } 1998 \\
\text { Gaworski et al., 1999a }\end{array}$ \\
\hline Butter & 1 & & & $\begin{array}{l}\text { M } 61 \\
\text { M } 60\end{array}$ & & $\begin{array}{l}\text { Gaworski et al., } 1998 \\
\text { Gaworski et al., 1999a }\end{array}$ \\
\hline
\end{tabular}




\begin{tabular}{|c|c|c|c|c|c|c|}
\hline \multirow[b]{2}{*}{ Ingredients } & \multirow{2}{*}{$\begin{array}{c}\text { Classification } \\
\text { Table } 1^{\mathrm{a}}\end{array}$} & \multirow{2}{*}{$\begin{array}{c}\text { MSS } \\
\text { Tables } 3 \& 4^{b}\end{array}$} & \multirow{2}{*}{$\begin{array}{l}\text { Pyrolysis } \\
\text { Table 5 }\end{array}$} & \multicolumn{2}{|c|}{ Biological activity } & \multirow[b]{2}{*}{ Reference(s) } \\
\hline & & & & Table $6^{\text {b }}$ & Table $7^{\mathrm{b}}$ & \\
\hline Butyl alcohol & 1,8 & M 63 & & M 63 & & Carmines, $2002^{c}$ \\
\hline Butyl butyrate & 1 & M 63 & & M 63 & & Carmines, $2002^{c}$ \\
\hline Butyl butyryllactate & 1 & M 63 & & M 63 & & Carmines, $2002^{c}$ \\
\hline 1,3-Butylene glycol & 2,8 & $\begin{array}{c}\text { M } 6 \\
\text { M } 10 \\
M 13,14 \\
\text { S } \\
\text { S }\end{array}$ & $\mathrm{S}$ & $\begin{array}{l}\text { M } 60 \\
\text { M } 61\end{array}$ & & $\begin{array}{l}\text { Carugno et al., } 1971 \\
\text { Detert and Ruchholz, } 1974 \\
\text { Doihara et al., } 1964 \\
\text { Dontenwill et al., } 1972 \\
\text { Gaworski et al., } 1999 \text { a } \\
\text { Gaworski et al., } 1998 \\
\text { Kobashi et al., } 1965 \\
\text { Kröller, 1964b } \\
\text { Smit, } 1970\end{array}$ \\
\hline 2,3-Butylene glycol & 2 & S & & & & Kobashi et al., 1965 \\
\hline 3-Butylidenephthalide & 1 & M 62, 63 & & M 62, 63 & & Carmines, $2002^{c}$ \\
\hline \multicolumn{2}{|c|}{ Butyl 2-ethyl-3-hydroxy-3-methyl-3-toluylpropionate } & \multicolumn{5}{|c|}{$\Rightarrow \quad$ ethyl 2-(2-butyl)-3-hydroxy-3-methyl-3-phenylpropionate } \\
\hline Butyl isovalerate & 1 & M 63 & & M 63 & & Carmines, $2002^{c}$ \\
\hline 2,6-di-tert. Butyl-v-methylphenol & 5,8 & $S$ & & & & Burton and Benner, 1972 \\
\hline Butyl phenylacetate & 1 & M 63 & & M 63 & & Carmines, $2002^{c}$ \\
\hline Butyric acid & 1 & M 62, 63 & & $\begin{array}{c}M 61 \\
M 60 \\
M 62,63\end{array}$ & & $\begin{array}{l}\text { Gaworski et al., } 1998 \\
\text { Gaworski et al., } 1999 \text { a } \\
\text { Carmines, } 2002^{\mathrm{c}}\end{array}$ \\
\hline Calcium alginate & 6 & M 53 & & & & Prouse et al., 1977 \\
\hline Calcium carbonate & 3 & $\begin{array}{c}\text { M 5 } \\
\text { M 10 } \\
\text { M 19-26 } \\
\text { M 48, 49 }\end{array}$ & & & $S$ & $\begin{array}{l}\text { Briskin, } 1979 \\
\text { Detert and Ruchholz, } 1974 \\
\text { Eicher and Müller, } 1985 \\
\text { NCI, Report No. } 4,1980 \\
\text { Wynder and Hoffmann, } 1961\end{array}$ \\
\hline Calcium ethylvanillin-5-carboxylate & $\Rightarrow$ & 5-carboxyvani & illin & & & \\
\hline Calcium nitrate & 9 & $\begin{array}{l}S \\
S\end{array}$ & & & & $\begin{array}{l}\text { Johnson et al., } 1973 \\
\text { Kallianos et al., } 1968\end{array}$ \\
\hline Calcium oxalate & 9 & S & & & & Chakraborty et al., 1971 \\
\hline Calcium vanillin-5-carboxylate & 5 -carbox & xyvanillin & & & & \\
\hline Campeachy wood extract & 7 & & $S$ & & & Kröller, 1963b \\
\hline Camphene & 1 & M 62 & & M 62 & & Carmines, $2002^{c}$ \\
\hline Cananga oil & 1 & M 63 & & M 63 & & Carmines, $2002^{c}$ \\
\hline Caramel colour & 1,7 & M 62, 63 & & $\begin{array}{c}\text { M } 61 \\
\text { M } 60 \\
\text { M } 62,63\end{array}$ & & $\begin{array}{l}\text { Gaworski et al., } 1998 \\
\text { Gaworski et al., } 1999 \mathrm{a} \\
\text { Carmines, } 2002^{\mathrm{C}}\end{array}$ \\
\hline Caraway oil & 1 & M 63 & & M 63 & & Carmines, $2002^{c}$ \\
\hline Carbon & 7 & M 36, 37 & & & & Miano and Keith, 1976 \\
\hline Carbon (activated) & 6 & M 1 & & & & An et al., 1996 \\
\hline Carbowax $\Leftrightarrow$ & ne glycols & & & & & \\
\hline 5-Carboxyethylvanillin $\Leftrightarrow$ & 5-Carboxyvanillin & & & & & \\
\hline Carboxymethylcellulose & 6 & $\begin{array}{c}\text { M } 1 \\
\text { M } 11 \\
\text { S, M 35-37 }\end{array}$ & $\begin{array}{l}S \\
S\end{array}$ & & & $\begin{array}{l}\text { An et al., } 1996 \\
\text { Dontenwill et al., } 1972 \\
\text { Kröller, 1964a } \\
\text { Miano and Keith, } 1976 \\
\text { Sjöberg and Pyysalo, } 1985\end{array}$ \\
\hline Carboxymethyl starch & 6 & & S & & & Kröller, 1966a \\
\hline 5-Carboxyvanillin & 1 & & $S$ & & & Southwick, 1992 \\
\hline Cardamom oil & 1 & & & $\begin{array}{l}\text { M } 61 \\
\text { M } 60\end{array}$ & & $\begin{array}{l}\text { Gaworski et al., } 1998 \\
\text { Gaworski et al., 1999a }\end{array}$ \\
\hline Cardamom seed oil & 1 & M 63 & & M 63 & & Carmines, $2002^{\mathrm{c}}$ \\
\hline Carob bean and extract & 1,6 & M 62, 63 & & $\begin{array}{c}M 61 \\
M 60 \\
M 62,63\end{array}$ & & $\begin{array}{l}\text { Gaworski et al., } 1998 \\
\text { Gaworski et al., } 1999 a \\
\text { Carmines, } 2002^{\mathrm{c}}\end{array}$ \\
\hline
\end{tabular}


Table 2 (contd.)

\begin{tabular}{|c|c|c|c|c|c|c|}
\hline \multirow[b]{2}{*}{ Ingredients } & \multirow{2}{*}{$\begin{array}{c}\text { Classification } \\
\text { Table } 1^{\mathrm{a}}\end{array}$} & \multirow{2}{*}{$\begin{array}{c}\text { MSS } \\
\text { Tables } 3 \& 4^{b}\end{array}$} & \multirow{2}{*}{$\begin{array}{l}\text { Pyrolysis } \\
\text { Table } 5^{\mathrm{b}}\end{array}$} & \multicolumn{2}{|c|}{ Biological activity } & \multirow[b]{2}{*}{ Reference(s) } \\
\hline & & & & Table $6^{\mathrm{b}}$ & Table $7^{\mathrm{b}}$ & \\
\hline Carob (locust bean gum) & $1,6,8$ & & $\mathrm{~S}$ & & & Sjöberg and Pyysalo, 1985 \\
\hline Carob seed powder & 1,6 & & S & & & Kröller, 1965b \\
\hline Carrot oil & 1 & M 62, 63 & & M 62, 63 & & Carmines, $2002^{c}$ \\
\hline 4-Carvomenthenol & 1 & M 63 & & M 63 & & Carmines, $2002^{c}$ \\
\hline L-Carvone & 1 & M 63 & & M 63 & & Carmines, $2002^{\circ}$ \\
\hline \multicolumn{3}{|c|}{ 1-Carvyl 2-methyl-3-hydroxy-3-methyl-3-toluylpropionate } & \multicolumn{4}{|c|}{ ethyl 2-(2-butyl)-3-hydroxy-3-methyl-3-phenylpropionate } \\
\hline$\beta$-Caryophyllene & 1 & M 62, 63 & & $\begin{array}{c}\text { M } 61 \\
\text { M } 60 \\
M \quad 62,63\end{array}$ & & $\begin{array}{l}\text { Gaworski et al., } 1998 \\
\text { Gaworski et al., } 1999 \mathrm{a} \\
\text { Carmines, } 2002^{\mathrm{c}}\end{array}$ \\
\hline$\beta$-Caryophyllene oxide & 1 & & & $\begin{array}{l}\text { M } 61 \\
\text { M } 60\end{array}$ & & $\begin{array}{l}\text { Gaworski et al., } 1998 \\
\text { Gaworski et al., } 1999 a\end{array}$ \\
\hline Cascarilla bark oil & 1 & M 62, 63 & & M 62, 63 & & Carmines, $2002^{\mathrm{c}}$ \\
\hline Casein & 9 & & $\begin{array}{l}\mathrm{S} \\
\mathrm{S}\end{array}$ & & & $\begin{array}{l}\text { Higman, E.B. et al., } 1970 \\
\text { Schmeltz et al., } 1972\end{array}$ \\
\hline Casein hydrolysate & 9 & $S$ & & & & Crosthwaite et al., 1979 \\
\hline Cassia absolute & 1 & M 63 & & M 63 & & Carmines, $2002^{c}$ \\
\hline Cassia bark & 1 & & & $\begin{array}{l}\text { M } 61 \\
\text { M } 60\end{array}$ & & $\begin{array}{l}\text { Gaworski et al., } 1998 \\
\text { Gaworski et al., 1999a }\end{array}$ \\
\hline Castoreum extract & 1 & M 62, 63 & & $\begin{array}{c}\text { M } 61 \\
\text { M 60 } \\
\text { M 62, 63 }\end{array}$ & & $\begin{array}{l}\text { Gaworski et al., } 1998 \\
\text { Gaworski et al., } 1999 \mathrm{a} \\
\text { Carmines, } 2002^{\mathrm{C}}\end{array}$ \\
\hline Catalyst $\left(\mathrm{MoO}_{3}+\mathrm{Al}_{2} \mathrm{O}_{3}\right)$ & 9 & S & & & & Terrell and Schmeltz, 1970 \\
\hline Celery oleoresin & 1 & M 63 & & M 63 & & Carmines, $2002^{c}$ \\
\hline Celery seed oil & 1 & M 63 & & M 63 & & Carmines, $2002^{\mathrm{c}}$ \\
\hline Cellobiose & 9 & & $S$ & & & Schlotzhauer et al., 1967 \\
\hline Cellubiose & 9 & & $S$ & & & Kato, 1967 \\
\hline Cellulose & 6 & $\begin{array}{c}\text { M } 5 \\
\text { S } \\
\text { M 16, } 17 \\
\text { S } \\
\text { S, M } 48 \\
\text { M } 53\end{array}$ & $\begin{array}{l}\mathrm{S} \\
\mathrm{S} \\
\mathrm{S} \\
\mathrm{S} \\
\mathrm{S} \\
\mathrm{S}\end{array}$ & $S$ & & $\begin{array}{l}\text { Bell et al., } 1966 \\
\text { Briskin, } 1979 \\
\text { Carmella et al., 1984 } \\
\text { Cullis et al., 1983a } \\
\text { Cullis et al., 1983b } \\
\text { Dontenwill et al., } 1976 \\
\text { Gilbert and Lindsey, } 1957 \\
\text { Higman, E.B. et al., } 1970 \\
\text { Jenkins et al., } 1980 \\
\text { Kato, 1967 } \\
\text { Kröller, 1964a } \\
\text { NCl, Report No. 4, } 1980 \\
\text { Prouse et al., 1977 } \\
\text { Robb et al., 1966 } \\
\text { Sakuma et al., 1981 } \\
\text { Schlotzhauer et al., } 1967 \\
\text { Schlotzhauer et al., } 1982 \\
\text { Schlotzhauer et al., } 1985 \\
\text { Wakeham and Silberman, } 1966\end{array}$ \\
\hline Cellulose acetate & 6 & M 10 & & & & Detert and Ruchholz, 1974 \\
\hline Cellulose ether gums & 6 & M 46, 47, 49 & & & M 46, 47 & NCI, Report No. 4, 1980 \\
\hline Cellulose monoacetate & 9 & & $S$ & & & Kröller, 1964a \\
\hline Cellulose sulfate & 6 & M 19-26 & & & & Eicher and Müller, 1985 \\
\hline Chalk & 3,6 & M 31-34 & & & & McAdam, 1997 \\
\hline $\begin{array}{l}\text { Chamomile, flower, Hungarian, } \\
\text { oil }\end{array}$ & 1 & M 62, 63 & & M 62, 63 & & Carmines, $2002^{c}$ \\
\hline $\begin{array}{l}\text { Chamomile, flower, Roman, } \\
\text { extract }\end{array}$ & 1 & M 63 & & M 63 & & Carmines, $2002^{c}$ \\
\hline Chamomile, flower, Roman, oil & 1 & M 62, 63 & & M 62, 63 & & Carmines, $2002^{c}$ \\
\hline Chamomile flower oil & 1 & & & M 60 & & Gaworski et al., 1999a \\
\hline Chamomile oil & 1 & & & M 61 & & Gaworski et al., 1998 \\
\hline
\end{tabular}


Table 2 (contd.)

\begin{tabular}{|c|c|c|c|c|c|c|}
\hline \multirow[b]{2}{*}{ Ingredients } & \multirow{2}{*}{$\begin{array}{l}\text { Classification } \\
\text { Table } 1^{\mathrm{a}}\end{array}$} & \multirow{2}{*}{$\begin{array}{c}\text { MSS } \\
\text { Tables } 3 \& 4^{b}\end{array}$} & \multirow{2}{*}{$\begin{array}{l}\text { Pyrolysis } \\
\text { Table } 5^{\text {b }}\end{array}$} & \multicolumn{2}{|c|}{ Biological activity } & \multirow[b]{2}{*}{ Reference(s) } \\
\hline & & & & Table $6^{\text {b }}$ & Table $7^{b}$ & \\
\hline Chamomile oil, German & 1 & M 62, 63 & & M 62, 63 & & Carmines, $2002^{\mathrm{c}}$ \\
\hline Chemosol & 9 & & & & M 65 & Gargus et al., 1975 \\
\hline Chicory extract & 1 & M 62 & & M 62 & & Carmines, $2002^{c}$ \\
\hline Chlorogenic acid & 9 & $S$ & S & & & $\begin{array}{l}\text { Carmella et al., } 1984 \\
\text { Schlotzhauer et al., } 1982\end{array}$ \\
\hline Chlorophyll & 1 & $\begin{array}{l}\text { M } 28 \\
\text { M } 52\end{array}$ & & & & $\begin{array}{l}\text { Komatsu, } 1997 \\
\text { Ohshiro, } 1999\end{array}$ \\
\hline Chlorophyllin & 9 & S & & & & Crosthwaite et al., 1979 \\
\hline Chocolate & 1 & M 63 & & M 63 & & Carmines, $2002^{c}$ \\
\hline Cholesterol & 9 & $S$ & & & & Cheng, 1973 \\
\hline Cineol & 1 & $S$ & & & & Bavley and Robb, 1969 \\
\hline Cinnamaldehyde & 1 & M 62, 63 & & M 62, 63 & & Carmines, $2002^{c}$ \\
\hline Cinnamic acid & 1 & M 63 & & M 63 & & Carmines, $2002^{\mathrm{c}}$ \\
\hline Cinnamon bark oil & 1 & M 62, 63 & & M 62, 63 & & Carmines, $2002^{\mathrm{c}}$ \\
\hline Cinnamon leaf oil & 1 & M 62, 63 & & M 62, 63 & & Carmines, $2002^{c}$ \\
\hline Cinnamyl acetate & 1 & & & $\begin{array}{l}\text { M } 61 \\
\text { M } 60\end{array}$ & & $\begin{array}{l}\text { Gaworski et al., } 1998 \\
\text { Gaworski et al., 1999a }\end{array}$ \\
\hline Cinnamyl alcohol & 1 & M 62, 63 & & $\begin{array}{c}M 61 \\
M 60 \\
M 62,63\end{array}$ & & $\begin{array}{l}\text { Gaworski et al., } 1998 \\
\text { Gaworski et al., } 1999 \text { a } \\
\text { Carmines, } 2002^{\mathrm{c}}\end{array}$ \\
\hline Cinnamyl cinnamate & 1 & M 62, 63 & & M 62, 63 & & Carmines, $2002^{c}$ \\
\hline \multicolumn{6}{|c|}{ Cinnamyl 2-isopropyl-3-hydroxy-3-methyl-3-toluylpropionate $\Rightarrow$} & 3-methyl-3-phenylpropionate \\
\hline Cinnamyl isovalerate & 1 & $\begin{array}{c}S \\
M 63\end{array}$ & & M 63 & & $\begin{array}{l}\text { Mathis, } 1983 \\
\text { Carmines, } 2002^{\mathrm{c}}\end{array}$ \\
\hline Cinnamyl propionate & 1 & S & & & & Mathis, 1983 \\
\hline Citral & 1 & M 62, 63 & & M 62, 63 & & Carmines, $2002^{\mathrm{c}}$ \\
\hline Citric acid & $1,3,5$ & $\begin{array}{l}M 62 \\
M 11,12 \\
M 18\end{array}$ & $\begin{array}{l}S \\
S\end{array}$ & $\begin{array}{c}\text { M } 62 \\
\text { S } \\
\text { M } 61 \\
\text { M } 60\end{array}$ & M 47 & $\begin{array}{l}\text { Carmines, } 2002^{c} \\
\text { Dalhamn and Rylander, } 1971 \\
\text { Dontenwill et al., } 1972 \\
\text { Dontenwill et al., } 1976 \\
\text { Gaworski et al., } 1998 \\
\text { Gaworski et al., 1999a } \\
\text { Gilbert and Lindsey, } 1957 \\
\text { Kröller, 1966b } \\
\text { NCl, Report No. 4, } 1980 \\
\text { Ogawa, } 1998 \\
\text { Stedman et al., } 1969\end{array}$ \\
\hline Citronellal & 1 & S & & & & Bavley and Robb, 1969 \\
\hline Citronella oil & 1 & M 63 & & M 63 & & Carmines, $2002^{c}$ \\
\hline Citronellol (Rhodinol) & 1 & M 62, 63 & & M 62, 63 & & Carmines, $2002^{\mathrm{c}}$ \\
\hline $\mathrm{D}, \mathrm{L}-$ Citronellol & 1 & M 62, 63 & & M 62, 63 & & Carmines, $2002^{\mathrm{c}}$ \\
\hline Citronellyl isobutyrate & 1 & M 63 & & M 63 & & Carmines, $2002^{c}$ \\
\hline Citron oil & 1 & $S$ & & & & Bavley and Robb, 1969 \\
\hline Citrus fruit or herb & 1 & M 52 & & & & Ohshiro, 1999 \\
\hline Civet absolute & 1 & M 63 & & M 63 & & Carmines, $2002^{\mathrm{c}}$ \\
\hline Clary oil & 1 & M 63 & & M 63 & & Carmines, $2002^{c}$ \\
\hline Clay & 3,8 & M 48 & & & & NCI, Report No. 4, 1980 \\
\hline Cobalt (III) oxide & 9 & & & & S & Wynder and Hoffmann, 1961 \\
\hline (Cacao) & 1 & $\begin{array}{l}\text { M 31-34 } \\
\text { S } \\
\text { M } 63\end{array}$ & $\mathrm{~S}$ & $\begin{array}{c}S \\
\text { M } 63\end{array}$ & & 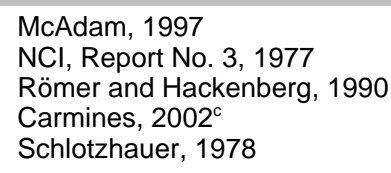 \\
\hline Cocoa extract & 1 & M 62, 63 & & $\begin{array}{c}M 61 \\
M 62,63\end{array}$ & & $\begin{array}{l}\text { Gaworski et al., } 1998 \\
\text { Carmines, } 2002^{\mathrm{c}}\end{array}$ \\
\hline Cocoa powder & 1 & & & $\begin{array}{l}\text { M } 61 \\
\text { M } 60\end{array}$ & & $\begin{array}{l}\text { Gaworski et al., } 1998 \\
\text { Gaworski et al., 1999a }\end{array}$ \\
\hline
\end{tabular}


Table 2 (contd.)

\begin{tabular}{|c|c|c|c|c|c|c|}
\hline \multirow[b]{2}{*}{ Ingredients } & \multirow{2}{*}{$\begin{array}{l}\text { Classification } \\
\text { Table } 1^{\mathrm{a}}\end{array}$} & \multirow{2}{*}{$\begin{array}{c}\text { MSS } \\
\text { Tables } 3 \& 4^{b}\end{array}$} & \multirow{2}{*}{$\begin{array}{c}\text { Pyrolysis } \\
\text { Table } 5^{\text {b }}\end{array}$} & \multicolumn{2}{|c|}{ Biological activity } & \multirow[b]{2}{*}{ Reference(s) } \\
\hline & & & & Table $6^{\text {b }}$ & Table $7^{b}$ & \\
\hline Cocoa shell extract & 1 & M 62, 63 & & M 62, 63 & & Carmines, $2002^{\mathrm{c}}$ \\
\hline Cocoa shells & 1 & M 64 & & M 64 & & Carmines, $2002^{\mathrm{c}}$ \\
\hline Coffee & 1 & & & $\begin{array}{l}\text { M } 61 \\
M 60\end{array}$ & & $\begin{array}{l}\text { Gaworski et al., } 1998 \\
\text { Gaworski et al., 1999a }\end{array}$ \\
\hline Coffee extract & 1 & M 62, 63 & & M 62, 63 & & Carmines, $2002^{\mathrm{c}}$ \\
\hline Cognac & 1 & & & M 61 & & Gaworski et al., 1998 \\
\hline Cognac, green, oil & 1 & M 62, 63 & & M 62, 63 & & Carmines, $2002^{\mathrm{c}}$ \\
\hline Cognac, white & 1 & & & M 60 & & Gaworski et al., 1999a \\
\hline Collagen & 9 & & $\begin{array}{l}S \\
S\end{array}$ & & & $\begin{array}{l}\text { Higman, E.B. et al., } 1970 \\
\text { Schmeltz et al., } 1972\end{array}$ \\
\hline Colorant & 7 & M 36, 37 & & & & Miano and Keith, 1976 \\
\hline Comfrey powder & 1 & M 51 & & & & Ogawa, 1998 \\
\hline Copaiba oil & 1 & M 63 & & M 63 & & Carmines, $2002^{\mathrm{c}}$ \\
\hline Copper nitrate & 9 & $\begin{array}{l}S \\
S \\
S\end{array}$ & & & $\begin{array}{l}S \\
S \\
S\end{array}$ & $\begin{array}{l}\text { Bentley and Burgan, } 1960 \\
\text { Hoffmann and Wynder, } 1968 \\
\text { Wynder and Hoffmann, } 1961 \\
\text { Wynder and Hoffmann, } 1963 \\
\text { Wynder and Hoffmann, } 1969\end{array}$ \\
\hline Copper sulfate & 9 & S & & & & Bentley and Burgan, 1960 \\
\hline Coriander oil & 1 & M 62, 63 & & M 62, 63 & & Carmines, $2002^{\mathrm{C}}$ \\
\hline Corn silk & 1 & M 62 & & M 62 & & Carmines, $2002^{\mathrm{c}}$ \\
\hline Costus root oil & 1 & M 63 & & M 63 & & Carmines, $2002^{\mathrm{c}}$ \\
\hline$o-, m-, p$-Cresol & 1 & $S$ & & & & Bavley and Robb, 1969 \\
\hline Cubeb oil & 1 & M 62, 63 & & M 62, 63 & & Carmines, $2002^{c}$ \\
\hline Coumarin & 1 & S & & & & Bavley and Robb, 1969 \\
\hline Cyclodextrins & $1,5,6$ & & S & & & Robb et al., 1964 \\
\hline Cyclohexanone & $1,7,8$ & $\mathrm{~S}$ & & & & Bavley and Robb, 1969 \\
\hline \multicolumn{2}{|c|}{ Cyclohexyl 3-hydroxy-3-methyloctanoate $\Rightarrow$} & \multicolumn{5}{|c|}{ ethyl 2-(2-butyl)-3-hydroxy-3-methyl-3-phenylpropionate } \\
\hline Cyclopentadiene & 1 & & S & & & Robb et al., 1964 \\
\hline$p$-Cymene & 1 & M 62, 63 & & M 62, 63 & & Carmines, $2002^{\mathrm{c}}$ \\
\hline p-Cymol & 1 & S & & & & Bavley and Robb, 1969 \\
\hline$\beta$-Damascenone & 1 & $\begin{array}{c}\mathrm{S} \\
\mathrm{M} 38\end{array}$ & & & & $\begin{array}{l}\text { Jing and Xian, } 1999 \\
\text { Miranda et al., } 1999\end{array}$ \\
\hline$\beta$-Damascone & 1 & S & & M 61 & & $\begin{array}{l}\text { Jing and Xian, } 1999 \\
\text { Gaworski et al., } 1998\end{array}$ \\
\hline Dandelion root extract solid & 1 & M 62 & & M 62 & & Carmines, $2002^{c}$ \\
\hline Davana oil & 1 & M 62, 63 & & M 62, 63 & & Carmines, $2002^{\mathrm{C}}$ \\
\hline Y-Decalactone & 1 & M 62, 63 & & $\begin{array}{c}M 61 \\
M 60 \\
M 62,63\end{array}$ & & $\begin{array}{l}\text { Gaworski et al., } 1998 \\
\text { Gaworski et al., } 1999 \mathrm{a} \\
\text { Carmines, } 2002^{\mathrm{c}}\end{array}$ \\
\hline$\delta$-Decalactone & 1 & M 63 & & M 63 & & Carmines, $2002^{\mathrm{C}}$ \\
\hline Decanal & 1 & M 63 & & M 63 & & Carmines, $2002^{\mathrm{C}}$ \\
\hline Decanoic acid & 1 & M 62, 63 & & $\begin{array}{c}M 61 \\
M 60 \\
M 62,63\end{array}$ & & $\begin{array}{l}\text { Gaworski et al., } 1998 \\
\text { Gaworski et al., } 1999 \mathrm{a} \\
\text { Carmines, } 2002^{\mathrm{c}}\end{array}$ \\
\hline 1-Decanol & 1,8 & $\begin{array}{l}\text { M } 58 \\
\text { M } 62\end{array}$ & & $\begin{array}{l}\text { M } 58 \\
\text { M } 62\end{array}$ & & $\begin{array}{l}\text { Tso, } 1975 \\
\text { Carmines, } 2002^{\mathrm{c}}\end{array}$ \\
\hline Deertongue leaf powder & 1 & & $S$ & & & Higman, H.C. et al., 1974 \\
\hline endo-Dehydronorborneol & 1 & & $\mathrm{~S}$ & & & Robb et al., 1964 \\
\hline Dextrin & 1,6 & & $S$ & & & Schlotzhauer et al., 1985 \\
\hline Diacetyl & 1 & M 62, 63 & & M 62, 63 & & Carmines, $2002^{\mathrm{c}}$ \\
\hline Dialdehyde crosslinker & 6 & M 46, 47, 49 & & & M 46, 47 & $\mathrm{NCl}$, Report No. 4, 1980 \\
\hline
\end{tabular}


Table 2 (contd.)

\begin{tabular}{|c|c|c|c|c|c|c|}
\hline \multirow[b]{2}{*}{ Ingredients } & \multirow{2}{*}{$\begin{array}{c}\text { Classification } \\
\text { Table } 1^{\mathrm{a}}\end{array}$} & \multirow{2}{*}{$\begin{array}{c}\text { MSS } \\
\text { Tables } 3 \& 4^{b}\end{array}$} & \multirow{2}{*}{$\begin{array}{c}\text { Pyrolysis } \\
\text { Table } 5^{\text {b }}\end{array}$} & \multicolumn{2}{|c|}{ Biological activity } & \multirow[b]{2}{*}{ Reference(s) } \\
\hline & & & & Table $6^{\mathrm{b}}$ & Table $7^{b}$ & \\
\hline Dialdehyde starch (Oxystarch) & 6 & & S & & & Kröller, 1966a \\
\hline Diammonium palladiumnitrite & 9 & $S$ & & & & Bryant et al., 1979 \\
\hline Diammonium phosphate & $1,3,6,8$ & $\begin{array}{l}\text { M } 62 \\
\text { S } \\
M 54\end{array}$ & & $\begin{array}{c}\text { M } 62 \\
\text { S }\end{array}$ & & $\begin{array}{l}\text { Carmines, } 2002^{c} \\
\text { Mariner et al., } 2000 \\
\text { Saint-Jalm et al., } 2000 \\
\text { Misra et al., } 2001\end{array}$ \\
\hline Diammonium platinnitrite & 9 & $S$ & & & & Bryant et al., 1979 \\
\hline Dibutyl phthalate & 4 & & $S$ & & & Kröller, 1968 \\
\hline Diethylamine & 1 & $S$ & & & & Stedman et al., 1969 \\
\hline Diethylamine citrate & 9 & & & & $S$ & Dalhamn and Rylander, 1971 \\
\hline Diethylene glycol & 2 & $\begin{array}{c}\mathrm{S} \\
\mathrm{M} 6 \\
\mathrm{M} 12,15 \\
\mathrm{M} 16-18 \\
\mathrm{~S} \\
\mathrm{~S}\end{array}$ & $S$ & & & $\begin{array}{l}\text { Aksu, } 1969 \\
\text { Carugno et al., } 1971 \\
\text { Dontenwill et al., } 1972 \\
\text { Dontenwill et al., } 1976 \\
\text { Kratchanova et al., } 1995 \\
\text { Kröller, 1964b } \\
\text { Stoilova et al., } 1994\end{array}$ \\
\hline 2,3-Diethylpyrazine & 1 & M 63 & & $\begin{array}{l}\text { M } 61 \\
\text { M } 60 \\
\text { M } 63\end{array}$ & & $\begin{array}{l}\text { Gaworski et al., } 1998 \\
\text { Gaworski et al., } 1999 \mathrm{a} \\
\text { Carmines, } 2002^{\mathrm{c}}\end{array}$ \\
\hline Diethyl sebacate & 1,4 & M 62 & & M 62 & & Carmines, $2002^{c}$ \\
\hline Dill oil & 1 & M 62, 63 & & M 62, 63 & & Carmines, $2002^{\mathrm{C}}$ \\
\hline$m$-Dimethoxybenzene & 1 & M 63 & & M 63 & & Carmines, $2002^{\mathrm{c}}$ \\
\hline$p$-Dimethoxybenzene & 1 & M 63 & & $\begin{array}{l}\text { M } 61 \\
\text { M } 60 \\
\text { M } 63\end{array}$ & & $\begin{array}{l}\text { Gaworski et al., } 1998 \\
\text { Gaworski et al., } 1999 \mathrm{a} \\
\text { Carmines, 2002 }\end{array}$ \\
\hline 2,4-Dimethylacetophenone & 1 & M 62 & & M 62 & & Carmines, $2002^{c}$ \\
\hline $\begin{array}{l}\text { 3,4-Dimethyl-1,2- } \\
\text { cyclopentanedione }\end{array}$ & 1 & & & M 61 & & Gaworski et al., 1998 \\
\hline $\begin{array}{l}\text { 4,5-Dimethyl-3-hydroxy-2,5- } \\
\text { dihydrofuran-2-one }\end{array}$ & 1 & & & $\begin{array}{l}\text { M } 61 \\
\text { M } 60\end{array}$ & & $\begin{array}{l}\text { Gaworski et al., } 1998 \\
\text { Gaworski et al., 1999a }\end{array}$ \\
\hline 3,7-Dimethyl-1,3,6-octatriene & 1 & M 62 & & M 62 & & Carmines, $2002^{\mathrm{C}}$ \\
\hline 3,7-Dimethyl-1,6-octadiene-3-ol & 1 & & & M 60 & & Gaworski et al., 1999a \\
\hline 3,7-Dimethyl-6-octenoic acid & 1 & M 63 & & M 63 & & Carmines, $2002^{c}$ \\
\hline$\alpha, \alpha$-Dimethylphenethyl acetate & 1 & M 62 & & M 62 & & Carmines, $2002^{\circ}$ \\
\hline$\alpha, \alpha$-Dimethylphenethyl butyrate & 1 & M 62 & & M 62 & & Carmines, $2002^{\mathrm{C}}$ \\
\hline 2,3-Dimethylpyrazine & 1 & & & $\begin{array}{l}\text { M } 61 \\
\text { M } 60\end{array}$ & & $\begin{array}{l}\text { Gaworski et al., } 1998 \\
\text { Gaworski et al., 1999a }\end{array}$ \\
\hline 2,5-Dimethylpyrazine & 1 & M 63 & & $\begin{array}{l}\text { M } 61 \\
M 60 \\
M 63\end{array}$ & & $\begin{array}{l}\text { Gaworski et al., } 1998 \\
\text { Gaworski et al., } 1999 \text { a } \\
\text { Carmines, } 2002^{\mathrm{c}}\end{array}$ \\
\hline 2,6-Dimethylpyrazine & 1 & & & M 60 & & Gaworski et al., 1999a \\
\hline $\begin{array}{l}\text { Dimethyltetrahydro-benzo- } \\
\text { furanone }\end{array}$ & 1 & M 62 & & M 62 & & Carmines, $2002^{\mathrm{c}}$ \\
\hline $\begin{array}{l}\text { 6,10-Dimethyl-5,9-undecadien-2- } \\
\text { one }\end{array}$ & 1 & M 62 & & M 62 & & Carmines, $2002^{c}$ \\
\hline Dipropylamine & 9 & $\begin{array}{l}S \\
S\end{array}$ & & & & $\begin{array}{l}\text { Lakritz et al., } 1969 \\
\text { Stedman et al., } 1969\end{array}$ \\
\hline Disodium carbonate & 3,6 & $S$ & & & & Stedman et al., 1969 \\
\hline Disodium hydrogen phosphate & 3,8 & $\begin{array}{c}S \\
M 5\end{array}$ & & & & $\begin{array}{l}\text { Baldry et al., } 1988 \\
\text { Briskin, } 1979\end{array}$ \\
\hline Docosane & 1 & & $S$ & & & Bell et al., 1966 \\
\hline Y-Dodecalactone & 1 & M 63 & & M 63 & & Carmines, $2002^{c}$ \\
\hline$\delta$-Dodecalactone & 1 & M 62, 63 & & $\begin{array}{c}M 61 \\
M 60 \\
M 62,63\end{array}$ & & $\begin{array}{l}\text { Gaworski et al., } 1998 \\
\text { Gaworski et al., } 1999 \text { a } \\
\text { Carmines, } 2002^{\mathrm{c}}\end{array}$ \\
\hline
\end{tabular}


Table 2 (contd.)

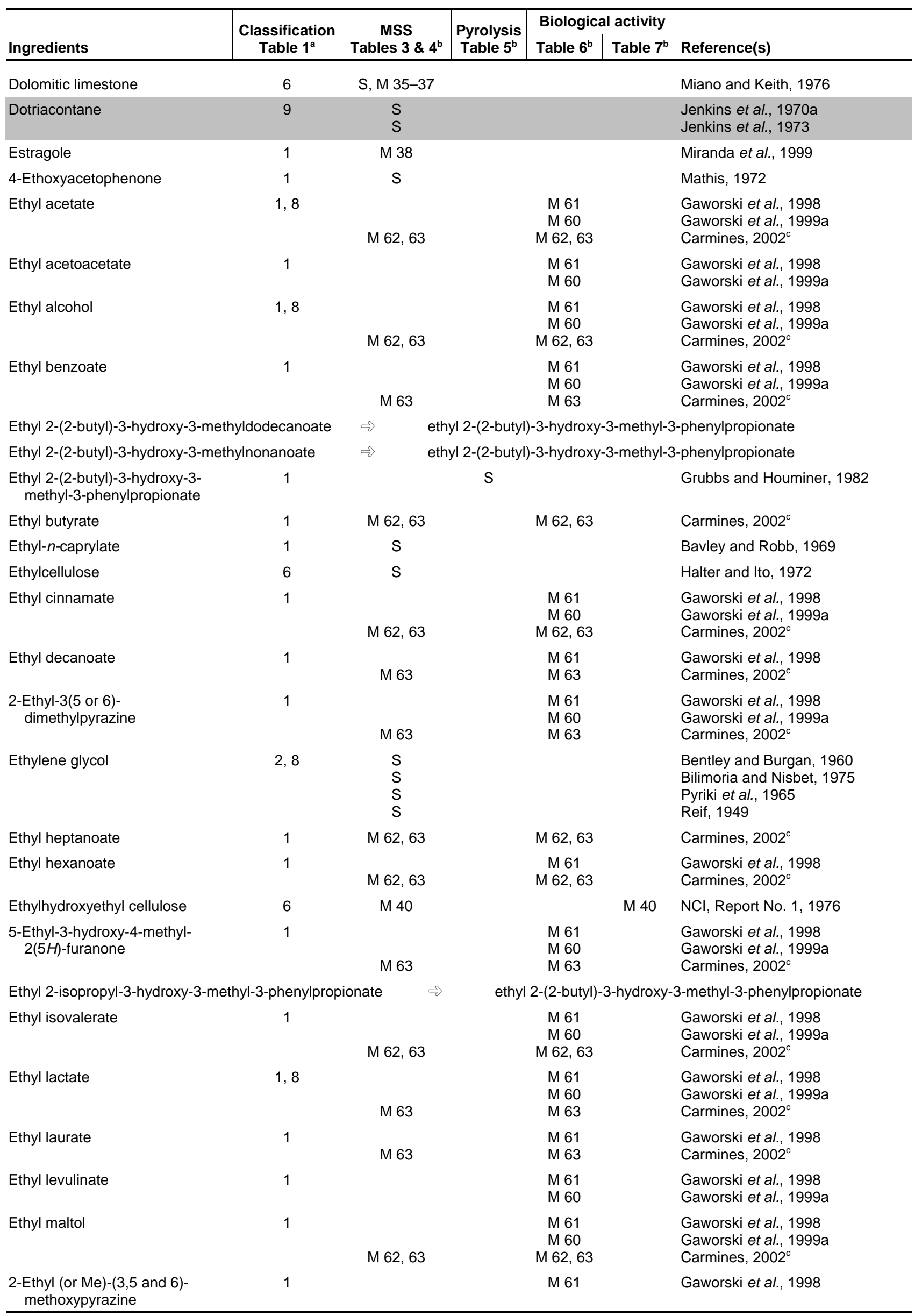




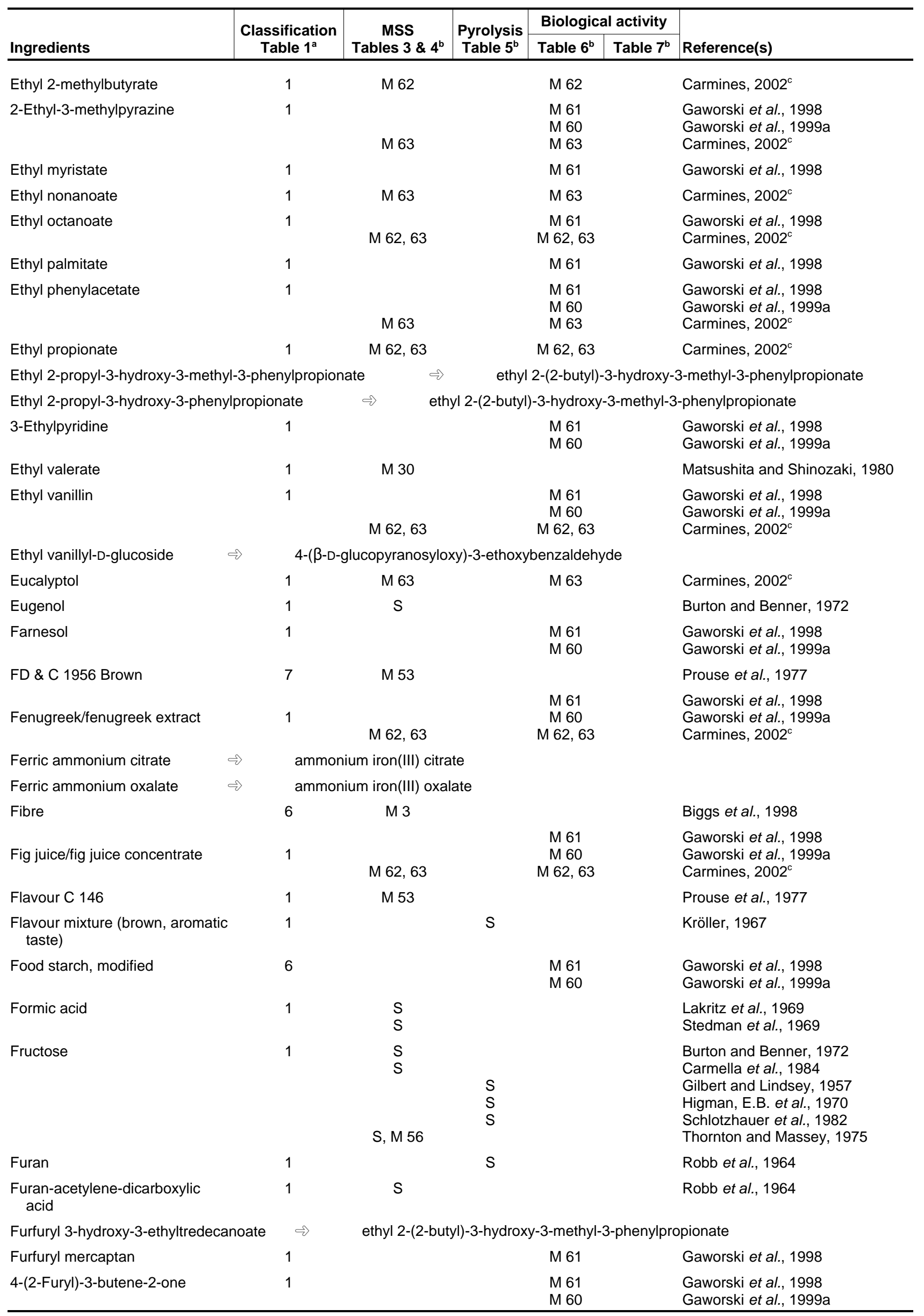


Table 2 (contd.)

\begin{tabular}{|c|c|c|c|c|c|c|}
\hline \multirow[b]{2}{*}{ Ingredients } & \multirow{2}{*}{$\begin{array}{c}\text { Classification } \\
\text { Table } 1^{\mathrm{a}}\end{array}$} & \multirow{2}{*}{$\begin{array}{c}\text { MSS } \\
\text { Tables } 3 \& 4^{b}\end{array}$} & \multirow{2}{*}{$\begin{array}{l}\text { Pyrolysis } \\
\text { Table } 5^{\text {b }}\end{array}$} & \multicolumn{2}{|c|}{ Biological activity } & \multirow[b]{2}{*}{ Reference(s) } \\
\hline & & & & Table $6^{\text {b }}$ & Table $7^{\mathrm{b}}$ & \\
\hline Gaballon & 1 & M 28 & & & & Komatsu, 1997 \\
\hline Galacto-mannan gums & 6 & M 46, 47, 49 & & & M 46, 47 & $\mathrm{NCl}$, Report No. 4, 1980 \\
\hline Galbanum oil & 1 & M 63 & & M 63 & & Carmines, $2002^{\mathrm{C}}$ \\
\hline Gallic acid & 9 & $S$ & & & & Burton and Benner, 1972 \\
\hline Galvinoxyl & 9 & $\mathrm{~S}$ & & & & Burton and Benner, 1972 \\
\hline Genet absolute & 1 & M 63 & & M 63 & & Carmines, $2002^{c}$ \\
\hline Geraniol & 1,9 & $\begin{array}{c}S \\
M 62,63\end{array}$ & & M 62, 63 & & $\begin{array}{l}\text { Bavley and Robb, } 1969 \\
\text { Carmines, } 2002^{c}\end{array}$ \\
\hline Geranium rose oil & 1 & M 62, 63 & & M 62, 63 & & Carmines, $2002^{c}$ \\
\hline Geranyl acetate & 1 & M 62, 63 & & M 62, 63 & & Carmines, $2002^{\mathrm{c}}$ \\
\hline Geranyl acetone & 1 & S & & & & Jing and Xian, 1999 \\
\hline Geranyl butyrate & 1 & M 63 & & M 63 & & Carmines, $2002^{c}$ \\
\hline Geranyl formate & 1 & M 63 & & M 63 & & Carmines, $2002^{\mathrm{c}}$ \\
\hline Geranyl 3-hydroxy-3-methyloctanoate & $\Leftrightarrow$ & ethyl 2-(2-but) & yl)-3-hydrox & -3-methyl-s & 3-phenylpro & opionate \\
\hline Geranyl phenylacetate & 1 & M 62 & & M 62 & & Carmines, $2002^{\mathrm{c}}$ \\
\hline Ginger oil & 1 & M 62, 63 & & $\begin{array}{c}\text { M } 61 \\
M 60 \\
M 62,63\end{array}$ & & $\begin{array}{l}\text { Gaworski et al., } 1998 \\
\text { Gaworski et al., } 1999 a \\
\text { Carmines, } 2002^{\mathrm{c}}\end{array}$ \\
\hline $\begin{array}{l}\text { 4-( } \beta \text {-D-glucopyranosyloxy)-3- } \\
\text { ethoxybenzaldehyde }\end{array}$ & 1 & & $S$ & & & Herron, 1988 \\
\hline Glucose & 1 & $\begin{array}{l}\mathrm{S} \\
\mathrm{S} \\
\mathrm{S} \\
\mathrm{S}\end{array}$ & $\begin{array}{l}\mathrm{S} \\
\mathrm{S} \\
\mathrm{S} \\
\mathrm{S} \\
\end{array}$ & $\begin{array}{l}\text { M } 61 \\
M 60\end{array}$ & & $\begin{array}{l}\text { Bell et al., } 1966 \\
\text { Crosthwaite et al., } 1979 \\
\text { Gager et al., 1971a } \\
\text { Gager et al., 1971b } \\
\text { Gilbert and Lindsey, } 1957 \\
\text { Higman, E.B. et al., } 1970 \\
\text { Kato, } 1967 \\
\text { Schlotzhauer et al., } 1967 \\
\text { Thornton and Massey, } 1975 \\
\text { Thornton and Valentine, } 1968 \\
\text { Tomasik, } 1989 \\
\text { Gaworski et al., 1998 } \\
\text { Gaworski et al., 1999a }\end{array}$ \\
\hline Glucuronic acid & 9 & & S & & & Schlotzhauer et al., 1967 \\
\hline Glutamic acid & 1 & S & & & & Kaburaki et al., 1969 \\
\hline Glycerol & 2 & $\begin{array}{c}S \\
S \\
S \\
S \\
S \\
M 31-34 \\
S, M 41-44 \\
S \\
M 62,63 \\
M 55 \\
S \\
S\end{array}$ & S & $\begin{array}{c}\text { M } 61 \\
\text { M } 60 \\
\text { S, M } 59\end{array}$ & & 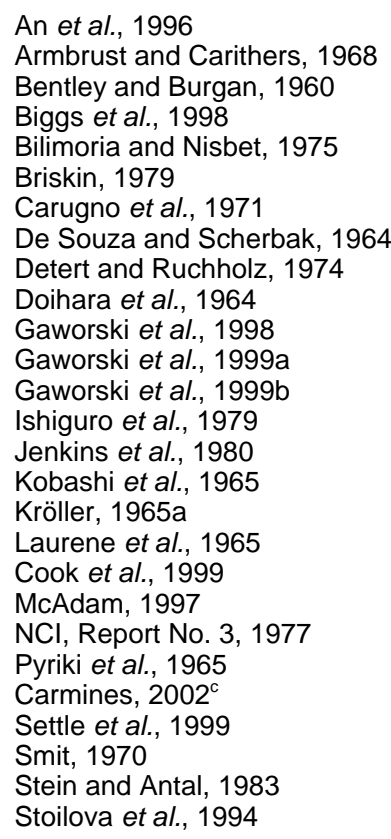 \\
\hline $\begin{array}{l}\text { Glyceryl monoacetate } \\
\text { (monoacetin) }\end{array}$ & 4,6 & & $S$ & & & Kröller, 1968 \\
\hline
\end{tabular}


Table 2 (contd.)

\begin{tabular}{|c|c|c|c|c|c|c|}
\hline \multirow[b]{2}{*}{ Ingredients } & \multirow{2}{*}{$\begin{array}{c}\text { Classification } \\
\text { Table } 1^{\mathrm{a}}\end{array}$} & \multirow{2}{*}{$\begin{array}{c}\text { MSS } \\
\text { Tables } 3 \& 4^{b}\end{array}$} & \multirow{2}{*}{$\begin{array}{l}\text { Pyrolysis } \\
\text { Table }^{\mathrm{b}}\end{array}$} & \multicolumn{2}{|c|}{ Biological activity } & \multirow[b]{2}{*}{ Reference(s) } \\
\hline & & & & Table $6^{\text {b }}$ & Table $7^{b}$ & \\
\hline Glycine & 1 & $S$ & $S$ & & & $\begin{array}{l}\text { Johnson et al., } 1973 \\
\text { Schmeltz et al., } 1972\end{array}$ \\
\hline Glycosylamine & 1 & $S$ & & & & Cox et al., 1987 \\
\hline Glycyrrhetinic acid & 1 & $S$ & & & & Sakagami, 1973 \\
\hline Glycyrrhizae radix & 1 & M 51 & & & & Ogawa, 1998 \\
\hline Glycyrrhizic acid & 1 & $S$ & S & & & $\begin{array}{l}\text { Sakagami, } 1973 \\
\text { Yongkuan and Wangyun, } 1995\end{array}$ \\
\hline Glycyrrhizic acid disodium salt & 1 & & $S$ & & & Yongkuan and Wangyun, 1995 \\
\hline $\begin{array}{l}\text { Glycyrrhizic acid monosodium } \\
\text { salt }\end{array}$ & 1 & & $S$ & & & Yongkuan and Wangyun, 1995 \\
\hline Glycyrrhizic acid trisodium salt & 1 & & $S$ & & & Yongkuan and Wangyun, 1995 \\
\hline Glyoxal & 5,6 & $\begin{array}{l}\text { M } 12 \\
\text { M } 18\end{array}$ & $S$ & & & $\begin{array}{l}\text { Dontenwill et al., } 1972 \\
\text { Dontenwill et al., } 1976 \\
\text { Kröller, } 1970\end{array}$ \\
\hline Guaiac wood oil & 1 & M 63 & & $\begin{array}{l}\text { M } 61 \\
\text { M } 60 \\
\text { M } 63\end{array}$ & & $\begin{array}{l}\text { Gaworski et al., } 1998 \\
\text { Gaworski et al., 1999a } \\
\text { Carmines, } 2002^{\mathrm{c}}\end{array}$ \\
\hline Guaiacol & 1 & & & $\begin{array}{l}\text { M } 61 \\
\text { M } 60\end{array}$ & & $\begin{array}{l}\text { Gaworski et al., } 1998 \\
\text { Gaworski et al., } 1999 a\end{array}$ \\
\hline Guar (oxygenated) & 6 & & $S$ & & & Kröller, 1968 \\
\hline Guar gum & 6 & M 2 & S & & & $\begin{array}{l}\text { Armbrust and Carithers, } 1968 \\
\text { Kröller, } 1965 \mathrm{~b} \\
\text { Sjöberg and Pyysalo, } 1985\end{array}$ \\
\hline Gummi arabicum & 6 & & $\begin{array}{l}S \\
S\end{array}$ & & & $\begin{array}{l}\text { Kröller, 1965b } \\
\text { Sjöberg and Pyysalo, } 1985\end{array}$ \\
\hline 2,4-Heptadienal & 1 & M 63 & & M 63 & & Carmines, $2002^{c}$ \\
\hline Y-Heptalactone & 1 & M 62, 63 & & $\begin{array}{c}\text { M 61 } \\
\text { M 60 } \\
\text { M 62, } 63\end{array}$ & & $\begin{array}{l}\text { Gaworski et al., } 1998 \\
\text { Gaworski et al., } 1999 a \\
\text { Carmines, } 2002^{\mathrm{c}}\end{array}$ \\
\hline Heptanoic acid & 1 & & & $\begin{array}{l}\text { M } 61 \\
\text { M } 60\end{array}$ & & $\begin{array}{l}\text { Gaworski et al., } 1998 \\
\text { Gaworski et al., } 1999 a\end{array}$ \\
\hline 2-Heptanone & 1 & M 63 & & M 63 & & Carmines, $2002^{\mathrm{c}}$ \\
\hline 3-Hepten-2-one & 1 & M 62 & & M 62 & & Carmines, $2002^{\mathrm{c}}$ \\
\hline$\omega-6-$ Hexadecenlactone & 1 & M 63 & & $\begin{array}{l}\text { M } 61 \\
\text { M } 60 \\
\text { M } 63\end{array}$ & & $\begin{array}{l}\text { Gaworski et al., } 1998 \\
\text { Gaworski et al., } 1999 \mathrm{a} \\
\text { Carmines, 2002 }\end{array}$ \\
\hline Hexadien-(2,4)-al & 1 & S & & & & Bavley and Robb, 1969 \\
\hline $\mathrm{Y}$-Hexalactone & 1 & M 62 & & $\begin{array}{l}\text { M } 61 \\
\text { M } 60 \\
\text { M } 62\end{array}$ & & $\begin{array}{l}\text { Gaworski et al., } 1998 \\
\text { Gaworski et al., } 1999 \mathrm{a} \\
\text { Carmines, } 2002^{\mathrm{c}}\end{array}$ \\
\hline Hexanal & 1 & M 63 & & M 63 & & Carmines, $2002^{c}$ \\
\hline Hexanoic acid & 1 & M 62, 63 & & $\begin{array}{c}M 61 \\
M 60 \\
M 62,63\end{array}$ & & $\begin{array}{l}\text { Gaworski et al., } 1998 \\
\text { Gaworski et al., } 1999 a \\
\text { Carmines, } 2002^{\mathrm{c}}\end{array}$ \\
\hline Hexen-2-al & 1 & M 62, 63 & & M 62, 63 & & Carmines, $2002^{\mathrm{c}}$ \\
\hline trans-2-Hexenoic acid & 1 & M 62 & & M 62 & & Carmines, $2002^{c}$ \\
\hline 3-Hexen-1-ol & 1 & M 62, 63 & & M 62, 63 & & Carmines, $2002^{c}$ \\
\hline Hexyl acetate & 1 & M 63 & & M 63 & & Carmines, $2002^{c}$ \\
\hline Hexyl 2-methylbutanoate & 1 & M 63 & & M 63 & & Carmines, $2002^{c}$ \\
\hline Hexyl phenylacetate & 1 & M 63 & & M 63 & & Carmines, $2002^{\mathrm{C}}$ \\
\hline Honey & 1 & & & $\begin{array}{l}\text { M } 61 \\
\text { M } 60\end{array}$ & & $\begin{array}{l}\text { Gaworski et al., } 1998 \\
\text { Gaworski et al., 1999a }\end{array}$ \\
\hline Humectant & 2 & M 51 & & & & Ogawa, 1998 \\
\hline Humic acid, sodium salt & 7 & & $S$ & & & Kröller, 1963c \\
\hline p-Hydroxybenzoic acid ethylester & 5 & & $S$ & & & Kröller, 1970 \\
\hline $\begin{array}{l}\text { 4-Hydroxy-2,5-dimethyl-3(2H)- } \\
\text { furanone }\end{array}$ & 1 & M 63 & & $\begin{array}{l}\text { M } 61 \\
M 60 \\
M 63\end{array}$ & & $\begin{array}{l}\text { Gaworski et al., } 1998 \\
\text { Gaworski et al., } 1999 \mathrm{a} \\
\text { Carmines, } 2002^{\mathrm{c}}\end{array}$ \\
\hline
\end{tabular}


Table 2 (contd.)

\begin{tabular}{|c|c|c|c|c|c|c|}
\hline \multirow[b]{2}{*}{ Ingredients } & \multirow{2}{*}{$\begin{array}{c}\text { Classification } \\
\text { Table } 1^{\mathrm{a}}\end{array}$} & \multirow{2}{*}{$\begin{array}{c}\text { MSS } \\
\text { Tables } 3 \& 4^{b} \\
\end{array}$} & \multirow{2}{*}{$\begin{array}{l}\text { Pyrolysis } \\
\text { Table 5 }\end{array}$} & \multicolumn{2}{|c|}{ Biological activity } & \multirow[b]{2}{*}{ Reference(s) } \\
\hline & & & & Table $6^{\text {b }}$ & Table $7^{\mathrm{b}}$ & \\
\hline Hydroxyethyl cellulose & 6 & & $S$ & & & Kröller, 1964a \\
\hline 4-( $p$-Hydroxyphenyl)-2-butanone & 1 & M 62 & & $\begin{array}{l}\text { M } 61 \\
\text { M } 60 \\
\text { M } 62\end{array}$ & & $\begin{array}{l}\text { Gaworski et al., } 1998 \\
\text { Gaworski et al., } 1999 a \\
\text { Carmines, } 2002^{\mathrm{c}}\end{array}$ \\
\hline Hyssop oil & 1 & M 63 & & M 63 & & Carmines, $2002^{c}$ \\
\hline $\mathrm{Hz}-1$ catalyst & 9 & $S$ & & & & Terrell and Schmeltz, 1970 \\
\hline Immortelle & 1 & & & $\begin{array}{l}\text { M } 61 \\
\text { M } 60\end{array}$ & & $\begin{array}{l}\text { Gaworski et al., } 1998 \\
\text { Gaworski et al., } 1999 a\end{array}$ \\
\hline Immortelle extract & 1 & M 63 & & M 63 & & Carmines, $2002^{c}$ \\
\hline Indole & 1 & $S$ & & & & Burton and Benner, 1972 \\
\hline Inositol & 2 & M 5 & & & & Briskin, 1979 \\
\hline Invert sugar $\Rightarrow$ & & & & & & \\
\hline Ionone & 1 & M 62, 63 & & M 62, 63 & & Carmines, $2002^{c}$ \\
\hline$\alpha$-lonone & 1 & M 62, 63 & & M 62, 63 & & Carmines, $2002^{c}$ \\
\hline$\beta$-Ionone & 1 & S & & & & Jing and Xian, 1999 \\
\hline Iron(III) chloride & $3,6,7,9$ & M 26 & & & & Eicher and Müller, 1985 \\
\hline Iron(III) oxide hydrate & 7 & M 21-24 & & & & Eicher and Müller, 1985 \\
\hline Isoamyl acetate & 1 & M 62, 63 & & M 62, 63 & & Carmines, $2002^{c}$ \\
\hline Isoamyl benzoate & 1 & $\stackrel{S}{\mathrm{M} 63}$ & & M 63 & & $\begin{array}{l}\text { Mathis, } 1983 \\
\text { Carmines, } 2002^{\mathrm{c}}\end{array}$ \\
\hline Isoamyl butyrate & 1 & M 63 & & M 63 & & Carmines, $2002^{\circ}$ \\
\hline Isoamyl cinnamate & 1 & $\stackrel{\mathrm{S}}{\mathrm{M} 63}$ & & M 63 & & $\begin{array}{l}\text { Mathis, } 1983 \\
\text { Carmines, } 2002^{c}\end{array}$ \\
\hline Isoamyl formate & 1 & M 63 & & M 63 & & Carmines, $2002^{\circ}$ \\
\hline Isoamyl hexanoate & 1 & M 63 & & M 63 & & Carmines, $2002^{\mathrm{C}}$ \\
\hline Isoamyl isovalerate & 1 & $\begin{array}{c}S \\
S \\
S \\
M 63\end{array}$ & & M 63 & & $\begin{array}{l}\text { Green et al., } 1989 \\
\text { Mathis, } 1983 \\
\text { Stotesbury et al., } 1999 \\
\text { Carmines, } 2002^{\mathrm{c}}\end{array}$ \\
\hline Isoamyl phenylacetate & 1 & $\stackrel{S}{M} 63$ & & $\begin{array}{l}\text { M } 61 \\
\text { M } 60 \\
\text { M } 63\end{array}$ & & 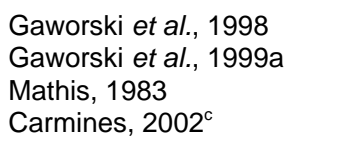 \\
\hline Isoamyl salicylate & 1 & M 62 & & M 62 & & Carmines, $2002^{c}$ \\
\hline Isobutyl acetate & 1 & M 63 & & M 63 & & Carmines, $2002^{c}$ \\
\hline Isobutyl alcohol & $1,6,7$ & M 62, 63 & & M 62, 63 & & Carmines, $2002^{\mathrm{C}}$ \\
\hline Isobutyl cinnamate & 1 & M 63 & & $\begin{array}{l}\text { M } 61 \\
\text { M } 60 \\
\text { M } 63\end{array}$ & & $\begin{array}{l}\text { Gaworski et al., } 1998 \\
\text { Gaworski et al., } 1999 a \\
\text { Carmines, } 2002^{\mathrm{c}}\end{array}$ \\
\hline 2-Isobutyl-3-methoxypyrazine & 1 & & & $\begin{array}{l}\text { M } 61 \\
\text { M } 60\end{array}$ & & $\begin{array}{l}\text { Gaworski et al., } 1998 \\
\text { Gaworski et al., 1999a }\end{array}$ \\
\hline$\alpha$-Isobutylphenethyl alcohol & 1 & & & $\begin{array}{l}\text { M } 61 \\
\text { M } 60\end{array}$ & & $\begin{array}{l}\text { Gaworski et al., } 1998 \\
\text { Gaworski et al., } 1999 a\end{array}$ \\
\hline Isobutyl phenylacetate & 1 & M 63 & & $\begin{array}{l}\text { M } 61 \\
\text { M } 63\end{array}$ & & $\begin{array}{l}\text { Gaworski et al., } 1998 \\
\text { Carmines, } 2002^{\mathrm{C}}\end{array}$ \\
\hline Isobutyraldehyde & 1 & M 63 & & $\begin{array}{l}\text { M } 61 \\
\text { M } 60 \\
\text { M } 63\end{array}$ & & $\begin{array}{l}\text { Gaworski et al., } 1998 \\
\text { Gaworski et al., } 1999 a \\
\text { Carmines, } 2002^{\mathrm{c}}\end{array}$ \\
\hline Isobutyric acid & 1 & M 62, 63 & & $\begin{array}{c}\text { M 61 } \\
\text { M 60 } \\
\text { M 62, 63 }\end{array}$ & & $\begin{array}{l}\text { Gaworski et al., } 1998 \\
\text { Gaworski et al., } 1999 a \\
\text { Carmines, } 2002^{\mathrm{c}}\end{array}$ \\
\hline Isoeugenol & 1 & & $S$ & & & Schlotzhauer et al., 1967 \\
\hline Isoprene & 1 & $S$ & $\mathrm{~S}$ & & & $\begin{array}{l}\text { Robb et al., } 1964 \\
\text { Van Auken et al., } 1979\end{array}$ \\
\hline
\end{tabular}


Table 2 (contd.)

\begin{tabular}{|c|c|c|c|c|c|c|}
\hline \multirow[b]{2}{*}{ Ingredients } & \multirow{2}{*}{$\begin{array}{c}\text { Classification } \\
\text { Table } 1^{\mathrm{a}}\end{array}$} & \multirow{2}{*}{$\begin{array}{c}\text { MSS } \\
\text { Tables } 3 \& 4^{b}\end{array}$} & \multirow{2}{*}{$\begin{array}{l}\text { Pyrolysis } \\
\text { Table } 5^{\text {b }}\end{array}$} & \multicolumn{2}{|c|}{ Biological activity } & \multirow[b]{2}{*}{ Reference(s) } \\
\hline & & & & Table $6^{\text {b }}$ & Table $7^{\mathrm{b}}$ & \\
\hline Isovaleric acid & 1 & M 62, 63 & & $\begin{array}{c}M 61 \\
M 60 \\
M 62,63\end{array}$ & & $\begin{array}{l}\text { Gaworski et al., } 1998 \\
\text { Gaworski et al., } 1999 a \\
\text { Carmines, } 2002^{\mathrm{c}}\end{array}$ \\
\hline Jasmine absolute & 1 & M 63 & & M 63 & & Carmines, $2002^{c}$ \\
\hline Kola nut extract & 1 & M 62, 63 & & M 62, 63 & & Carmines, $2002^{\mathrm{c}}$ \\
\hline Labdanum absolute & 1 & M 62 & & $\begin{array}{l}\text { M } 61 \\
M 60 \\
M 62\end{array}$ & & $\begin{array}{l}\text { Gaworski et al., } 1998 \\
\text { Gaworski et al., } 1999 \mathrm{a} \\
\text { Carmines, 2002 }\end{array}$ \\
\hline Lactic acid & 1 & S & $S$ & $\begin{array}{l}\text { M } 61 \\
\text { M } 60\end{array}$ & & $\begin{array}{l}\text { Lakritz et al., } 1969 \\
\text { Gaworski et al., } 1998 \\
\text { Gaworski et al., 1999a } \\
\text { Kröller, 1966b }\end{array}$ \\
\hline Lactose & 1,9 & & $S$ & & & Tomasik, 1989 \\
\hline Lauric acid & 1 & M 63 & & M 63 & & Carmines, $2002^{c}$ \\
\hline Lavender oil & 1 & M 63 & & M 63 & & Carmines, $2002^{\mathrm{c}}$ \\
\hline Lead borate & 9 & $S$ & & & & Terrell and Schmeltz, 1970 \\
\hline Lead nitrate & 9 & $S$ & & & & Bentley and Burgan, 1960 \\
\hline Lemongrass oil & 1 & M 63 & & M 63 & & Carmines, $2002^{\mathrm{C}}$ \\
\hline Lemon oil & 1 & M 62, 63 & & M 62, 63 & & Carmines, $2002^{\mathrm{c}}$ \\
\hline Lemon oil terpenes & 1 & M 63 & & M 63 & & Carmines, $2002^{\circ}$ \\
\hline Lettuce leaves & 1 & & S & & & Kröller, 1970 \\
\hline Licorice & 1 & M 31-34 & $\begin{array}{l}S \\
S \\
S\end{array}$ & M 61 & & $\begin{array}{l}\text { Chung and Aldridge, } 1999 \\
\text { Fratini et al., } 1977 \\
\text { Gaworski et al., } 1998 \\
\text { Kröller, } 1967 \\
\text { McAdam, } 1997\end{array}$ \\
\hline Licorice extract & 1,7 & M 62,64 & & $\begin{array}{c}\text { M } 61 \\
\text { M } 60 \\
\text { M 62, } 64\end{array}$ & & $\begin{array}{l}\text { Gaworski et al., } 1998 \\
\text { Gaworski et al., } 1999 \mathrm{a} \\
\text { Carmines, 2002 }\end{array}$ \\
\hline Lignin & 9 & & $\begin{array}{l}S \\
S \\
S \\
S\end{array}$ & & & $\begin{array}{l}\text { Gilbert and Lindsey, } 1957 \\
\text { Schlotzhauer et al., } 1967 \\
\text { Schlotzhauer et al., } 1982 \\
\text { Schlotzhauer et al., } 1985\end{array}$ \\
\hline Lime oil & 1 & M 63 & & M 63 & & Carmines, $2002^{\mathrm{c}}$ \\
\hline Lime oil, terpeneless & 1 & M 63 & & M 63 & & Carmines, $2002^{\mathrm{c}}$ \\
\hline$d$-Limonene & 1 & S & & & & Bavley and Robb, 1969 \\
\hline Linalool & 1 & $\begin{array}{c}S \\
M 63\end{array}$ & & $\begin{array}{l}\text { M } 61 \\
\text { M } 63\end{array}$ & & $\begin{array}{l}\text { Bavley and Robb, } 1969 \\
\text { Gaworski et al., } 1998 \\
\text { Carmines, } 2002^{\mathrm{c}}\end{array}$ \\
\hline Linalyl acetate & 1 & M 63 & & M 63 & & Carmines, $2002^{\mathrm{c}}$ \\
\hline Lithium nitrate & 9 & $S$ & & & & Burton and Benner, 1972 \\
\hline Lovage extract & 1 & M 62, 63 & & M 62, 63 & & Carmines, $2002^{c}$ \\
\hline Lovage oil & 1 & & & $\begin{array}{l}\text { M } 61 \\
\text { M } 60\end{array}$ & & $\begin{array}{l}\text { Gaworski et al., } 1998 \\
\text { Gaworski et al., 1999a }\end{array}$ \\
\hline $\begin{array}{l}\text { Lycopodium bisdepuratum } \\
\text { (seeds of club moss) }\end{array}$ & 9 & M 29 & & & & Kossack, 1987 \\
\hline L-Lysine & 1 & & & M 61 & & Gaworski et al., 1998 \\
\hline Mace oil & 1 & M 63 & & M 63 & & Carmines, $2002^{\mathrm{C}}$ \\
\hline Madder lake & 7 & & $S$ & & & Kröller, 1963d \\
\hline Magnesium acetate & 3,6 & S & & & & Aksu, 1969 \\
\hline Magnesium aluminium citrate & 3 & M 25 & & & & Eicher and Müller, 1985 \\
\hline Magnesium carbonate & $3,6,7$ & $\begin{array}{l}S \\
S\end{array}$ & & & & $\begin{array}{l}\text { Burton and Benner, } 1972 \\
\text { Terrell and Schmeltz, } 1970\end{array}$ \\
\hline Magnesium iron(III) citrate & 3 & M 19-24 & & & & Eicher and Müller, 1985 \\
\hline
\end{tabular}


Table 2 (contd.)

\begin{tabular}{|c|c|c|c|c|c|c|}
\hline \multirow[b]{2}{*}{ Ingredients } & \multirow{2}{*}{$\begin{array}{c}\begin{array}{c}\text { Classification } \\
\text { Table } 1^{\mathrm{a}}\end{array} \\
\end{array}$} & \multirow{2}{*}{$\begin{array}{c}\text { MSS } \\
\text { Tables } 3 \& 4^{\text {b }} \\
\end{array}$} & \multirow{2}{*}{$\begin{array}{c}\text { Pyrolysis } \\
\text { Table }^{\mathbf{b}}\end{array}$} & \multicolumn{2}{|c|}{ Biological activity } & \multirow[b]{2}{*}{ Reference(s) } \\
\hline & & & & Table $6^{\text {b }}$ & Table $7^{\mathrm{b}}$ & \\
\hline Magnesium nitrate & 9 & $\begin{array}{c}S, M 7-9 \\
S, M ~ 42,44,45 \\
S, M 50\end{array}$ & & & $\stackrel{S}{S}, \stackrel{M}{M} 45$ & $\begin{array}{l}\text { Collins et al.., } 1981 \\
\text { Kier et al., } 1974 \\
\text { NCI, Report No. 3, } 1977 \\
\text { Norman and Bryant, } 1975\end{array}$ \\
\hline Magnesium oxide & $3,6,7$ & & & & S & Wynder and Hoffmann, 1961 \\
\hline Magnesium vanillin-5-carboxylate & $\Rightarrow$ & \multicolumn{2}{|c|}{ 5-carboxyvanillin } & & & \\
\hline Maleic anhydride & 9 & S & & & & Thornton and Valentine, 1968 \\
\hline Malic acid & 1 & & $\begin{array}{l}S \\
S\end{array}$ & \multicolumn{2}{|l|}{ M 61} & $\begin{array}{l}\text { Kröller, 1966b } \\
\text { Gaworski et al., } 1998 \\
\text { Gilbert and Lindsey, } 1957\end{array}$ \\
\hline Malt & 1 & & & \multicolumn{2}{|l|}{$\begin{array}{l}\text { M } 61 \\
\text { M } 60\end{array}$} & $\begin{array}{l}\text { Gaworski et al., } 1998 \\
\text { Gaworski et al., } 1999 a\end{array}$ \\
\hline Malt extract & 1 & M 62 & & \multicolumn{2}{|l|}{ M 62} & Carmines, $2002^{c}$ \\
\hline Maltodextrin & 1,6 & & & \multicolumn{2}{|l|}{$\begin{array}{l}\text { M } 61 \\
\text { M } 60\end{array}$} & $\begin{array}{l}\text { Gaworski et al., } 1998 \\
\text { Gaworski et al., 1999a }\end{array}$ \\
\hline Maltol & 1 & M 62, 63 & & \multirow[t]{2}{*}{$\begin{array}{c}\text { M } 61 \\
M 60 \\
M 62,63\end{array}$} & & $\begin{array}{l}\text { Gaworski et al., } 1998 \\
\text { Gaworski et al., } 1999 a \\
\text { Carmines, } 2002^{\mathrm{c}}\end{array}$ \\
\hline Maltose & 1 & M 51 & & & & Ogawa, 1998 (Patent) \\
\hline Mandarin oil & 1 & M 63 & & \multicolumn{2}{|l|}{ M 63} & Carmines, $2002^{\mathrm{c}}$ \\
\hline Manganese iron(III) citrate & 9 & M 19-24 & & \multicolumn{2}{|l|}{ ivi 00} & Eicher and Müller, 1985 \\
\hline Manganese nitrate & 9 & S & & & & Burton and Benner, 1972 \\
\hline Maple syrup & 1 & M 62 & & \multicolumn{2}{|l|}{ M 62} & Carmines, $2002^{c}$ \\
\hline Mate absolute & 1 & M 62, 63 & & \multicolumn{2}{|l|}{ M 62, 63} & Carmines, $2002^{\mathrm{C}}$ \\
\hline Mate leaf & 1 & & & \multicolumn{2}{|l|}{ M 61} & Gaworski et al., 1998 \\
\hline Megastigmatrienone & 1 & $S$ & & & Yang et al., 2001 \\
\hline Melamine-formaldehyde resin & 6 & & $S$ & & & Kröller, 1968 \\
\hline Melilot & 1 & & $S$ & & & Kröller, 1967 \\
\hline Menthol & 1 & $\begin{array}{c}S \\
S \\
S \\
S \\
S \\
M 30 \\
M 38 \\
S \\
S \\
S \\
S \\
S \\
M 55 \\
S \\
M 57\end{array}$ & 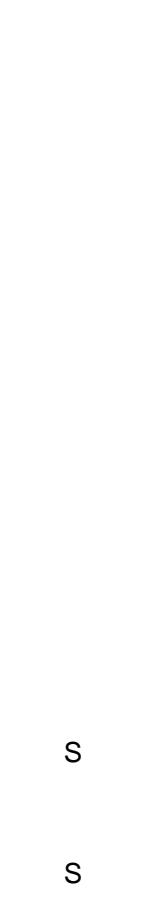 & $\begin{array}{c}S \\
M 63,64 \\
\text { S } \\
\text { M } 61 \\
\text { M } 60\end{array}$ & & 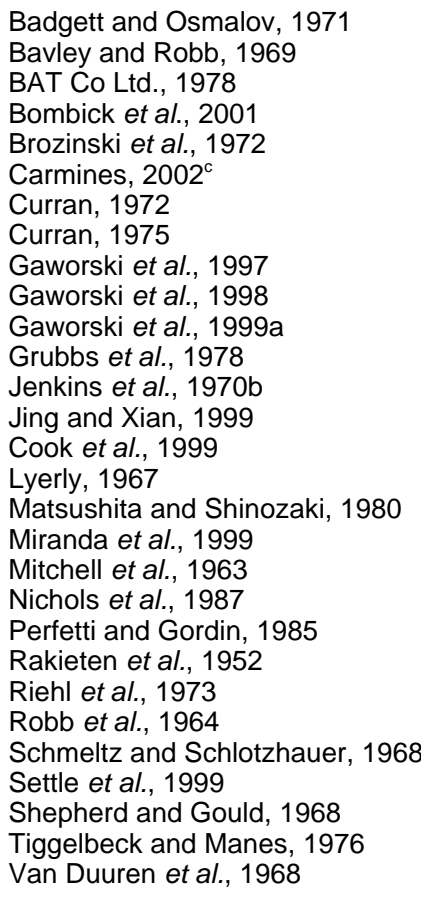 \\
\hline Menthone & 1 & $\begin{array}{c}\text { S } \\
\text { M } 62\end{array}$ & & $\begin{array}{l}\text { M } 61 \\
\text { M } 60 \\
\text { M } 62\end{array}$ & & $\begin{array}{l}\text { Bavley and Robb, } 1969 \\
\text { Gaworski et al., } 1998 \\
\text { Gaworski et al., } 1999 \mathrm{a} \\
\text { Carmines, } 2002^{\mathrm{c}}\end{array}$ \\
\hline Methanol & 9 & M 10 & & & & Detert and Ruchholz, 1974 \\
\hline Methocel & lose & & & & & \\
\hline
\end{tabular}




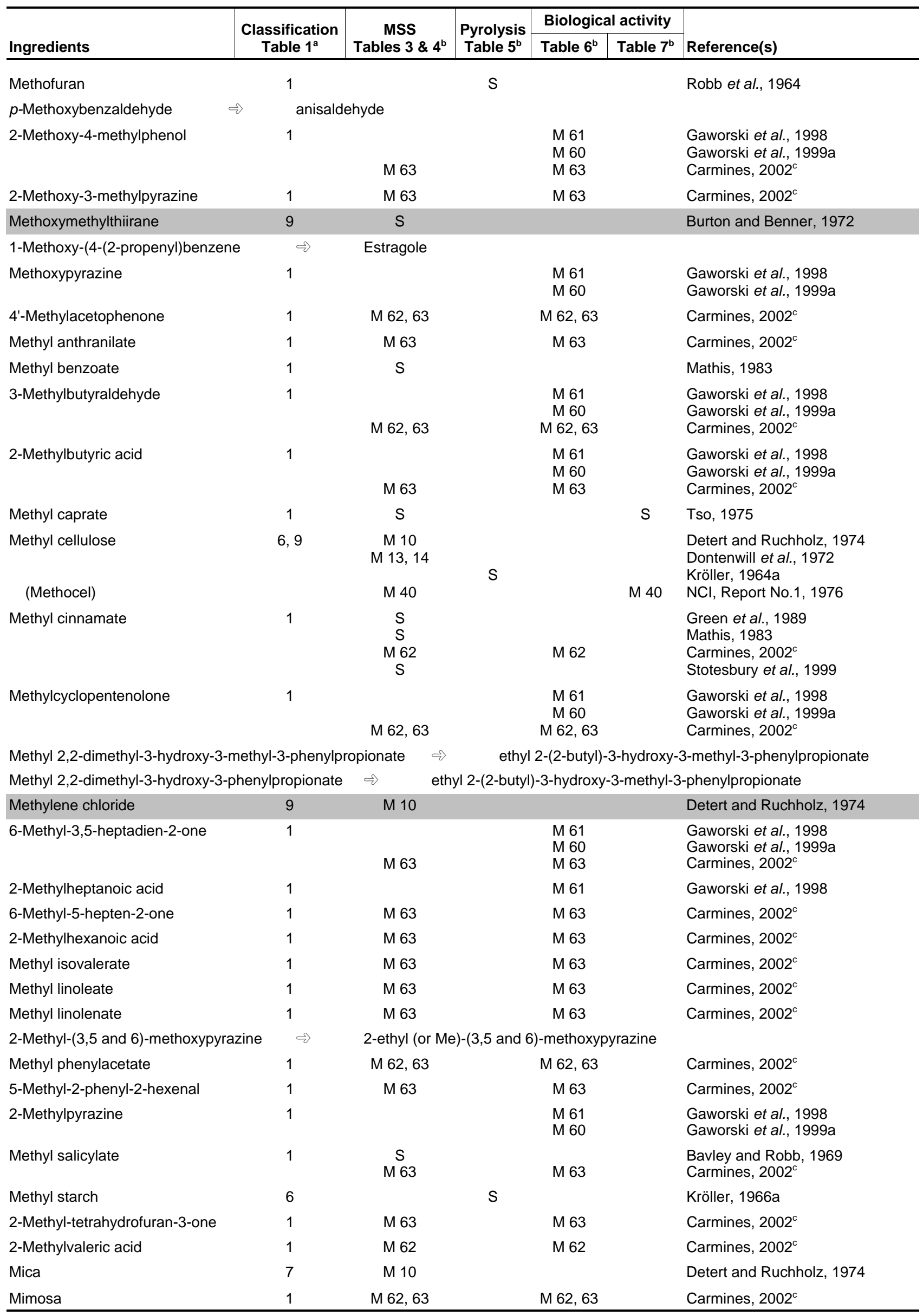


Table 2 (contd.)

\begin{tabular}{|c|c|c|c|c|c|c|}
\hline \multirow[b]{2}{*}{ Ingredients } & \multirow{2}{*}{$\begin{array}{c}\text { Classification } \\
\text { Table } 1^{\mathrm{a}}\end{array}$} & \multirow{2}{*}{$\begin{array}{c}\text { MSS } \\
\text { Tables } 3 \& 4^{b}\end{array}$} & \multirow{2}{*}{$\begin{array}{l}\text { Pyrolysis } \\
\text { Table } 5^{\text {b }}\end{array}$} & \multicolumn{2}{|c|}{ Biological activity } & \multirow[b]{2}{*}{ Reference(s) } \\
\hline & & & & Table $6^{\text {b }}$ & Table $7^{b}$ & \\
\hline Molasses, blackstrap & 1 & M 62 & & M 62 & & Carmines, $2002^{\mathrm{c}}$ \\
\hline Molybdenum trioxide + aluminiu & oxide & Catalyst & & & & \\
\hline Momordica grosvenori & 9 & M 28 & & & & Komatsu, 1997 \\
\hline \multicolumn{7}{|c|}{ Monoacetin $\Rightarrow \quad$ glyceryl monoacetate } \\
\hline Mountain maple solid extract & 1 & & & $\begin{array}{l}\text { M } 61 \\
\text { M } 60\end{array}$ & & $\begin{array}{l}\text { Gaworski et al., } 1998 \\
\text { Gaworski et al., } 1999 a\end{array}$ \\
\hline Myrcene & 1 & S & S & & & $\begin{array}{l}\text { Bavley and Robb, } 1969 \\
\text { Robb et al., } 1964\end{array}$ \\
\hline Myrrh oil & 1 & & & $\begin{array}{l}\text { M } 61 \\
\text { M } 60\end{array}$ & & $\begin{array}{l}\text { Gaworski et al., } 1998 \\
\text { Gaworski et al., 1999a }\end{array}$ \\
\hline Neophytadiene & 1 & $\mathrm{~S}$ & & & & Schmeltz et al., 1978 \\
\hline Nerol & 1 & M 62 & & M 62 & & Carmines, $2002^{\mathrm{c}}$ \\
\hline Neroli bigarade oil & 1 & M 63 & & M 63 & & Carmines, $2002^{\mathrm{c}}$ \\
\hline Nickel acetate & 9 & S & & & S & $\begin{array}{l}\text { Wynder and Hoffmann, } 1963 \\
\text { Hoffmann and Wynder, } 1968\end{array}$ \\
\hline Nickel oxalate & 9 & S & & & & Terrell and Schmeltz, 1970 \\
\hline Nitrate & 9 & & & & $\begin{array}{l}S \\
S\end{array}$ & $\begin{array}{l}\text { Dontenwill et al., } 1976 \\
\text { Collins et al., } 1981\end{array}$ \\
\hline $\mathrm{N}$-Nitrosodimethylamine & 9 & $S$ & & & & Morie and Sloan, 1973 \\
\hline Nona-2-trans, 6-cis-dienal & 1 & M 62, 63 & & M 62, 63 & & Carmines, $2002^{c}$ \\
\hline Y-Nonalactone & 1 & M 62, 63 & & $\begin{array}{c}M 61 \\
M 60 \\
M 62,63\end{array}$ & & $\begin{array}{l}\text { Gaworski et al., } 1998 \\
\text { Gaworski et al., } 1999 a \\
\text { Carmines, 2002 }\end{array}$ \\
\hline Nonanal & 1 & M 63 & & M 63 & & Carmines, $2002^{\mathrm{C}}$ \\
\hline Nonanoic acid & 1 & M 63 & & M 63 & & Carmines, $2002^{\mathrm{c}}$ \\
\hline trans-2-Nonen-1-ol & 1 & M 63 & & M 63 & & Carmines, $2002^{\mathrm{c}}$ \\
\hline Nonyl acetate & 1 & M 63 & & M 63 & & Carmines, $2002^{\mathrm{c}}$ \\
\hline Nutmeg oil & 1 & M 62, 63 & & M 62, 63 & & Carmines, $2002^{\mathrm{C}}$ \\
\hline Oak moss & 1 & M 63 & & $\begin{array}{l}\text { M 61 } \\
\text { M 60 } \\
\text { M 63 }\end{array}$ & & $\begin{array}{l}\text { Gaworski et al., } 1998 \\
\text { Gaworski et al., 1999a } \\
\text { Carmines, } 2002^{\mathrm{c}}\end{array}$ \\
\hline Y-Octalactone & 1 & M 62, 63 & & $\begin{array}{c}M 61 \\
M 60 \\
M 62,63\end{array}$ & & $\begin{array}{l}\text { Gaworski et al., } 1998 \\
\text { Gaworski et al., } 1999 \mathrm{a} \\
\text { Carmines, } 2002^{\mathrm{c}}\end{array}$ \\
\hline ঠ-Octalactone & 1 & M 63 & & M 63 & & Carmines, $2002^{\mathrm{c}}$ \\
\hline Octanal & 1 & M 62, 63 & & M 62, 63 & & Carmines, $2002^{\mathrm{c}}$ \\
\hline n-Octane & 1,8 & $S$ & & & & Bavley and Robb, 1969 \\
\hline Octanoic acid & 1 & M 63 & & $\begin{array}{l}\text { M } 61 \\
M 60 \\
M 63\end{array}$ & & $\begin{array}{l}\text { Gaworski et al., } 1998 \\
\text { Gaworski et al., 1999a } \\
\text { Carmines, 2002 }\end{array}$ \\
\hline 1-Octanol & 1,8 & M 58 & & M 58 & & Tso, 1975 \\
\hline 1-Octen-3-ol & 1 & & & $\begin{array}{l}\text { M } 60 \\
\text { M } 61\end{array}$ & & $\begin{array}{l}\text { Gaworski et al., 1999a } \\
\text { Gaworski et al., } 1998\end{array}$ \\
\hline 1-Octen-3-yl acetate & 1 & M 62 & & M 62 & & Carmines, $2002^{c}$ \\
\hline Octyl isobutyrate & 1 & M 63 & & M 63 & & Carmines, $2002^{\mathrm{c}}$ \\
\hline Opoponax gum & 1 & M 63 & & M 63 & & Carmines, $2002^{\mathrm{c}}$ \\
\hline Opoponax oil & 1 & M 62, 63 & & M 62, 63 & & Carmines, $2002^{\mathrm{c}}$ \\
\hline Orange oil and products & 1 & M 62, 63 & & $\begin{array}{c}M 61 \\
M 60 \\
M \quad 62,63\end{array}$ & & $\begin{array}{l}\text { Bavley and Robb, } 1969 \\
\text { Gaworski et al., } 1998 \\
\text { Gaworski et al., } 1999 \mathrm{a} \\
\text { Carmines, } 2002^{\mathrm{c}}\end{array}$ \\
\hline Orange oil terpenes & 1 & M 62, 63 & & M 62, 63 & & Carmines, $2002^{\mathrm{c}}$ \\
\hline Origanum oil & 1 & M 62, 63 & & M 62, 63 & & Carmines, $2002^{\mathrm{c}}$ \\
\hline
\end{tabular}




\begin{tabular}{|c|c|c|c|c|c|c|}
\hline \multirow[b]{2}{*}{ Ingredients } & \multirow{2}{*}{$\begin{array}{c}\text { Classification } \\
\text { Table } 1^{\mathrm{a}}\end{array}$} & \multirow{2}{*}{$\begin{array}{c}\text { MSS } \\
\text { Tables } 3 \& 4^{b} \\
\end{array}$} & \multirow{2}{*}{$\begin{array}{c}\text { Pyrolysis } \\
\text { Table 5 }^{\text {b }} \\
\end{array}$} & \multicolumn{2}{|c|}{ Biological activity } & \multirow[b]{2}{*}{ Reference(s) } \\
\hline & & & & Table $6^{\text {b }}$ & Table $7^{\mathrm{b}}$ & \\
\hline Orris root extract & 1 & M 62, 63 & & M 62, 63 & & Carmines, $2002^{\mathrm{C}}$ \\
\hline Oxo-isophorone & 1 & $\mathrm{~S}$ & & & & Jing and Xian, 1999 \\
\hline Oxolamine citrate & 9 & & & & S & Dalhamn, 1969 \\
\hline Oxystarch $\Rightarrow$ & \multicolumn{6}{|c|}{ dialdehyde starch } \\
\hline Palladium & 9 & $\begin{array}{c}S \\
S, M ~ 7-9\end{array}$ & & & $\mathrm{~S}$ & $\begin{array}{l}\text { Bryant et al., } 1979 \\
\text { Collins et al., } 1981\end{array}$ \\
\hline Palladium nitrate & 9 & M 29 & & & & Kossack, 1987 \\
\hline Palladium salts & 9 & S, M 50 & & & & Norman and Bryant, 1975 \\
\hline Palmarosa oil & 1 & M 62, 63 & & M 62, 63 & & Carmines, $2002^{\mathrm{C}}$ \\
\hline Palmitic acid & 1 & S & & & & Schmeltz et al., 1978 \\
\hline Parsley oil & 1 & M 62, 63 & & M 62, 63 & & Carmines, $2002^{\mathrm{C}}$ \\
\hline Peach concentrate & 1 & S & & & & Bavley and Robb, 1969 \\
\hline Pectin & 1,6 & $\begin{array}{l}S \\
s\end{array}$ & $\begin{array}{l}S \\
S \\
S \\
S\end{array}$ & & & $\begin{array}{l}\text { Bell et al., } 1966 \\
\text { Gilbert and Lindsey, } 1957 \\
\text { Kratchanova et al.., } 1995 \\
\text { Schlotzhauer et al., } 1967 \\
\text { Sjöberg and Pyysalo, } 1985 \\
\text { Stoilova et al., } 1994\end{array}$ \\
\hline$\omega$-Pentadecalactone & 1 & M 62, 63 & & M 62, 63 & & Carmines, $2002^{c}$ \\
\hline 2,3-Pentanedione & 1 & & & $\begin{array}{l}\text { M } 61 \\
\text { M } 60\end{array}$ & & $\begin{array}{l}\text { Gaworski et al., } 1998 \\
\text { Gaworski et al., } 1999 a\end{array}$ \\
\hline Pentyl 2-(1-hydroxycyclohe & etate & \multicolumn{5}{|c|}{ ethyl 2-(2-butyl)-3-hydroxy-3-methyl-3-phenylpropionate } \\
\hline \multicolumn{2}{|c|}{ Pentyl 3-hydroxy-3-methyl-3-phenylpropionate } & \multicolumn{5}{|c|}{$\Rightarrow \quad$ ethyl 2-(2-butyl)-3-hydroxy-3-methyl-3-phenylpropionate } \\
\hline Peppermint leaves & 1 & & $\mathrm{~S}$ & & & Kröller, 1970 \\
\hline Peppermint oil & 1 & M 62, 63 & & $\begin{array}{c}\text { M } 61 \\
\text { M } 60 \\
\text { M } 62,63\end{array}$ & & $\begin{array}{l}\text { Gaworski et al., } 1998 \\
\text { Gaworski et al., } 1999 a \\
\text { Carmines, } 2002^{\mathrm{c}}\end{array}$ \\
\hline Pepper oil, black & 1 & M 62, 63 & & M 62, 63 & & Carmines, $2002^{\mathrm{C}}$ \\
\hline Perfume & 1 & $\begin{array}{l}\text { M } 1 \\
\text { M } 51\end{array}$ & & & & $\begin{array}{l}\text { An et al., } 1996 \\
\text { Ogawa, } 1998\end{array}$ \\
\hline Perlite & 6 & M 3 & & & & Biggs et al., 1998 \\
\hline Petitgrain oil & 1 & M 63 & & M 63 & & Carmines, $2002^{\mathrm{c}}$ \\
\hline Petitgrain oil, terpeneless & 1 & M 63 & & M 63 & & Carmines, $2002^{\mathrm{C}}$ \\
\hline$\alpha$-Phellandrene & 1 & M 62, 63 & S & M 62, 63 & & $\begin{array}{l}\text { Robb et al., } 1964 \\
\text { Carmines, } 2002^{c}\end{array}$ \\
\hline Phenethyl acetate & 1 & M 62, 63 & & $\begin{array}{c}\text { M } 61 \\
M 60 \\
M \text { 62, } 63\end{array}$ & & $\begin{array}{l}\text { Gaworski et al., } 1998 \\
\text { Gaworski et al., } 1999 \mathrm{a} \\
{\text { Carmines, } 2002^{\mathrm{C}}}\end{array}$ \\
\hline Phenethyl alcohol & 1 & M 62, 63 & & $\begin{array}{c}\text { M } 61 \\
M 60 \\
M \text { 62, } 63\end{array}$ & & $\begin{array}{l}\text { Gaworski et al., } 1998 \\
\text { Gaworski et al., } 1999 a \\
\text { Carmines, } 2002^{\mathrm{C}}\end{array}$ \\
\hline Phenethyl butyrate & 1 & M 63 & & M 63 & & Carmines, $2002^{\mathrm{c}}$ \\
\hline Phenethyl isobutyrate & 1 & M 63 & & M 63 & & Carmines, $2002^{\circ}$ \\
\hline Phenethyl isovalerate & 1 & M 63 & & M 63 & & Carmines, $2002^{\mathrm{C}}$ \\
\hline Phenethyl phenylacetate & 1 & M 63 & & M 63 & & Carmines, $2002^{\mathrm{C}}$ \\
\hline Phenol & 9 & S & & & & Bentley and Burgan, 1960 \\
\hline Phenylacetaldehyde & 1 & M 62, 63 & & $\begin{array}{c}\text { M } 61 \\
\text { M } 60 \\
M 62,63\end{array}$ & & $\begin{array}{l}\text { Gaworski et al., } 1998 \\
\text { Gaworski et al., } 1999 a \\
\text { Carmines, } 2002^{\mathrm{c}}\end{array}$ \\
\hline Phenylacetic acid & 1 & M 62, 63 & & $\begin{array}{c}\text { M 61 } \\
\text { M 60 } \\
\text { M 62, } 63\end{array}$ & & $\begin{array}{l}\text { Gaworski et al., } 1998 \\
\text { Gaworski et al., } 1999 a \\
\text { Carmines, } 2002^{c}\end{array}$ \\
\hline 2-Phenyl-2-butenal & 1 & M 63 & & M 63 & & Carmines, $2002^{c}$ \\
\hline 4-Phenyl-3-buten-2-one & 1 & M 63 & & M 63 & & Carmines, $2002^{\mathrm{C}}$ \\
\hline
\end{tabular}


Table 2 (contd.)

\begin{tabular}{|c|c|c|c|c|c|c|}
\hline \multirow[b]{2}{*}{ Ingredients } & \multirow{2}{*}{$\begin{array}{c}\text { Classification } \\
\text { Table } 1^{\mathrm{a}}\end{array}$} & \multirow{2}{*}{$\begin{array}{c}\text { MSS } \\
\text { Tables } 3 \& 4^{b}\end{array}$} & \multirow{2}{*}{$\begin{array}{c}\text { Pyrolysis } \\
\text { Table } 5^{\text {b }}\end{array}$} & \multicolumn{2}{|c|}{ Biological activity } & \multirow[b]{2}{*}{ Reference(s) } \\
\hline & & & & Table $6^{\mathrm{b}}$ & Table $7^{\text {b }}$ & \\
\hline Phenyl disulfide & 9 & S & & & & Burton and Benner, 1972 \\
\hline $\begin{array}{l}\text { Phenylmethyl-oxadiazole } \\
\text { (PMO) }\end{array}$ & 9 & $\begin{array}{l}\mathrm{S} \\
\mathrm{S}\end{array}$ & & & $\begin{array}{l}\mathrm{S} \\
\mathrm{S} \\
\mathrm{S} \\
\mathrm{S} \\
\mathrm{S}\end{array}$ & $\begin{array}{l}\text { Dalhamn and Rylander, } 1971 \\
\text { Jones et al., } 1972 \\
\text { Jones et al., } 1973 \\
\text { Marmor and Minnemeyer, } 1975 \\
\text { NCl, Report No. 4, } 1980 \\
\text { Rylander, } 1971 \\
\text { Rylander, } 1973\end{array}$ \\
\hline Phenylpropionic acid & 1 & $S$ & & & & Burton and Benner, 1972 \\
\hline Phenyl sulfide & 9 & $S$ & & & & Burton and Benner, 1972 \\
\hline Phenylvinyloxadiazole & 9 & & & & S & Dalhamn and Rylander, 1971 \\
\hline Phosphoric acid & 2 & $\begin{array}{l}\text { M } 1 \\
\mathrm{~S}\end{array}$ & & & & $\begin{array}{l}\text { An et al., } 1996 \\
\text { Stedman et al., } 1969\end{array}$ \\
\hline Phytosterols & 9 & S & & & & Schmeltz et al., 1978 \\
\hline Pineapple juice & 1 & & & M 61 & & Gaworski et al., 1998 \\
\hline Pineapple juice concentrate & 1 & & & M 60 & & Gaworski et al., 1999a \\
\hline Pinene & 1 & $S$ & & & & Bavley and Robb, 1969 \\
\hline$\alpha$-Pinene & 1 & M 62 & & M 62 & & Carmines, $2002^{c}$ \\
\hline$\beta$-Pinene & 1 & M 62 & & M 62 & & Carmines, $2002^{\mathrm{c}}$ \\
\hline Pine needle oil & 1 & M 62, 63 & & M 62, 63 & & Carmines, $2002^{\circ}$ \\
\hline Pine oil, scotch & 1 & M 62 & & M 62 & & Carmines, $2002^{c}$ \\
\hline$\delta$-Piperitone & 1 & M 62 & & M 62 & & Carmines, $2002^{c}$ \\
\hline Piperonal & 1 & M 62, 63 & & $\begin{array}{c}\text { M } 61 \\
\text { M } 60 \\
M 62,63\end{array}$ & & $\begin{array}{l}\text { Gaworski et al., } 1998 \\
\text { Gaworski et al., } 1999 \text { a } \\
\text { Carmines, } 2002^{\mathrm{c}}\end{array}$ \\
\hline Pipsissewa leaf & 1 & & & M 61 & & Gaworski et al., 1998 \\
\hline Plasticiser & 4 & $\begin{array}{c}\text { M } 12 \\
\text { M } 18 \\
M 36,37\end{array}$ & & & & $\begin{array}{l}\text { Dontenwill et al., } 1972 \\
\text { Dontenwill et al., } 1976 \\
\text { Miano and Keith, } 1976\end{array}$ \\
\hline Platinum & 9 & $S$ & & & & Bryant et al., 1979 \\
\hline Polyethylene glycol & 2 & & S & & & Kröller, 1965a \\
\hline Polyethylene glycols (Carbowax) & 9 & $S$ & & & & Bilimoria and Nisbet, 1975 \\
\hline Polygalacturonic acid & 9 & & $S$ & & & Schlotzhauer et al., 1967 \\
\hline Polypropylene glycol & 2 & $\mathrm{~S}$ & & & & Bilimoria and Nisbet, 1975 \\
\hline Potassium acetate & 3 & $\begin{array}{l}S \\
S\end{array}$ & & & & $\begin{array}{l}\text { Aksu, } 1969 \\
\text { Keritsis, } 1981\end{array}$ \\
\hline Potassium bromate & 9 & $S$ & & & & Bentley and Burgan, 1960 \\
\hline Potassium bromide & 9 & S & & & & Bentley and Burgan, 1960 \\
\hline Potassium carbonate & 3,6 & $\begin{array}{l}\mathrm{S} \\
\mathrm{S} \\
\mathrm{S}\end{array}$ & & & & $\begin{array}{l}\text { Burdick et al., } 1969 \\
\text { Burton, } 1969 \\
\text { Burton and Benner, } 1972\end{array}$ \\
\hline Potassium chlorate & 9 & $\begin{array}{l}S \\
S \\
S\end{array}$ & & & & $\begin{array}{l}\text { Burdick et al., } 1969 \\
\text { Burton, } 1969 \\
\text { Burton and Benner, } 1972\end{array}$ \\
\hline Potassium chloride & 3,6 & $\begin{array}{l}S \\
S\end{array}$ & & & & $\begin{array}{l}\text { Bentley and Burgan, } 1960 \\
\text { Crosthwaite et al., } 1979\end{array}$ \\
\hline Potassium citrate & 3,5 & $\begin{array}{l}M 1 \\
M 5 \\
M 27 \\
S\end{array}$ & & & & $\begin{array}{l}\text { An et al., } 1996 \\
\text { Briskin, } 1979 \\
\text { Jodl, } 1969 \\
\text { Keritsis, } 1981\end{array}$ \\
\hline Potassium ethylvanillin-5-carboxylate & $\Leftrightarrow$ & 5-carboxyvan & iillin & & & \\
\hline Potassium iodide & 9 & S & & & & Bentley and Burgan, 1960 \\
\hline Potassium lactate & 3 & $S$ & & & & Aksu, 1969 \\
\hline Potassium malate & 3 & $\mathrm{~S}$ & & & & Aksu, 1969 \\
\hline
\end{tabular}


Table 2 (contd.)

\begin{tabular}{|c|c|c|c|c|c|c|}
\hline \multirow[b]{2}{*}{ Ingredients } & \multirow{2}{*}{$\begin{array}{c}\text { Classification } \\
\text { Table } 1^{\mathrm{a}}\end{array}$} & \multirow{2}{*}{$\begin{array}{c}\text { MSS } \\
\text { Tables } 3 \& 4^{b} \\
\end{array}$} & \multirow{2}{*}{$\begin{array}{c}\text { Pyrolysis } \\
\text { Table }^{\text {b }} \\
\end{array}$} & \multicolumn{2}{|c|}{ Biological activity } & \multirow[b]{2}{*}{ Reference(s) } \\
\hline & & & & Table $6^{\text {b }}$ & Table $7^{\text {b }}$ & \\
\hline Potassium nitrate & 3 & $\begin{array}{c}S \\
S \\
S \\
S \\
S \\
S \\
S \\
M 28 \\
M 29 \\
\text { S } \\
\text { M } 51 \\
\text { M 53 } \\
\text { S } \\
\text { S }\end{array}$ & & & S & $\begin{array}{l}\text { Bentley and Burgan, } 1960 \\
\text { Crosthwaite et al., } 1979 \\
\text { Garcia Roche et al., } 1986 \\
\text { Halter and Ito, } 1972 \\
\text { Johnson et al., } 1973 \\
\text { Kaburaki et al., } 1969 \\
\text { Kallianos et al., } 1968 \\
\text { Komatsu, } 1997 \\
\text { Kossack, } 1987 \\
\text { NCl, Report No.1, } 1976 \\
\text { Ogawa, } 1998 \\
\text { Prouse et al., } 1977 \\
\text { Pyriki et al.., 1965 } \\
\text { Rathkamp and Hoffmann, } 1970 \\
\text { Hoffmann and Wynder, } 1968 \\
\text { Hoffmann and Wynder, } 1972\end{array}$ \\
\hline Potassium sorbate & 5 & $\begin{array}{c}S \\
\text { M } 62\end{array}$ & S & $\begin{array}{l}\text { M } 61 \\
\text { M } 60 \\
\text { M } 62\end{array}$ & & $\begin{array}{l}\text { Brunnemann and Posset, } 1980 \\
\text { Gaworski et al., } 1998 \\
\text { Gaworski et al., } 1999 \text { a } \\
\text { Kröller, } 1970 \\
\text { Carmines, } 2002^{\mathrm{c}}\end{array}$ \\
\hline Potassium vanillin-5-carboxylate & $\Rightarrow$ & 5-carboxyvani & & & & \\
\hline Proline & 1 & S & $\begin{array}{l}S \\
S\end{array}$ & & & $\begin{array}{l}\text { Higman, E.B. et al., } 1970 \\
\text { Kaburaki et al., } 1969 \\
\text { Schmeltz et al., } 1972\end{array}$ \\
\hline Propenylguaethol & 1 & M 62, 63 & & $\begin{array}{c}M 61 \\
M 60 \\
M 62,63\end{array}$ & & $\begin{array}{l}\text { Gaworski et al., } 1998 \\
\text { Gaworski et al., } 1999 a \\
\text { Carmines, } 2002^{c}\end{array}$ \\
\hline Propionic acid & 1,5 & & & $\begin{array}{l}\text { M } 61 \\
\text { M } 60\end{array}$ & & $\begin{array}{l}\text { Gaworski et al., } 1998 \\
\text { Gaworski et al., 1999a }\end{array}$ \\
\hline Propylene glycol & 2,8 & $\begin{array}{c}\text { S } \\
M 6 \\
M 10 \\
\text { S } \\
S \\
S \\
S \\
S \\
M 55 \\
S \\
M 62,63 \\
\text { S }\end{array}$ & S & $\begin{array}{c}\text { M 60 } \\
\text { S, M 59 } \\
M 62,63\end{array}$ & & $\begin{array}{l}\text { Bilimoria and Nisbet, } 1975 \\
\text { Carugno et al., } 1971 \\
\text { Detert and Ruchholz, } 1974 \\
\text { Doihara et al., } 1964 \\
\text { Kagan et al., } 1999 \\
\text { Laurene et al., } 1965 \\
\text { Cook et al., } 1999 \\
\text { Lyerly, } 1967 \\
\text { Kobashi et al., } 1965 \\
\text { Kröller, 1964b } \\
\text { Settle et al., } 1999 \\
\text { Stoilova et al., } 1994 \\
\text { Gaworski et al., 1999a } \\
\text { Gaworski et al., 1999b } \\
\text { Carmines, 2002 } \\
\text { Smit, } 1970\end{array}$ \\
\hline Propylene glycol alginate & 6 & M 31-34 & & & & McAdam, 1997 \\
\hline Propyl p-hydroxybenzoate & 5 & M 63 & & M 63 & & Carmines, $2002^{c}$ \\
\hline 3-Propylidene phthalide & 1 & M 62, 63 & & $\begin{array}{c}M 61 \\
M 60 \\
M 62,63\end{array}$ & & $\begin{array}{l}\text { Gaworski et al., } 1998 \\
\text { Gaworski et al., } 1999 a \\
\text { Carmines, } 2002^{\mathrm{c}}\end{array}$ \\
\hline o-n-Propylphenol & 1 & & S & & & Schlotzhauer et al., 1967 \\
\hline Prune concentrate & 1 & & & M 61 & & Gaworski et al., 1998 \\
\hline Prune extract & 1 & & $\mathrm{~S}$ & & & Kröller, 1967 \\
\hline $\begin{array}{l}\text { Prune juice/prune juice } \\
\text { concentrate }\end{array}$ & 1 & M 62 & & $\begin{array}{l}\text { M } 61 \\
\text { M } 60 \\
\text { M } 62\end{array}$ & & $\begin{array}{l}\text { Gaworski et al., } 1998 \\
\text { Gaworski et al., } 1999 a \\
\text { Carmines, } 2002^{\mathrm{c}}\end{array}$ \\
\hline Pyridine & 1 & S & & & & Bavley and Robb, 1969 \\
\hline Pyroligneous acid & 1 & & & $\begin{array}{l}\text { M } 61 \\
\text { M } 60\end{array}$ & & $\begin{array}{l}\text { Gaworski et al., } 1998 \\
\text { Gaworski et al., } 1999 a\end{array}$ \\
\hline Pyromellitic acid & 9 & S & & & & Burton and Benner, 1972 \\
\hline Pyruvic acid & 1 & M 62, 63 & & M 62, 63 & & Carmines, $2002^{\mathrm{C}}$ \\
\hline Raisin juice concentrate & 1 & M 62 & & M 62 & & Carmines, $2002^{\mathrm{c}}$ \\
\hline
\end{tabular}


Table 2 (contd.)

\begin{tabular}{|c|c|c|c|c|c|c|}
\hline \multirow[b]{2}{*}{ Ingredients } & \multirow{2}{*}{$\begin{array}{c}\text { Classification } \\
\text { Table } 1^{\mathrm{a}}\end{array}$} & \multirow{2}{*}{$\begin{array}{c}\text { MSS } \\
\text { Tables } 3 \& 4^{b}\end{array}$} & \multirow{2}{*}{\begin{tabular}{|c|}
$\begin{array}{c}\text { Pyrolysis } \\
\text { Table } 5^{\text {b }}\end{array}$ \\
\end{tabular}} & \multicolumn{2}{|c|}{ Biological activity } & \multirow[b]{2}{*}{ Reference(s) } \\
\hline & & & & Table $6^{\mathrm{b}}$ & Table $7^{\mathrm{b}}$ & \\
\hline Rhizome (powder) & 6 & M 51 & & & & Ogawa, 1998 \\
\hline Rhodinol $\Rightarrow$ & & & & & & Carmines, $2002^{\mathrm{c}}$ \\
\hline Rose absolute & 1 & M 62, 63 & & M 62, 63 & & Carmines, $2002^{\mathrm{c}}$ \\
\hline Rose leaves & 1 & & $\mathrm{~S}$ & & & Kröller, 1967 \\
\hline Rose oil, bulgarian, true otto & 1 & M 63 & & M 63 & & Carmines, $2002^{\mathrm{c}}$ \\
\hline Rum & 1 & M 62, 63 & & $\begin{array}{c}M 62,63 \\
M 61\end{array}$ & & $\begin{array}{l}\text { Carmines, } 2002^{\mathrm{c}} \\
\text { Gaworski et al., } 1998\end{array}$ \\
\hline Rum ether & 1 & & & $\begin{array}{l}\text { M } 61 \\
\text { M } 60\end{array}$ & & $\begin{array}{l}\text { Gaworski et al., } 1998 \\
\text { Gaworski et al., 1999a }\end{array}$ \\
\hline Rutin & 9 & S & $\begin{array}{l}S \\
S\end{array}$ & & & $\begin{array}{l}\text { Bell et al., } 1966 \\
\text { Carmella et al., } 1984 \\
\text { Schlotzhauer et al., } 1982\end{array}$ \\
\hline Sage oleoresin & 1 & M 63 & & M 63 & & Carmines, $2002^{\mathrm{c}}$ \\
\hline Salicylaldehyde & 1 & M 62, 63 & & $\begin{array}{c}M 61 \\
M 62,63\end{array}$ & & $\begin{array}{l}\text { Gaworski et al., } 1998 \\
\text { Carmines, 2002 }\end{array}$ \\
\hline Sandalwood oil & 1 & & & $\begin{array}{l}\text { M } 61 \\
\text { M } 60\end{array}$ & & $\begin{array}{l}\text { Gaworski et al., } 1998 \\
\text { Gaworski et al., 1999a }\end{array}$ \\
\hline Sandalwood oil, yellow & 1 & M 63 & & M 63 & & Carmines, $2002^{c}$ \\
\hline Sclareolide & 1 & M 62 & & M 62 & & Carmines, $2002^{\mathrm{c}}$ \\
\hline Sepiolite & 9 & M 1 & & & & An et al., 1996 \\
\hline Shellac & 6 & & $S$ & & & Kröller, 1966d \\
\hline Silver nitrate & 9 & $S$ & & & & Bentley and Burgan, 1960 \\
\hline$\beta$-Sitosterol & 1 & S & & & & Cheng, 1973 \\
\hline Sodium acetate & 1,3 & & S & & & Kröller, 1966b \\
\hline Sodium alginate & 6 & M 3 & & & & Biggs et al., 1998 \\
\hline Sodium antimonate & 9 & $S$ & & & & Burton and Benner, 1972 \\
\hline Sodium benzoate & 5 & & S & $\begin{array}{l}\text { M } 61 \\
\text { M } 60\end{array}$ & & $\begin{array}{l}\text { Gaworski et al., } 1998 \\
\text { Gaworski et al., } 1999 a \\
\text { Kröller, } 1970\end{array}$ \\
\hline Sodium bicarbonate & 6 & M 5 & & & & Briskin, 1979 \\
\hline Sodium borate & 9 & $S$ & & & & Baldry et al., 1988 \\
\hline Sodium citrate & 3,5 & $\begin{array}{c}\text { S } \\
\text { M } 5 \\
\text { M } 27\end{array}$ & $\mathrm{~S}$ & $\begin{array}{l}\text { M } 61 \\
\text { M } 60\end{array}$ & & $\begin{array}{l}\text { Baldry et al., } 1988 \\
\text { Briskin, } 1979 \\
\text { Jodl, } 1969 \\
\text { Kröller, 1966b } \\
\text { Gaworski et al., } 1998 \\
\text { Gaworski et al., 1999a }\end{array}$ \\
\hline Sodium dichromate & 9 & S & & & & Burton and Benner, 1972 \\
\hline Sodium ethylvanillin-5-carboxylate & $\Rightarrow$ & 5-carboxyvan & illin & & & \\
\hline Sodium fluoride & 9 & S & & & & Burton and Benner, 1972 \\
\hline Sodium glycerophosphate & 9 & & S & & & Kröller, 1966d \\
\hline Sodium hydrogen carbonate & 9 & S & & & & Burton and Benner, 1972 \\
\hline Sodium hydroxide & 3,8 & $\begin{array}{l}\text { M } 39 \\
\text { M } 47\end{array}$ & & & $\begin{array}{l}\text { M } 39 \\
\text { M } 47\end{array}$ & $\begin{array}{l}\text { NCl, Report No.1, } 1976 \\
\text { NCl, Report No. 4, } 1980\end{array}$ \\
\hline Sodium iodate & 9 & S & & & & Burton and Benner, 1972 \\
\hline Sodium lactate & 1,3 & & $\mathrm{~S}$ & & & Kröller, 1966b \\
\hline Sodium malate & 3 & S & & & & Baldry et al., 1988 \\
\hline Sodium molybdate & 9 & S & & & & Burton and Benner, 1972 \\
\hline Sodium nitrate & 3 & $\begin{array}{c}\text { S } \\
\text { S } \\
\text { S } \\
\text { S } \\
\text { S, M } 14 \\
\text { S, M } 17\end{array}$ & & & $\begin{array}{l}S \\
S\end{array}$ & $\begin{array}{l}\text { Adams et al., } 1984 \\
\text { Burton, } 1969 \\
\text { Burdick et al., } 1969 \\
\text { Burton and Benner, } 1972 \\
\text { Dontenwill et al., } 1972 \\
\text { Dontenwill, } 1974 \\
\text { Dontenwill et al., } 1976\end{array}$ \\
\hline
\end{tabular}


Table 2 (contd.)

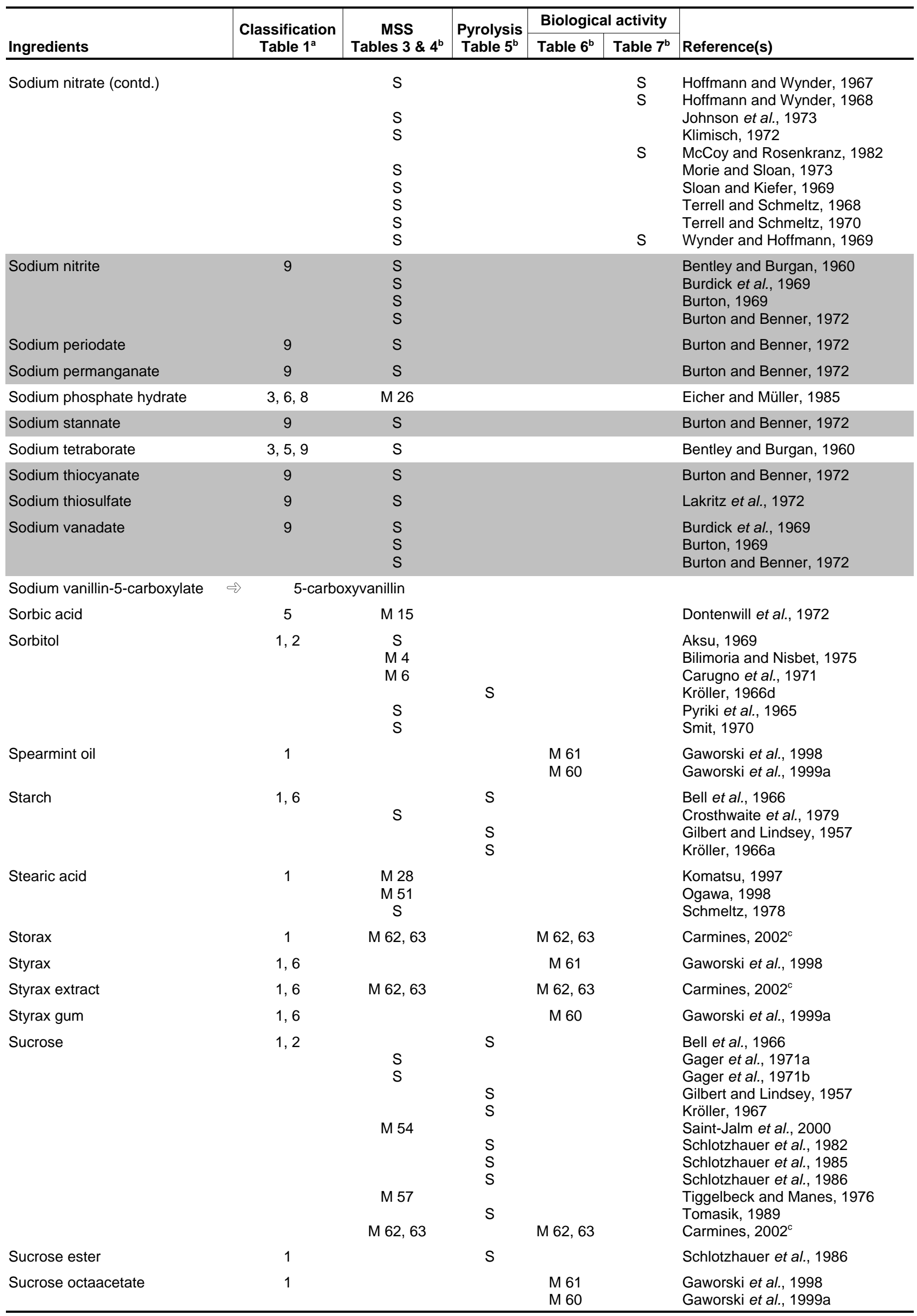


Table 2 (contd.)

\begin{tabular}{|c|c|c|c|c|c|c|}
\hline \multirow[b]{2}{*}{ Ingredients } & \multirow{2}{*}{$\begin{array}{c}\text { Classification } \\
\text { Table } 1^{\mathrm{a}}\end{array}$} & \multirow{2}{*}{$\begin{array}{c}\text { MSS } \\
\text { Tables } 3 \& 4^{b} \\
\end{array}$} & \multirow{2}{*}{$\begin{array}{c}\text { Pyrolysis } \\
\text { Table 5 }^{\text {b }} \\
\end{array}$} & \multicolumn{2}{|c|}{ Biological activity } & \multirow[b]{2}{*}{ Reference(s) } \\
\hline & & & & Table $6^{\text {b }}$ & Table $7^{b}$ & \\
\hline (Invert sugar) & 1,2 & $\begin{array}{c}\text { S } \\
\text { M } 31-34 \\
\text { S, M 41-44 } \\
\text { M } 62\end{array}$ & & $\begin{array}{l}S \\
\mathrm{~S} \\
\mathrm{M} 62\end{array}$ & & $\begin{array}{l}\text { Jenkins et al., } 1980 \\
\text { McAdam, } 1997 \\
\text { NCl, Report No. 3, } 1977 \\
\text { Sato et al., } 1979 \\
\text { Carmines, } 2002^{\circ}\end{array}$ \\
\hline Sugar alcohol & 2 & & & $\begin{array}{l}\text { M } 61 \\
\text { M } 60\end{array}$ & & $\begin{array}{l}\text { Gaworski et al., } 1998 \\
\text { Gaworski et al., } 1999 a\end{array}$ \\
\hline Sugar: corn syrup & 1 & M 63, 64 & & M 63, 64 & & Carmines, $2002^{\mathrm{c}}$ \\
\hline Sulfite pulp & 6 & $\begin{array}{c}\text { M } 40 \\
M \quad 46,47,49\end{array}$ & & & $\begin{array}{c}\text { M 40 } \\
\text { M 46, 47 }\end{array}$ & $\begin{array}{l}\mathrm{NCl}, \text { Report No. 1, } 1976 \\
\mathrm{NCl}, \text { Report No. 4, } 1980\end{array}$ \\
\hline Sulfuric acid & 1,8 & S & & & & Stedman et al., 1969 \\
\hline Tagetes oil & 1 & M 62, 63 & & M 62, 63 & & Carmines, $2002^{\mathrm{C}}$ \\
\hline Tangerine oil & 1 & M 63 & & M 63 & & Carmines, $2002^{c}$ \\
\hline Tartaric acid & $1,3,5,6$ & M 28 & & $\begin{array}{l}\text { M } 61 \\
\text { M } 60\end{array}$ & & $\begin{array}{l}\text { Komatsu, } 1997 \\
\text { Gaworski et al., } 1998 \\
\text { Gaworski et al., 1999a }\end{array}$ \\
\hline Tartaric acid (disodium salt) & $1,3,5,6$ & & $S$ & & & Kröller, 1966b \\
\hline$\alpha$-Terpineol & 1 & M 62, 63 & & M 62, 63 & & Carmines, $2002^{c}$ \\
\hline Terpinolene & 1 & M 62 & & M 62 & & Carmines, $2002^{\mathrm{c}}$ \\
\hline Terpinyl acetate & 1 & M 63 & & M 63 & & Carmines, $2002^{c}$ \\
\hline Tetracosane & 9 & & S & & & Bell et al., 1966 \\
\hline $\begin{array}{l}\text { 1,5,5,9-Tetramethyl-13- } \\
\text { oxatricyclo-(8.3.0.0.-(4,9)) } \\
\text { tridecane }\end{array}$ & 1 & & & $\begin{array}{l}\text { M } 60 \\
\text { M } 61\end{array}$ & & $\begin{array}{l}\text { Gaworski et al., 1999a } \\
\text { Gaworski et al., } 1998\end{array}$ \\
\hline 2,3,5,6-Tetramethylpyrazine & 1 & M 63 & & $\begin{array}{l}\text { M } 61 \\
\text { M } 60 \\
\text { M } 63\end{array}$ & & 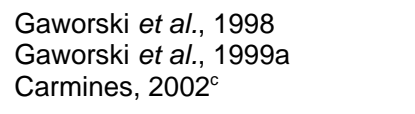 \\
\hline Thiabendazole & 5 & $S$ & S & & & $\begin{array}{l}\text { Kröller, } 1968 \\
\text { Kröller, } 1969\end{array}$ \\
\hline Thyme oil, white & 1 & M 62, 63 & & M 62, 63 & & Carmines, $2002^{c}$ \\
\hline Thymol & 1 & $S$ & & & & Bavley and Robb, 1969 \\
\hline Titanium dioxide & $3,6,7$ & $\begin{array}{l}\text { M } 11 \\
\text { M } 26\end{array}$ & & & & $\begin{array}{l}\text { Dontenwill et al., } 1972 \\
\text { Eicher and Müller, } 1985\end{array}$ \\
\hline Titanium oxide & $3,6,7$ & M 30 & & & & Matsushita and Shinozaki, 1980 \\
\hline Titanyl chloride & 9 & M 39 & & & M 39 & NCI, Report No.1, 1976 \\
\hline Tobacco (highly methylated) & 9 & M 10 & & & & Detert and Ruchholz, 1974 \\
\hline Tobacco extract & 1 & M 32, 34 & & & & McAdam, 1997 \\
\hline Tocopherols & 1 & M 63 & & M 63 & & Carmines, $2002^{\mathrm{c}}$ \\
\hline o-, m-, $p$-Tolualdehydes & 1 & M 62, 63 & & M 62, 63 & & Carmines, $2002^{\mathrm{c}}$ \\
\hline Tolu balsam gum and extract & 1 & & & $\begin{array}{l}\text { M } 61 \\
\text { M } 60\end{array}$ & & $\begin{array}{l}\text { Gaworski et al., } 1998 \\
\text { Gaworski et al., } 1999 a\end{array}$ \\
\hline Toluene & 9 & S & & & & Bavley and Robb, 1969 \\
\hline$p$-Tolyl acetate & 1 & M 62 & & M 62 & & Carmines, $2002^{c}$ \\
\hline$p$-Tolyl isobutyrate & 1 & M 63 & & $\begin{array}{l}\text { M } 61 \\
\text { M } 60 \\
\text { M } 63\end{array}$ & & $\begin{array}{l}\text { Gaworski et al., } 1998 \\
\text { Gaworski et al., } 1999 a \\
\text { Carmines, } 2002^{c}\end{array}$ \\
\hline$p$-Tolyl phenylacetate & 1 & M 63 & & $\begin{array}{l}\text { M } 61 \\
\text { M } 60 \\
\text { M } 63\end{array}$ & & $\begin{array}{l}\text { Gaworski et al., } 1998 \\
\text { Gaworski et al., } 1999 a \\
\text { Carmines, } 2002^{\mathrm{c}}\end{array}$ \\
\hline Tonka bean powder & 1 & & $S$ & & & Higman, H.C. et al., 1974 \\
\hline Tragacanth & 6 & & $\begin{array}{l}S \\
S\end{array}$ & & & $\begin{array}{l}\text { Kröller, 1965b } \\
\text { Sjöberg and Pyysalo, } 1985\end{array}$ \\
\hline Triacetin & 4 & M 3 & $\mathrm{~s}$ & $\begin{array}{l}\text { M } 61 \\
\text { M } 60\end{array}$ & & $\begin{array}{l}\text { Biggs et al., } 1998 \\
\text { Gaworski et al., } 1998 \\
\text { Gaworski et al., 1999a } \\
\text { Kröller, } 1968\end{array}$ \\
\hline
\end{tabular}


Table 2 (contd.)

\begin{tabular}{|c|c|c|c|c|c|c|}
\hline \multirow[b]{2}{*}{ Ingredients } & \multirow{2}{*}{$\begin{array}{c}\text { Classification } \\
\text { Table } 1^{\mathrm{a}}\end{array}$} & \multirow{2}{*}{$\begin{array}{c}\text { MSS } \\
\text { Tables } 3 \& 4^{b}\end{array}$} & \multirow{2}{*}{$\begin{array}{l}\text { Pyrolysis } \\
\text { Table } 5^{\mathrm{b}}\end{array}$} & \multicolumn{2}{|c|}{ Biological activity } & \multirow[b]{2}{*}{ Reference(s) } \\
\hline & & & & Table $6^{\text {b }}$ & Table $7^{\mathrm{b}}$ & \\
\hline Triacetin (contd.) & & $\begin{array}{c}S \\
\text { S } \\
M 62\end{array}$ & & M 62 & & 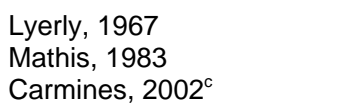 \\
\hline Triethyl citrate & 8 & & & M 61 & & Gaworski et al., 1998 \\
\hline Triethylene glycol & 2 & M 6 & S & & & $\begin{array}{l}\text { Carugno et al.., } 1971 \\
\text { Kröller, 1964b }\end{array}$ \\
\hline Triethyl orthoformate & 9 & $S$ & & & & Burton and Benner, 1972 \\
\hline Triglycerol & 2 & & $S$ & & & Kröller, 1966d \\
\hline $\begin{array}{l}\text { 4-(2,6,6-Trimethylcyclohexa-1,3- } \\
\text { dienyl)but-2-en-4-one }\end{array}$ & 1 & M 63 & & $\begin{array}{l}\text { M } 60 \\
\text { M } 63\end{array}$ & & $\begin{array}{l}\text { Gaworski et al., } 1999 \mathrm{a} \\
\text { Carmines, } 2002^{\mathrm{C}}\end{array}$ \\
\hline $\begin{array}{l}\text { 2,6,6-Trimethylcyclo-hex-2-ene- } \\
\text { 1,4-dione }\end{array}$ & 1 & & & $\begin{array}{l}\text { M } 60 \\
\text { M } 61\end{array}$ & & $\begin{array}{l}\text { Gaworski et al., 1999a } \\
\text { Gaworski et al., } 1998\end{array}$ \\
\hline $\begin{array}{l}\text { 4-(2,6,6-Trimethylcyclohex-1- } \\
\text { enyl)but-2-en-4-one }\end{array}$ & 1 & M 62, 63 & & M 62, 63 & & Carmines, $2002^{\mathrm{C}}$ \\
\hline 2,3,5-Trimethylpyrazine & 1 & M 63 & & $\begin{array}{l}\text { M } 61 \\
\text { M } 60 \\
\text { M } 63\end{array}$ & & $\begin{array}{l}\text { Gaworski et al., } 1998 \\
\text { Gaworski et al., } 1999 a \\
\text { Carmines, } 2002^{\mathrm{c}}\end{array}$ \\
\hline Trisodium phosphate & $3,6,8,9$ & $S$ & & & & Stedman et al., 1969 \\
\hline Trisodium vanadate & 9 & $S$ & & & & Burton and Benner, 1972 \\
\hline $\mathrm{Y}$-Undecalactone & 1 & $\begin{array}{l}\text { M } 38 \\
\text { M } 63\end{array}$ & & M 63 & & $\begin{array}{l}\text { Miranda et al., } 1999 \\
\text { Carmines, } 2002^{c}\end{array}$ \\
\hline Urea & 1 & $\begin{array}{c}\text { S } \\
\text { M 19-24 } \\
\text { S } \\
\text { S } \\
\text { M } 62\end{array}$ & & M 62 & & $\begin{array}{l}\text { Bentley and Burgan, } 1960 \\
\text { Eicher and Müller, } 1985 \\
\text { Mariner et al., } 2000 \\
\text { Pintaske, } 1981 \\
\text { Carmines, } 2002^{\circ}\end{array}$ \\
\hline Valeraldehyde & 1 & M 62 & & M 62 & & Carmines, $2002^{c}$ \\
\hline Valerian root & 1 & & & $\begin{array}{l}\text { M } 61 \\
\text { M } 60\end{array}$ & & $\begin{array}{l}\text { Gaworski et al., } 1998 \\
\text { Gaworski et al., 1999a }\end{array}$ \\
\hline Valerian root extract & 1 & M 63 & & M 63 & & Carmines, $2002^{\mathrm{C}}$ \\
\hline Valerian root oil & 1 & M 63 & & M 63 & & Carmines, $2002^{c}$ \\
\hline Valeric acid & 1 & M 62 & & M 62 & & Carmines, $2002^{c}$ \\
\hline Y-Valerolactone & 1 & M 62, 63 & & $\begin{array}{c}\text { M } 61 \\
\text { M } 60 \\
\text { M } 62,63\end{array}$ & & $\begin{array}{l}\text { Gaworski et al., } 1998 \\
\text { Gaworski et al., } 1999 \mathrm{a} \\
\text { Carmines, } 2002^{\mathrm{C}}\end{array}$ \\
\hline Vanilla extract & 1 & M 62, 63 & $S$ & $\begin{array}{c}M 61 \\
M 60 \\
M 62,63\end{array}$ & & $\begin{array}{l}\text { Gaworski et al., } 1998 \\
\text { Gaworski et al., } 1999 \mathrm{a} \\
\text { Higman, H.C. et al., } 1974 \\
\text { Carmines, } 2002^{\mathrm{c}}\end{array}$ \\
\hline Vanilla oleoresin & 1 & M 63 & & M 63 & & Carmines, $2002^{c}$ \\
\hline Vanilla roots & 1 & & $S$ & & & Kröller, 1967 \\
\hline Vanillin & 1 & $\begin{array}{c}S \\
S \\
\\
S \\
S \\
M 38 \\
M 62,63 \\
S \\
S\end{array}$ & & M 62, 63 & & $\begin{array}{l}\text { Bavley and Robb, } 1969 \\
\text { Chan et al., } 1992 \\
\text { Gaworski et al., } 1998 \\
\text { Gaworski et al., } 1999 \text { a } \\
\text { Green et al., } 1989 \\
\text { Kato and Shibayama, } 1962 \\
\text { Miranda et al., } 1999 \\
\text { Carmines, } 2002^{c} \\
\text { Stotesbury et al., } 1999 \\
\text { Stotesbury et al., } 2000\end{array}$ \\
\hline Veratraldehyde & 1 & M 62, 63 & & $\begin{array}{c}\text { M 61 } \\
\text { M 60 } \\
\text { M 62, } 63\end{array}$ & & $\begin{array}{l}\text { Gaworski et al., } 1998 \\
\text { Gaworski et al., } 1999 a \\
\text { Carmines, } 2002^{\mathrm{c}}\end{array}$ \\
\hline Vetiver oil & 1 & M 63 & & M 63 & & Carmines, $2002^{c}$ \\
\hline Walnut hull extract & 1 & M 62 & & M 62 & & Carmines, $2002^{c}$ \\
\hline Wetting agent & 2 & M 36, 37 & & & & Miano and Keith, 1976 \\
\hline Wine, Sherry & 1 & M 62 & & M 62 & & Carmines, $2002^{c}$ \\
\hline
\end{tabular}


Table 2 (contd.)

\begin{tabular}{|c|c|c|c|c|c|c|}
\hline \multirow[b]{2}{*}{ Ingredients } & \multirow{2}{*}{$\begin{array}{c}\text { Classification } \\
\text { Table } 1^{\mathrm{a}}\end{array}$} & \multirow{2}{*}{$\begin{array}{c}\text { MSS } \\
\text { Tables } 3 \& 4^{b}\end{array}$} & \multirow{2}{*}{$\begin{array}{l}\text { Pyrolysis } \\
{\text { Table } 5^{\mathrm{b}}}\end{array}$} & \multicolumn{2}{|c|}{ Biological activity } & \multirow[b]{2}{*}{ Reference(s) } \\
\hline & & & & Table $6^{\text {b }}$ & Table $7^{\mathrm{b}}$ & \\
\hline Wood pulp & 6 & M 39 & & & M 39 & NCI, Report No.1, 1976 \\
\hline Woodruff & 1 & & S & & & Kröller, 1967 \\
\hline Yellow wood extract & 7 & & $\begin{array}{l}S \\
S\end{array}$ & & & $\begin{array}{l}\text { Kröller, 1966c } \\
\text { Kröller, } 1968\end{array}$ \\
\hline Zeolite Y & 9 & $\mathrm{~S}$ & & & & Meier and Siegmann, 1999 \\
\hline Zinc nitrate & 9 & $\mathrm{~S}$ & & & & Bentley and Burgan, 1960 \\
\hline Zinc oxide & 9 & $\begin{array}{c}\text { S, M } 43-45 \\
\text { S }\end{array}$ & & & S, M 45 & $\begin{array}{l}\mathrm{NCl} \text {, Report No. 3, } 1977 \\
\text { Norman et al., } 1973\end{array}$ \\
\hline Zirconium salts & 9 & M 30 & & & & Matsushita and Shinozaki, 1980 \\
\hline
\end{tabular}

${ }^{a}$ Classification according to Table 1 .

${ }^{\mathrm{b} T}$ Tables 2 to $7: \mathrm{S}=$ single substance tested, $\mathrm{M}$ xx = substance tested in mixture with other ingredients. Numbering of mixtures, see relevant tables.

${ }^{\circ}$ Carmines, 2002: stands on behalf of the following series of publications: Carmines, 2002; Römer et al., 2002; Rustemeier et al., 2002 and Vanscheeuwijck et al., 2002. 


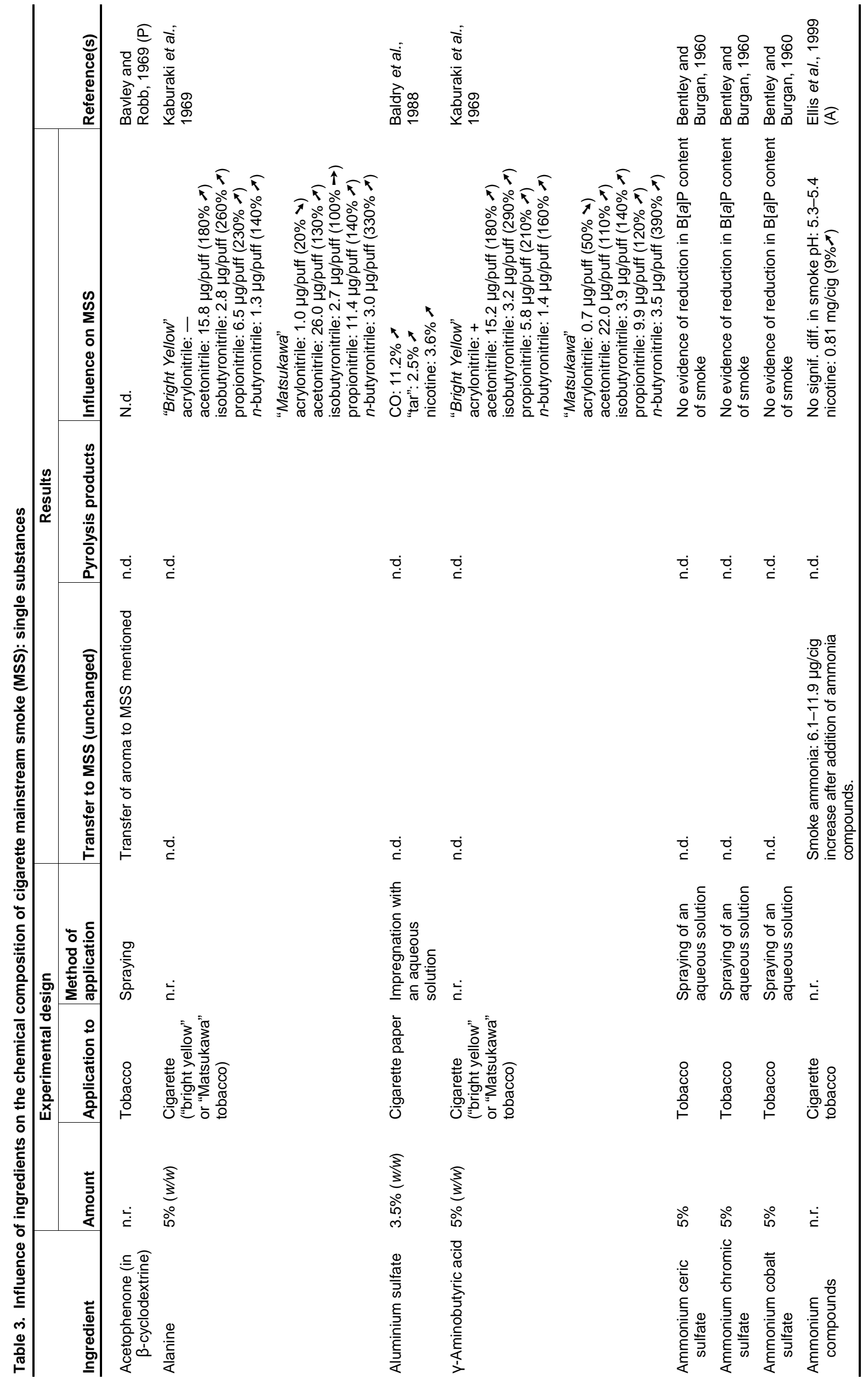




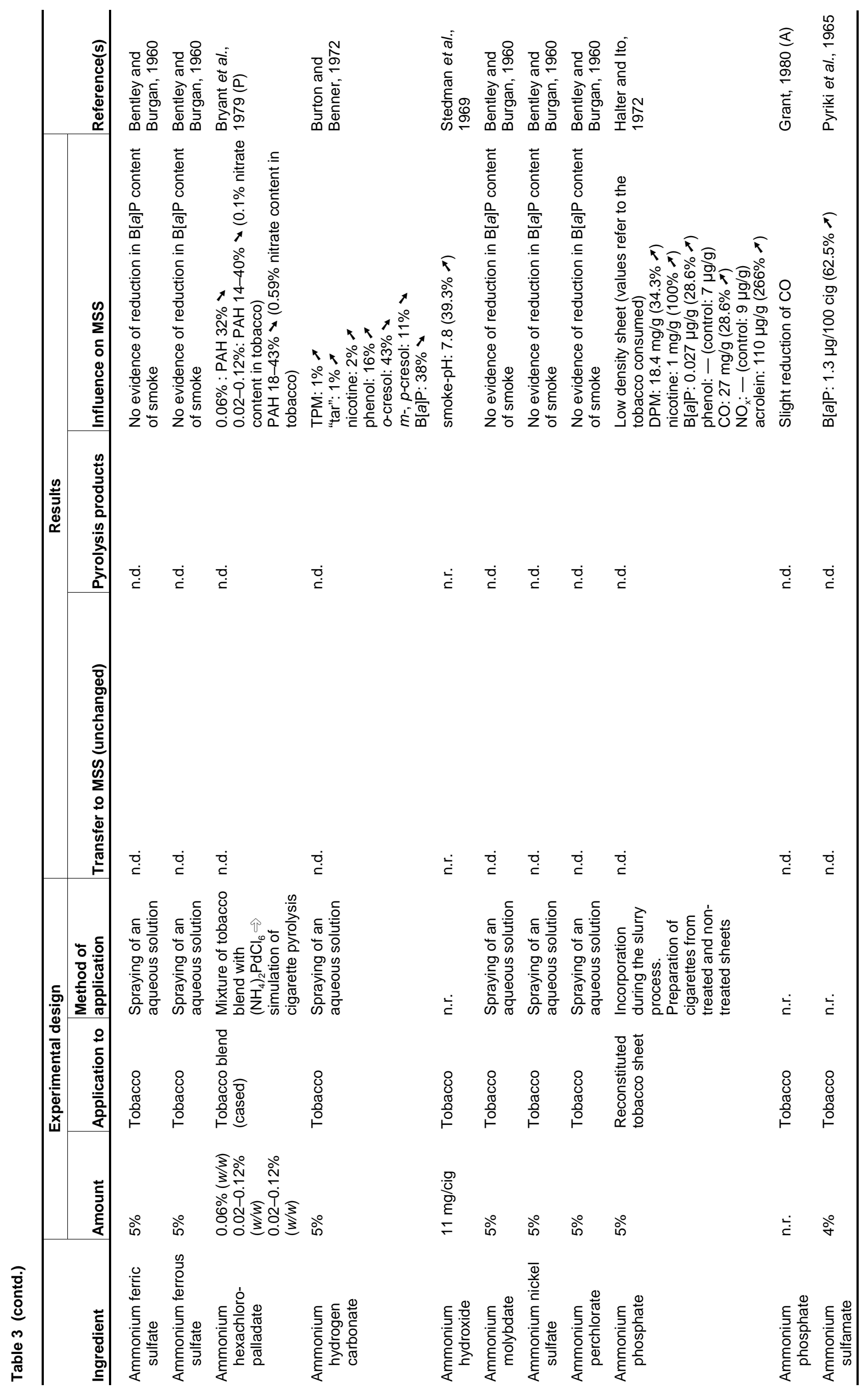




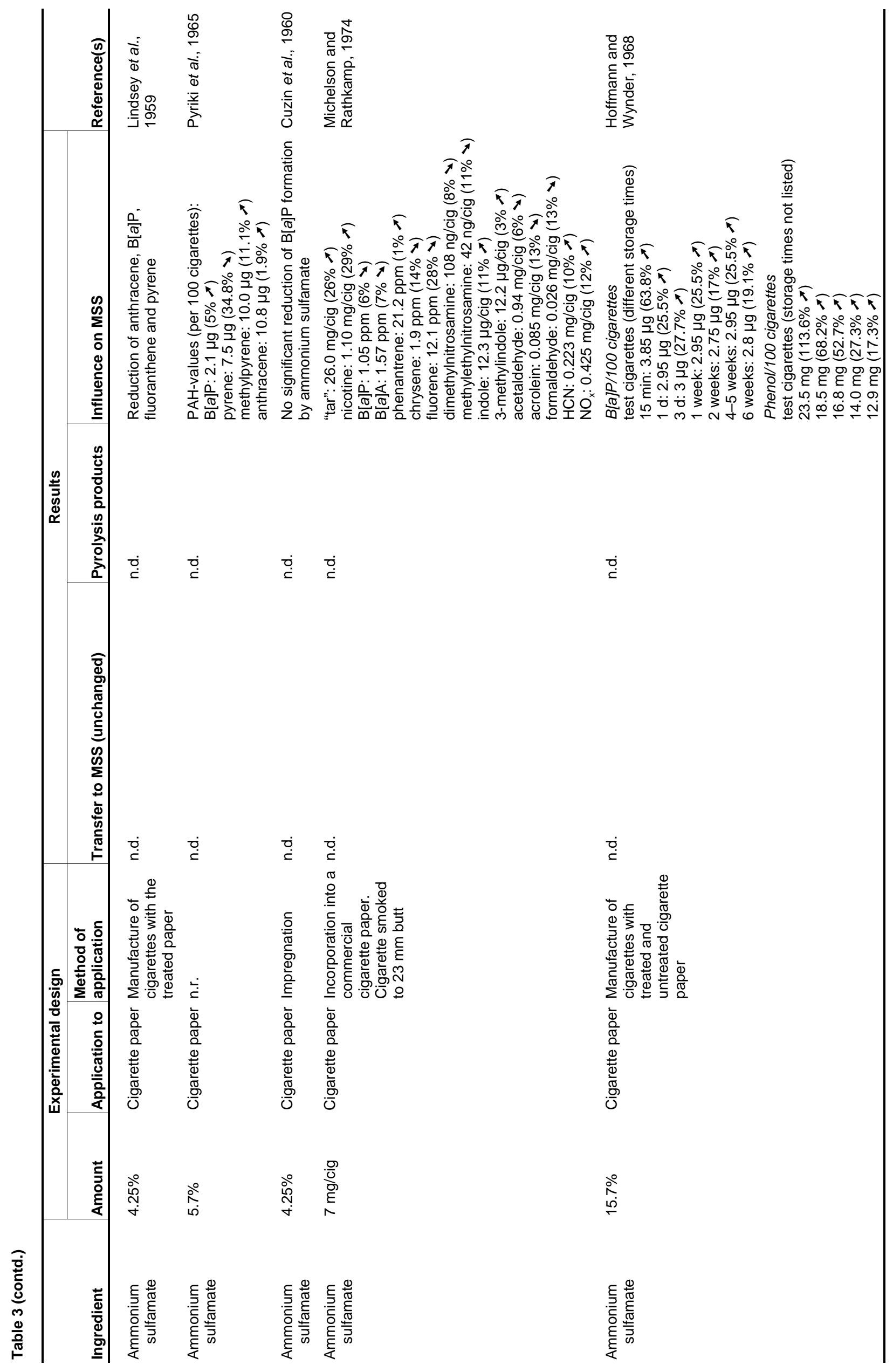




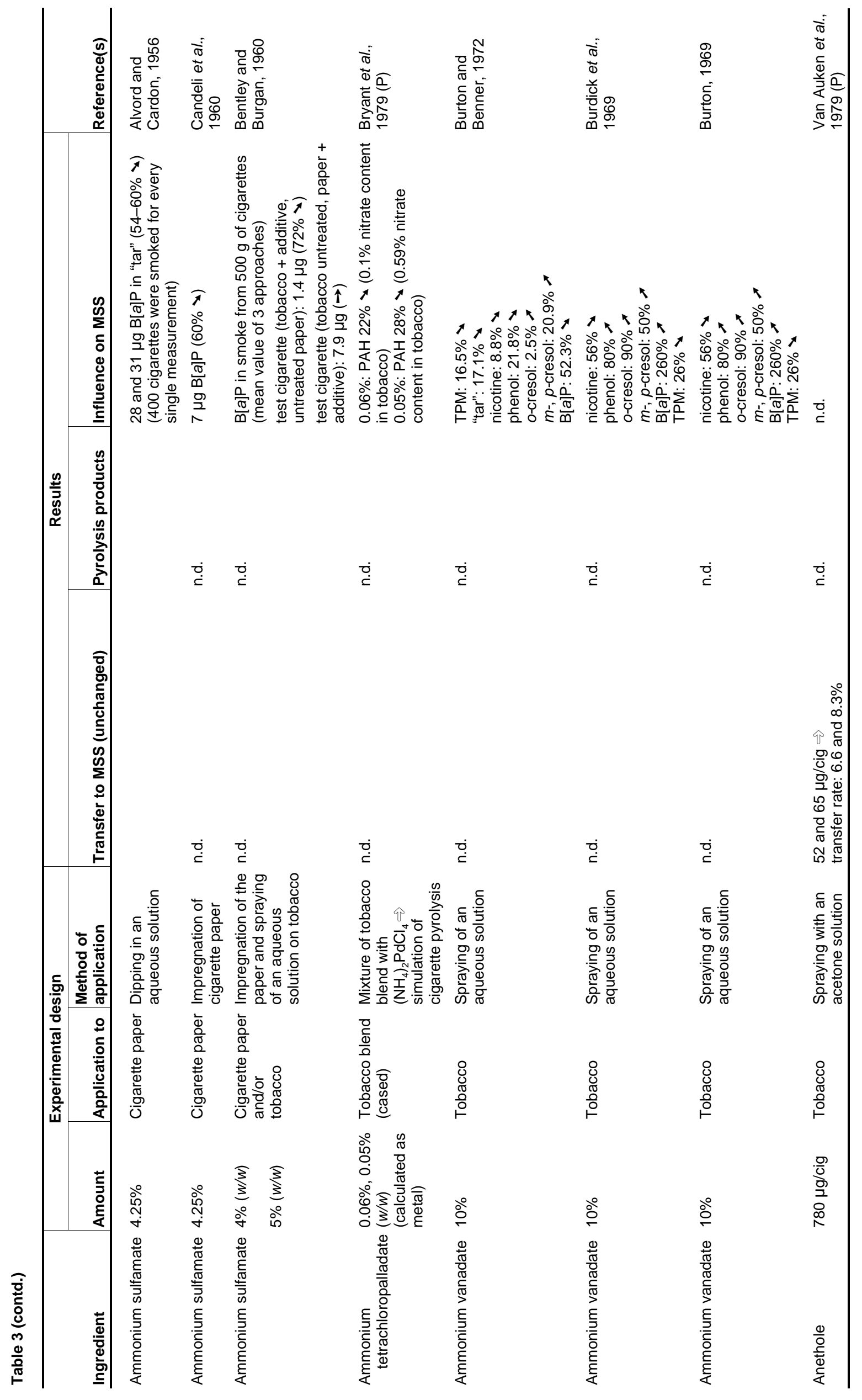




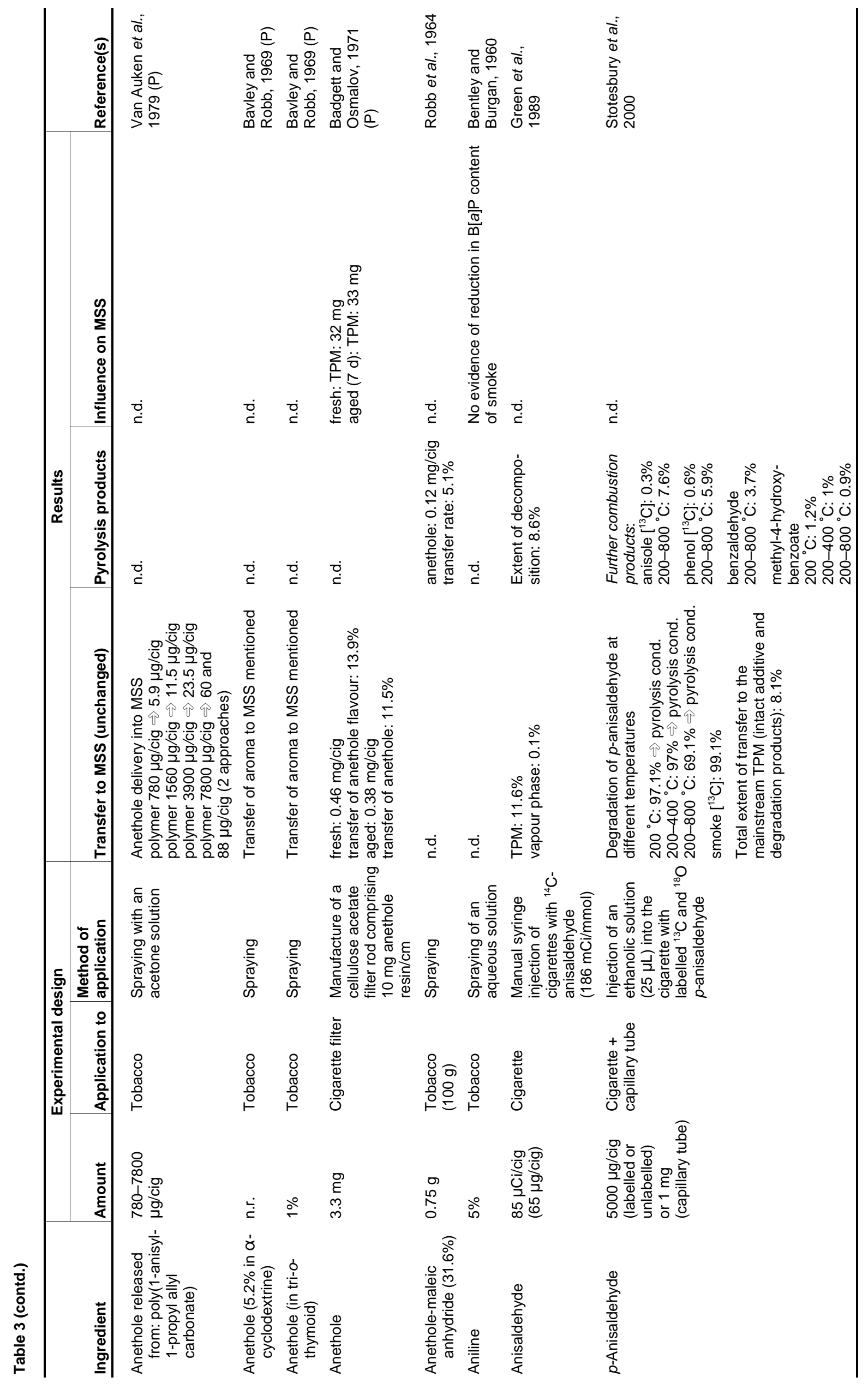




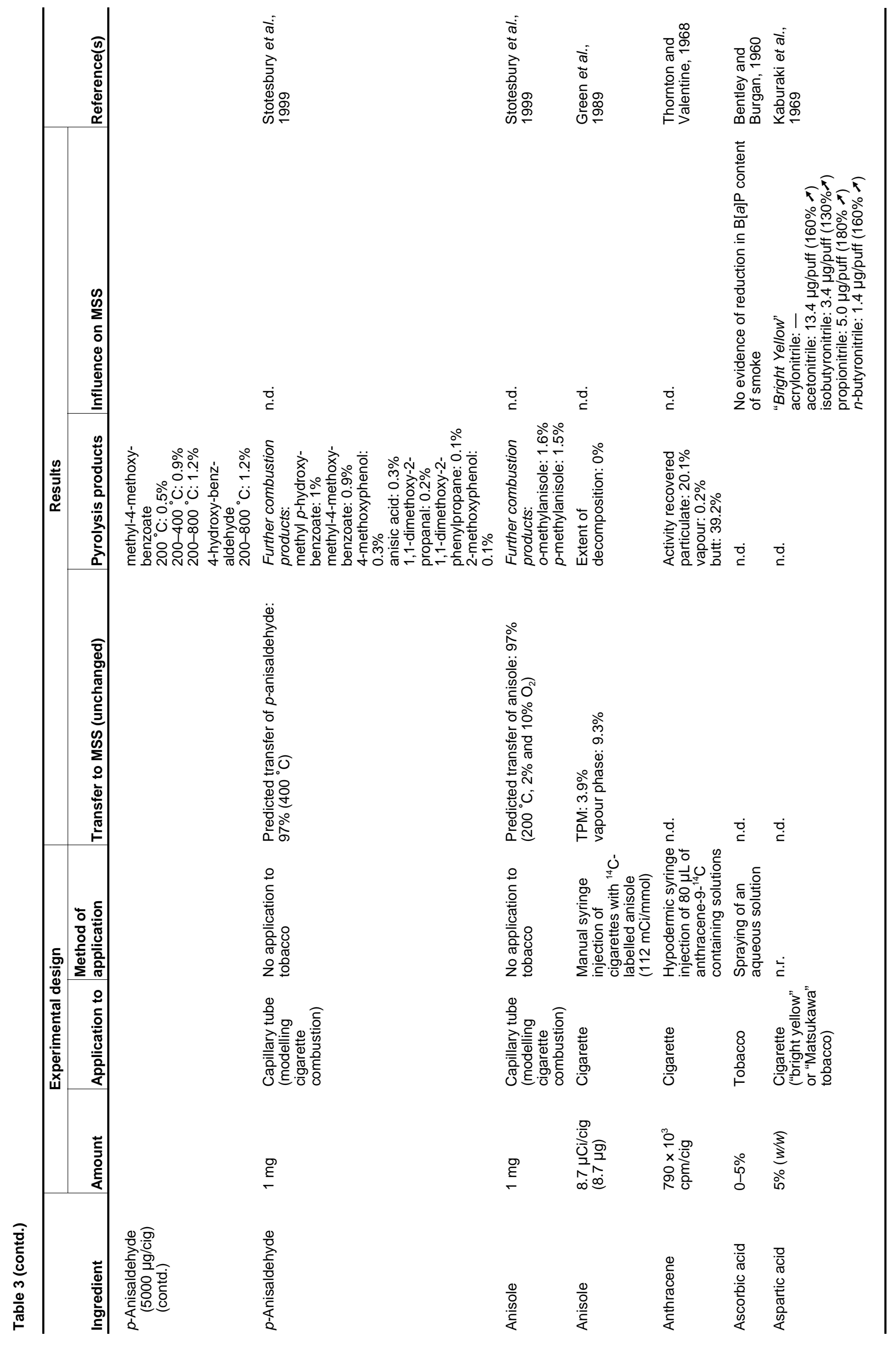




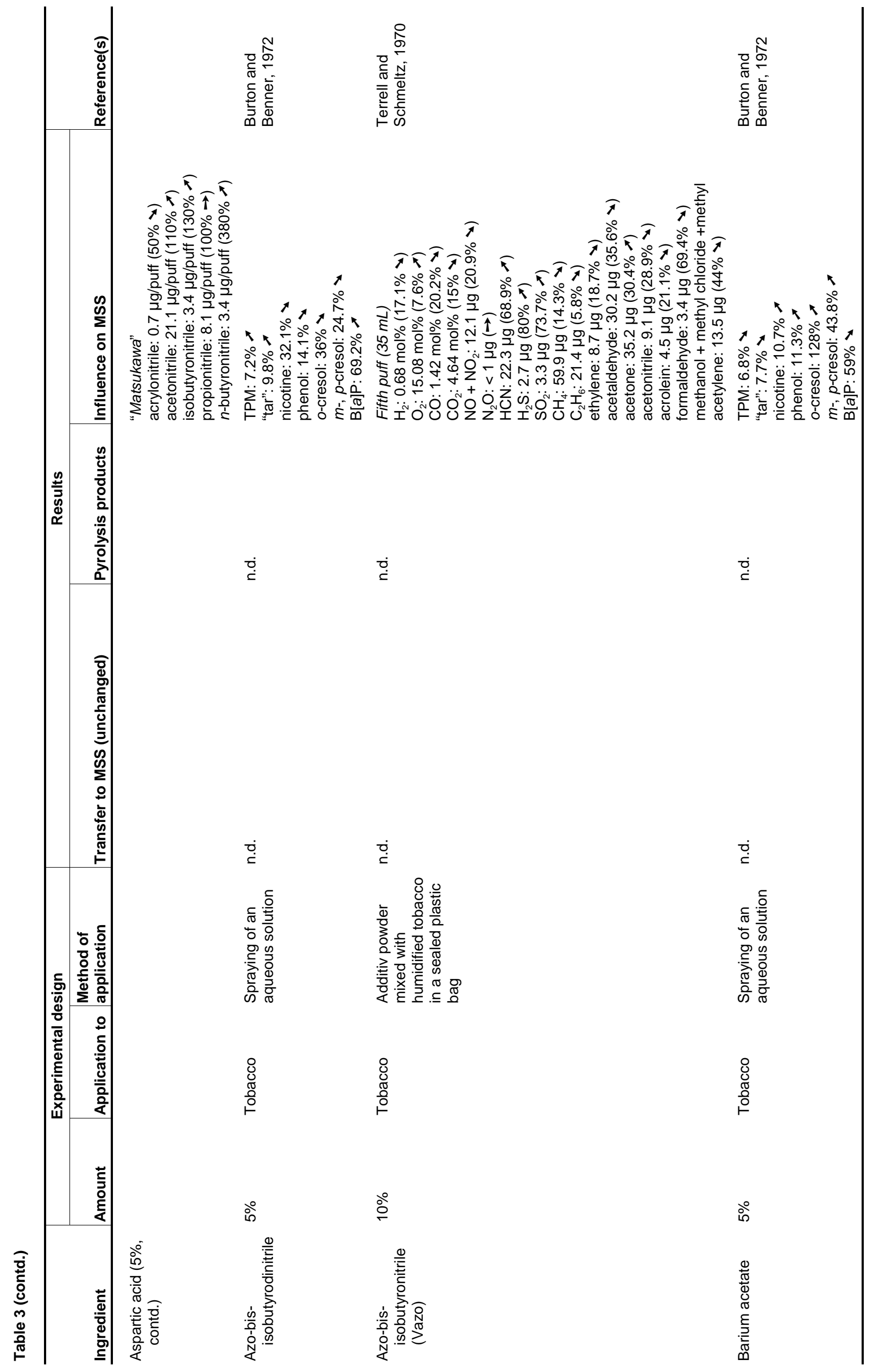




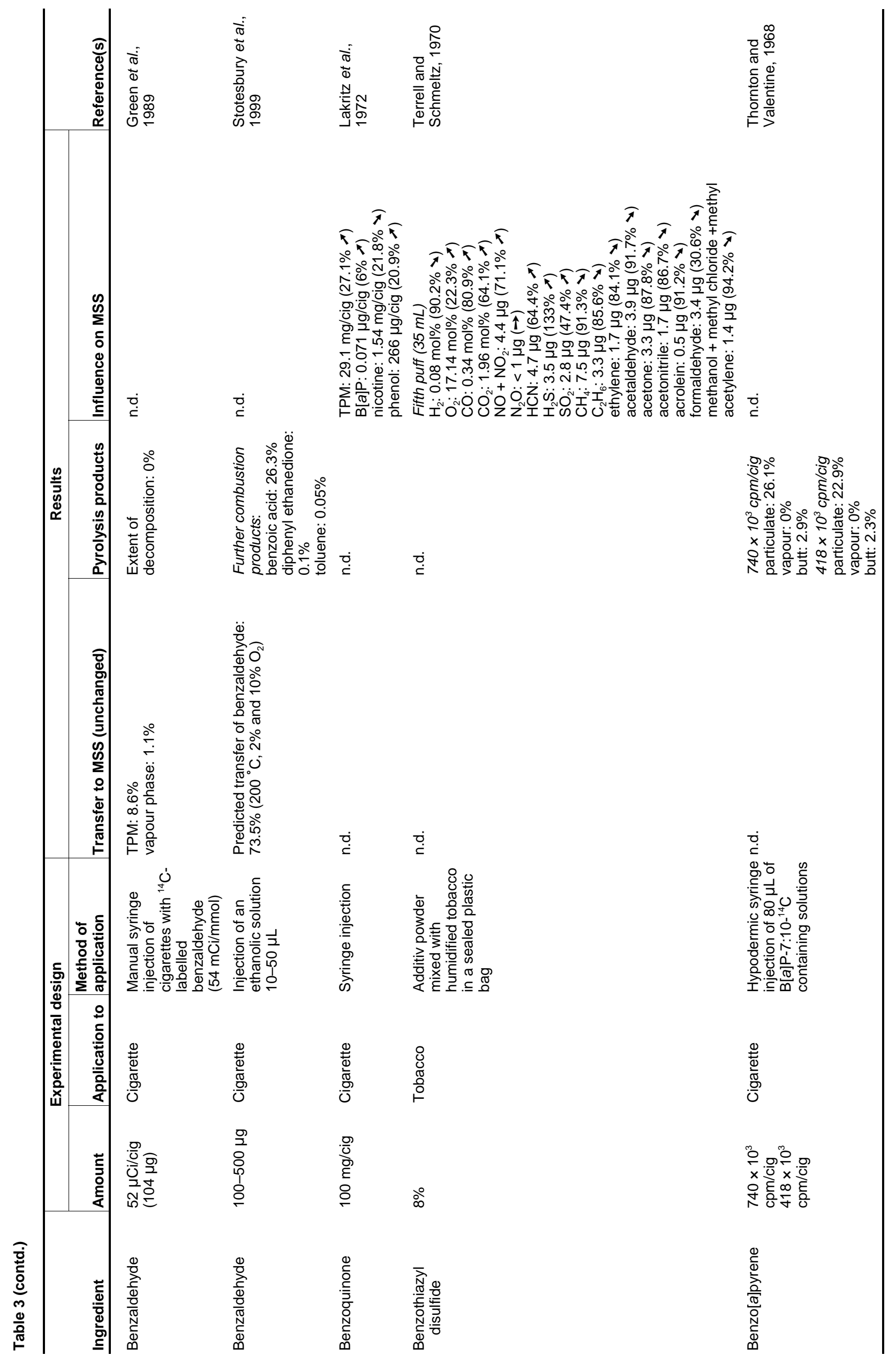




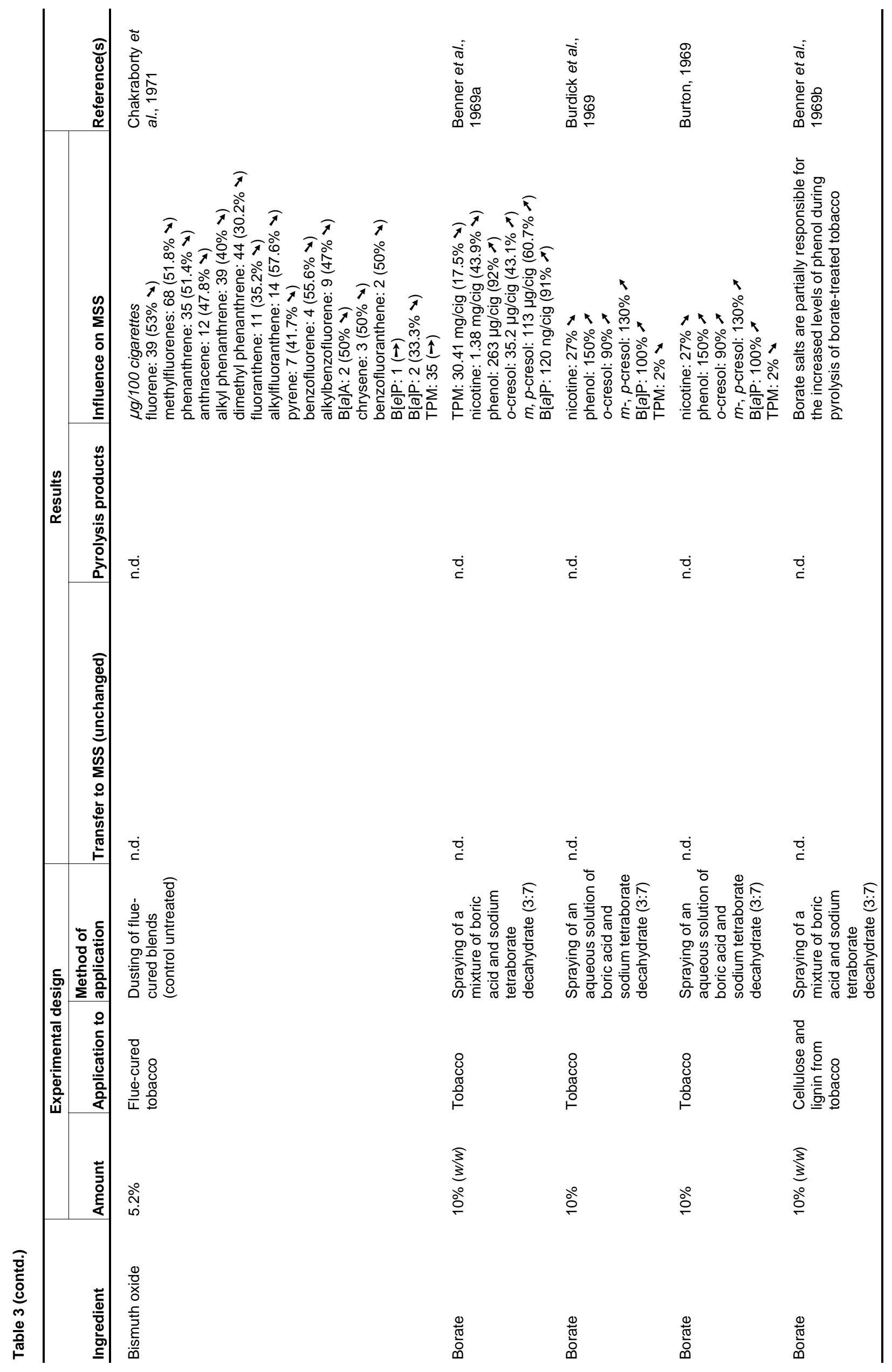




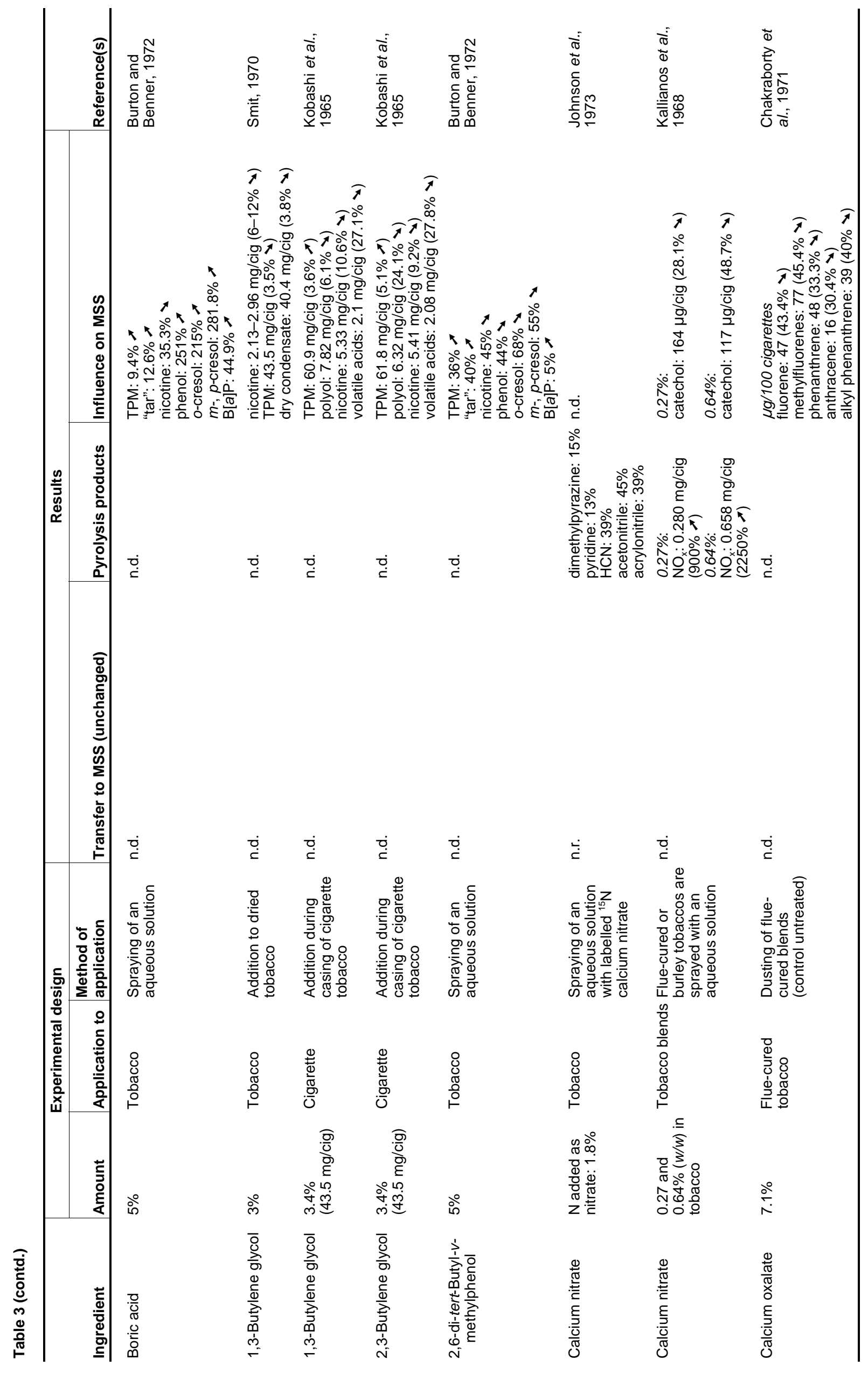




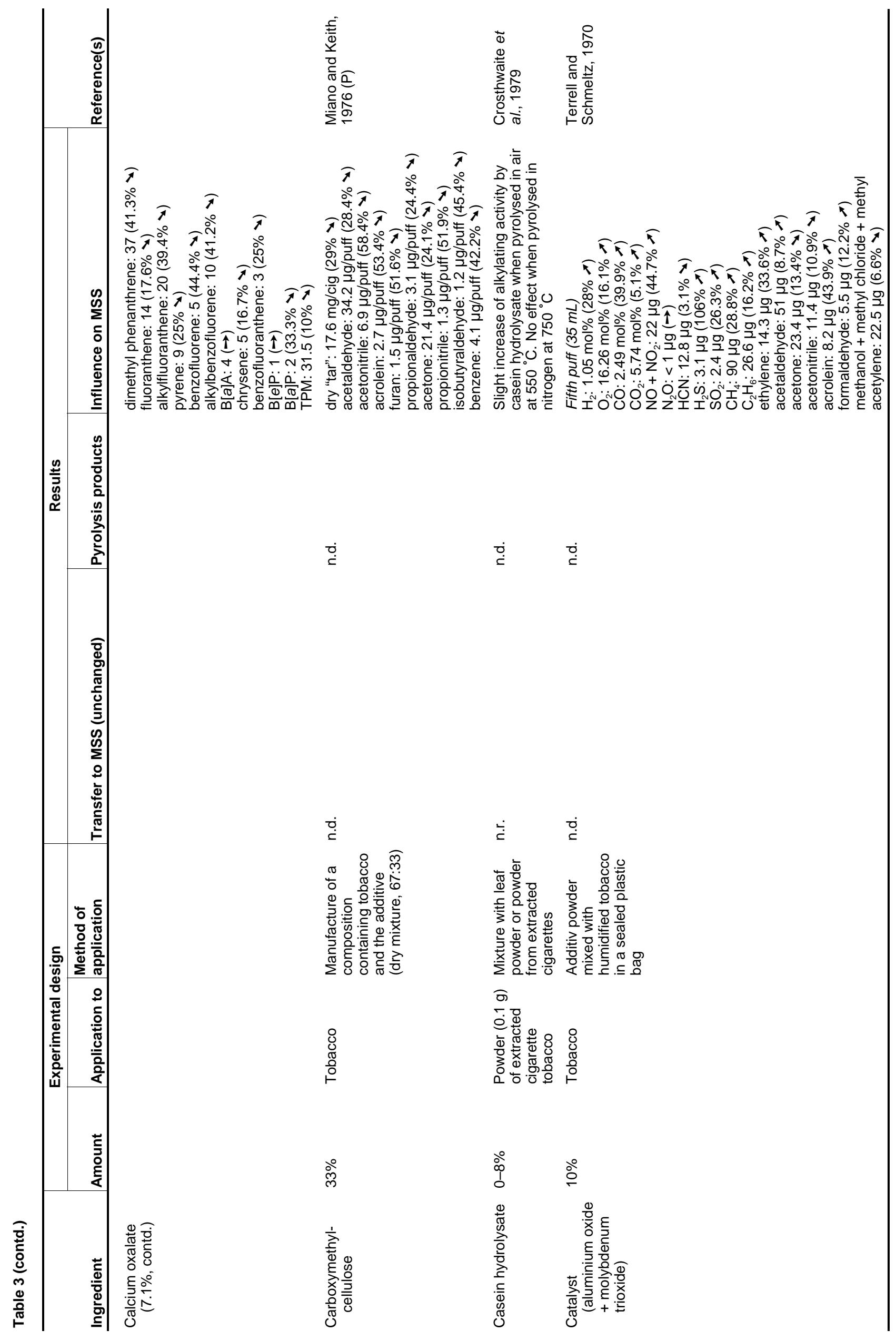




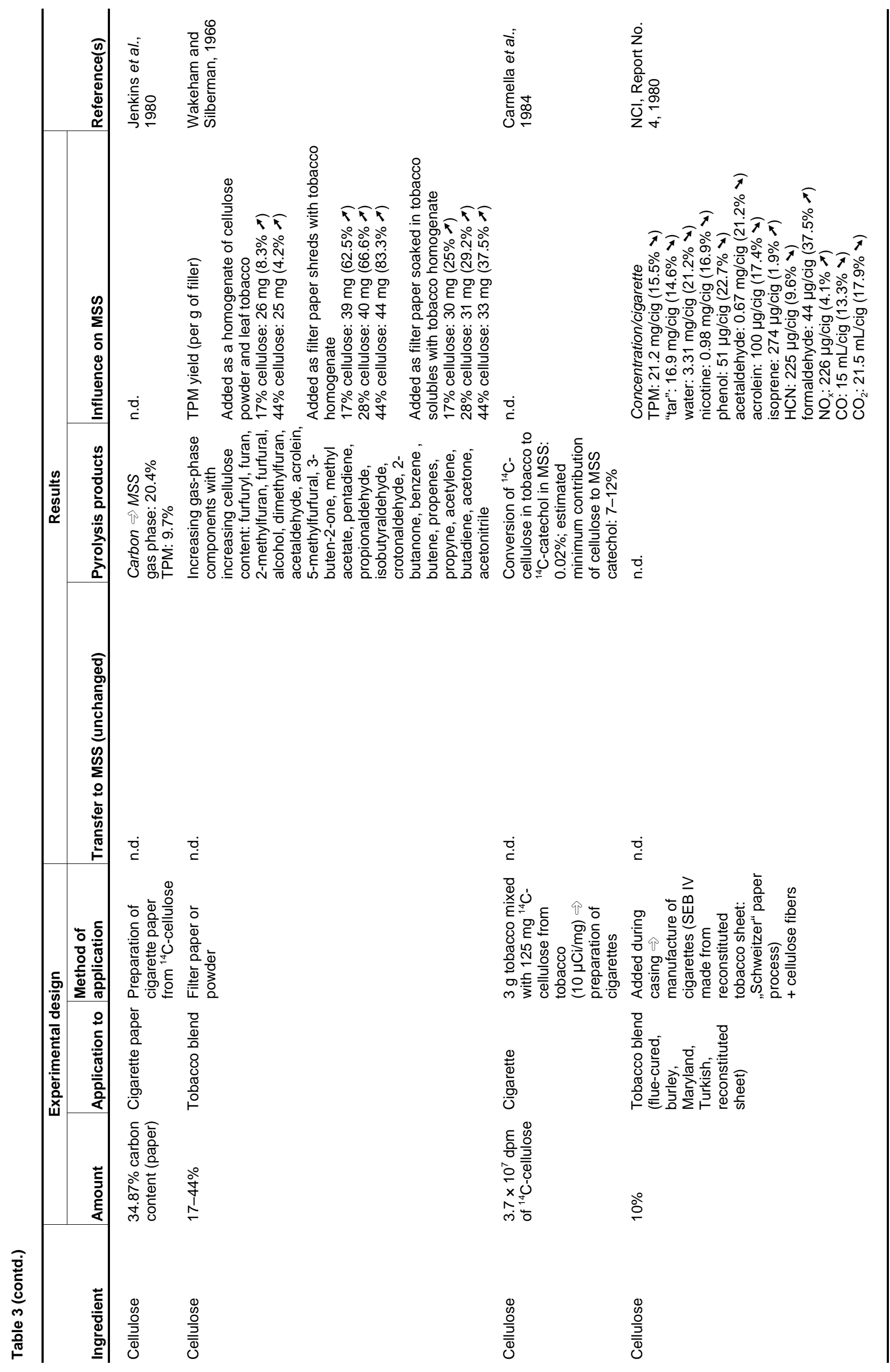




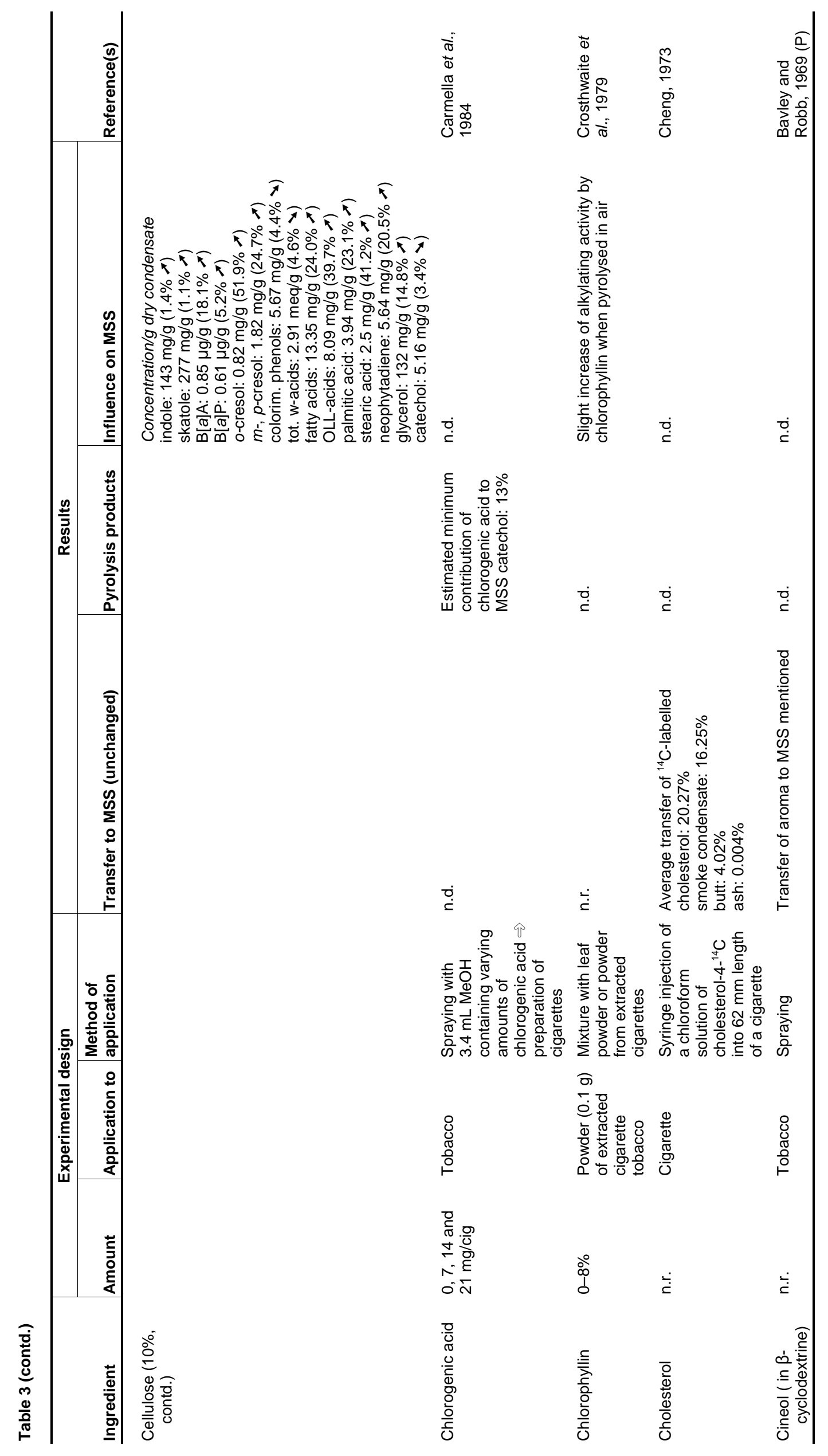




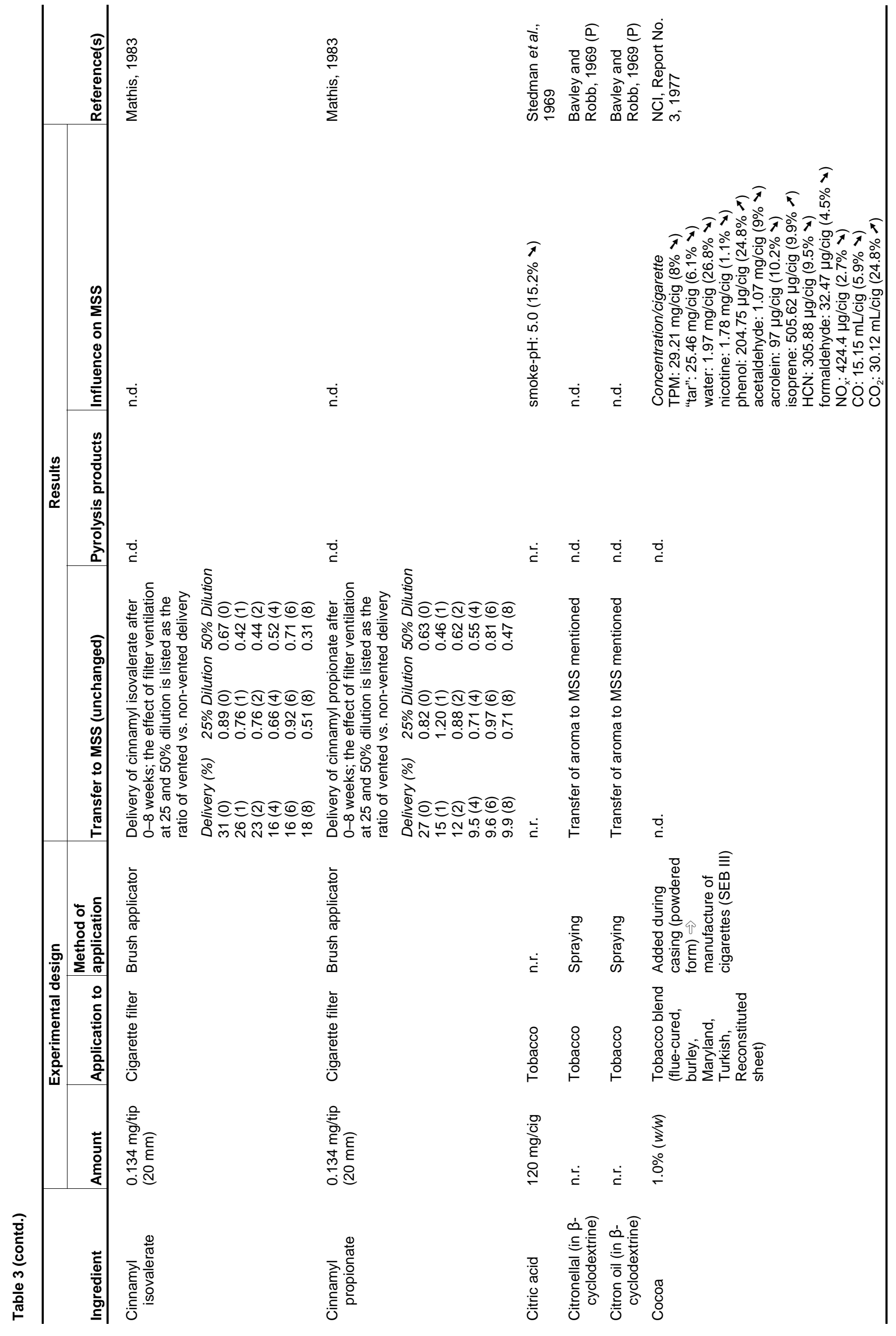




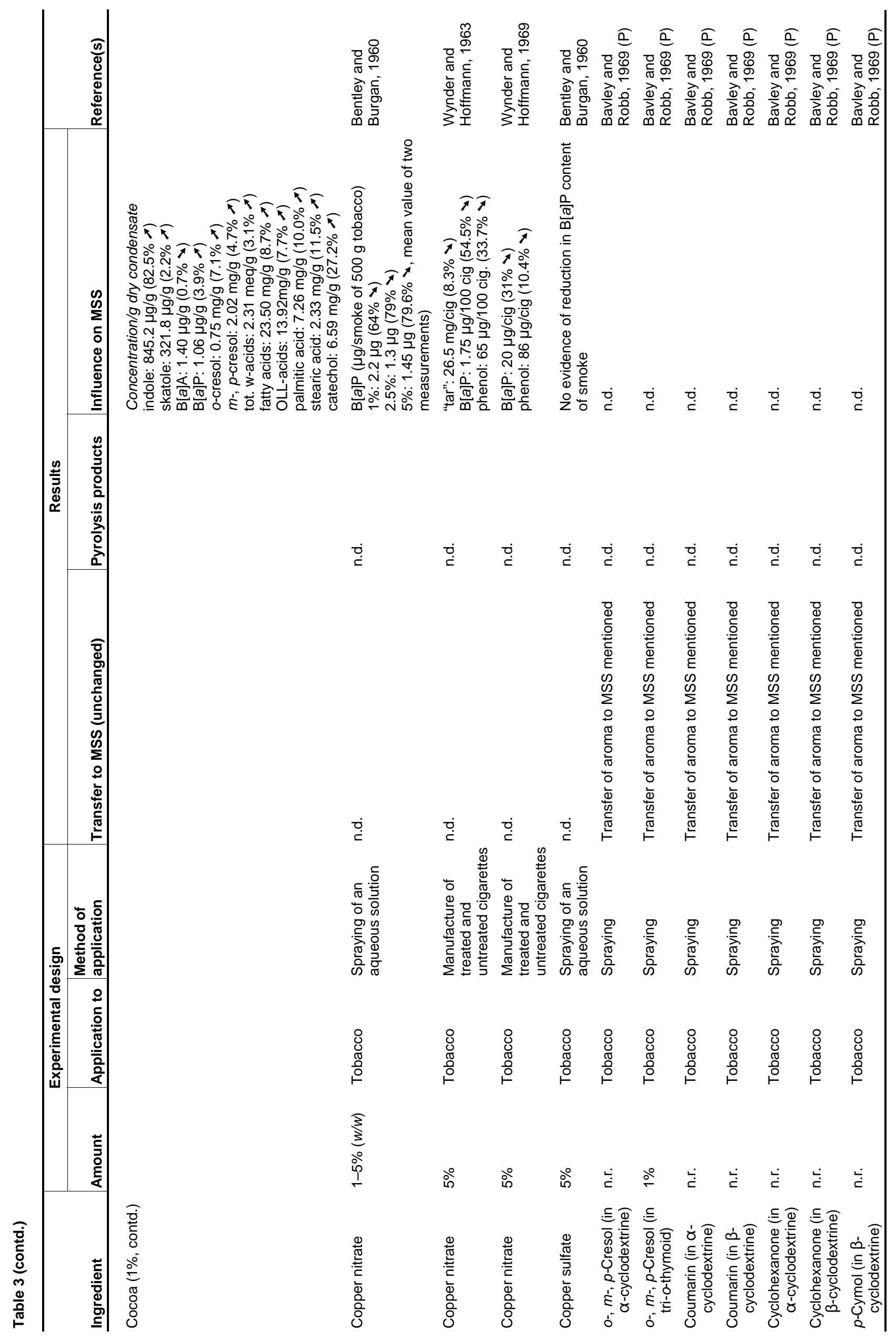




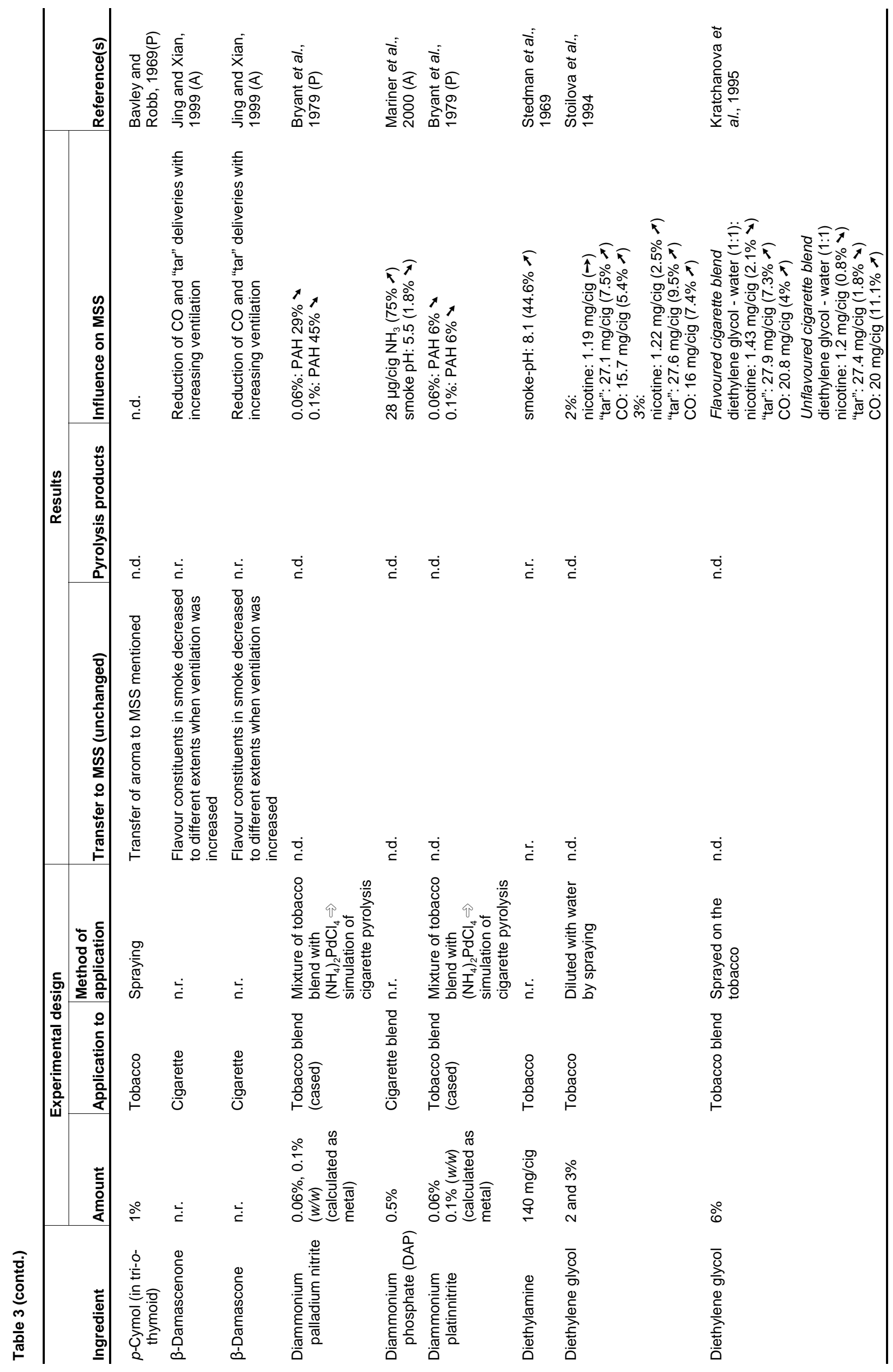




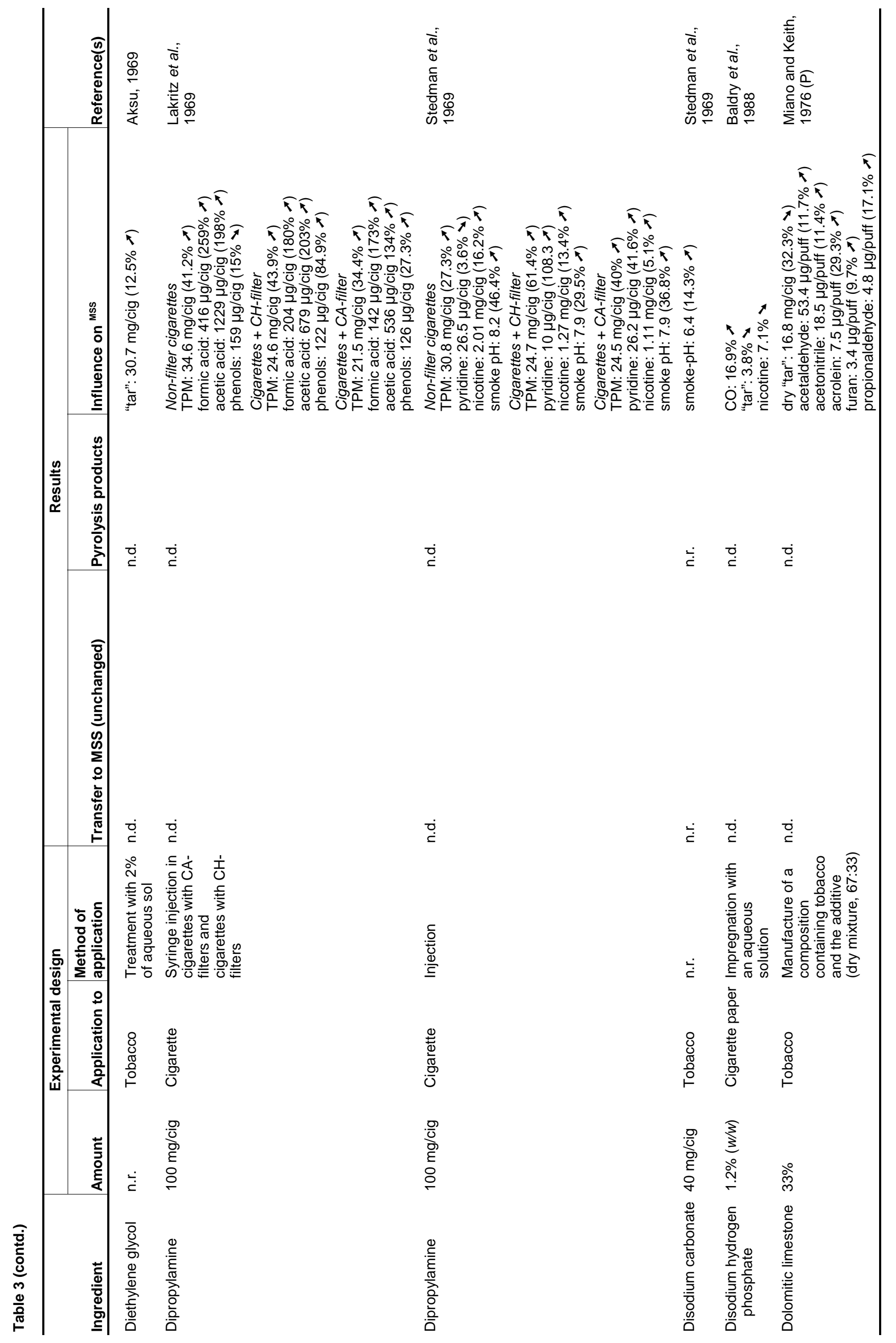




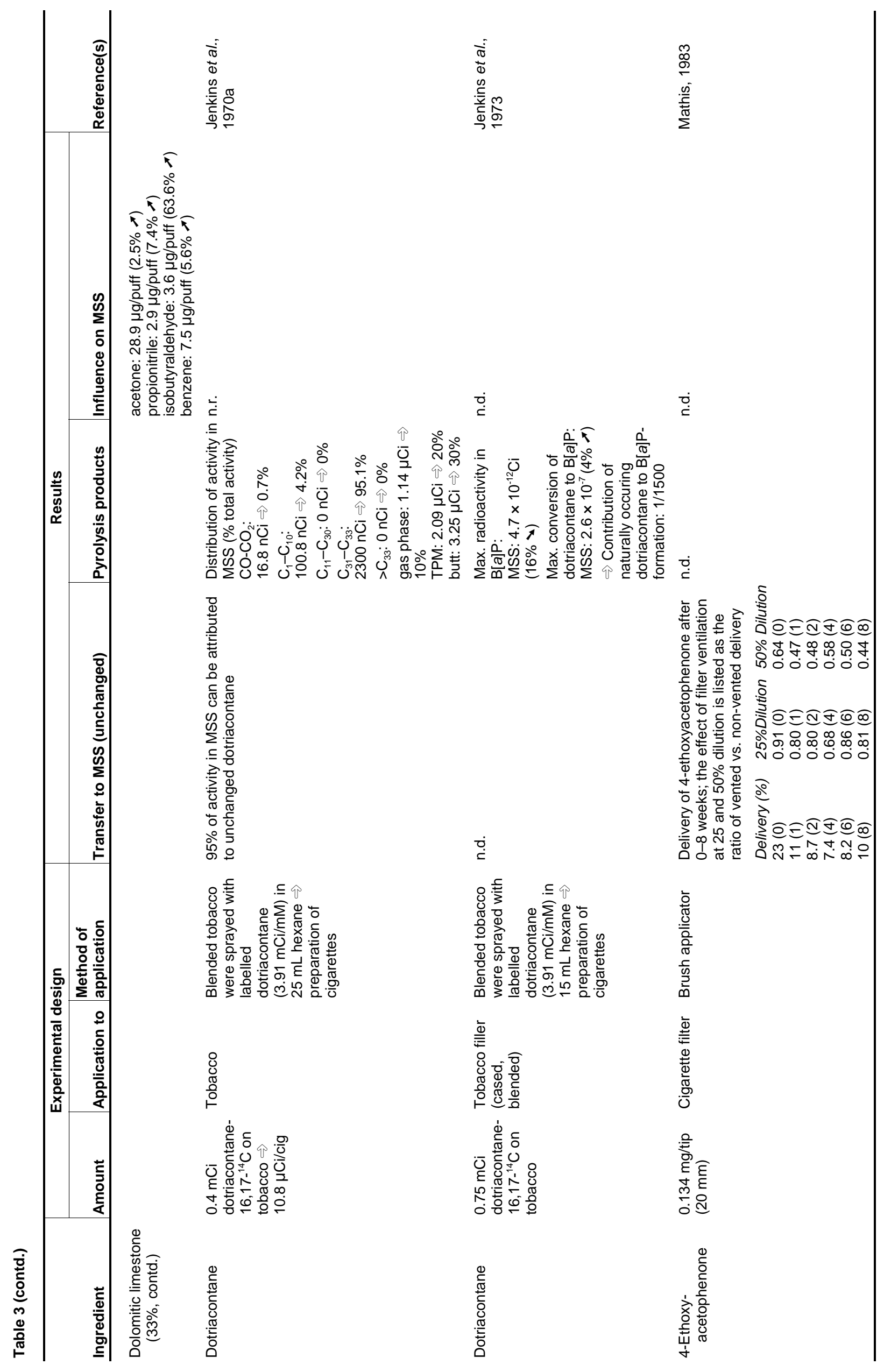




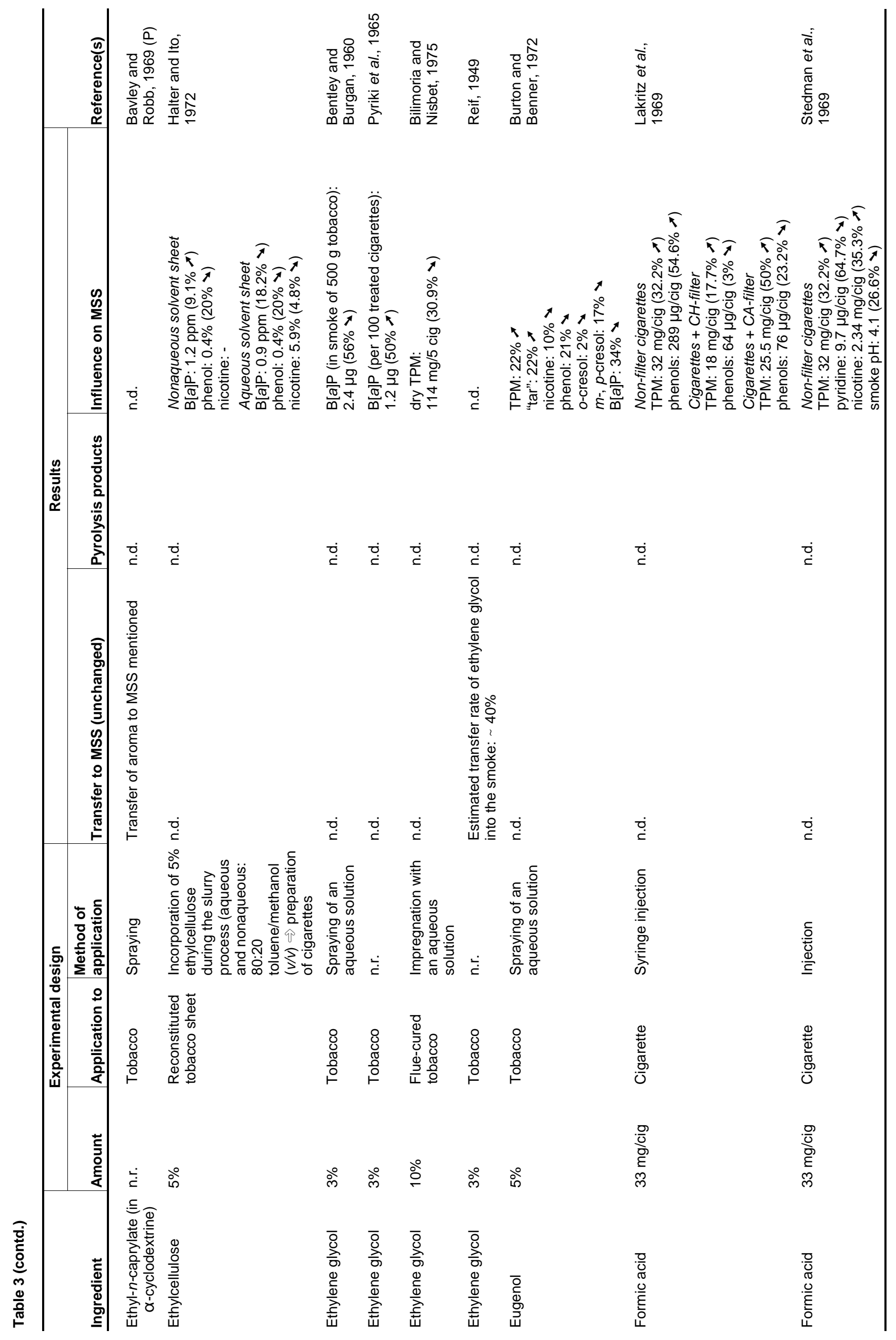




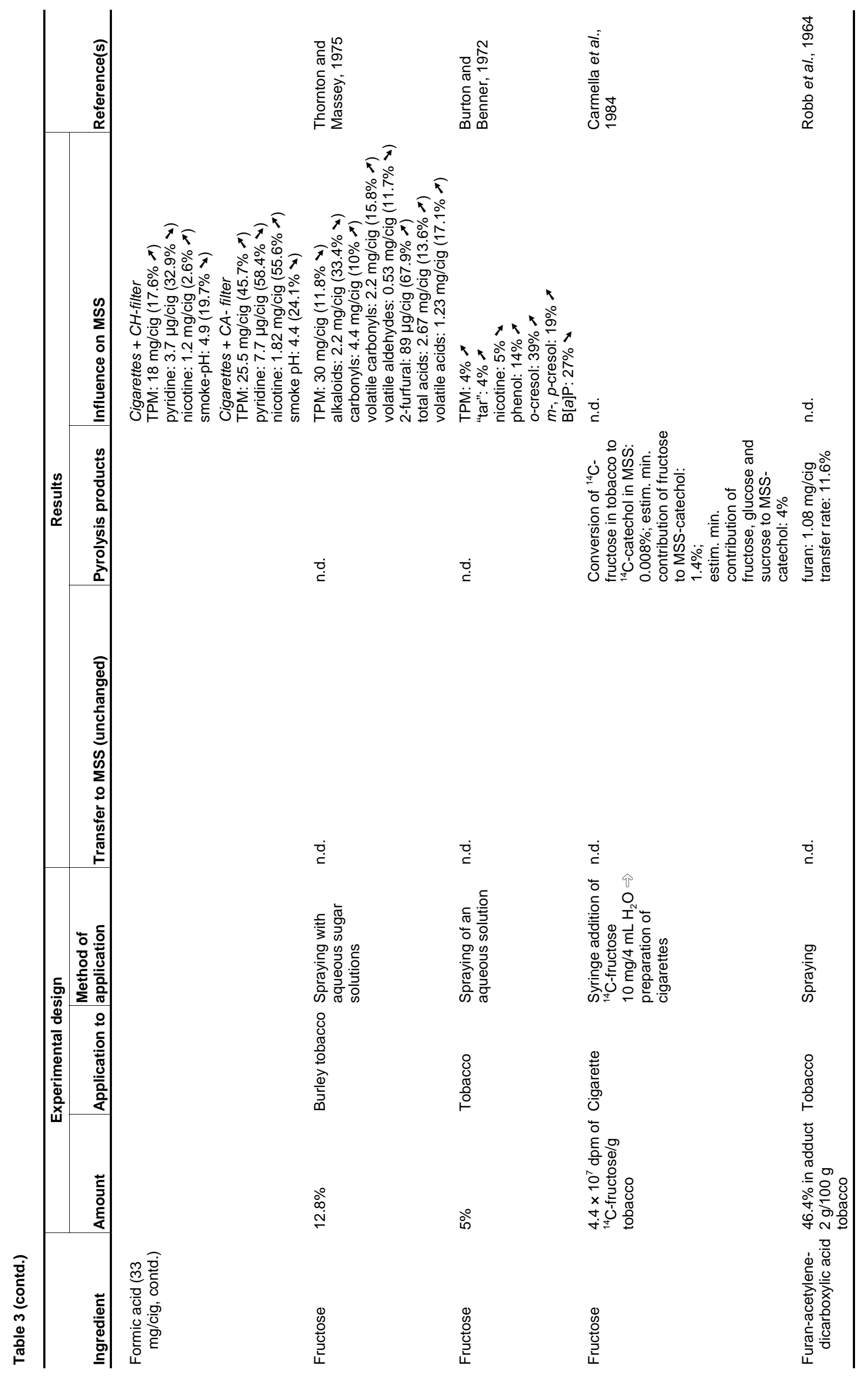




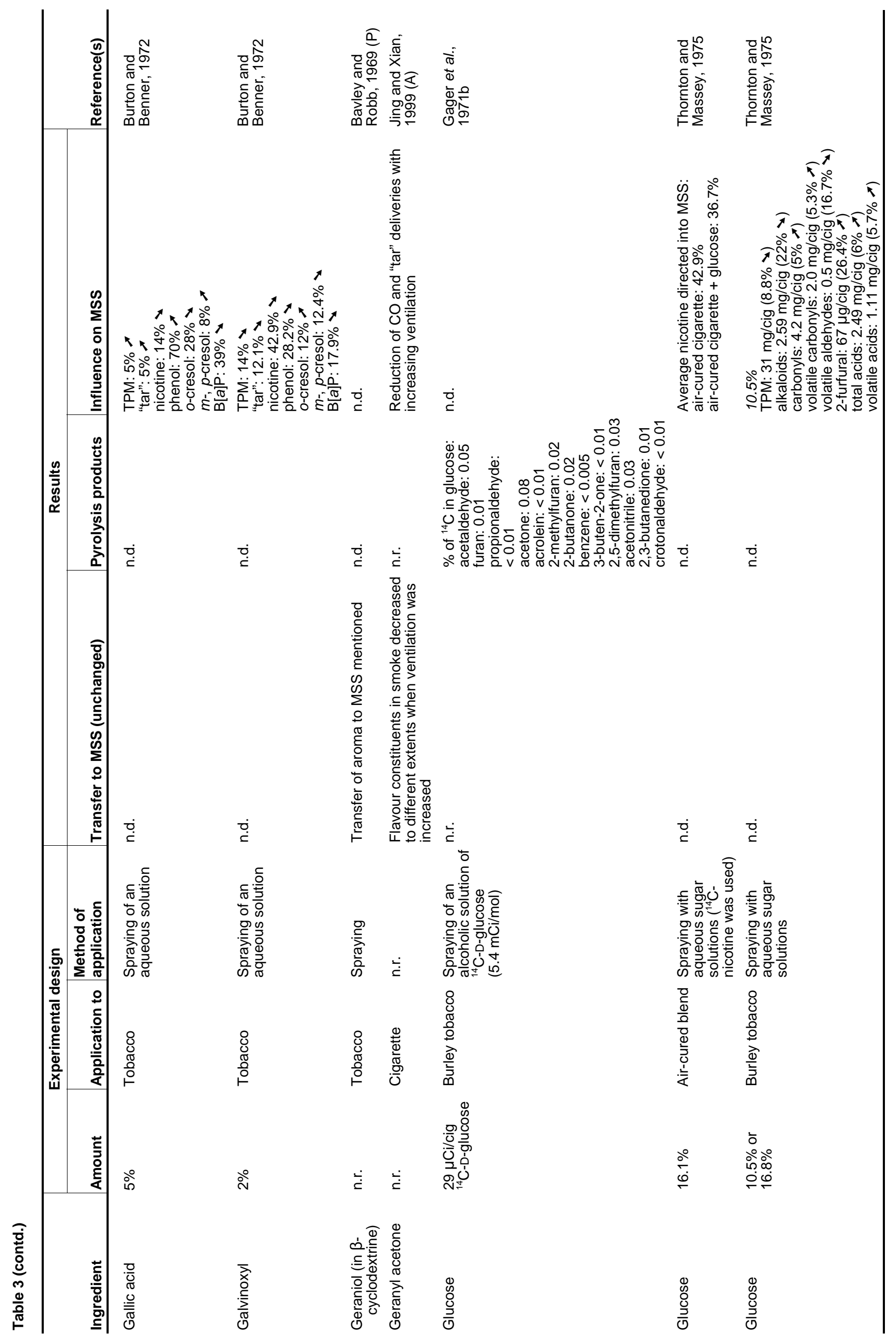




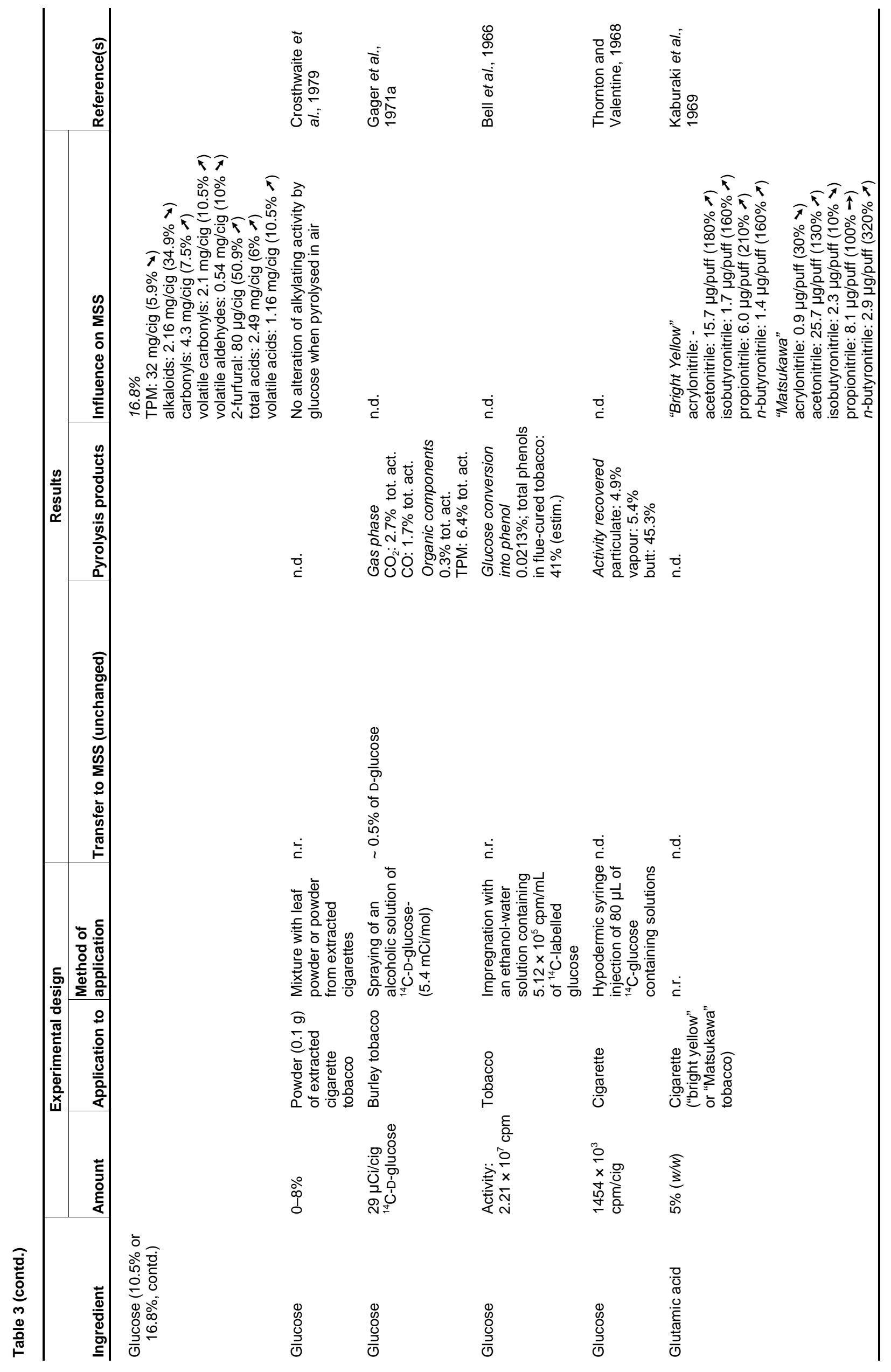




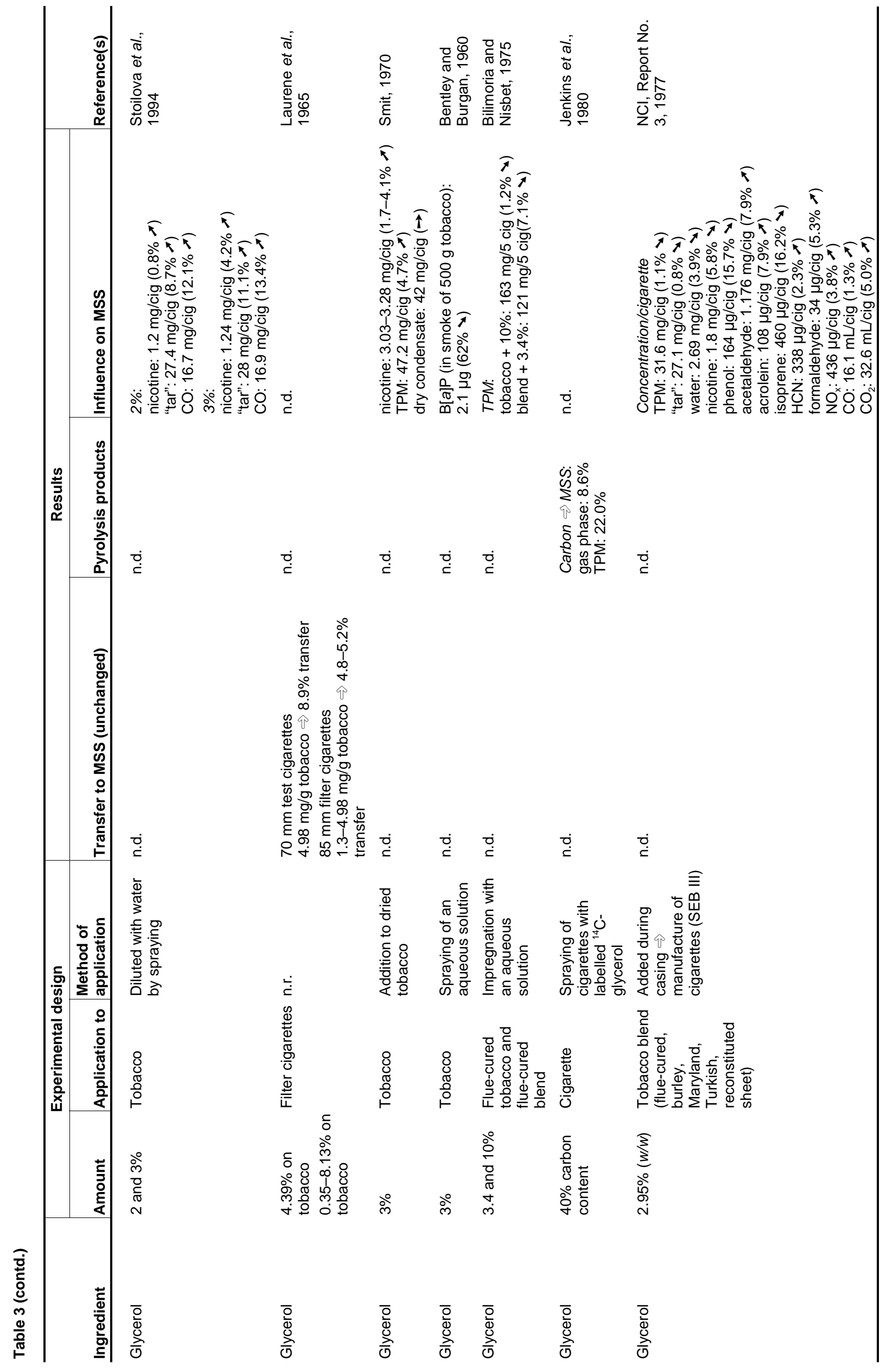




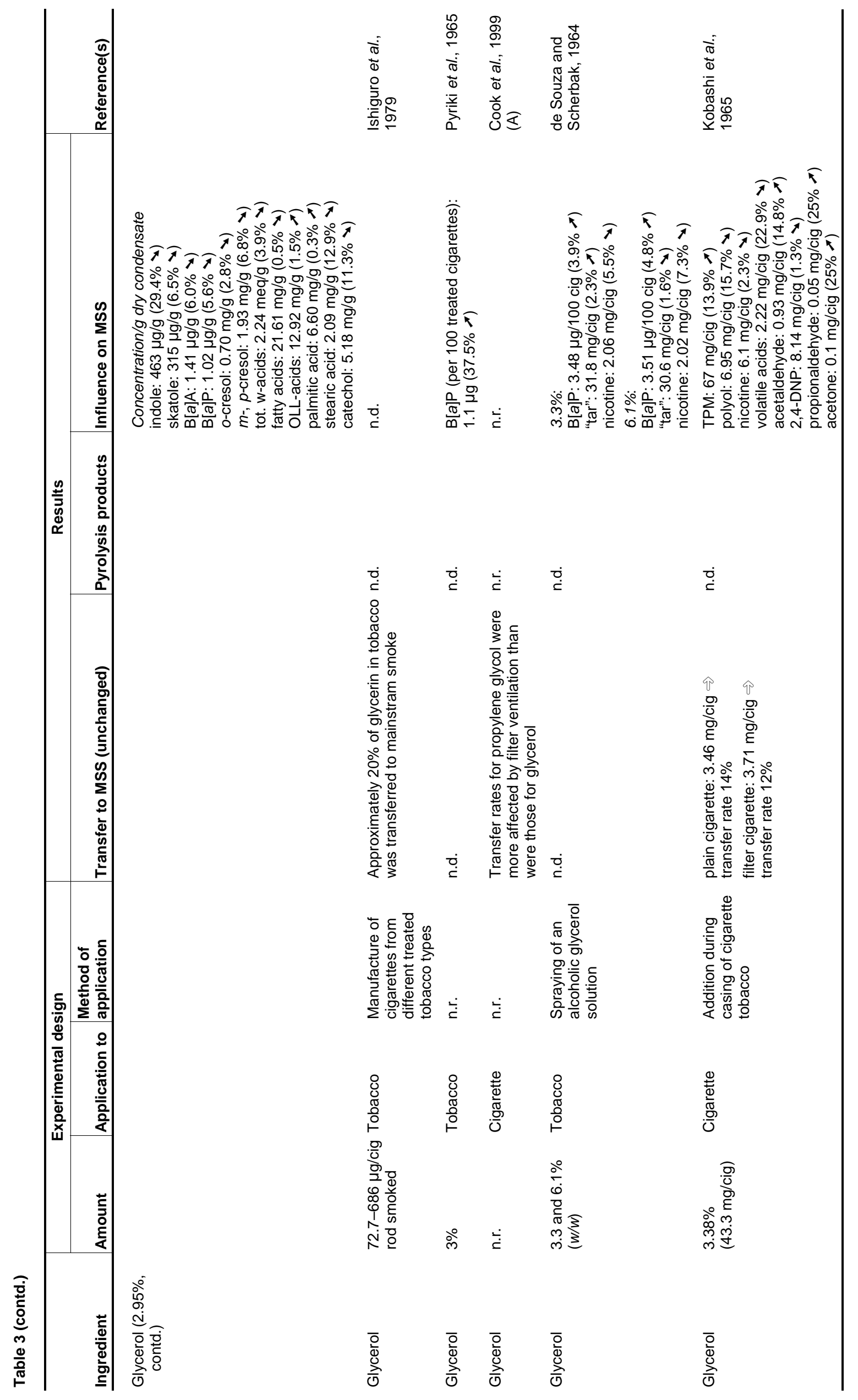




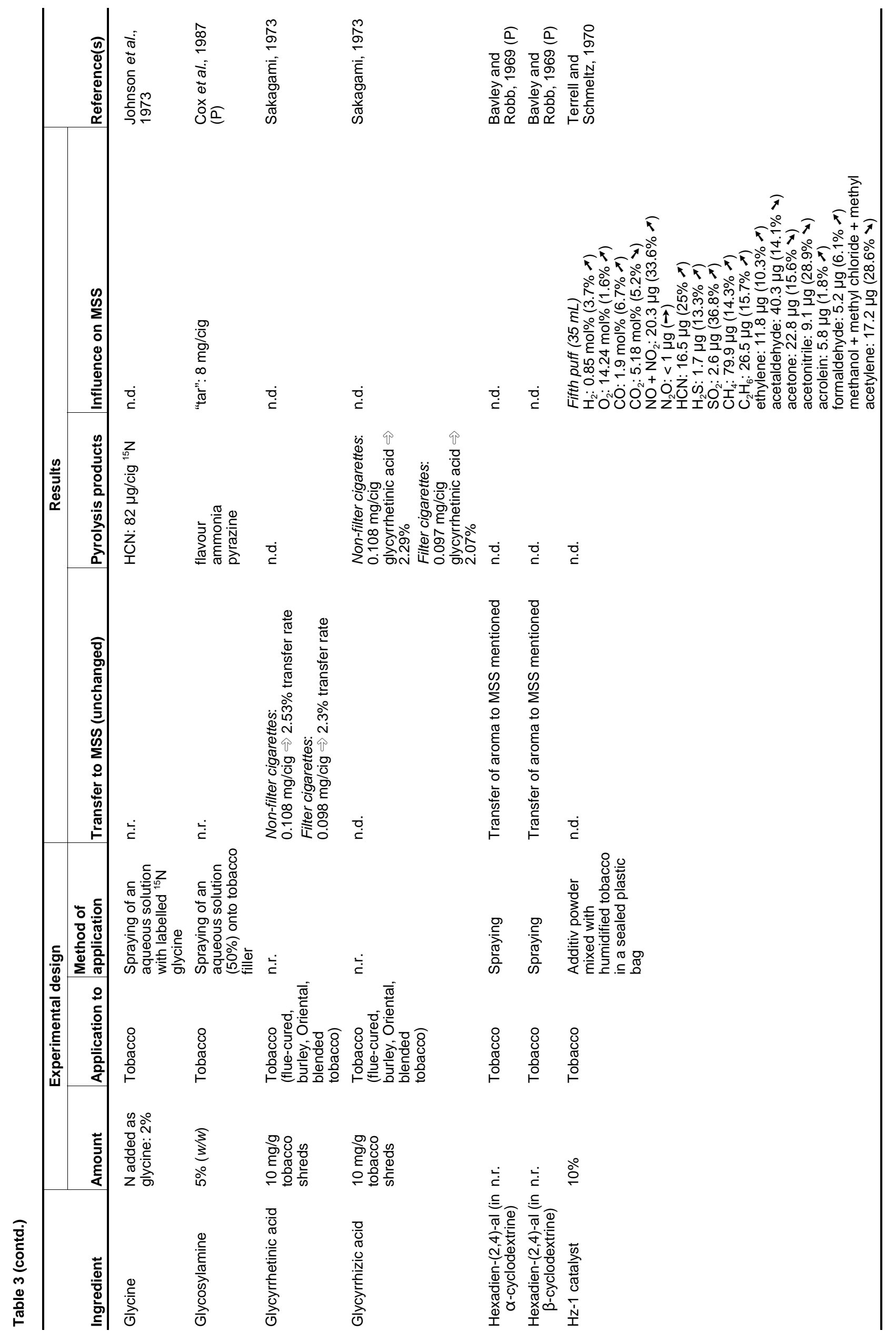




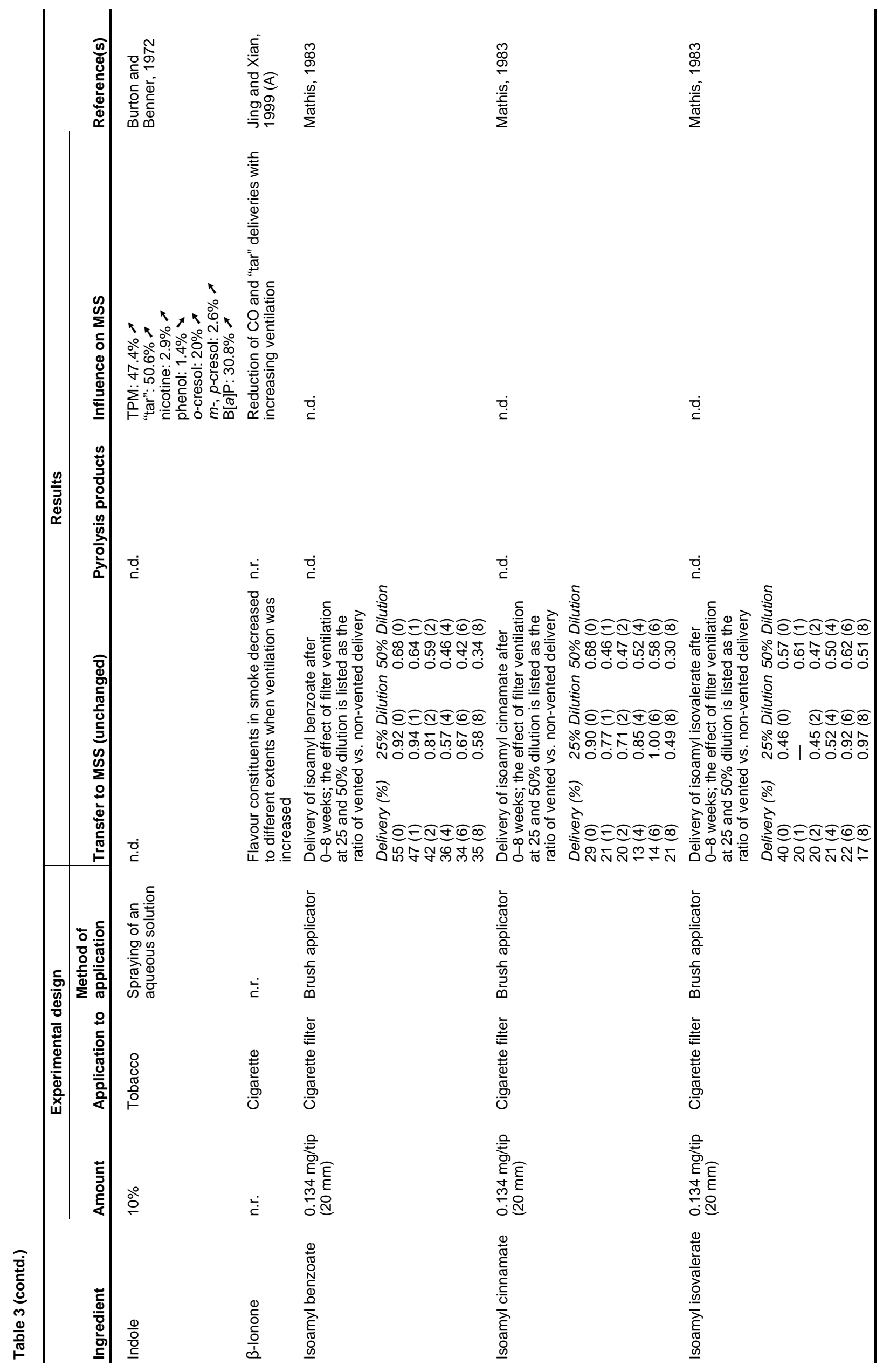




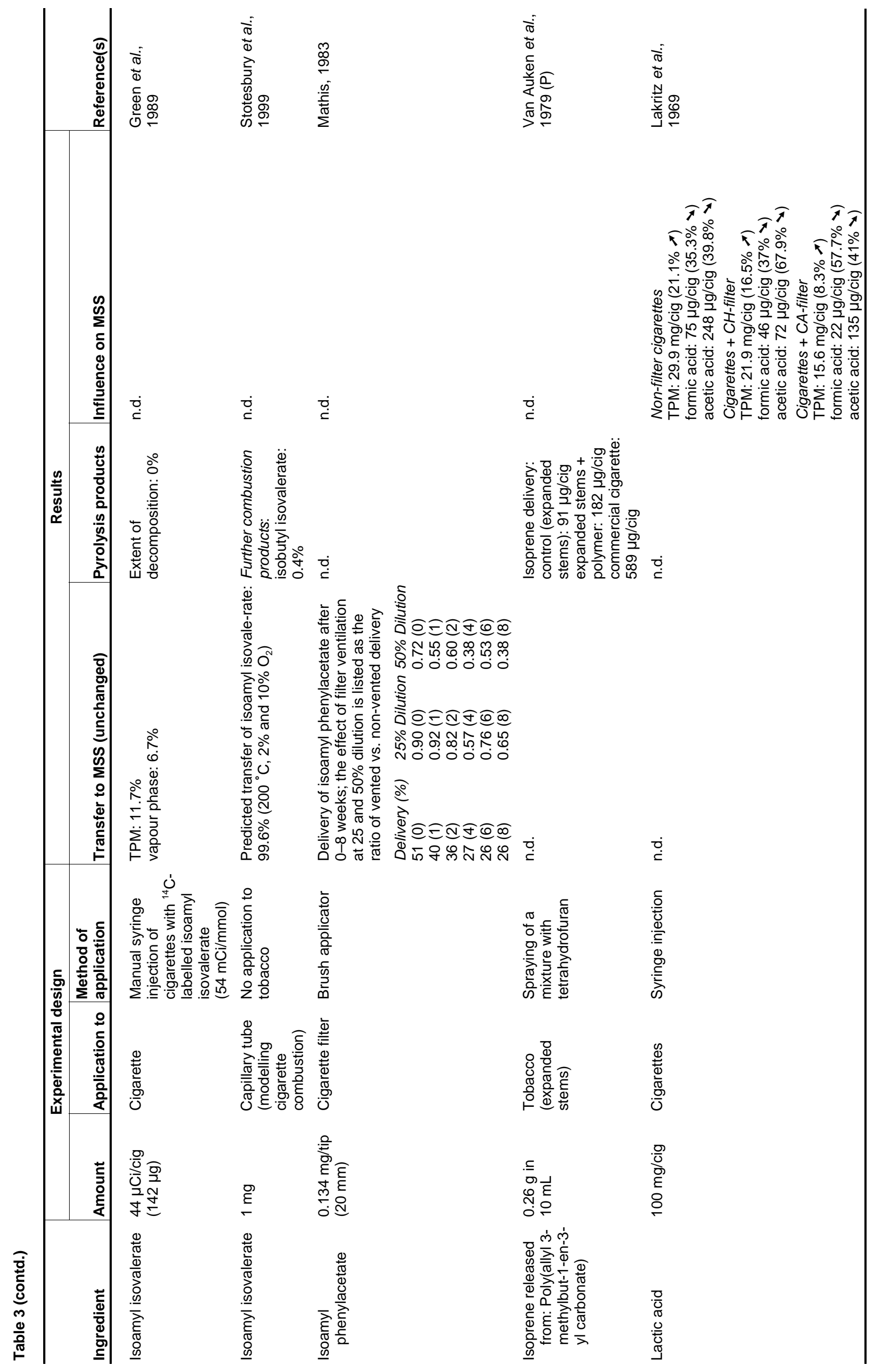




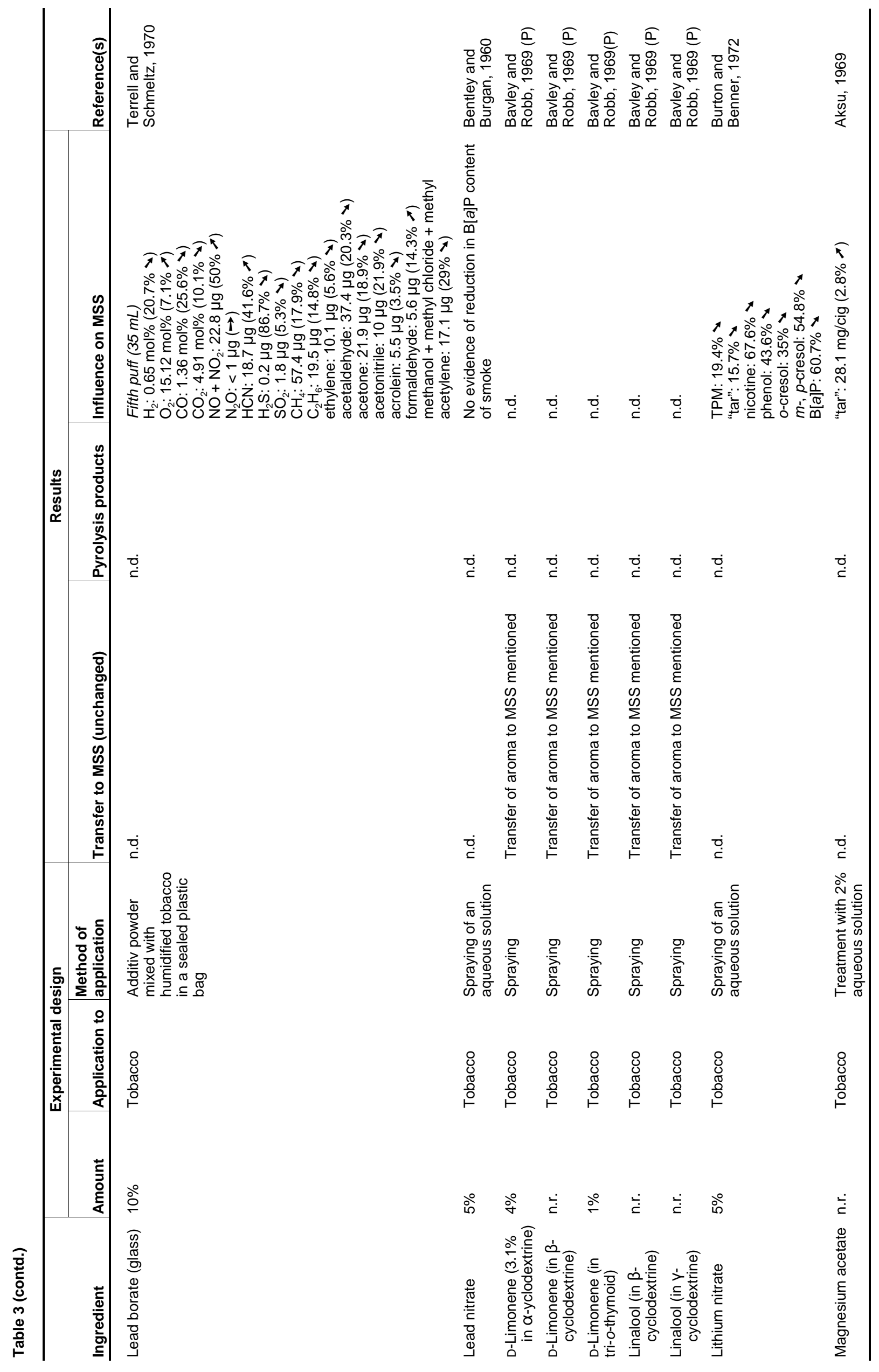




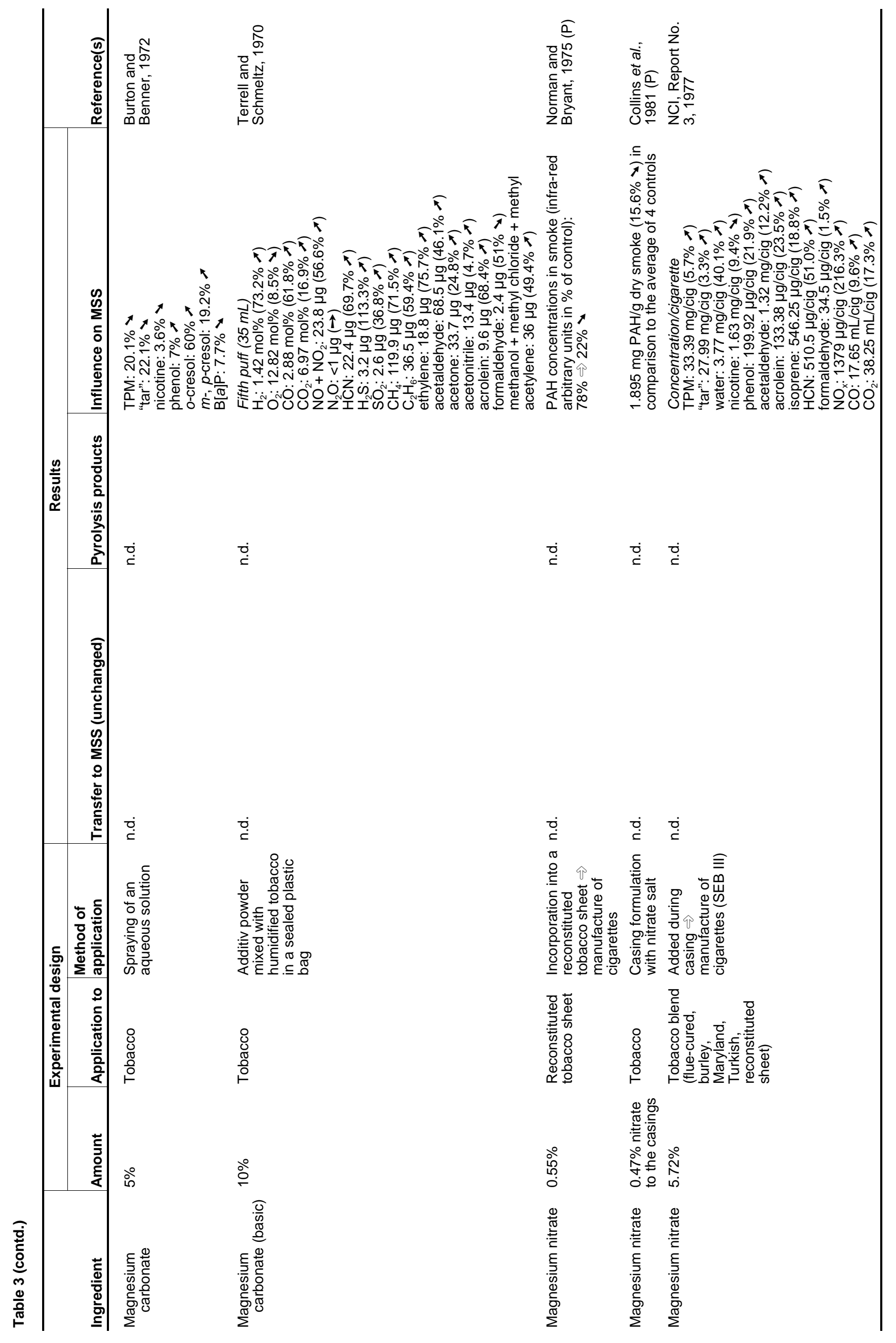




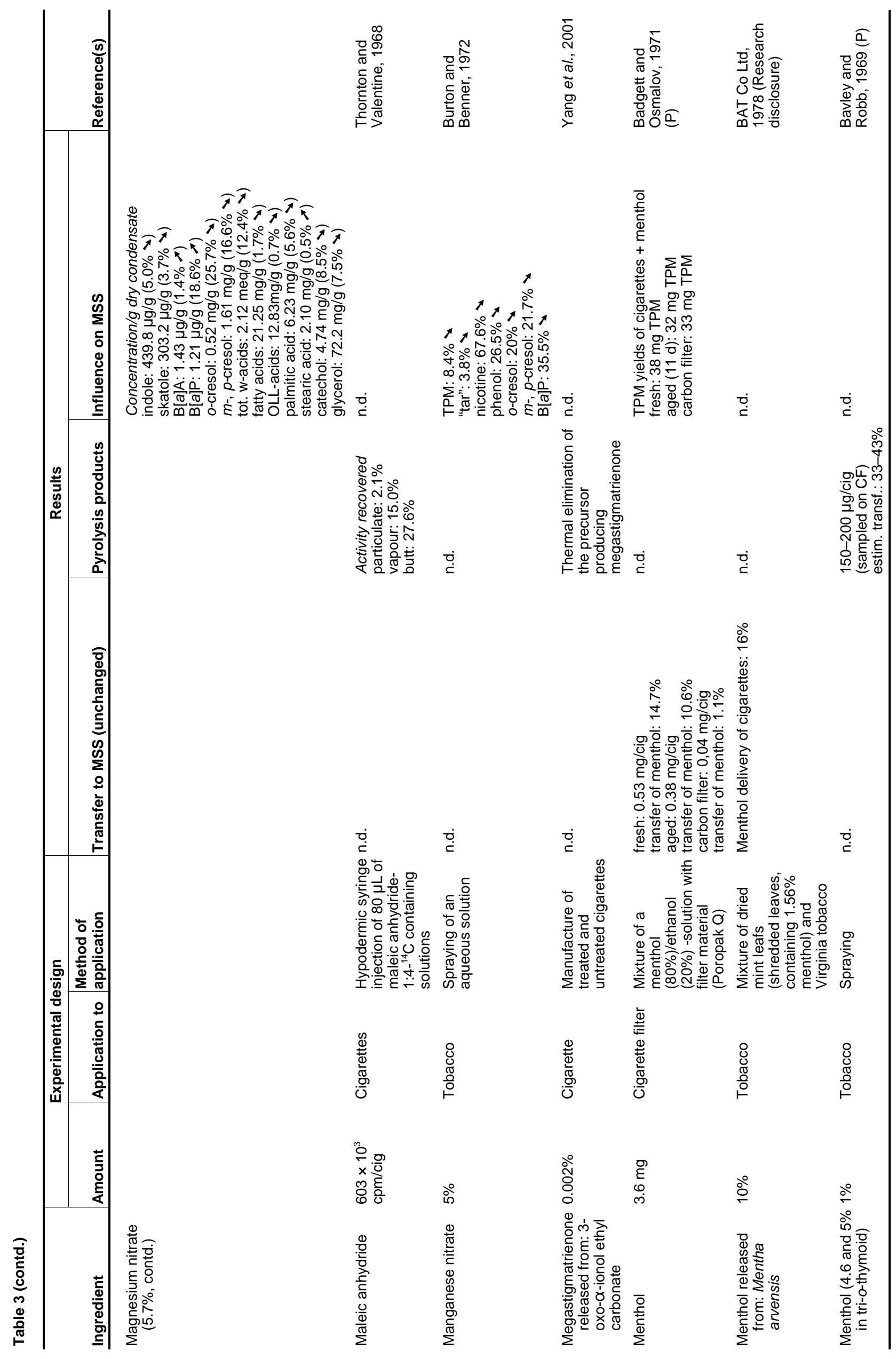




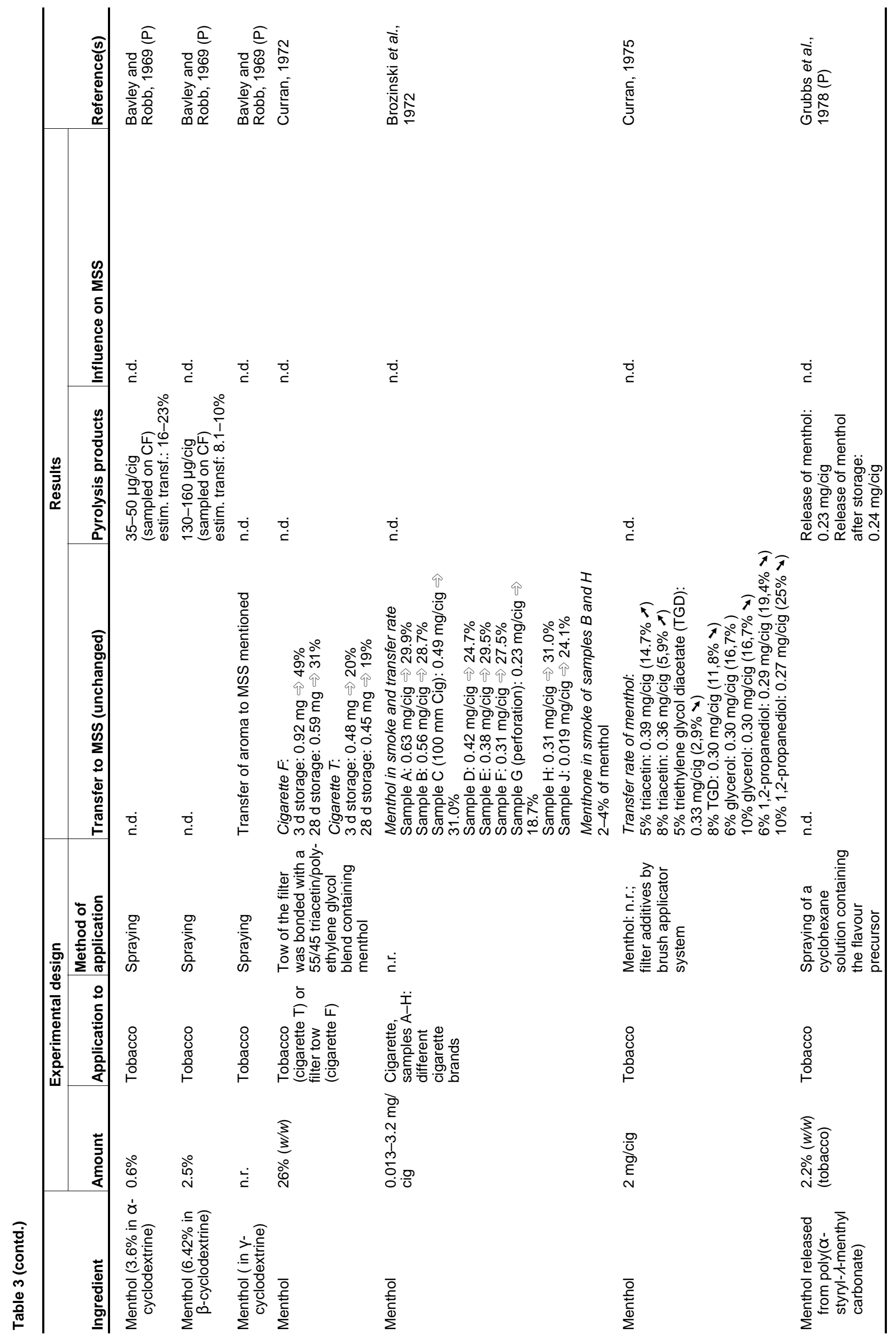




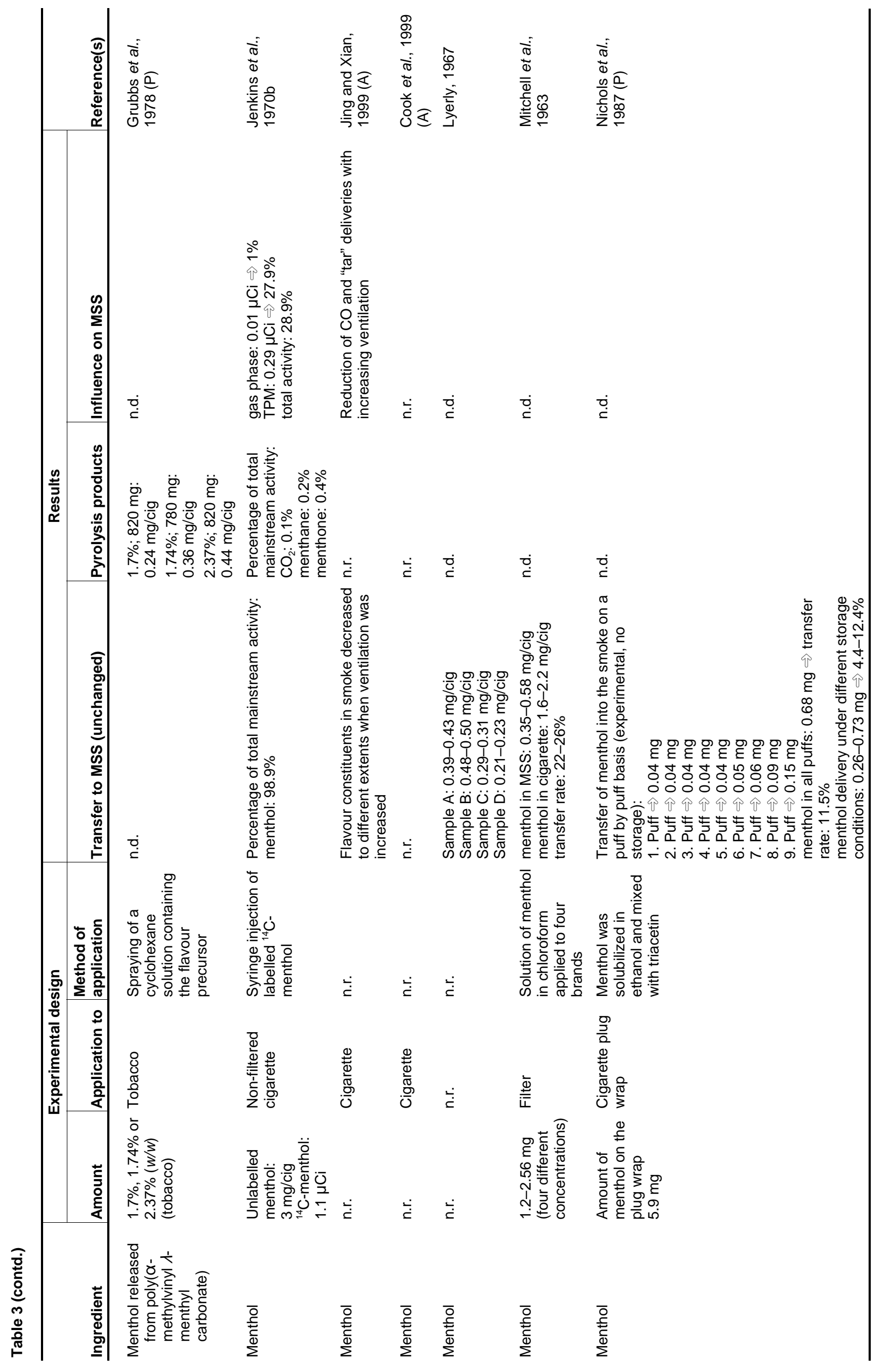




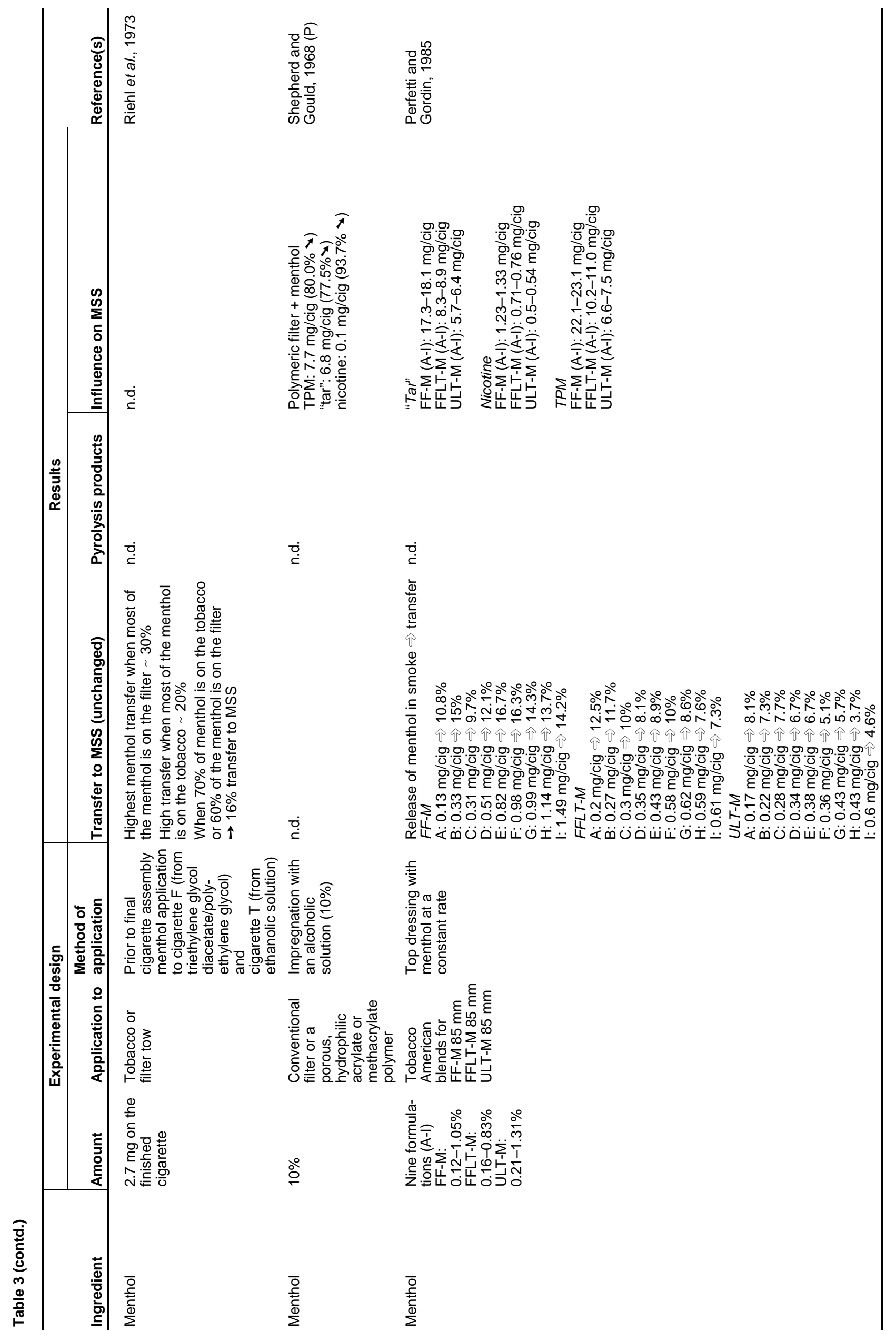




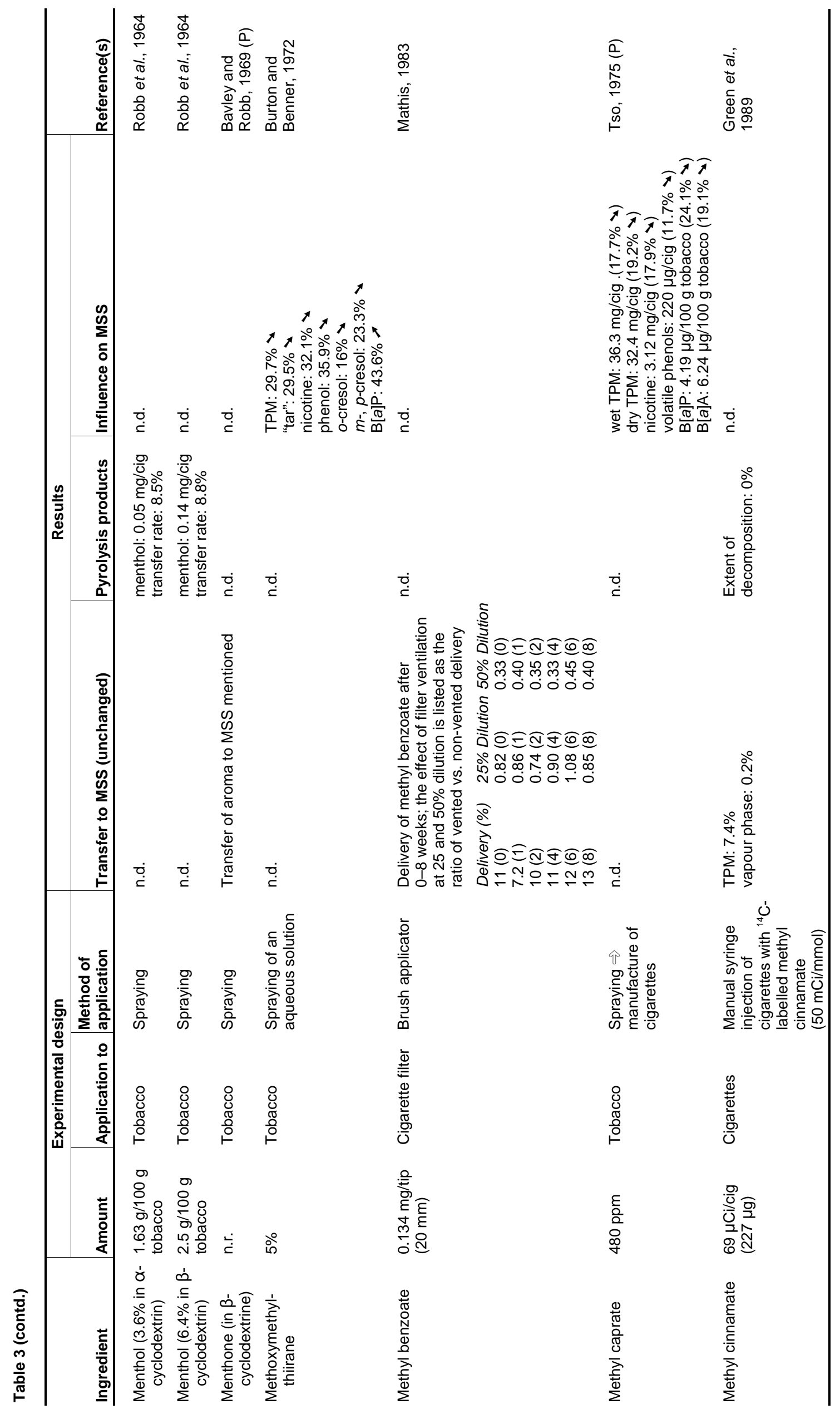




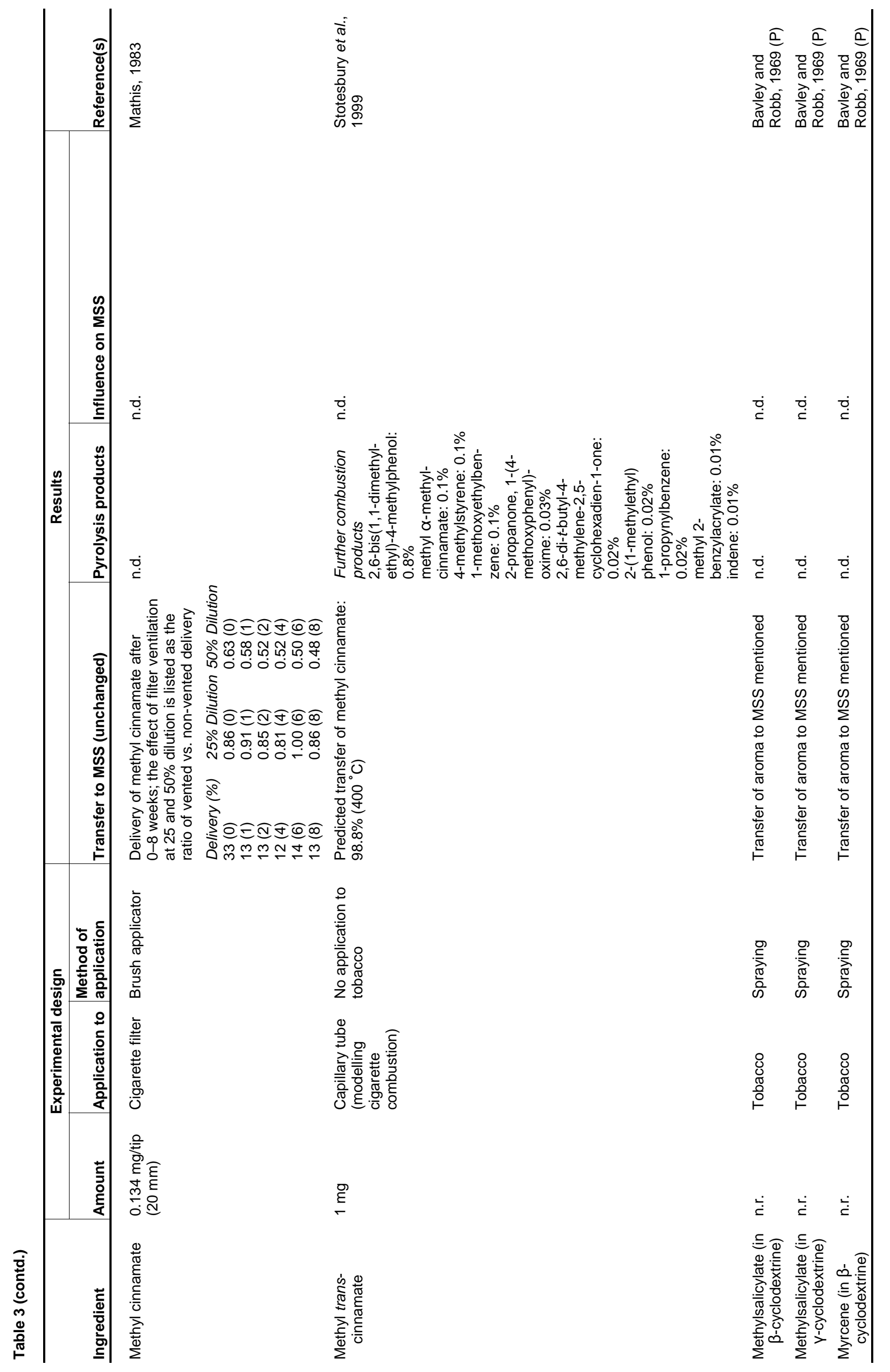




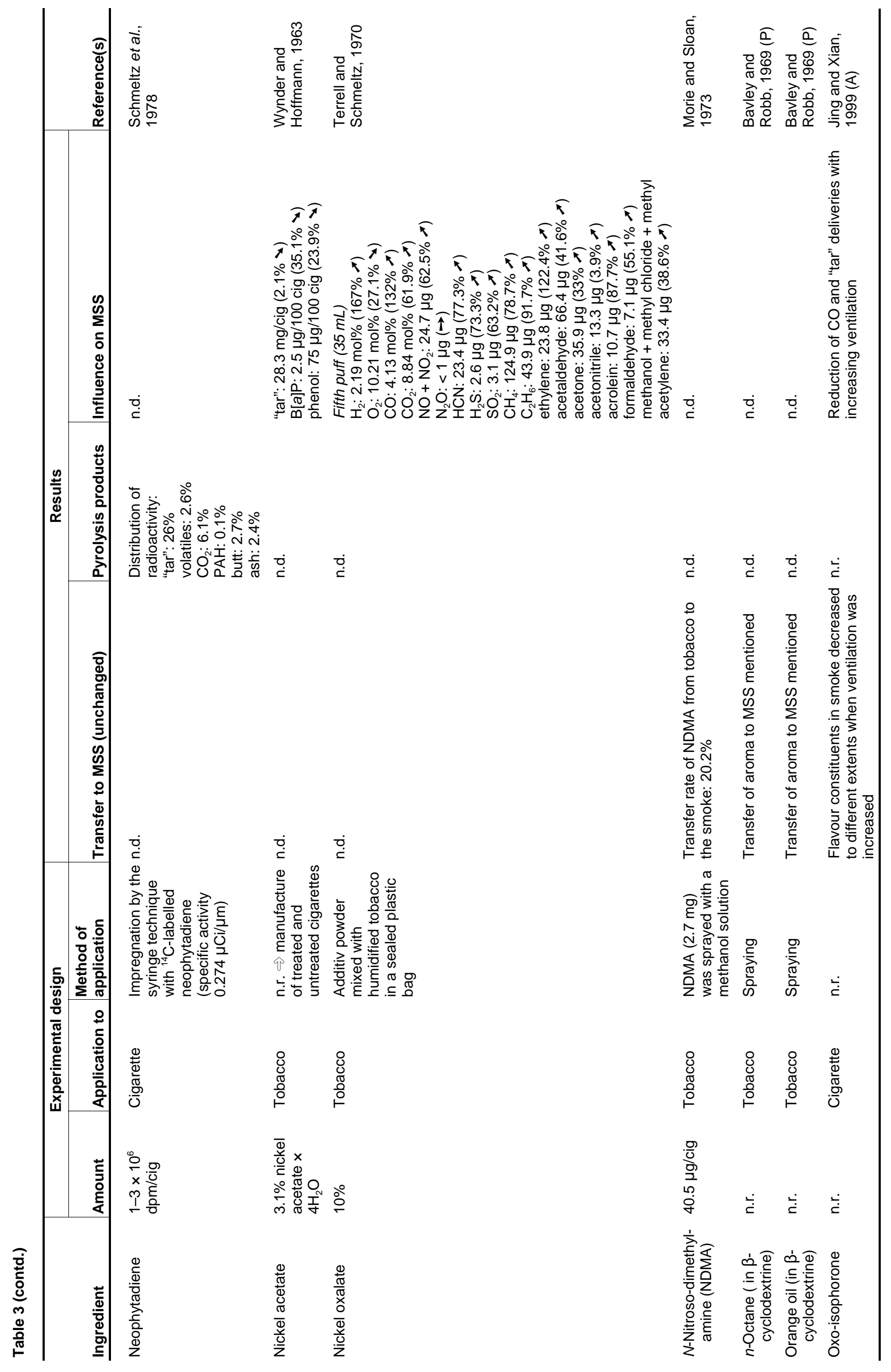




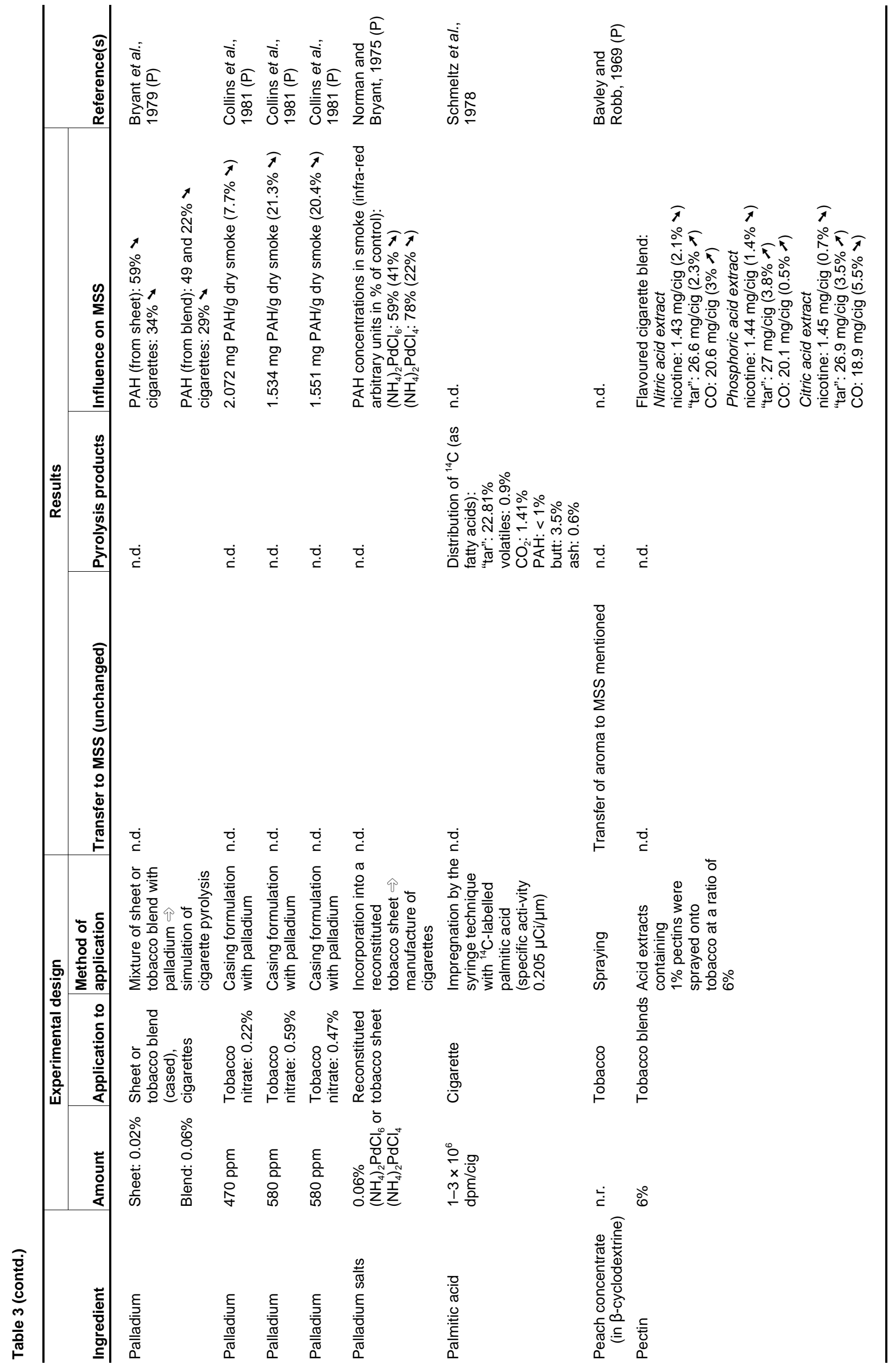




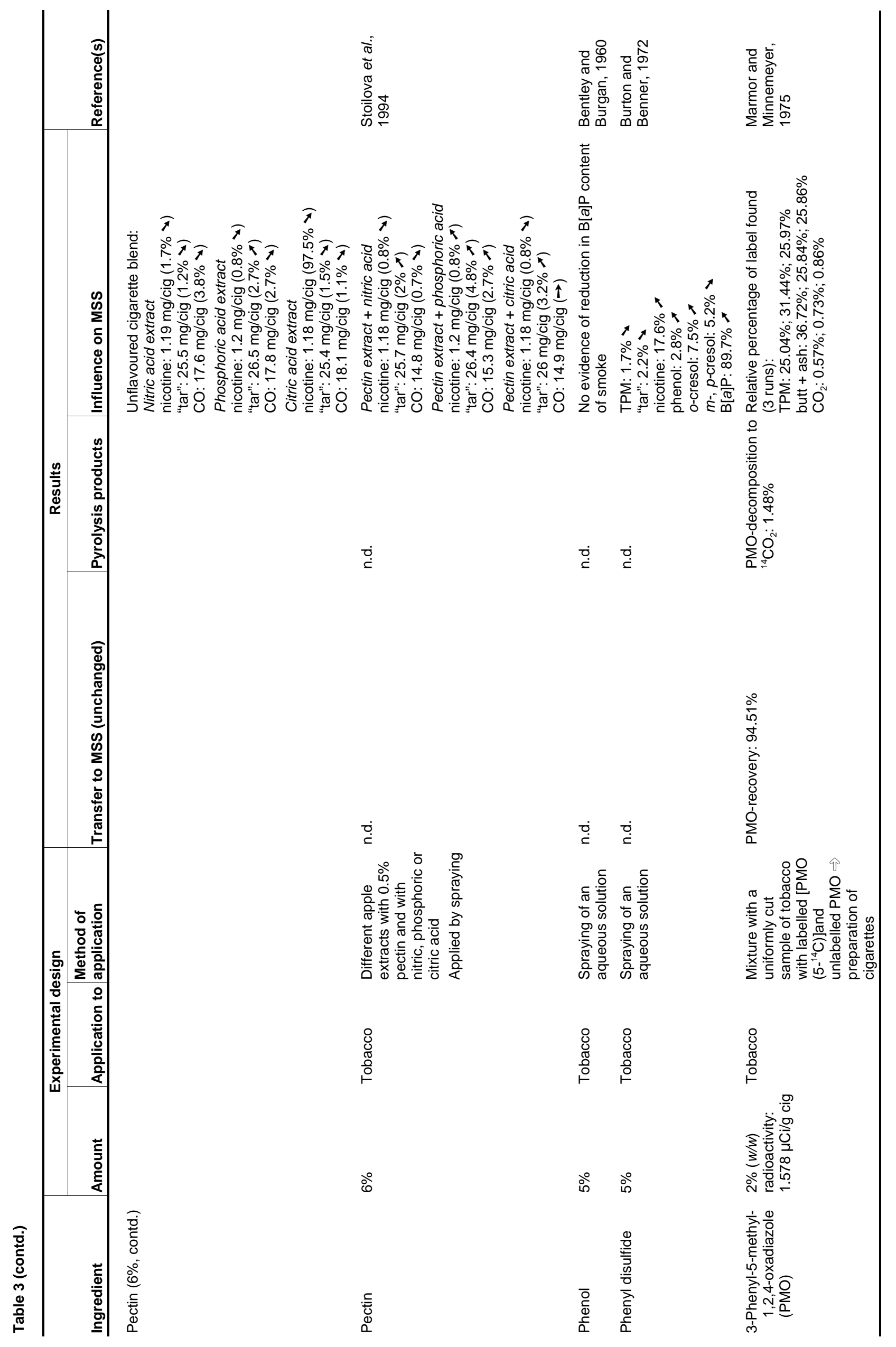




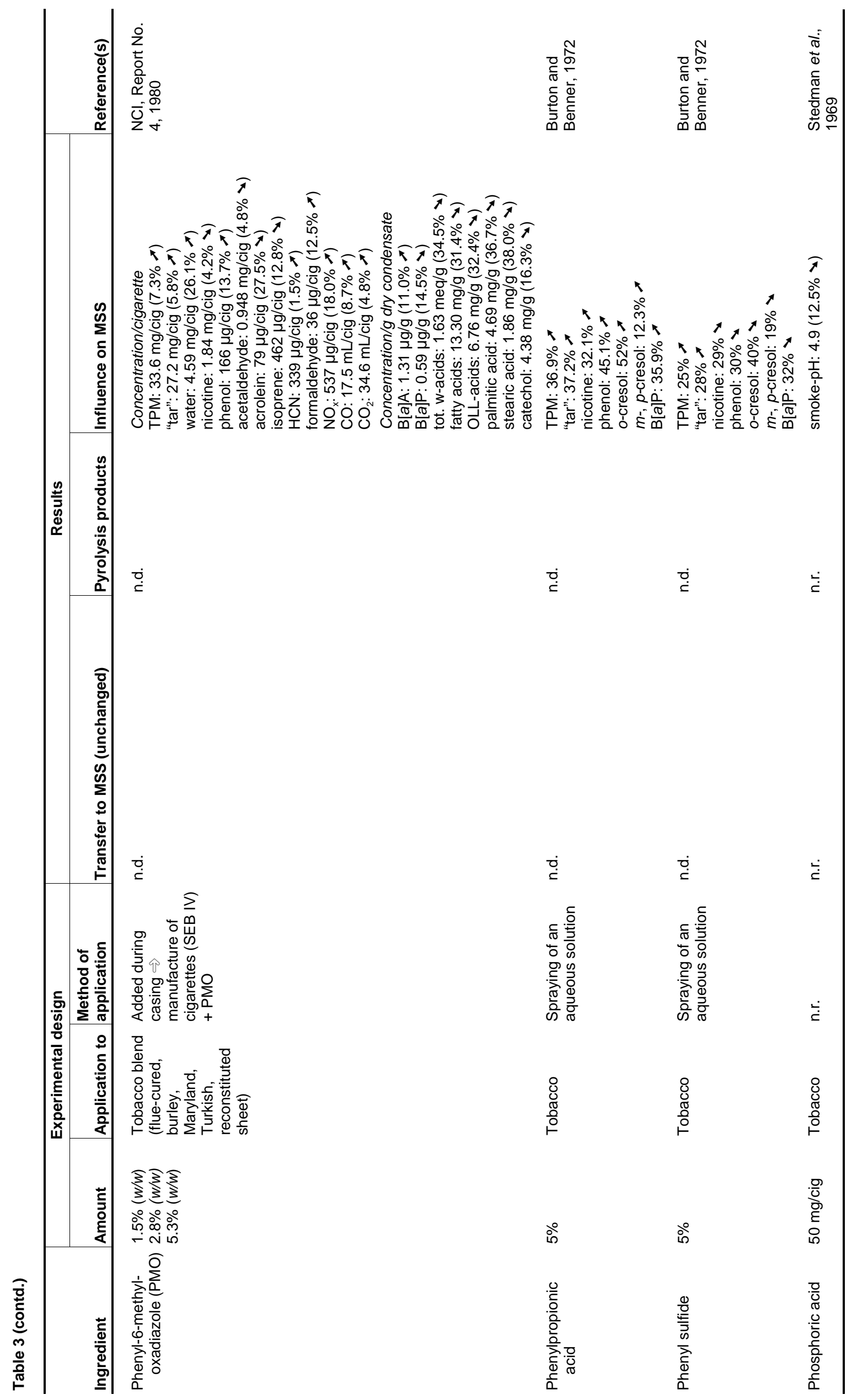




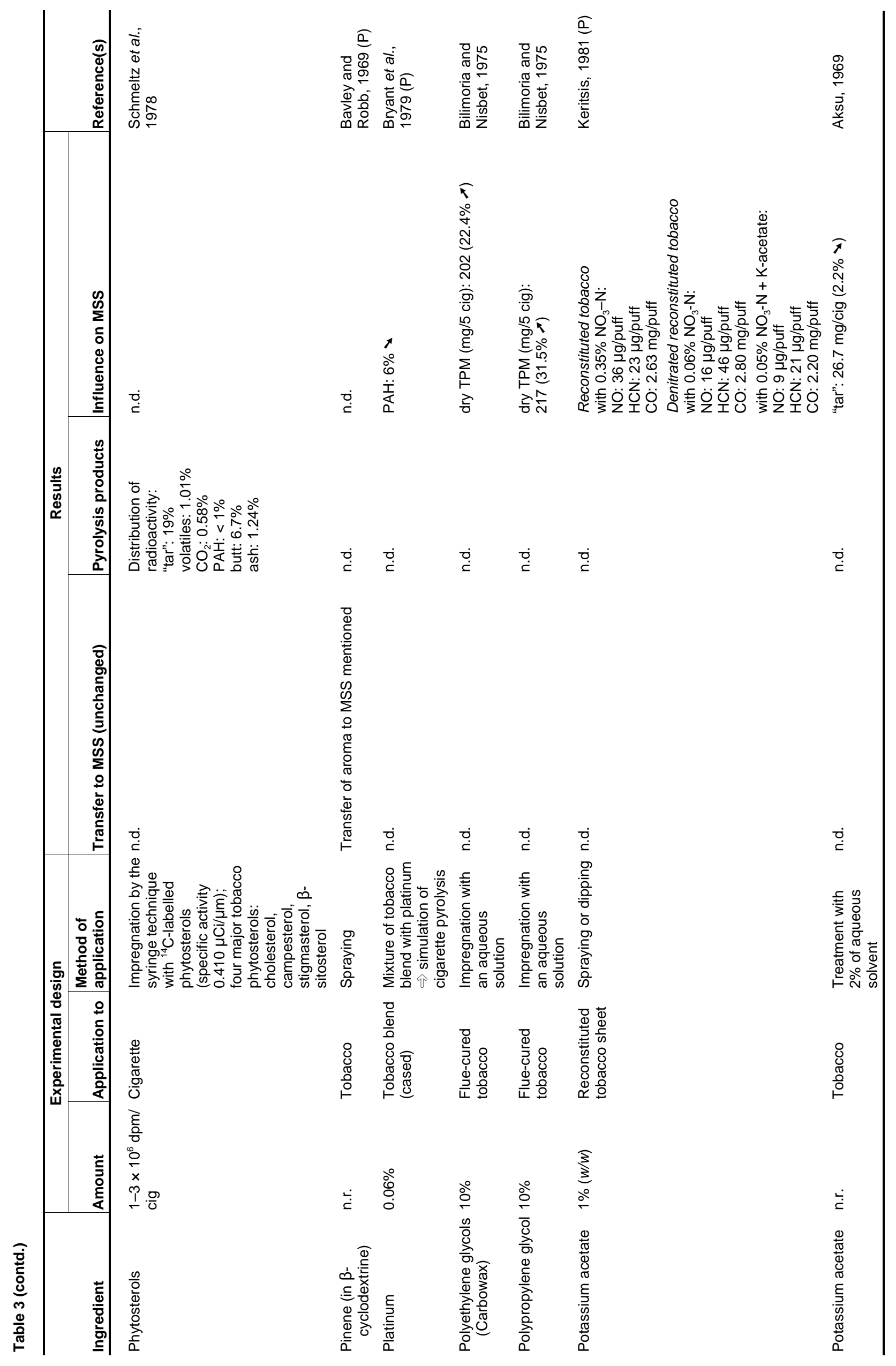




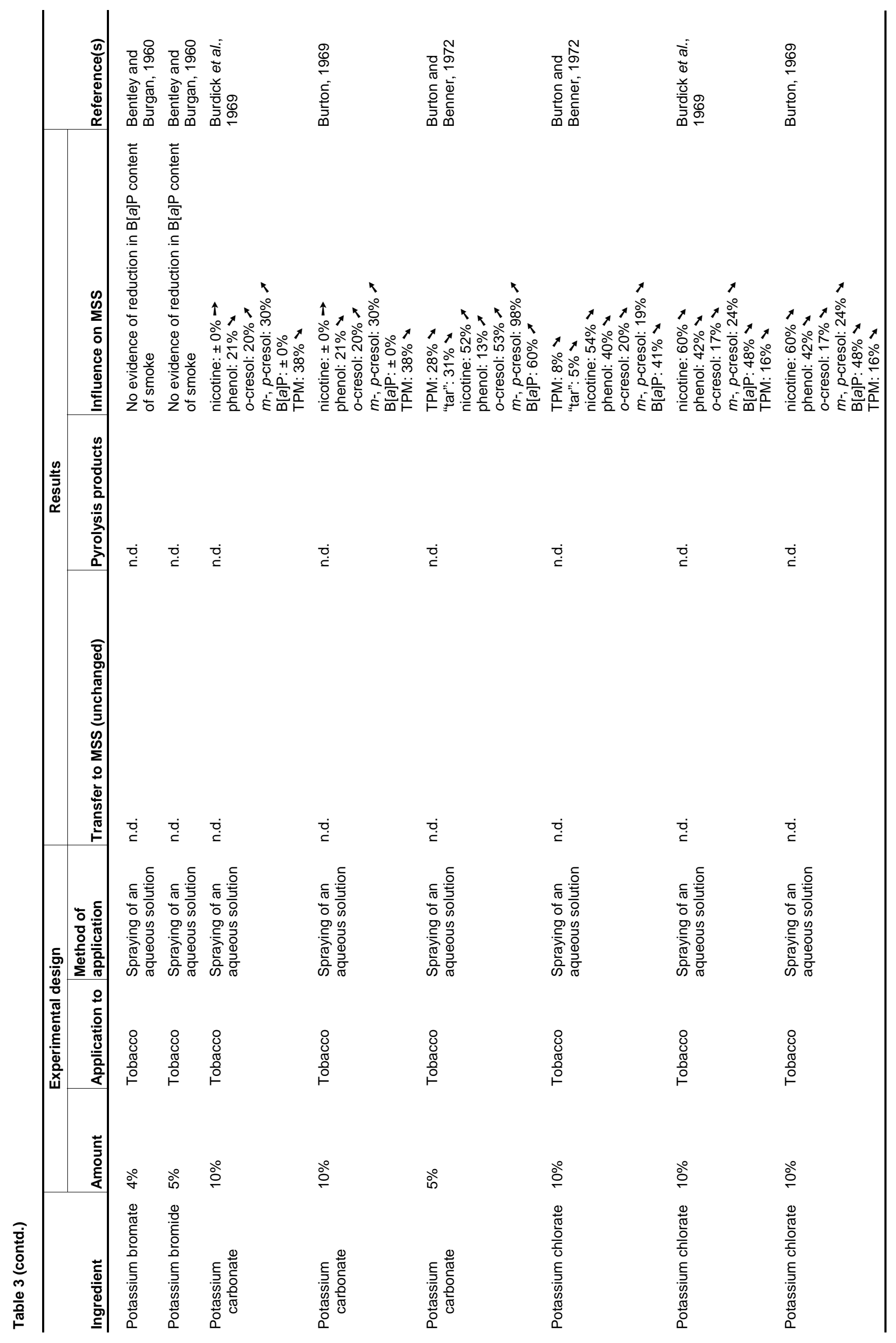




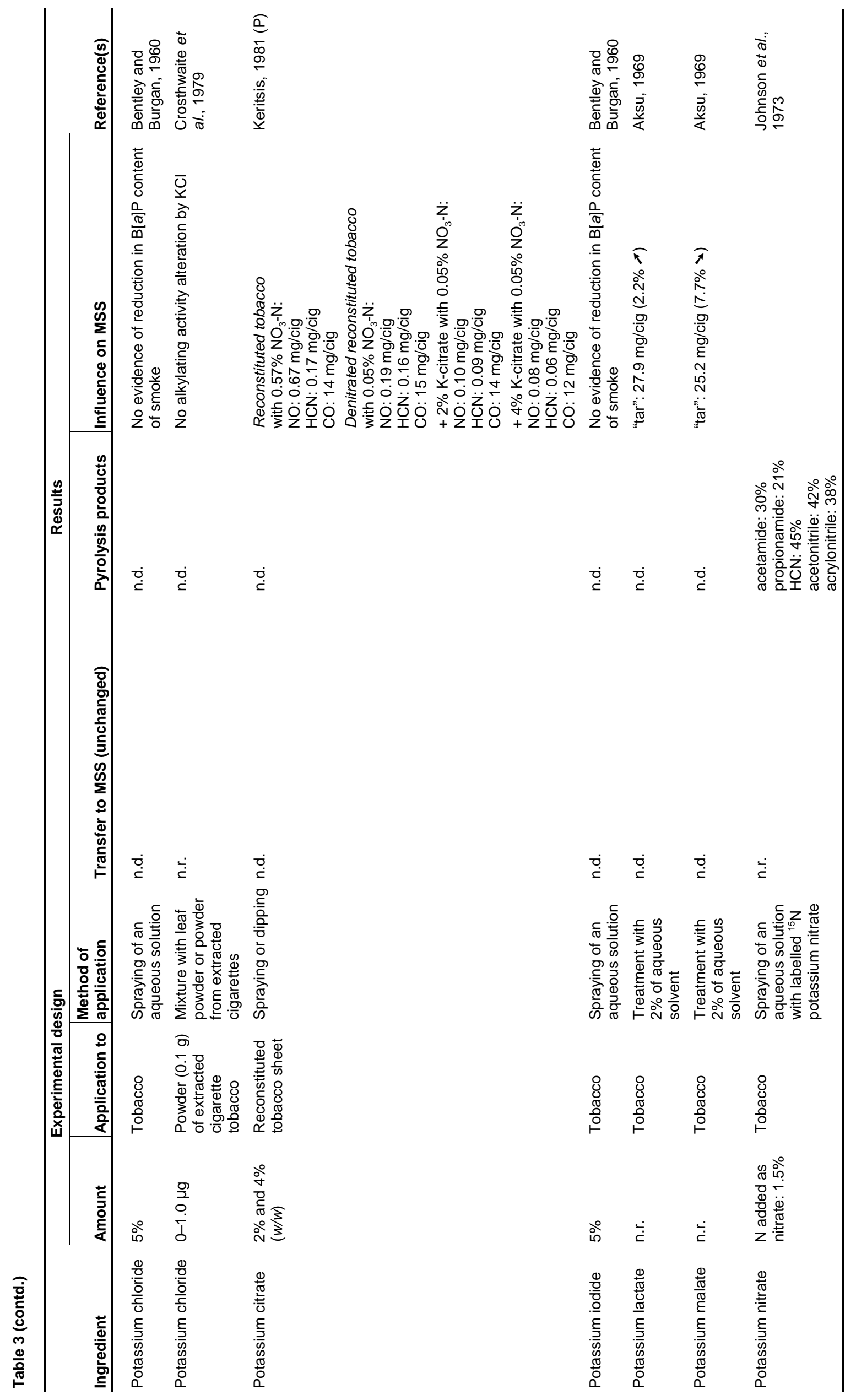




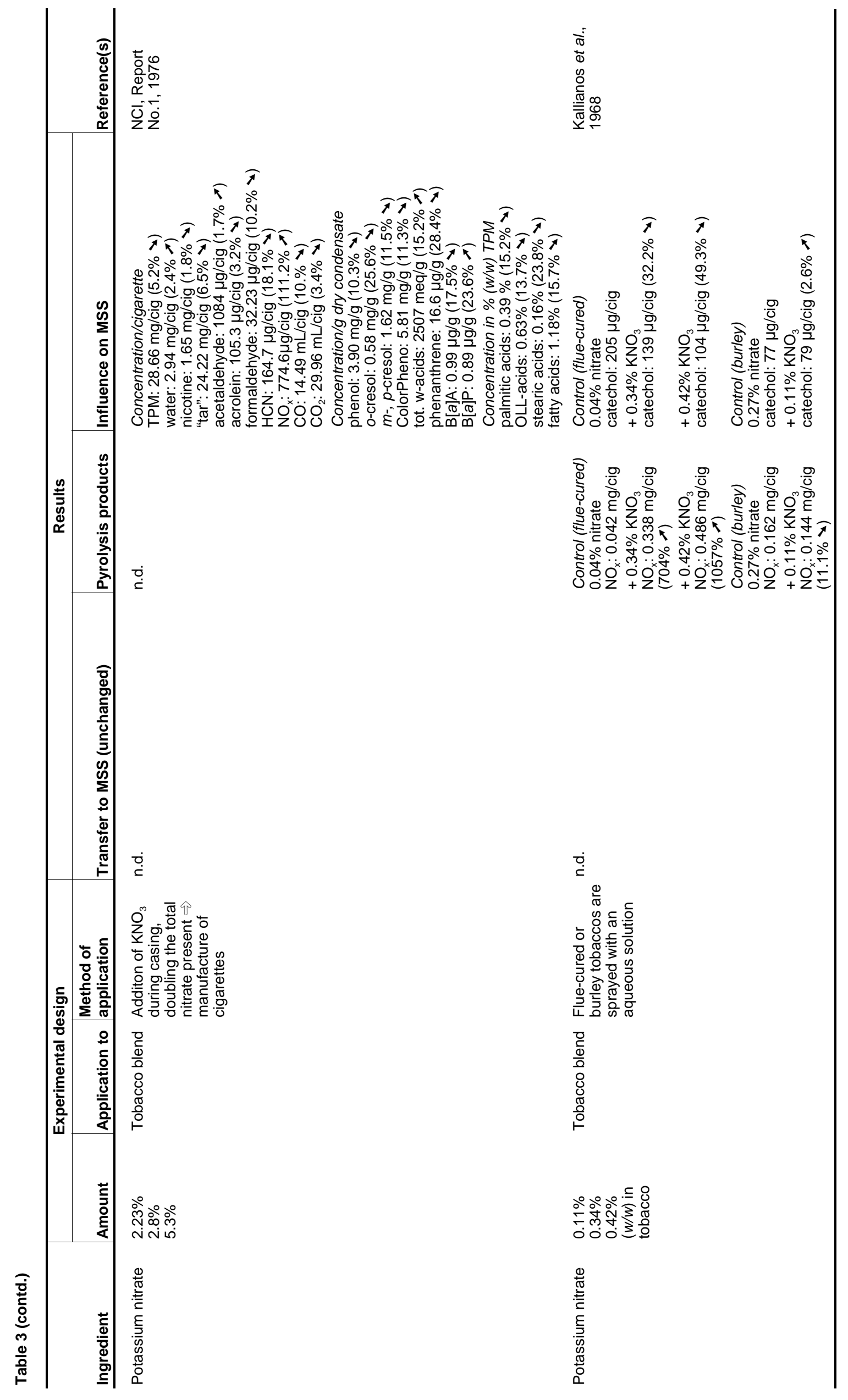




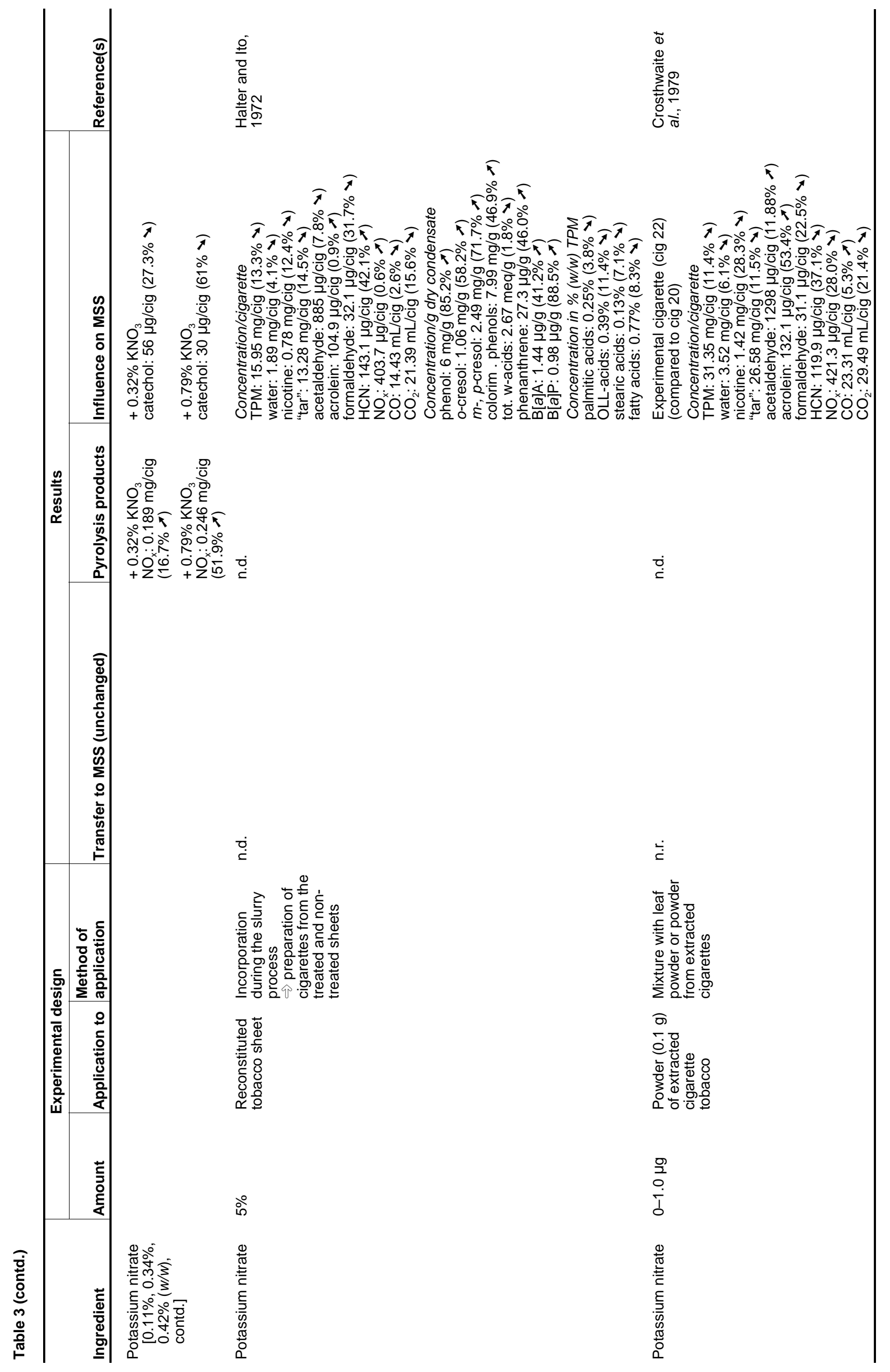




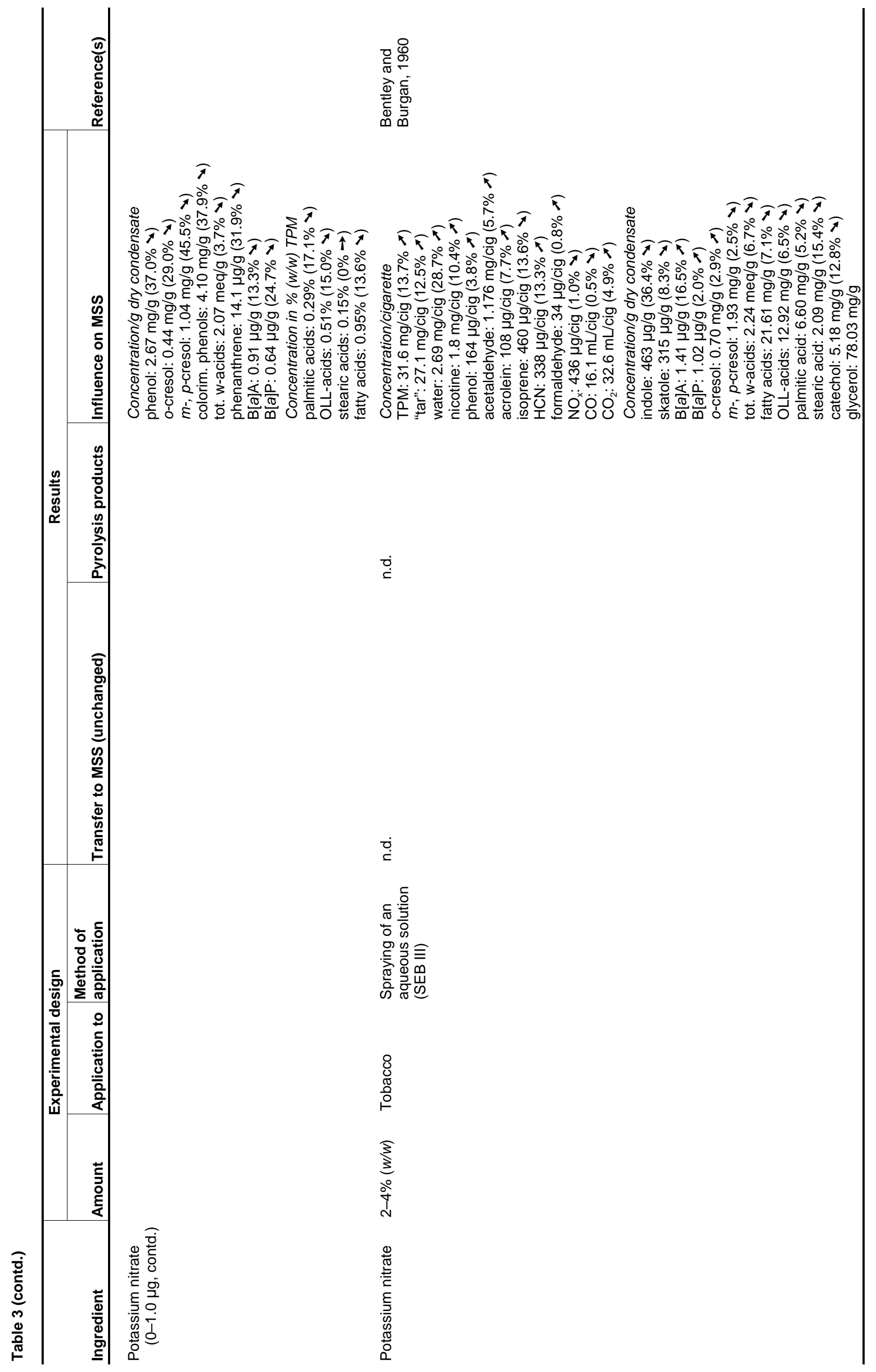




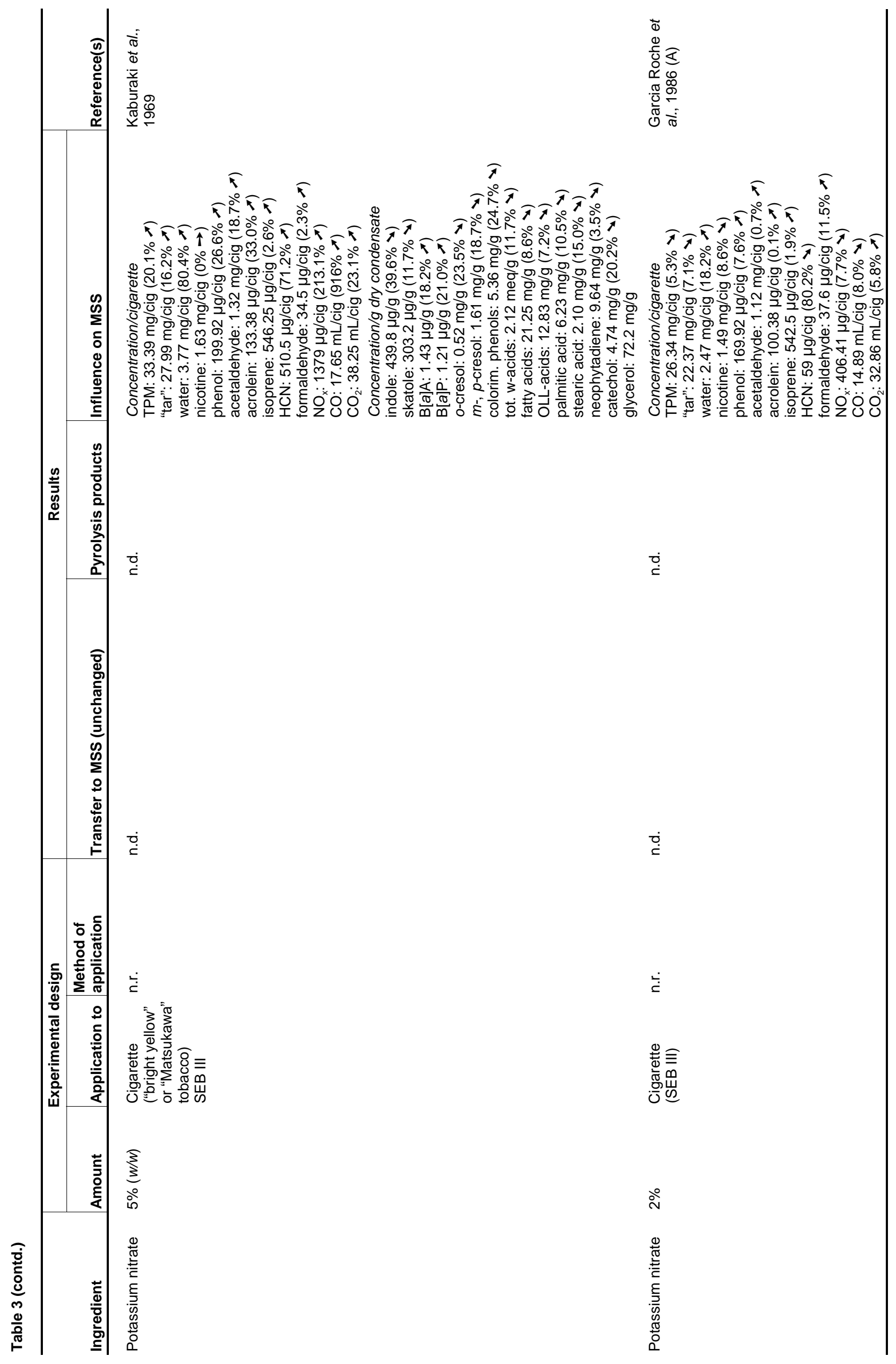




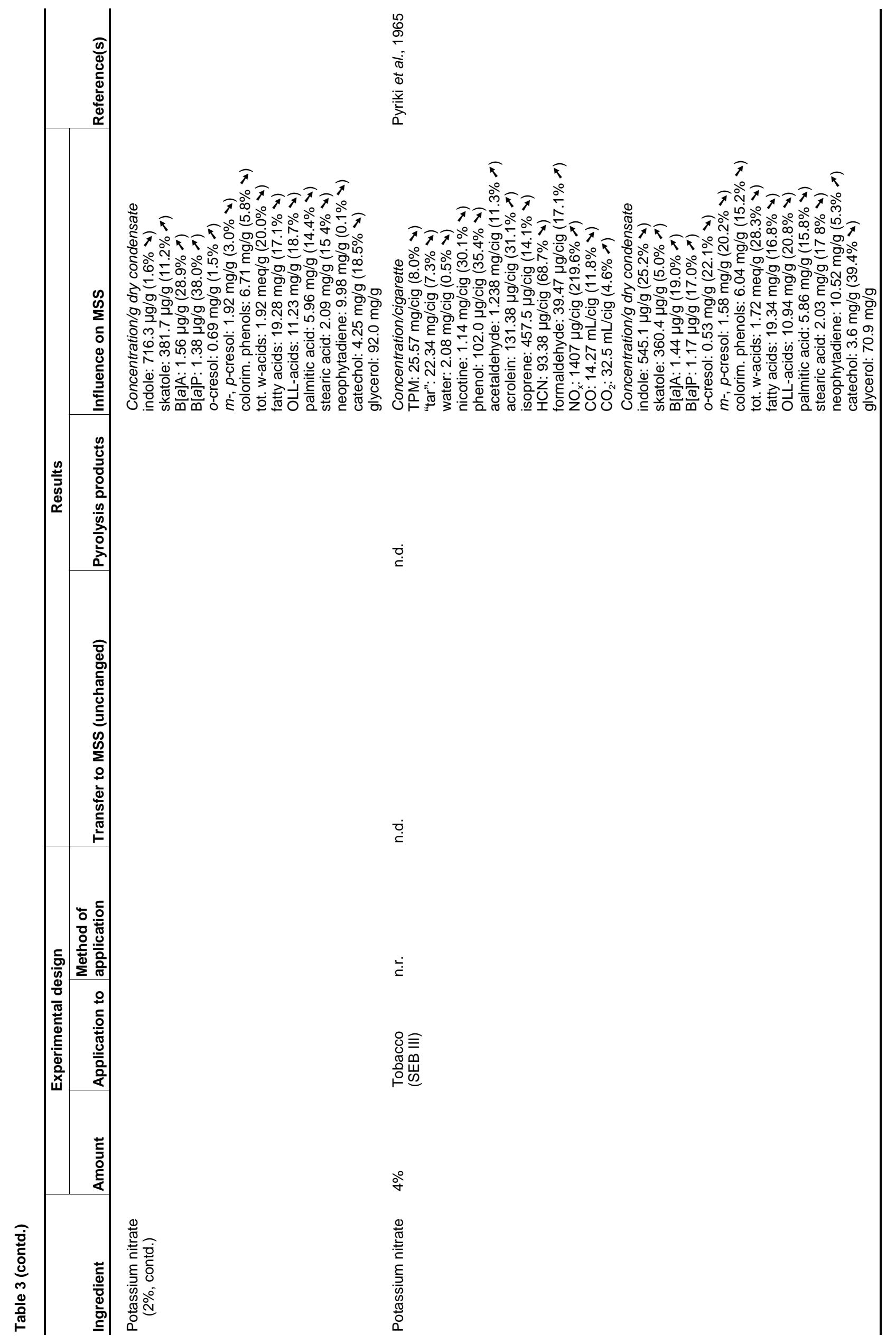




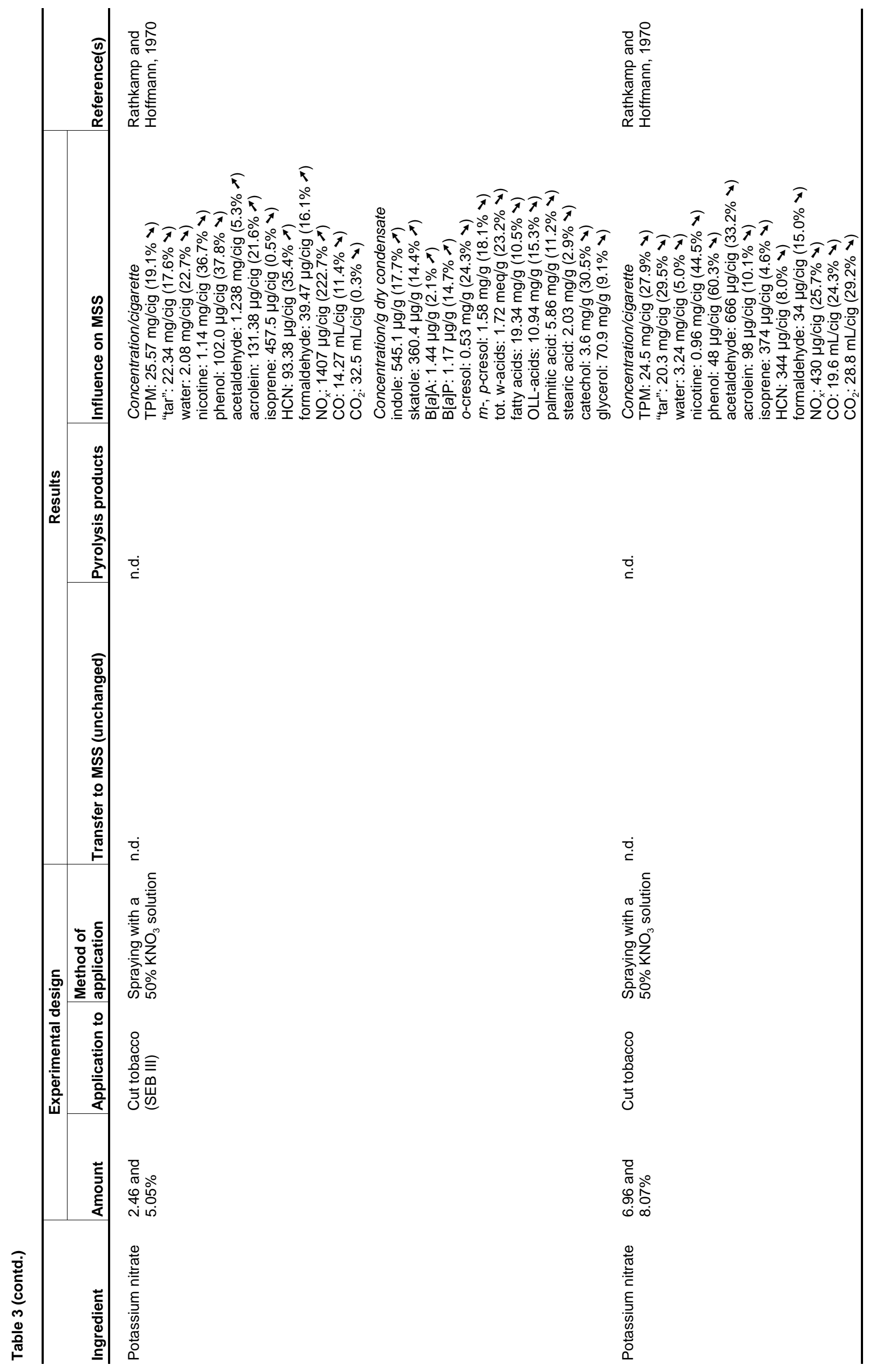




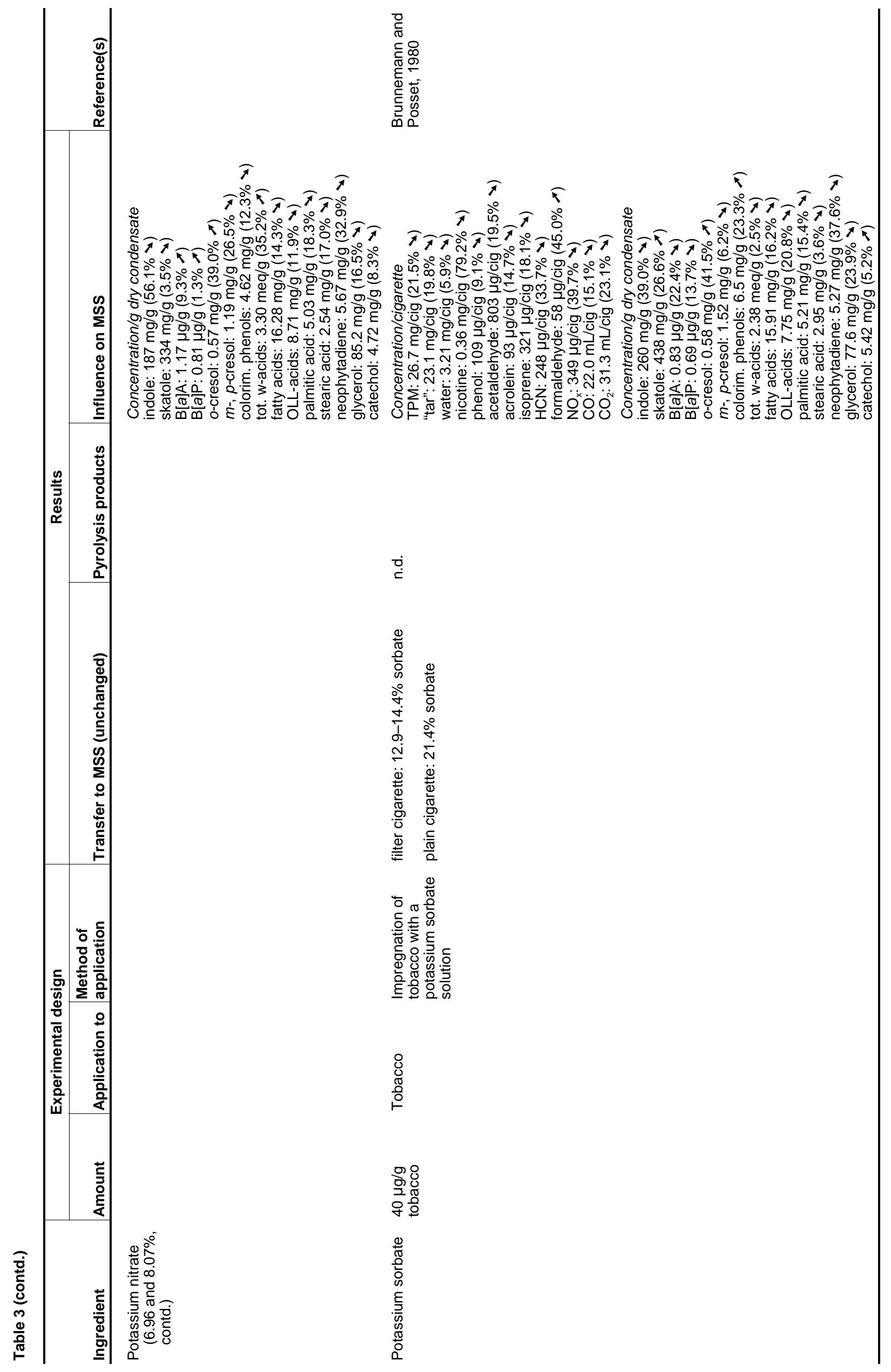




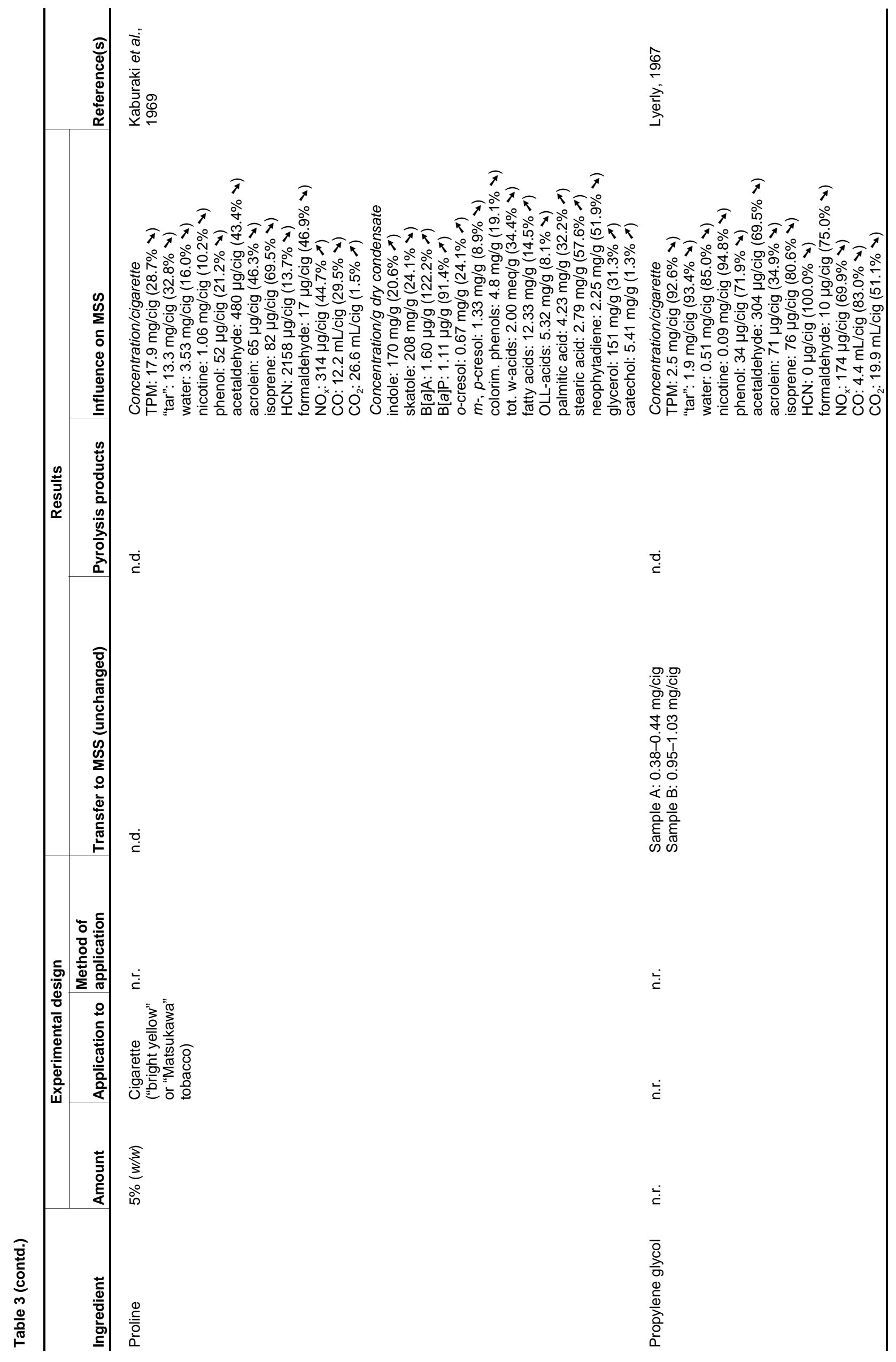




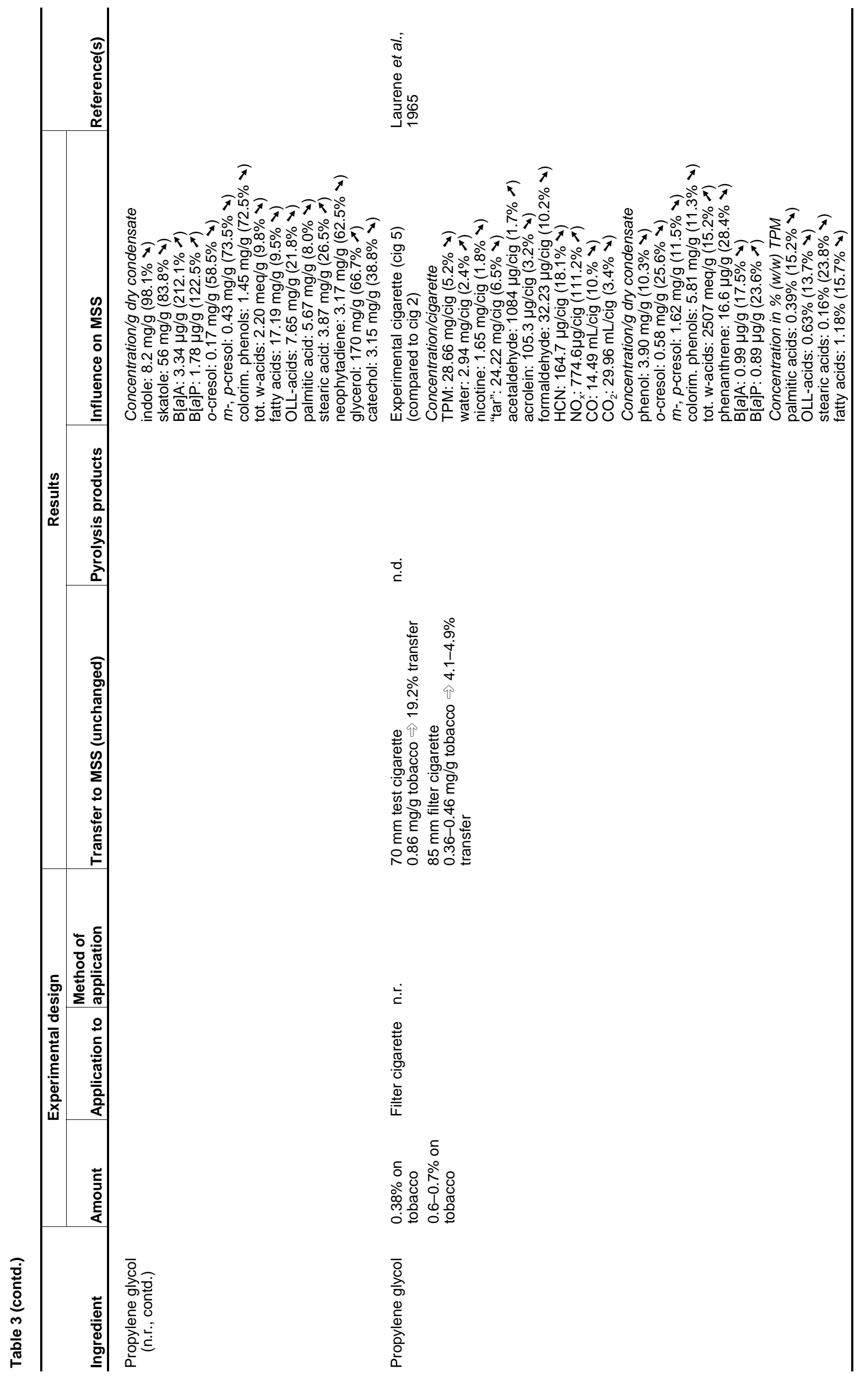




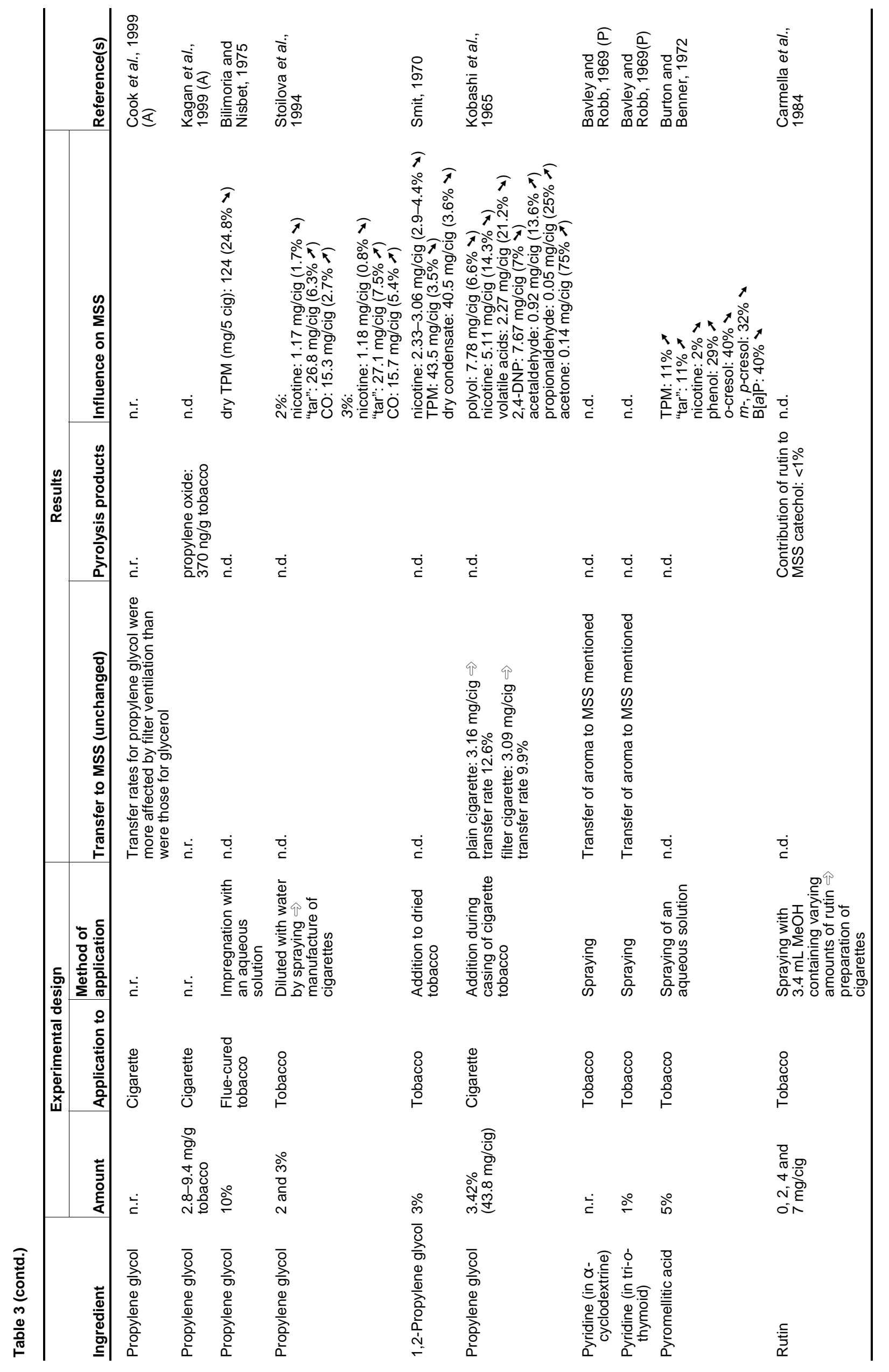




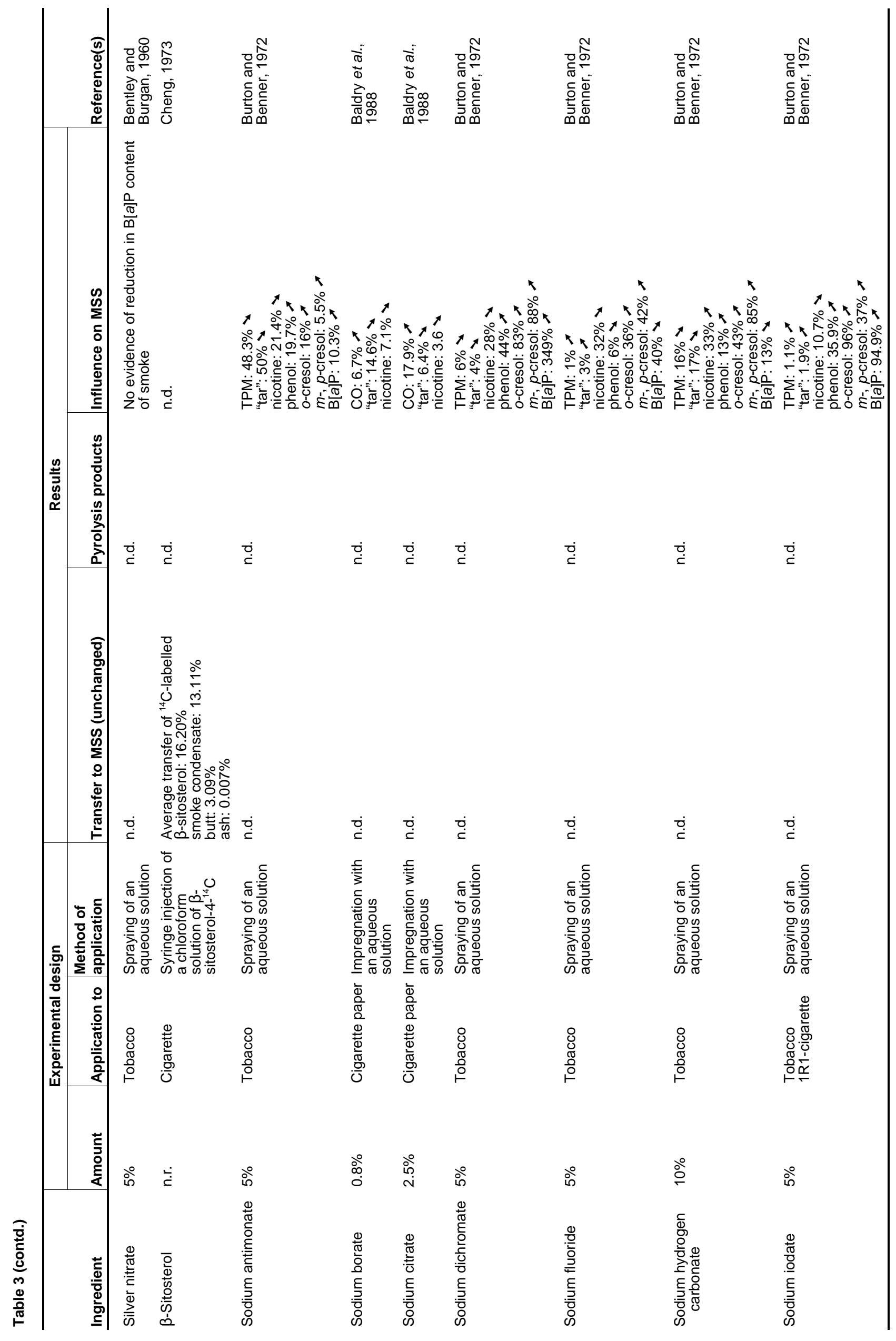




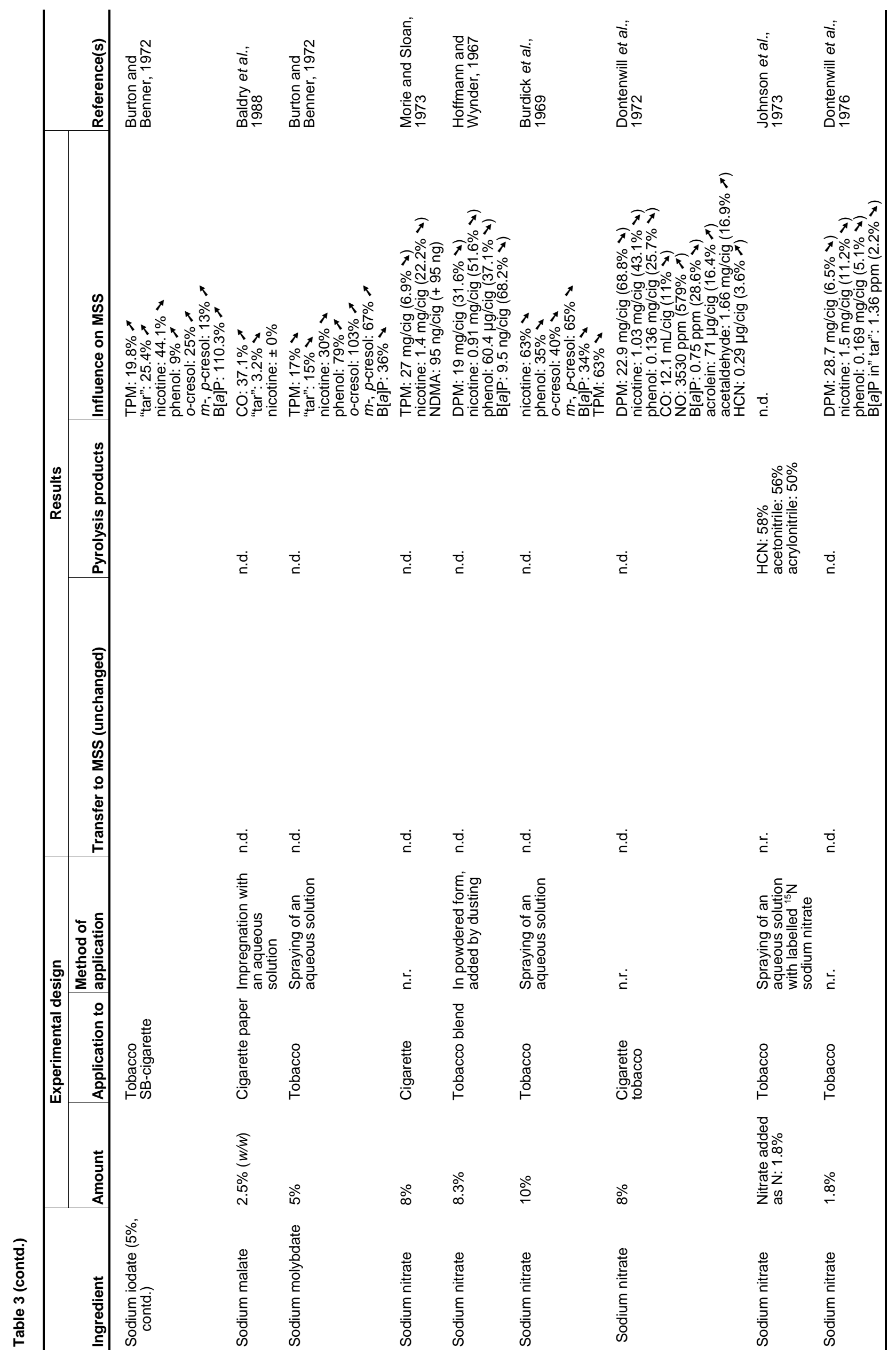




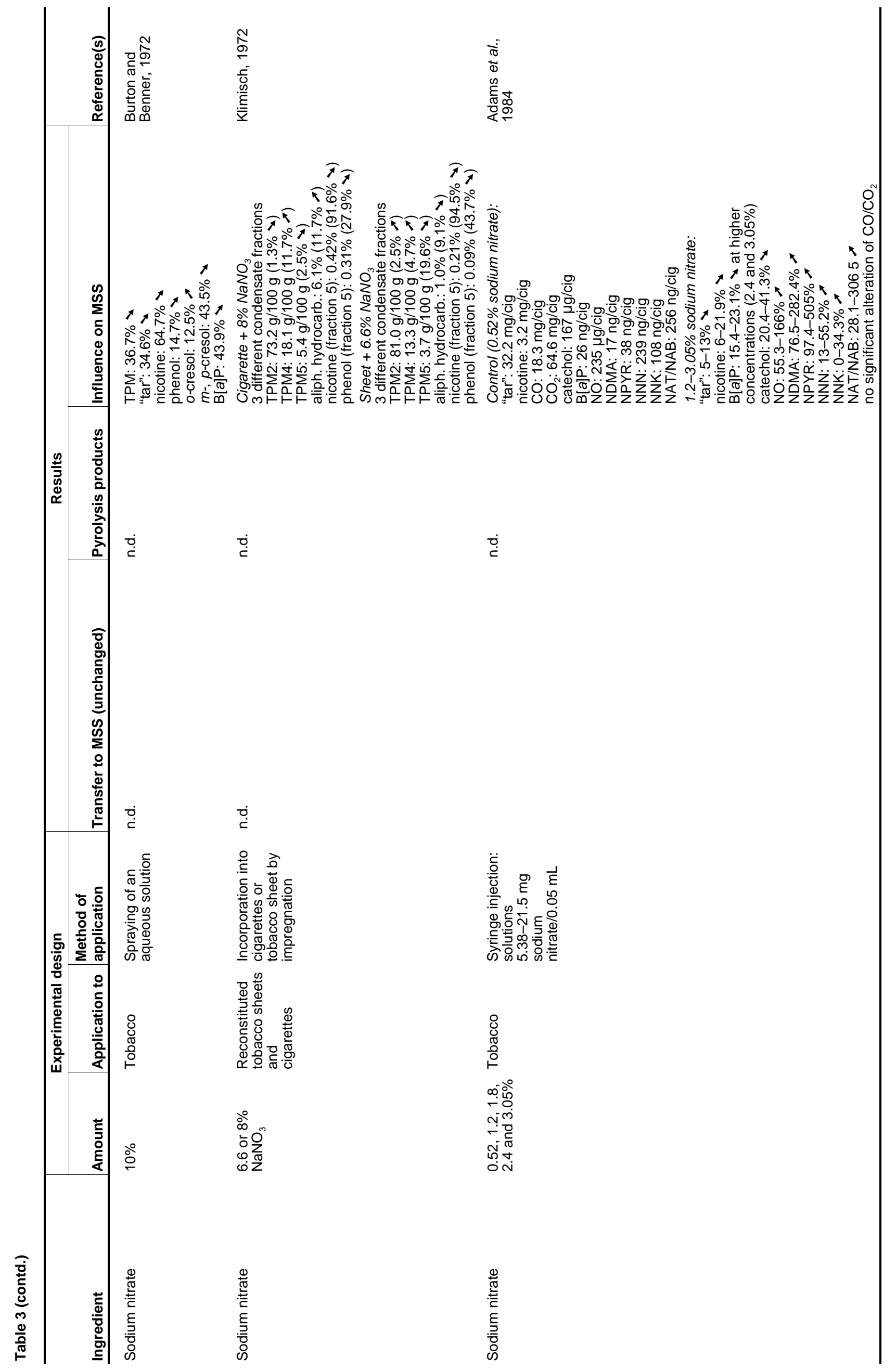




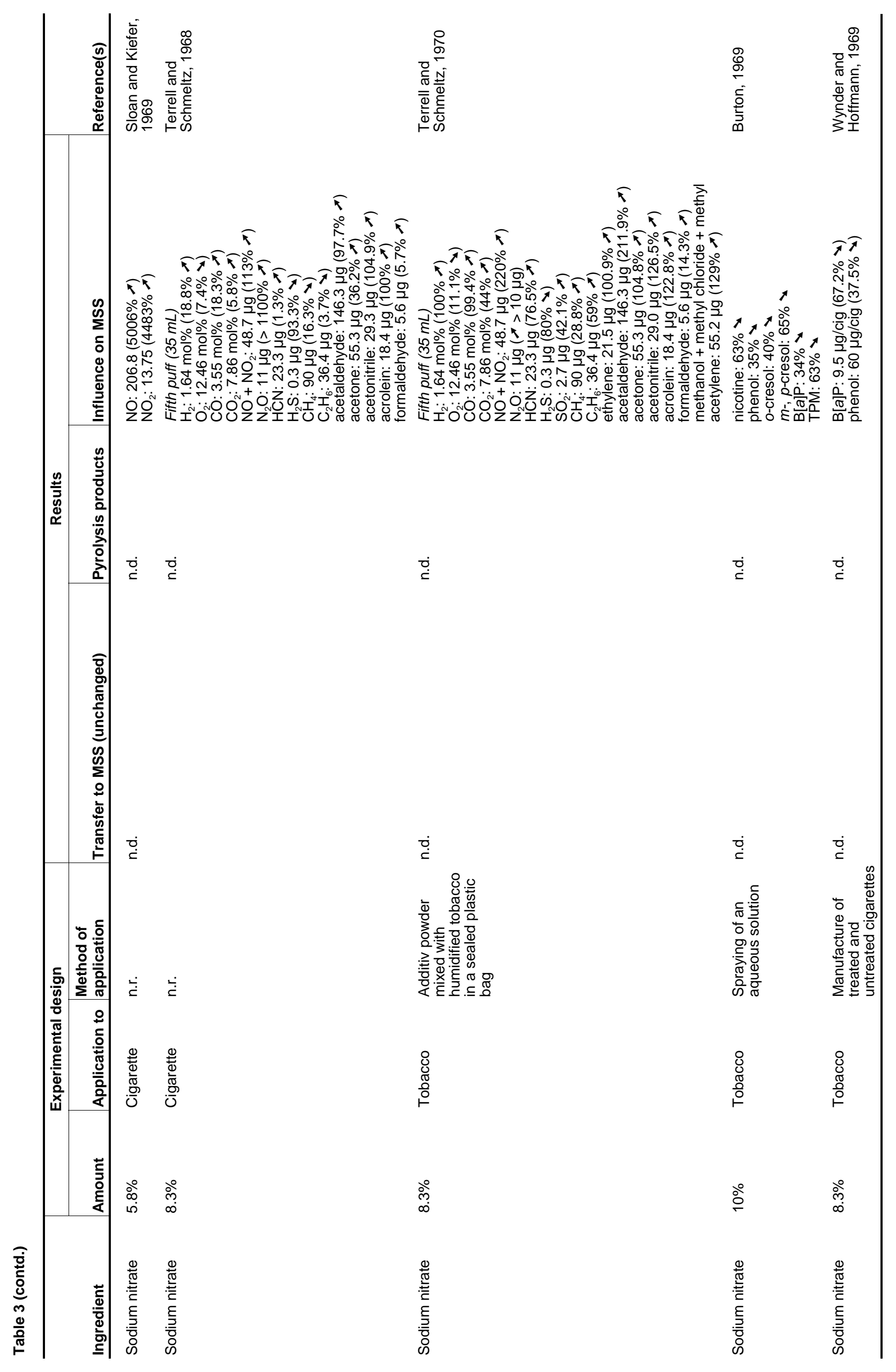




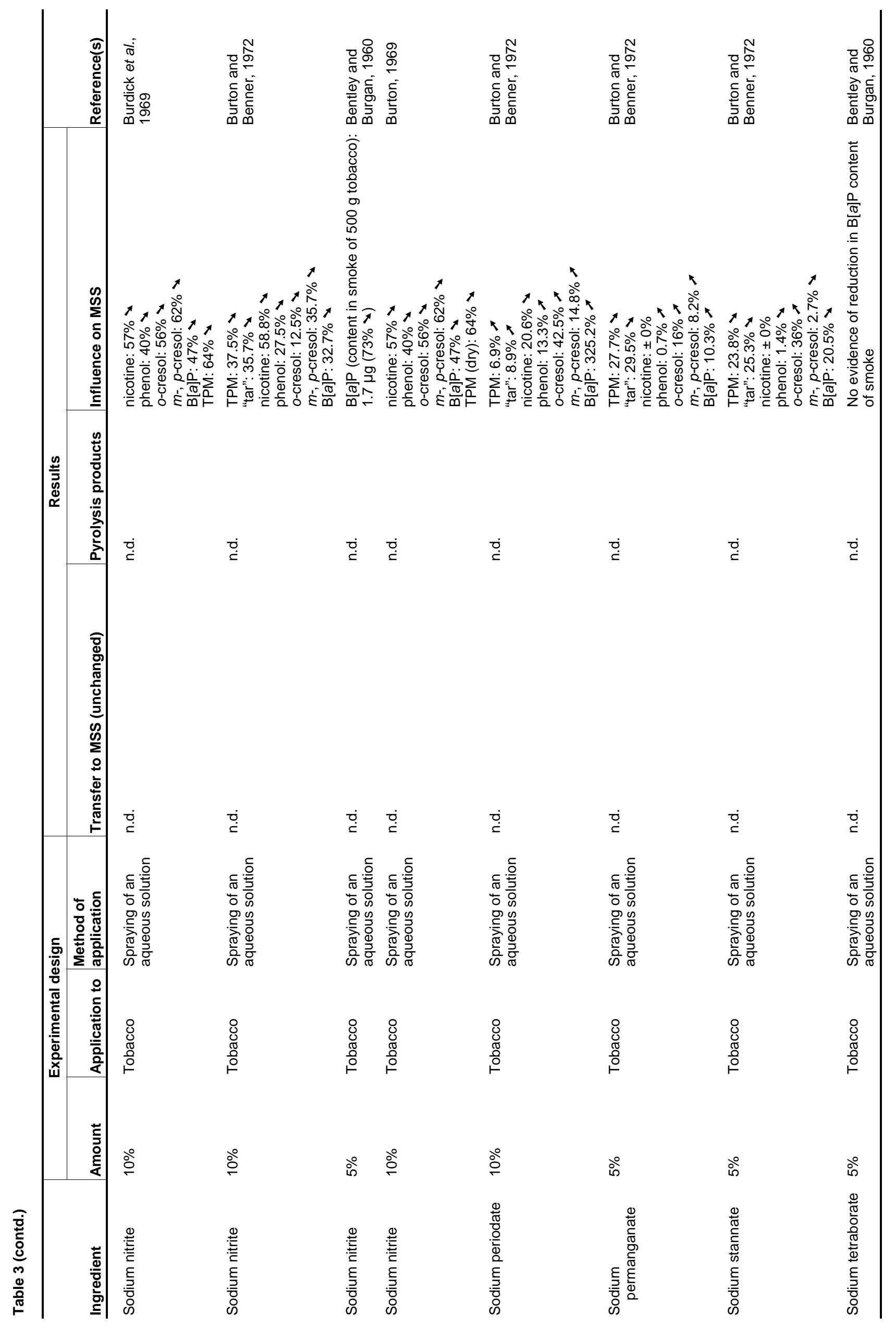




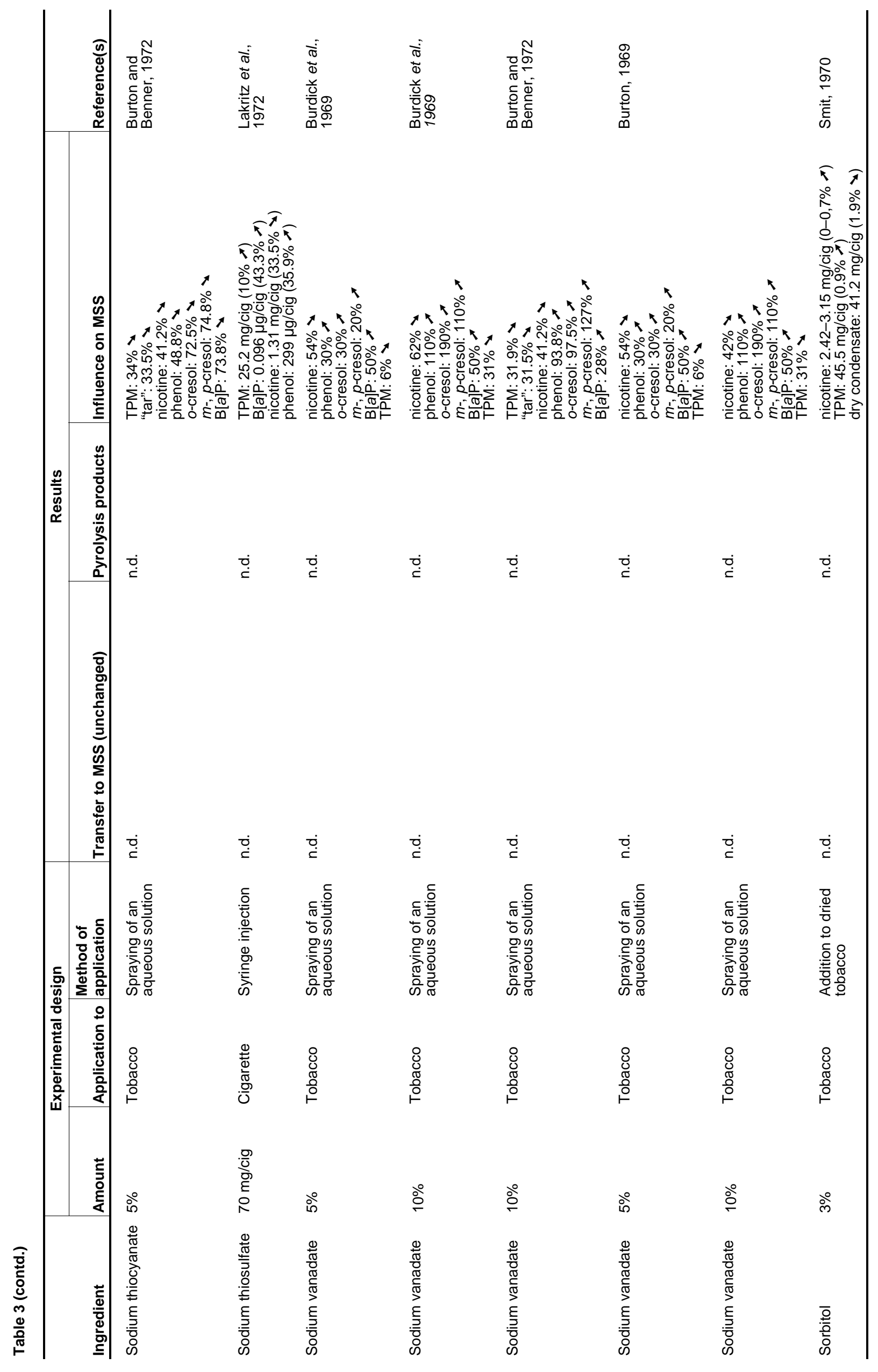




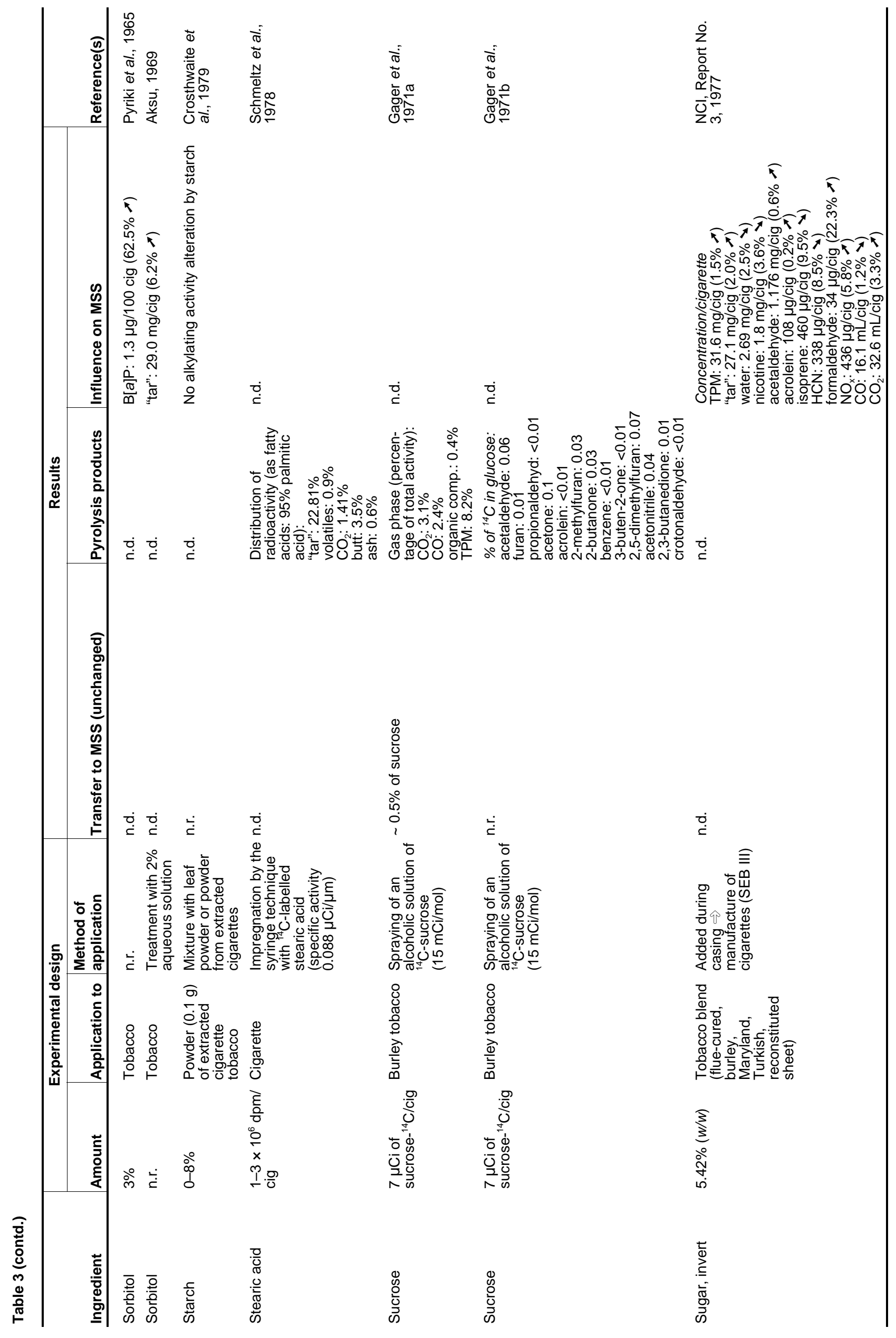




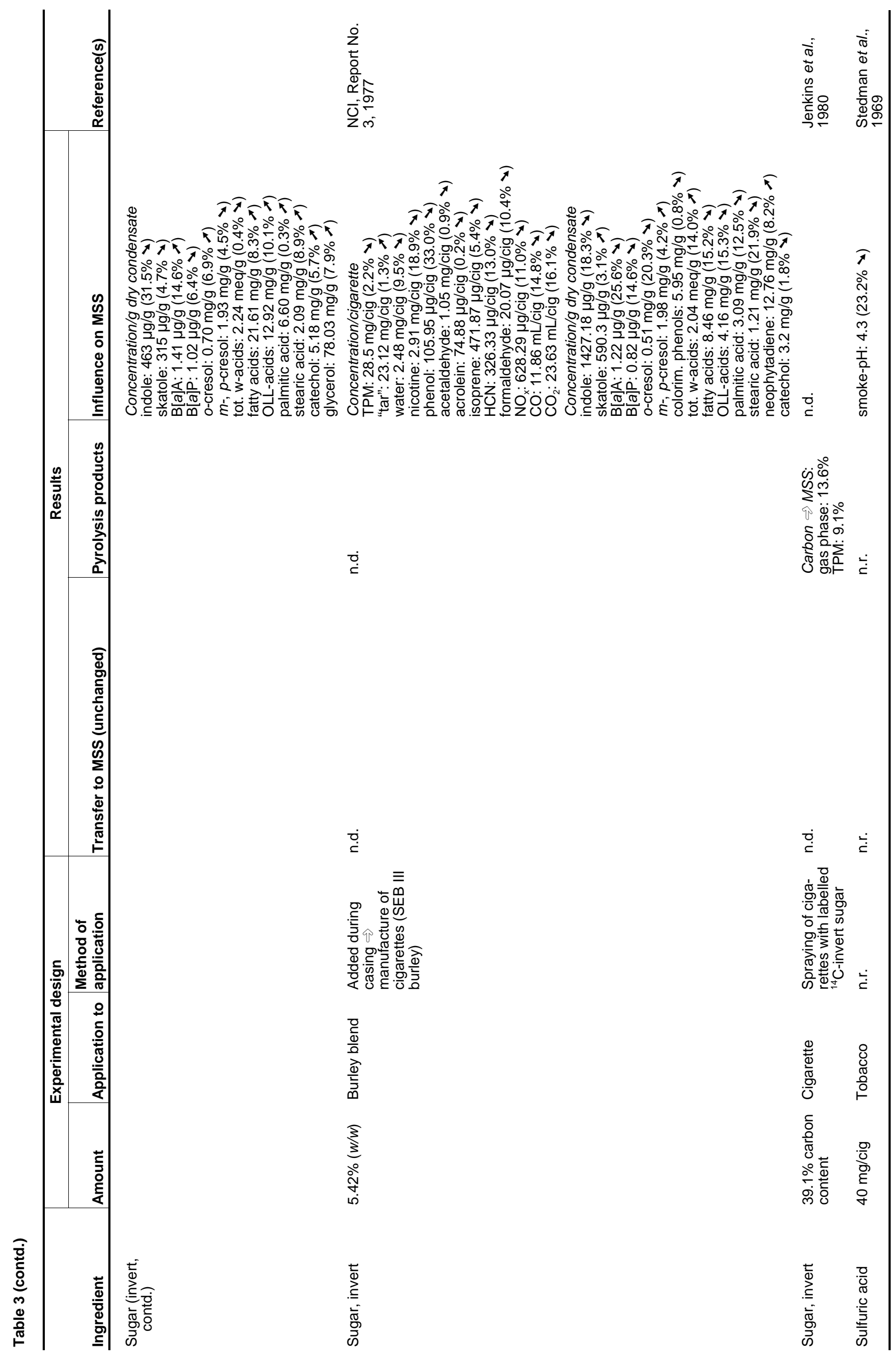




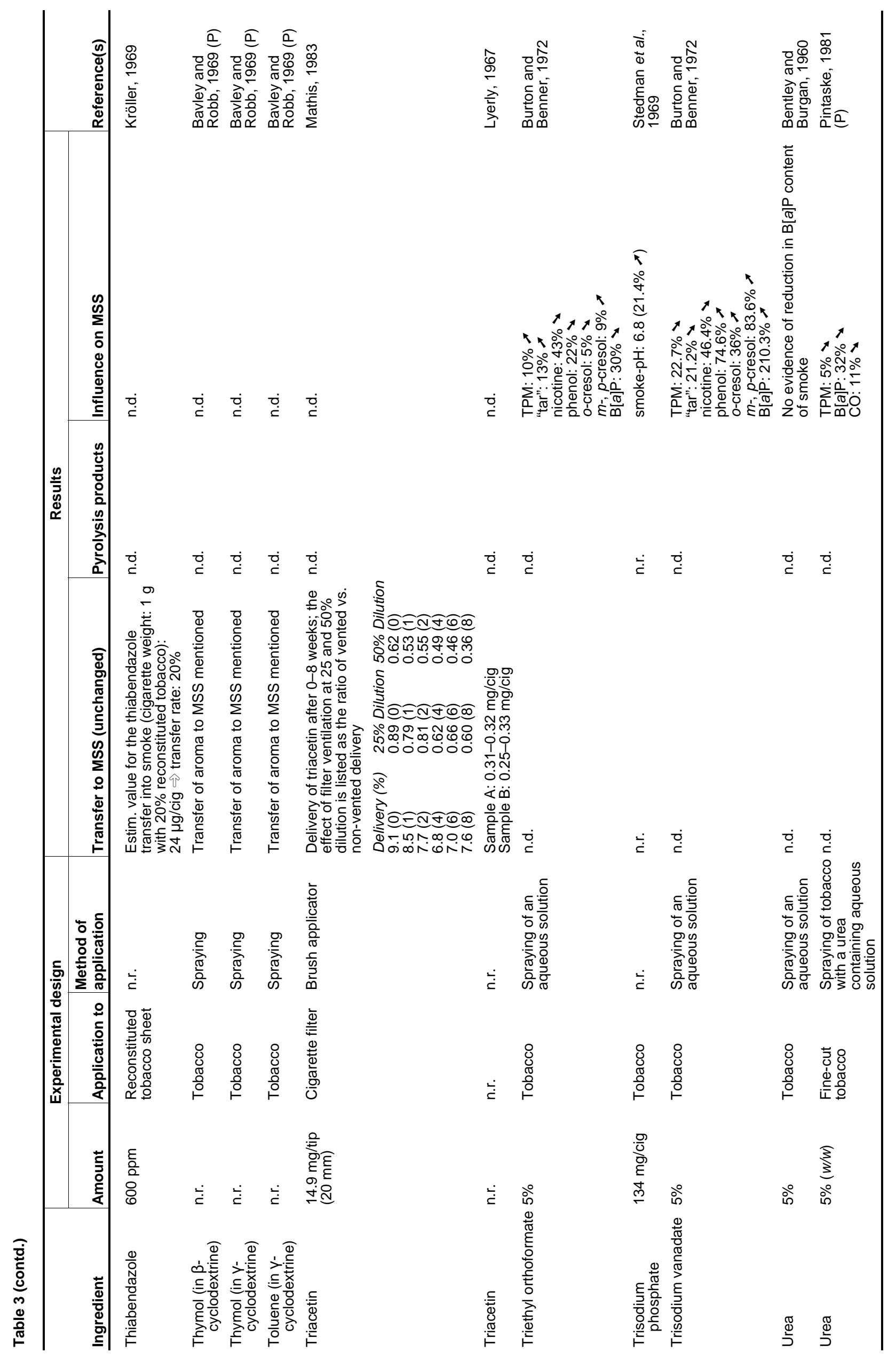




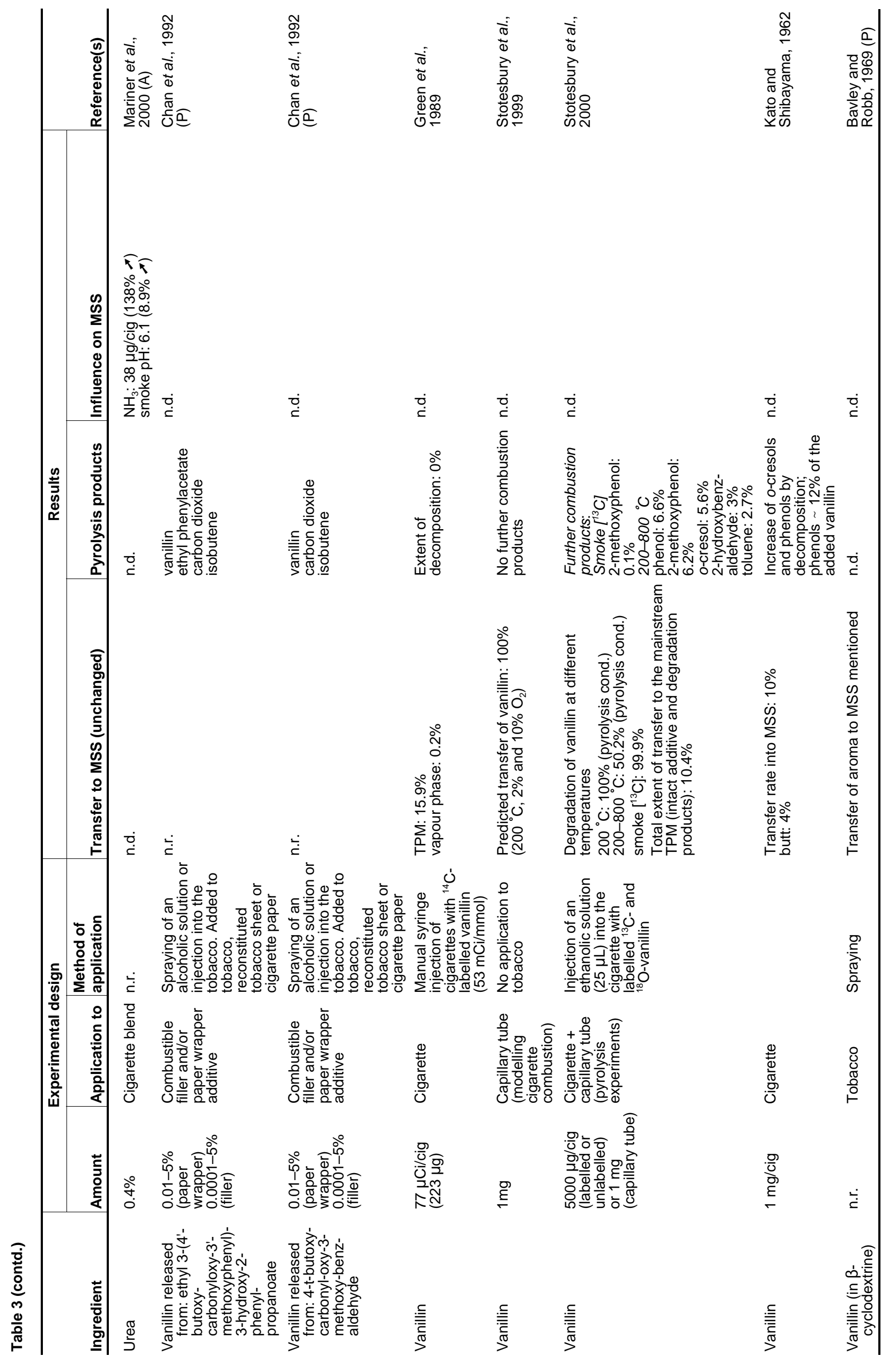




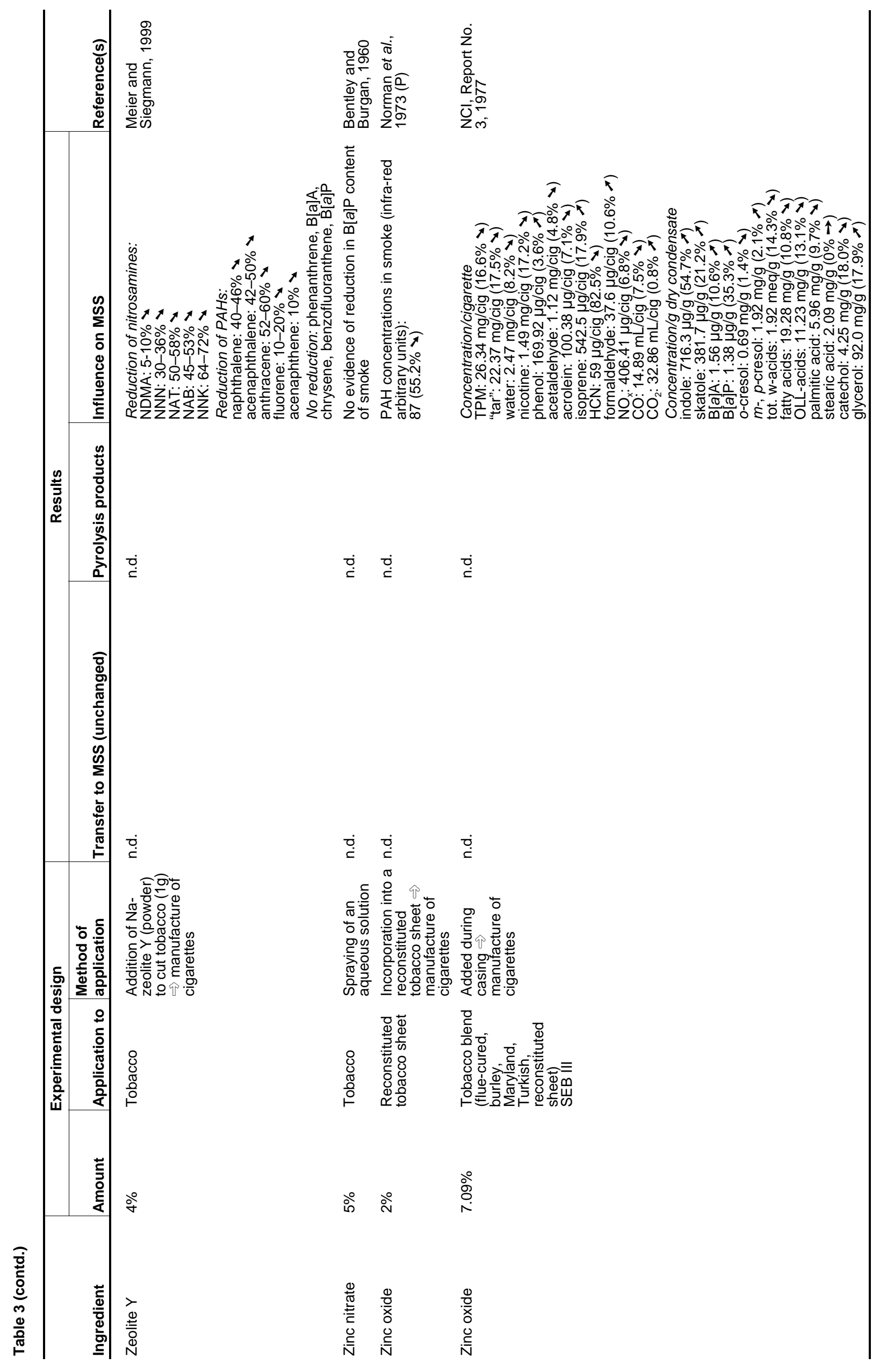




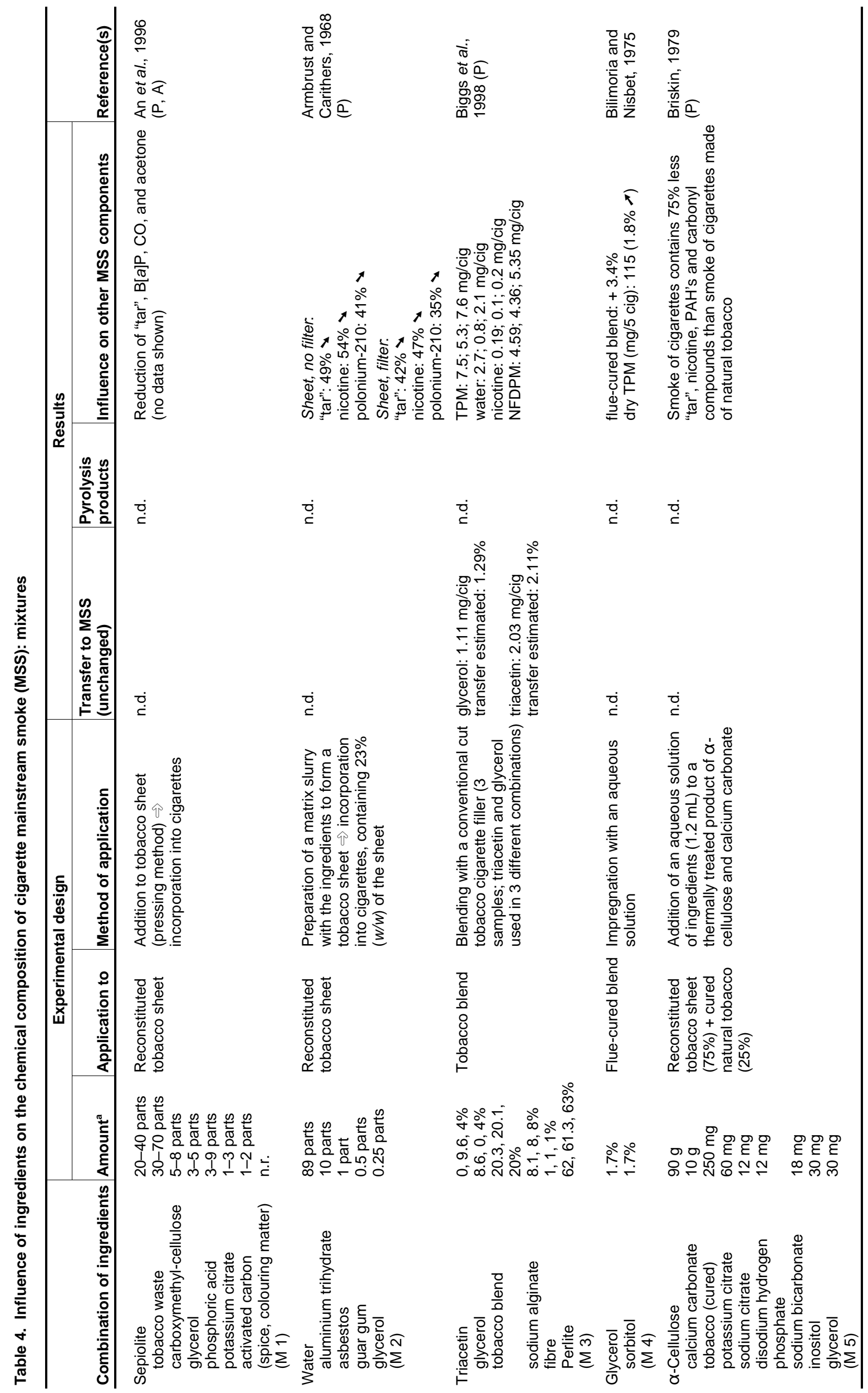




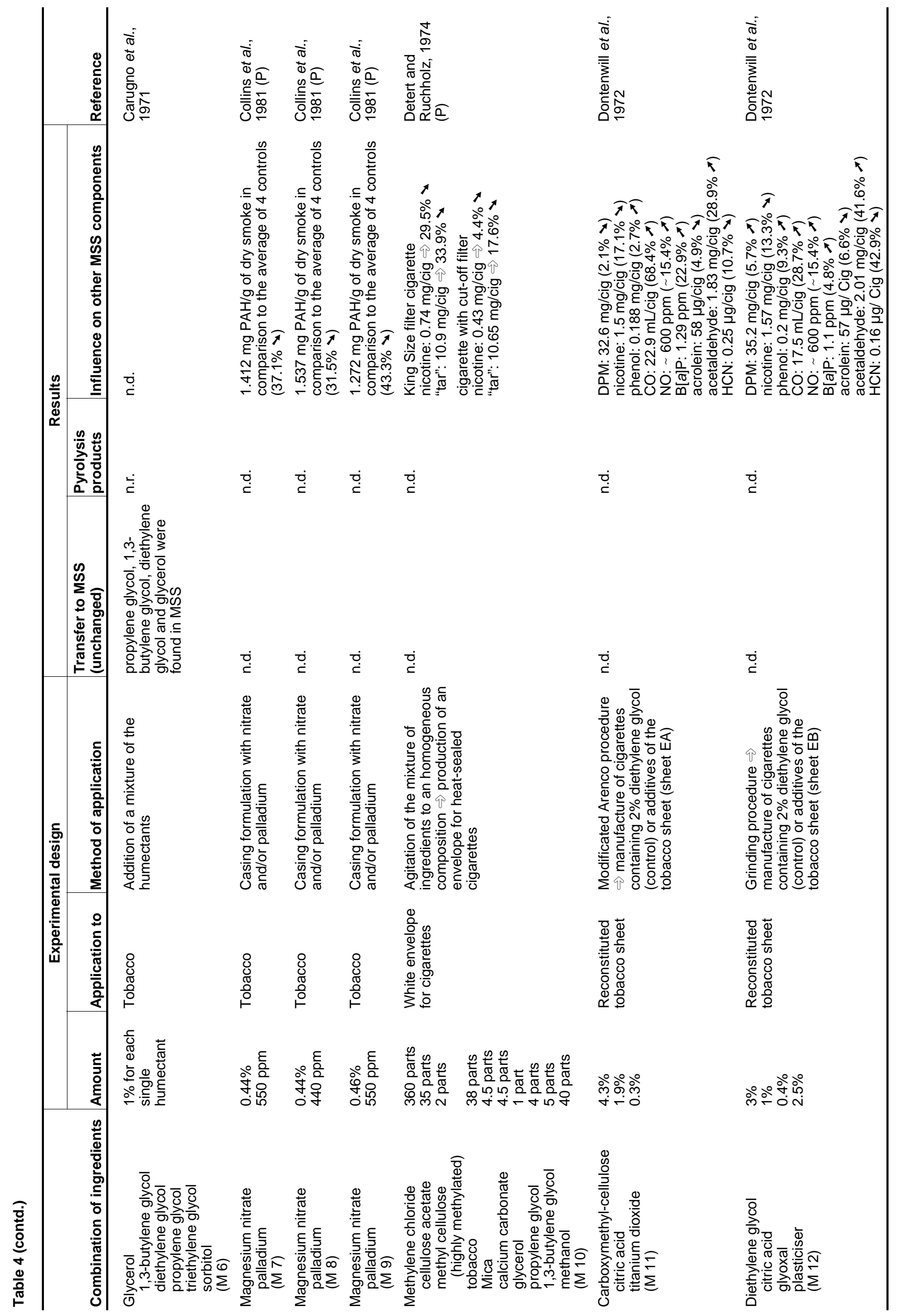




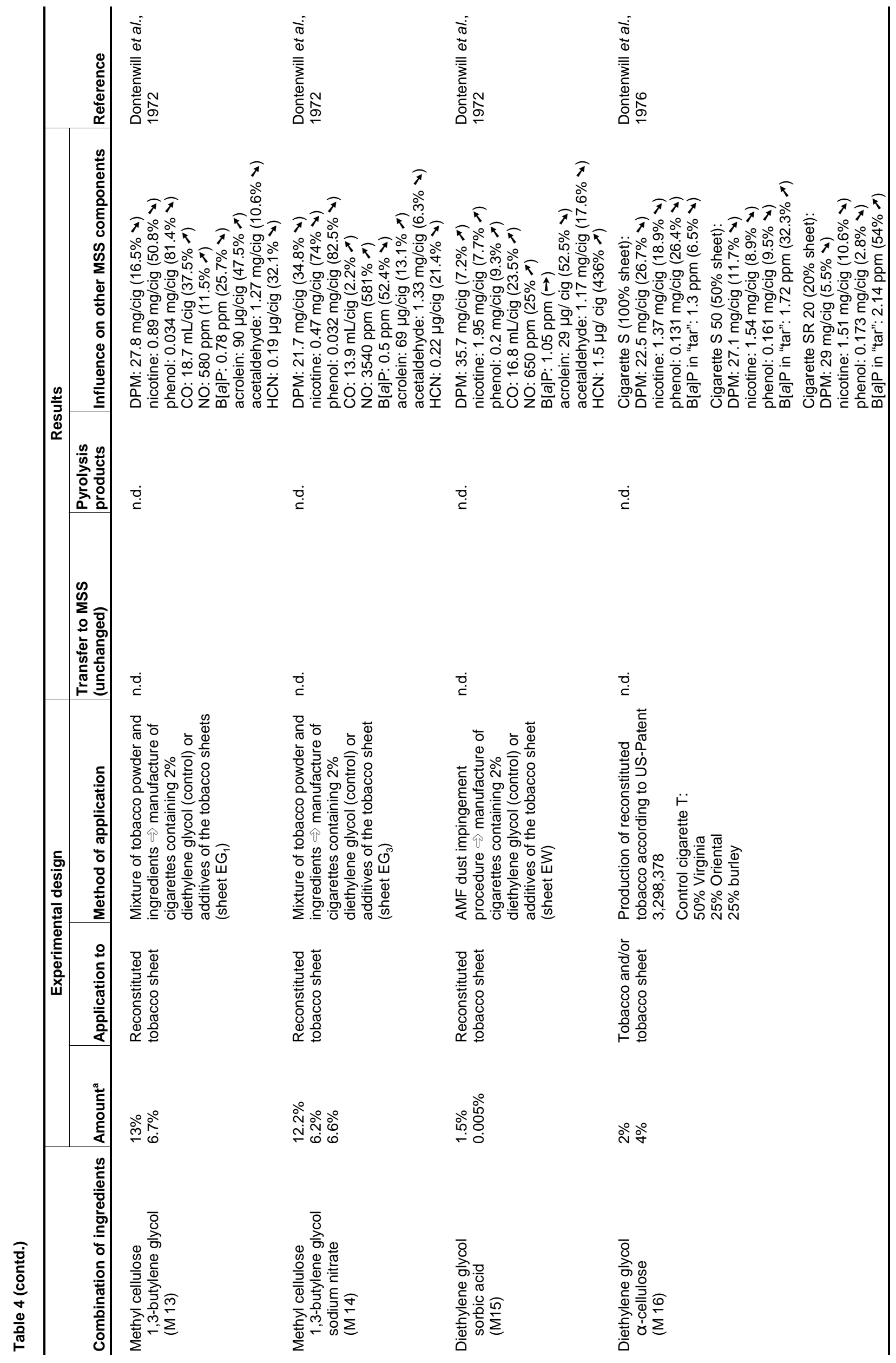




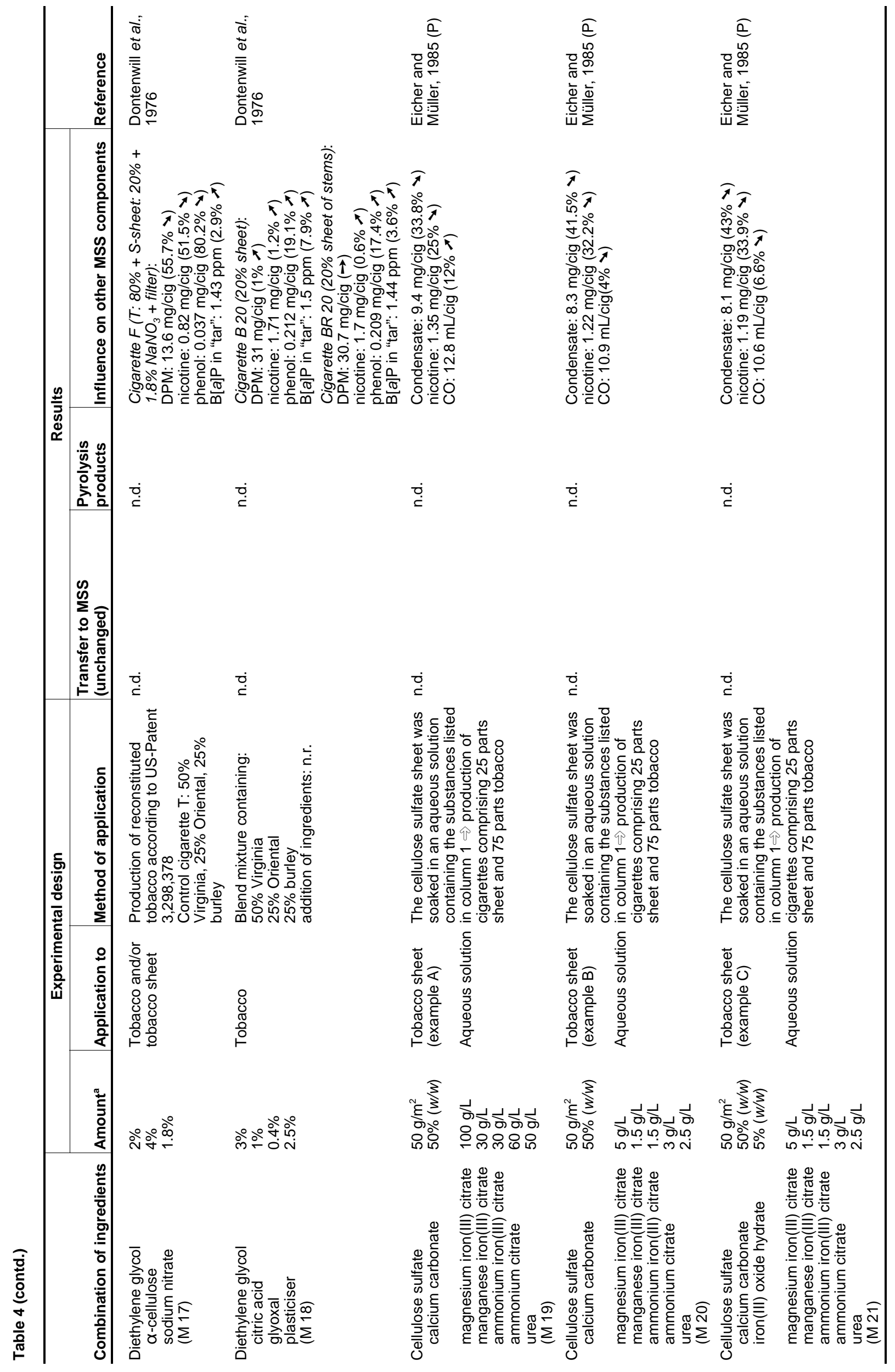




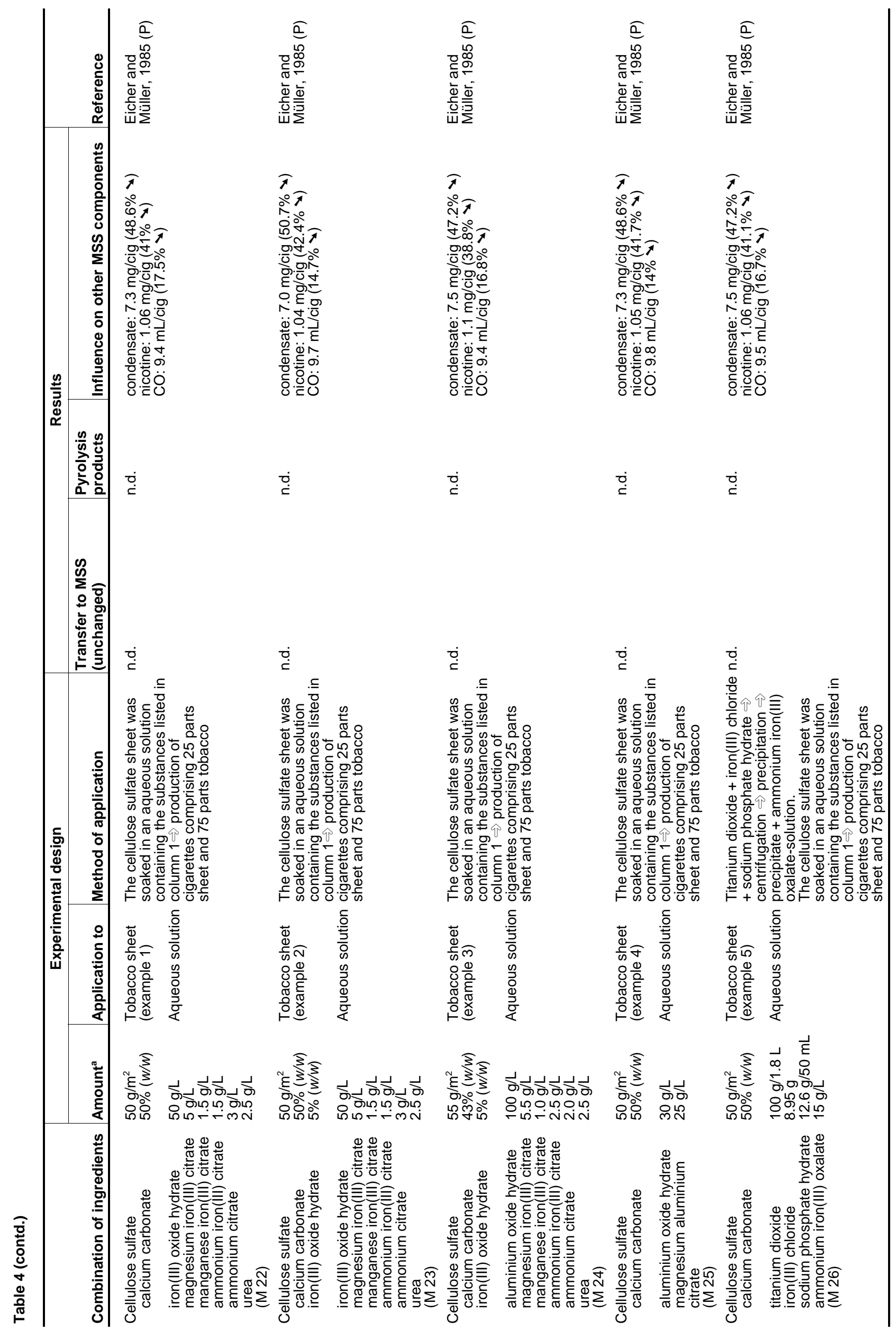




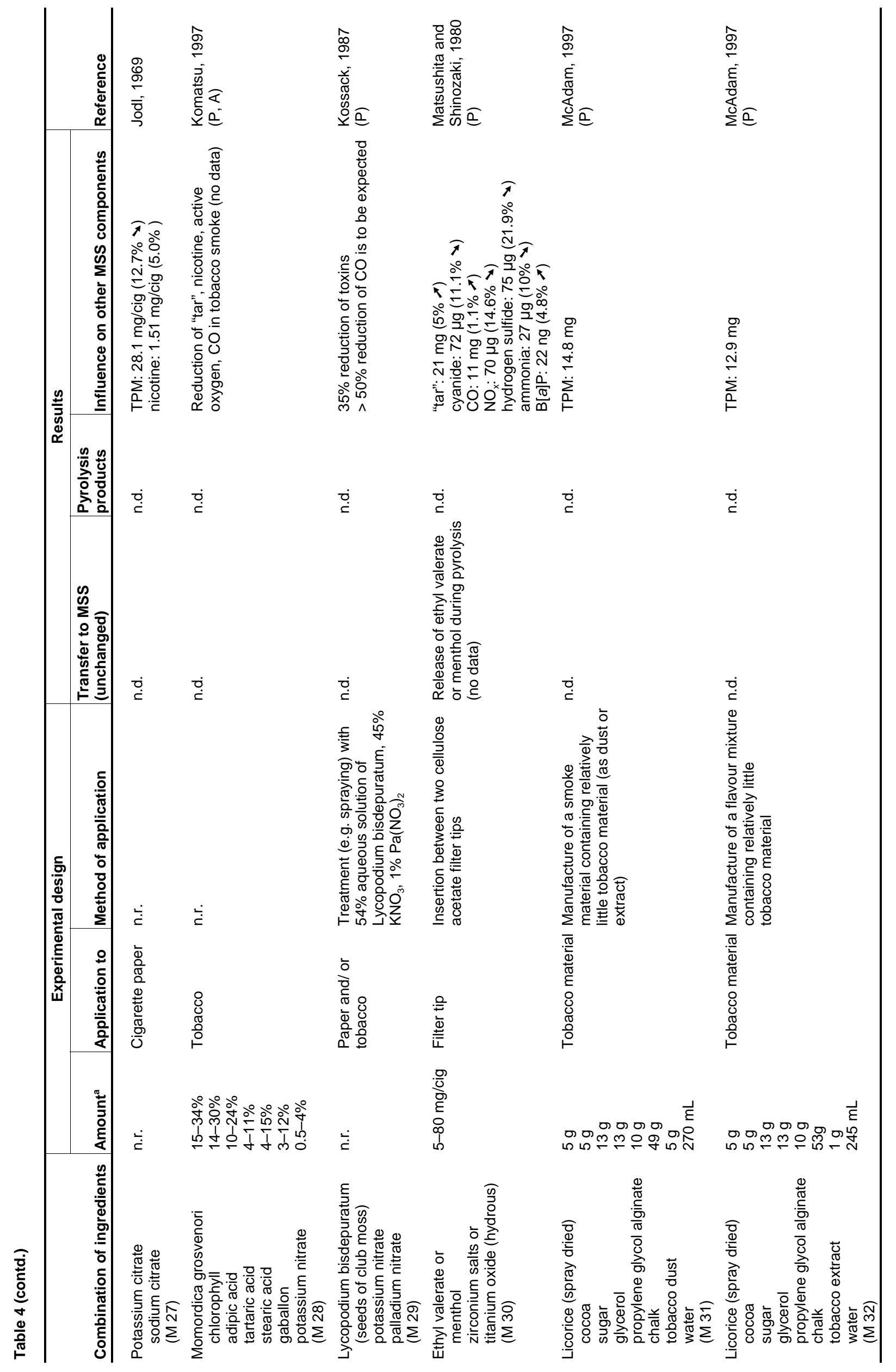




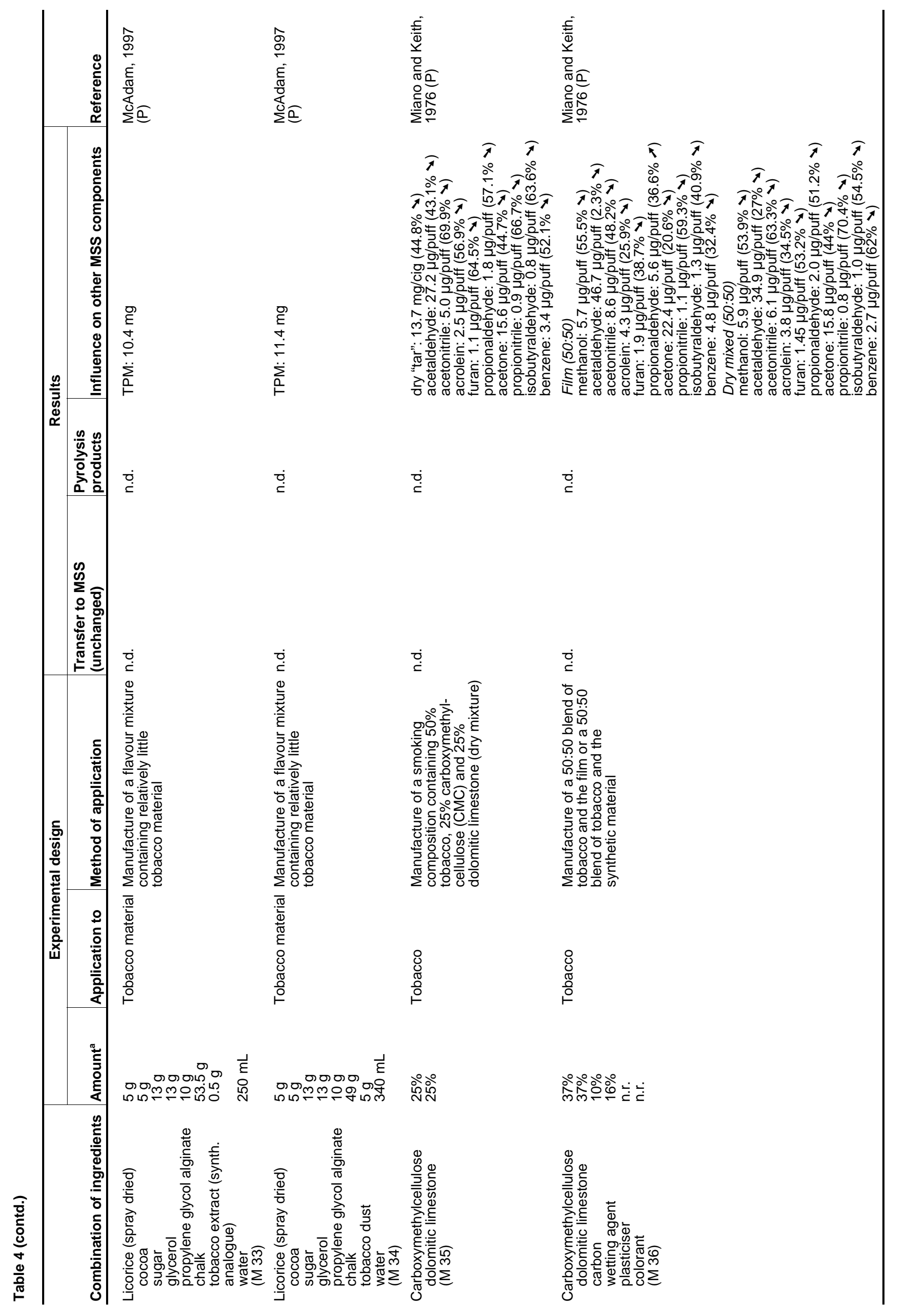




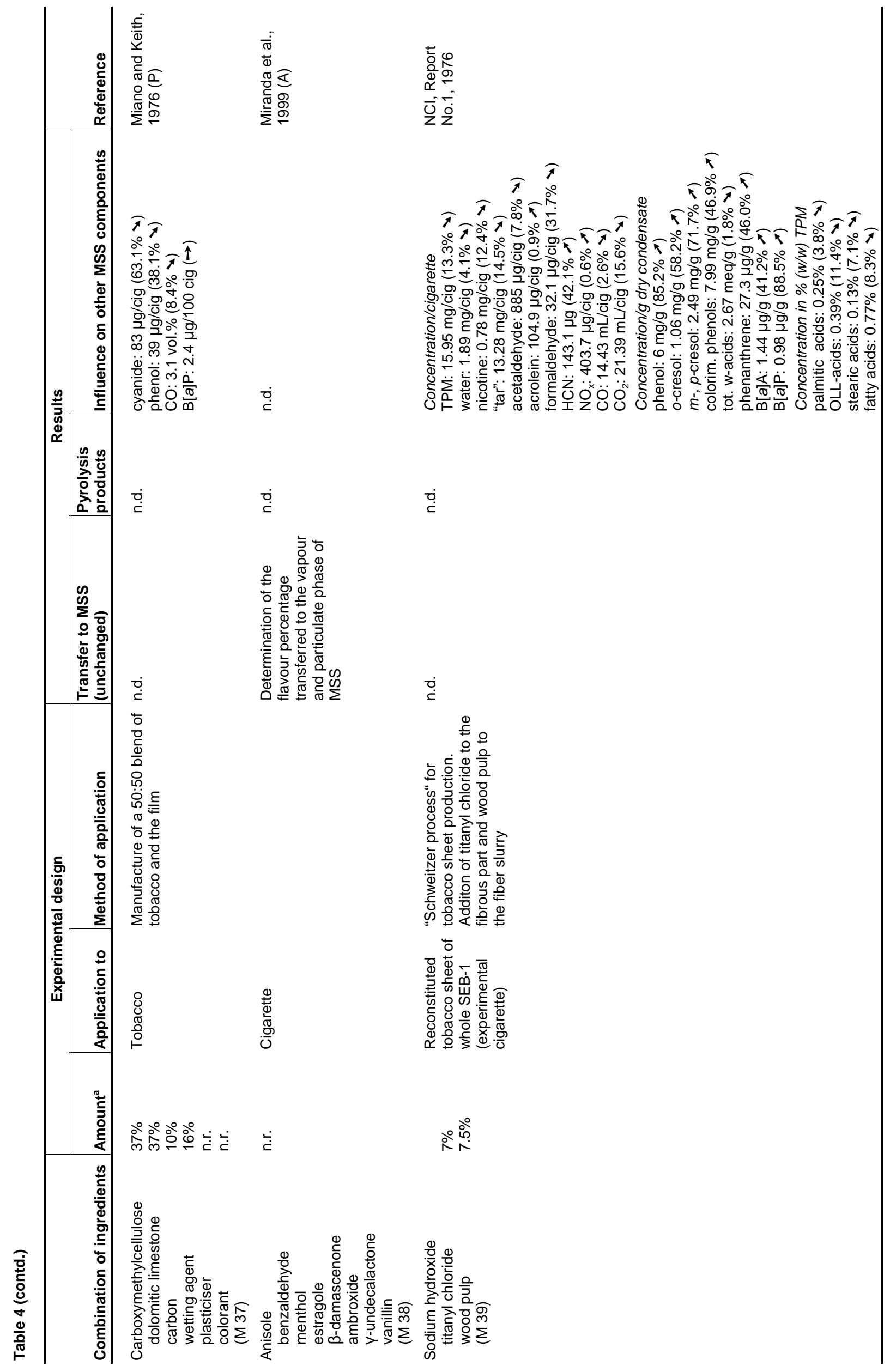




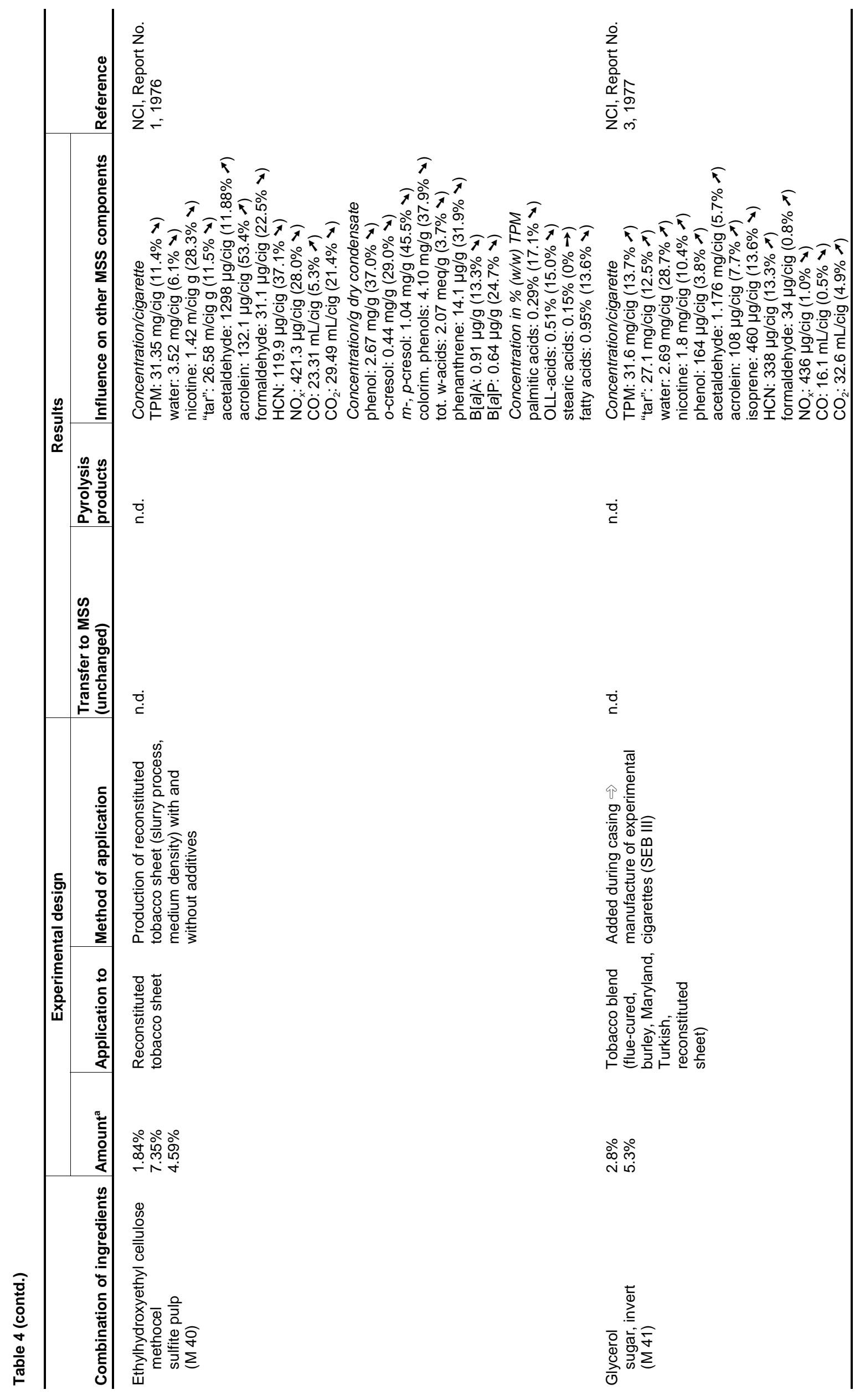




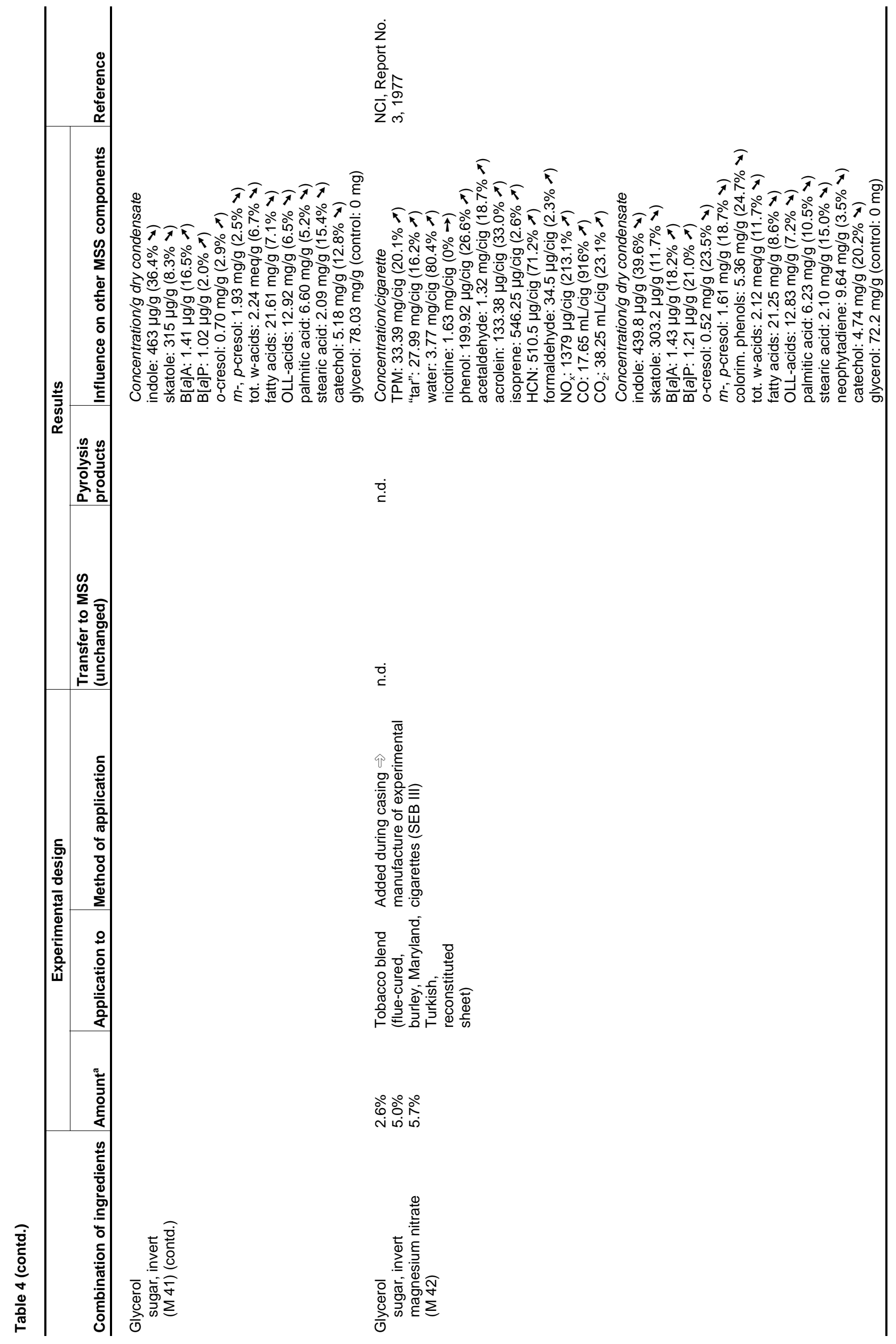




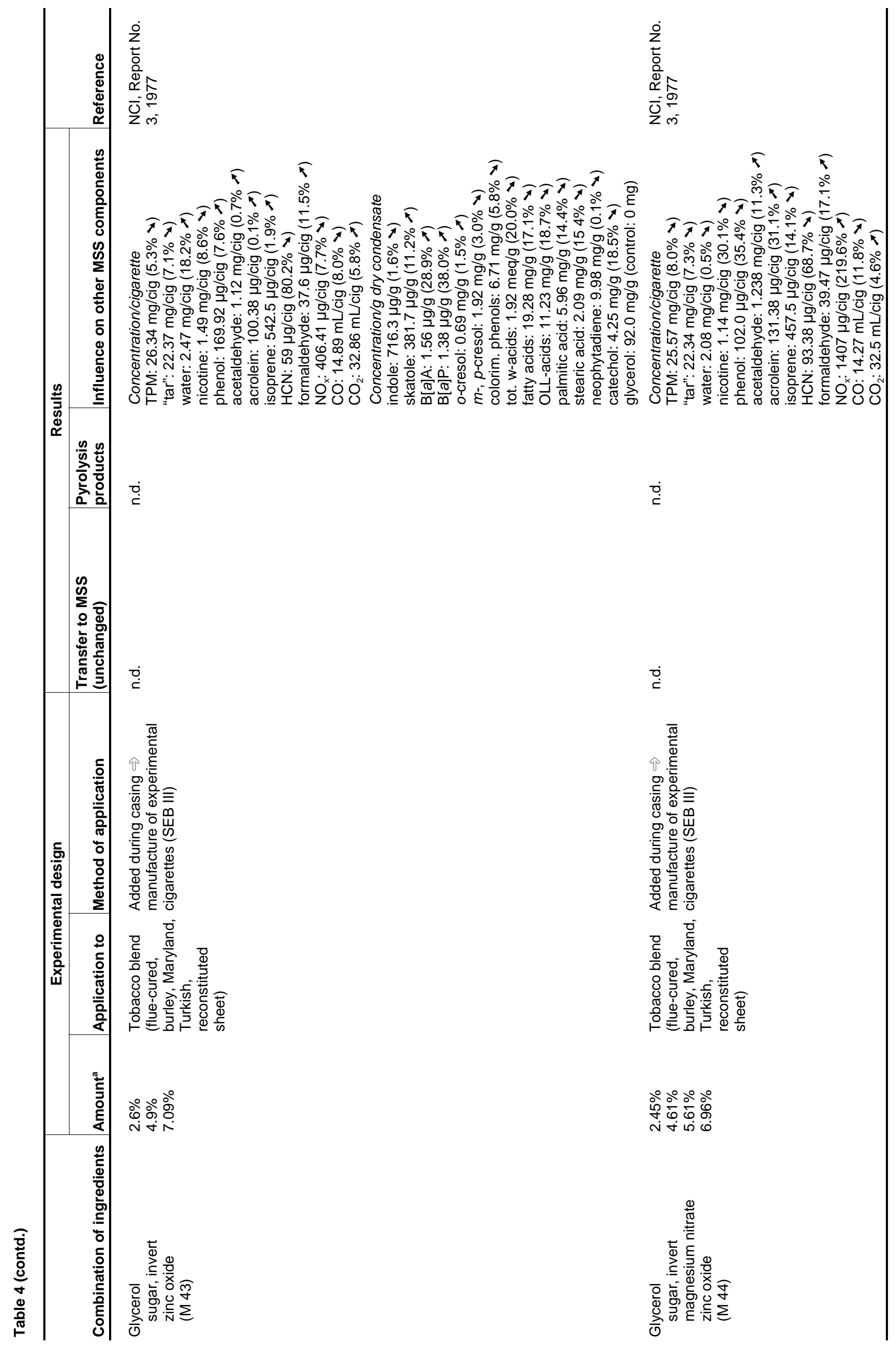




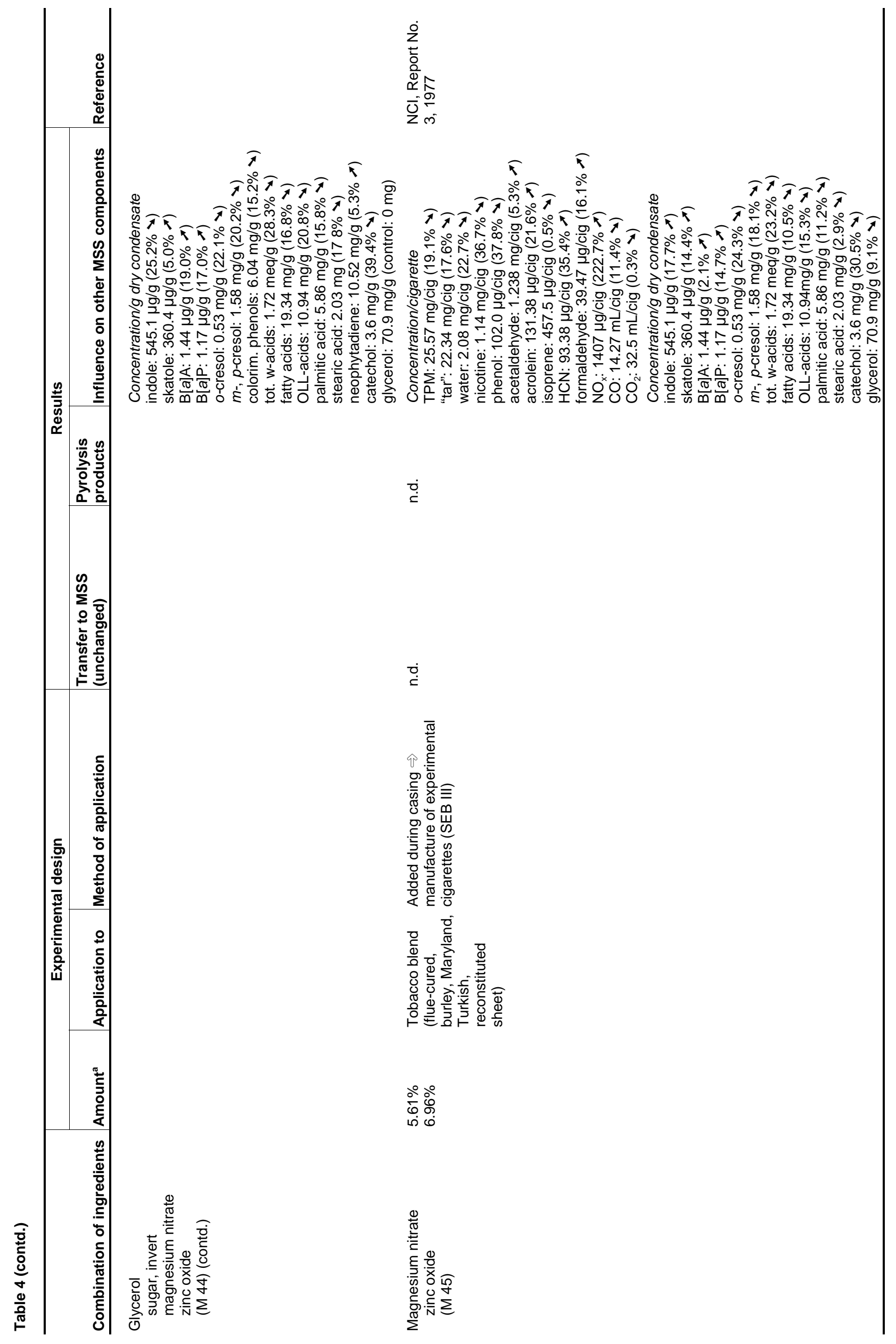




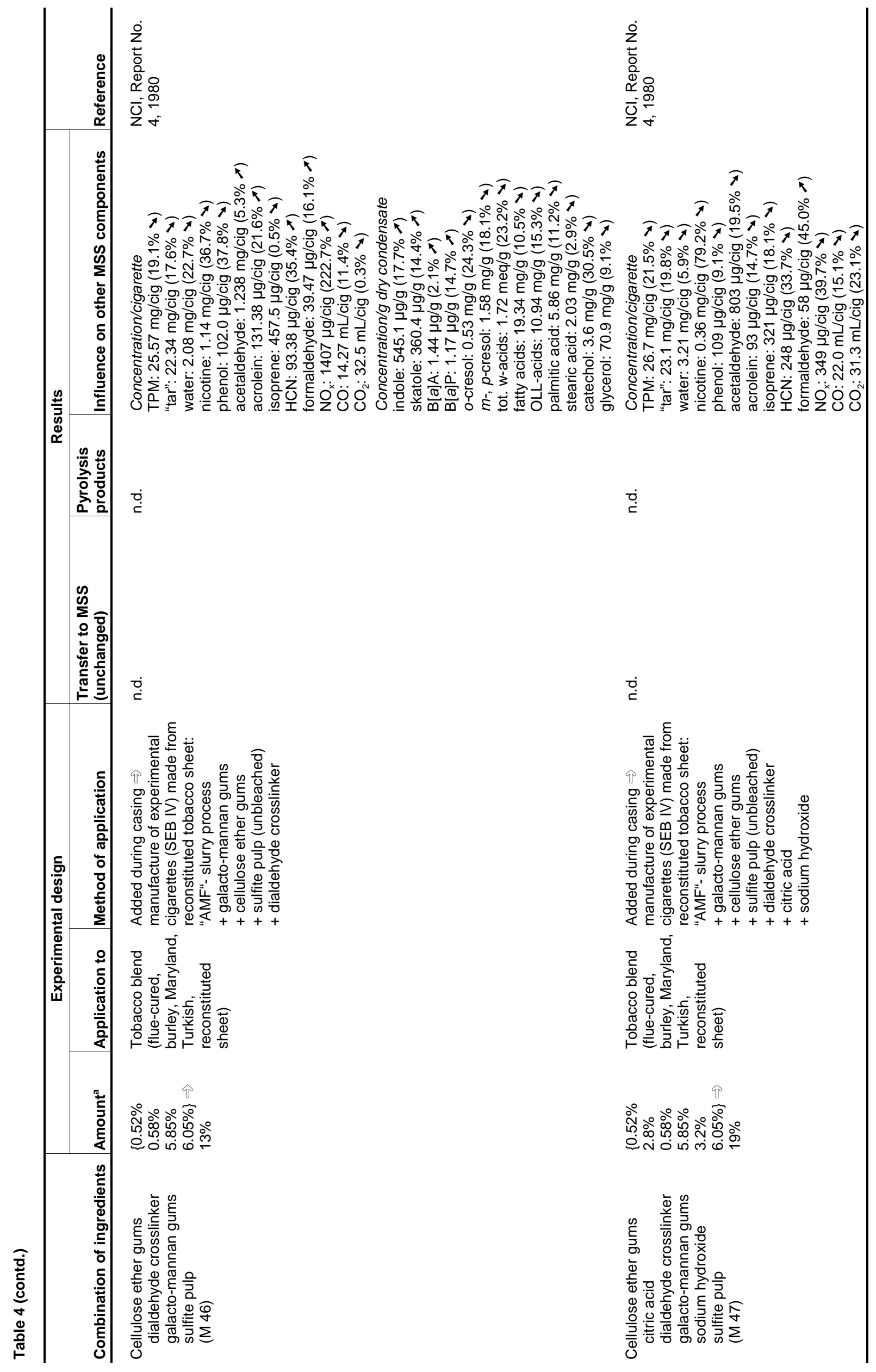




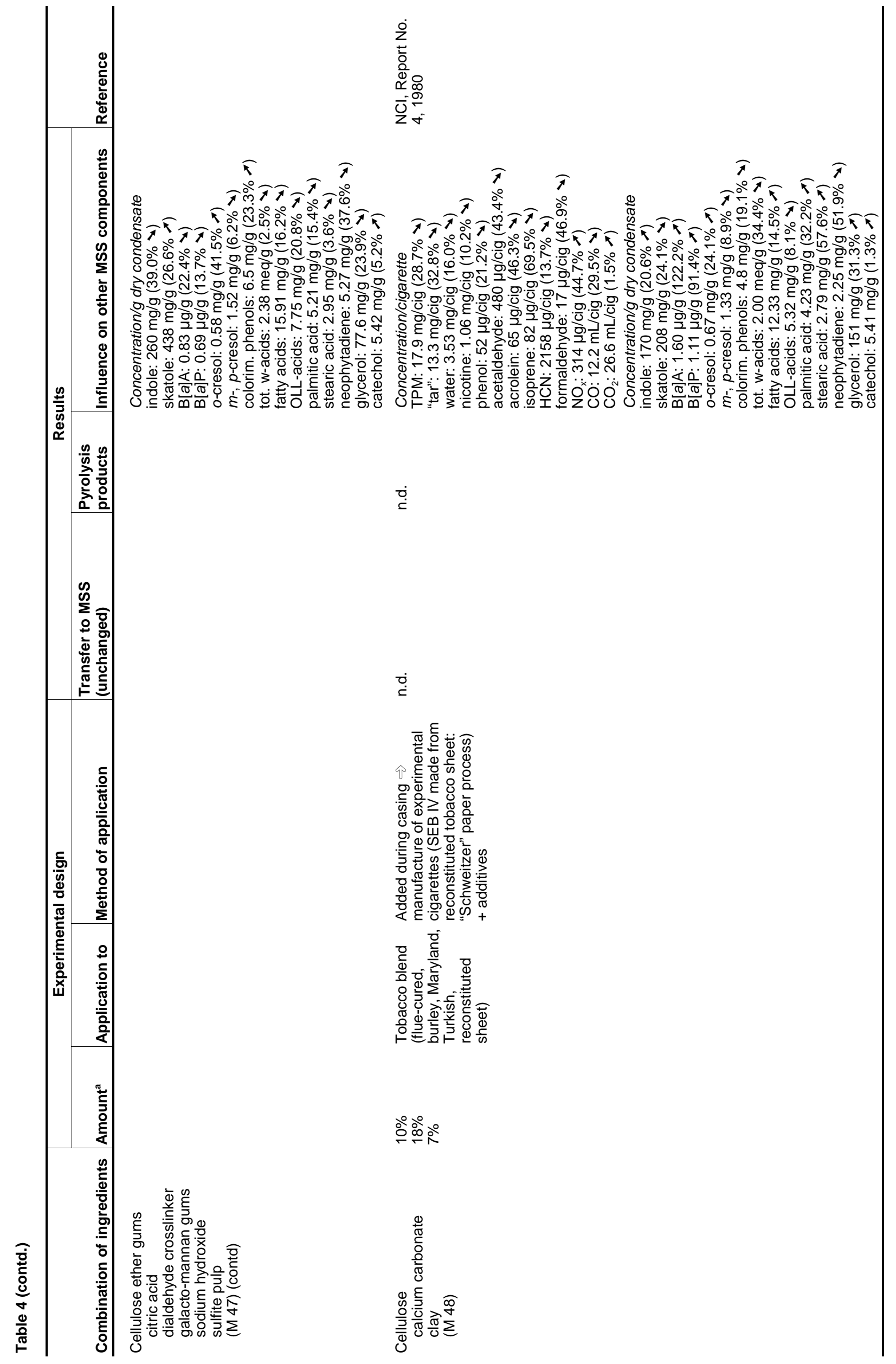




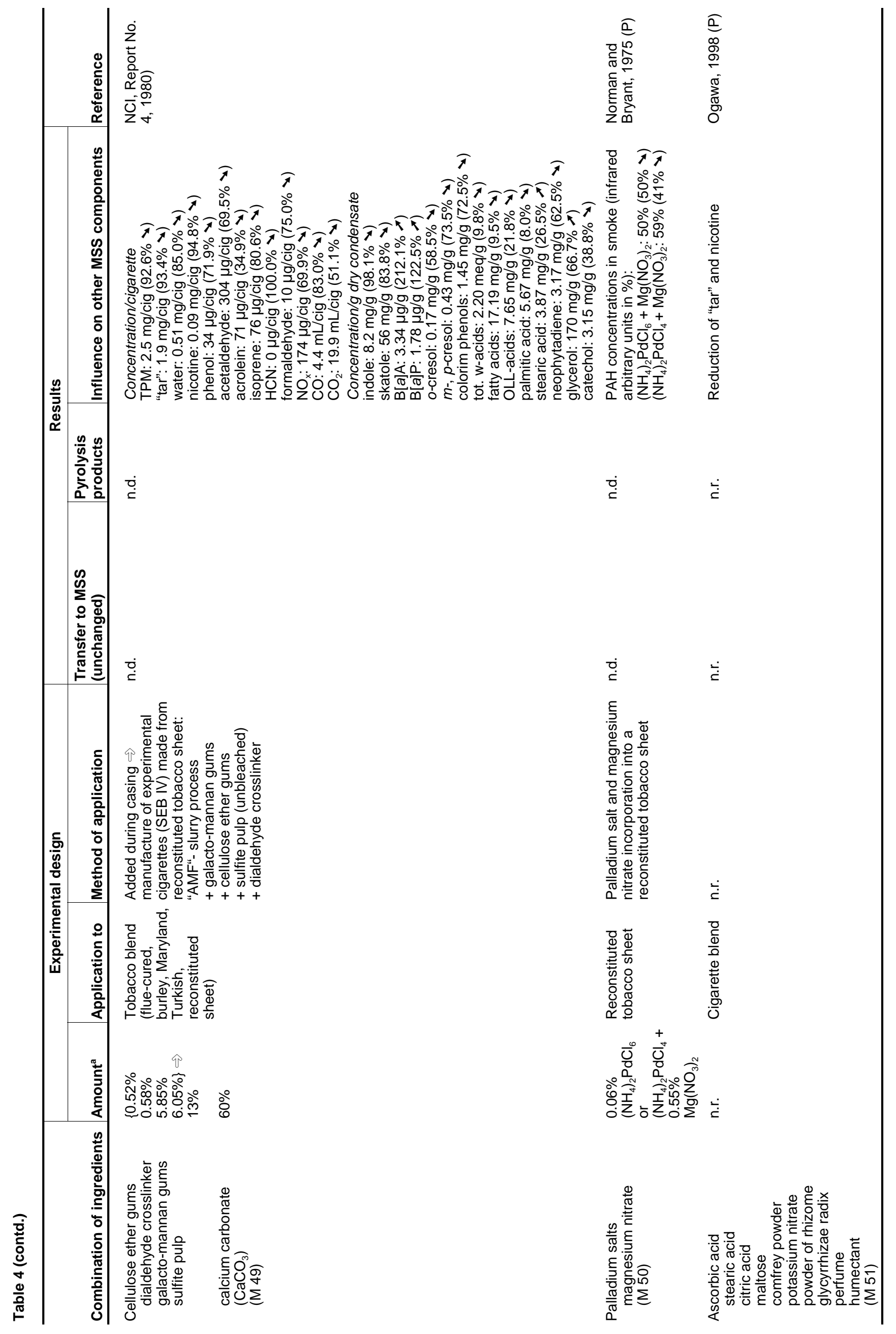




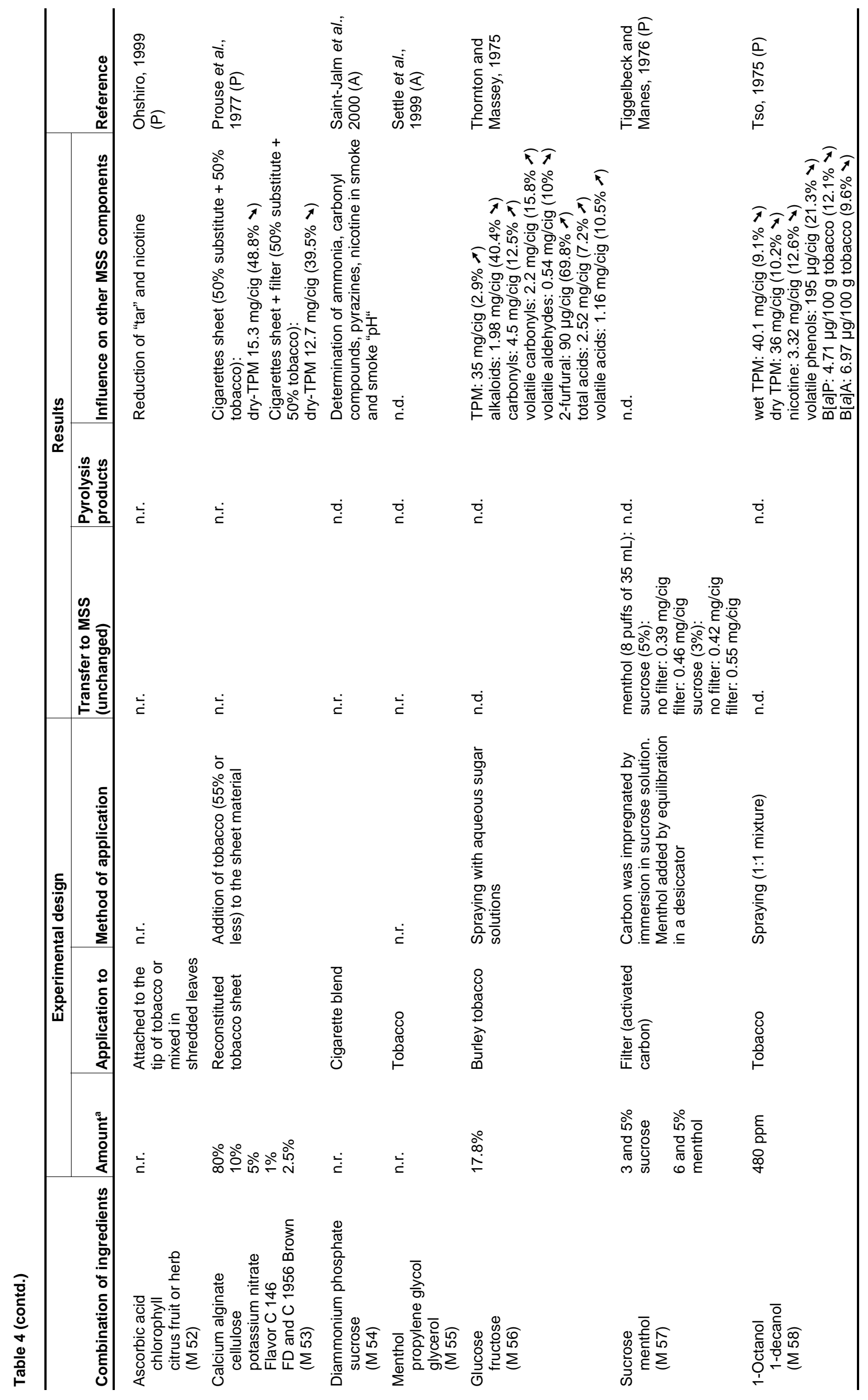




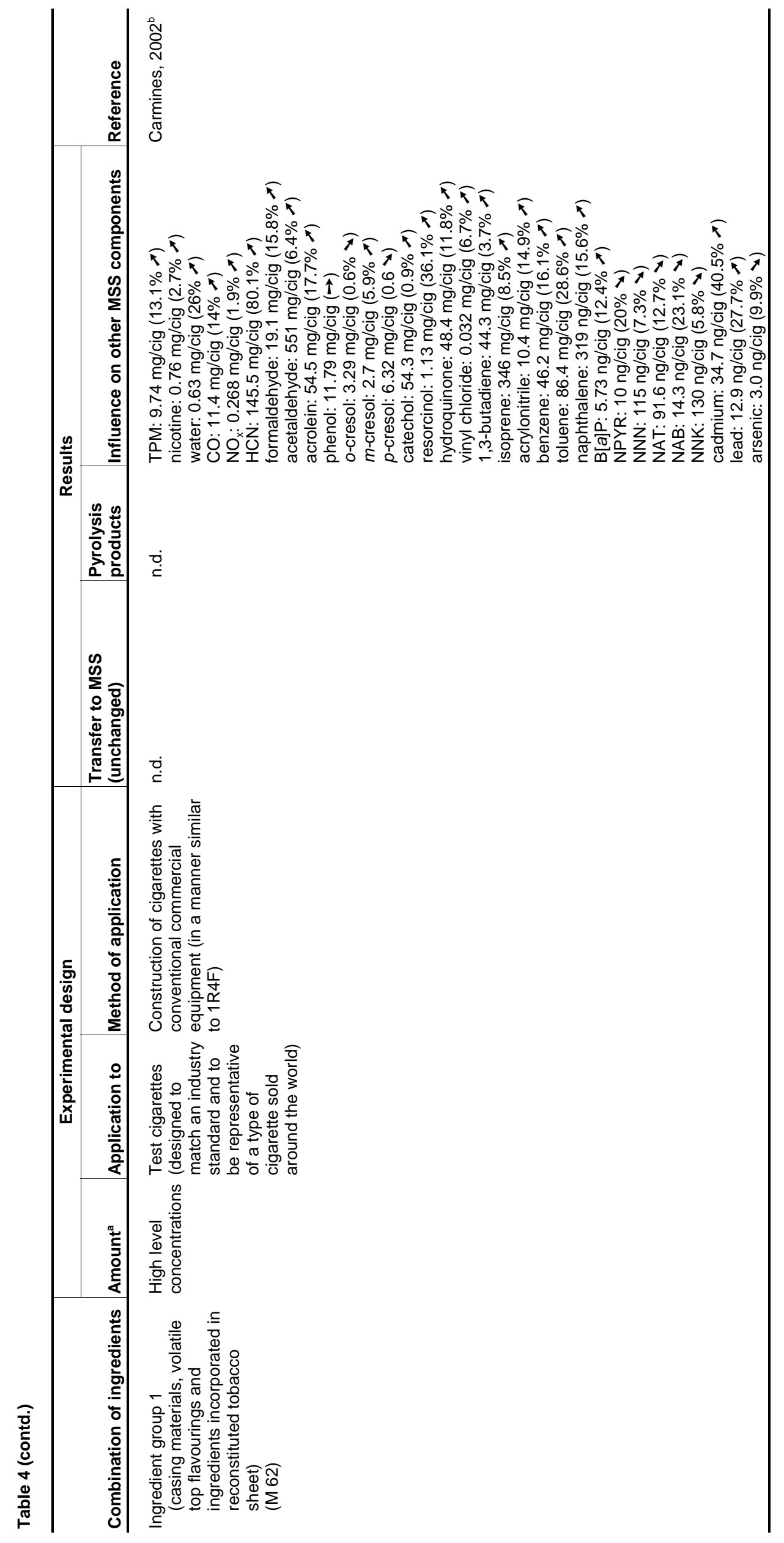




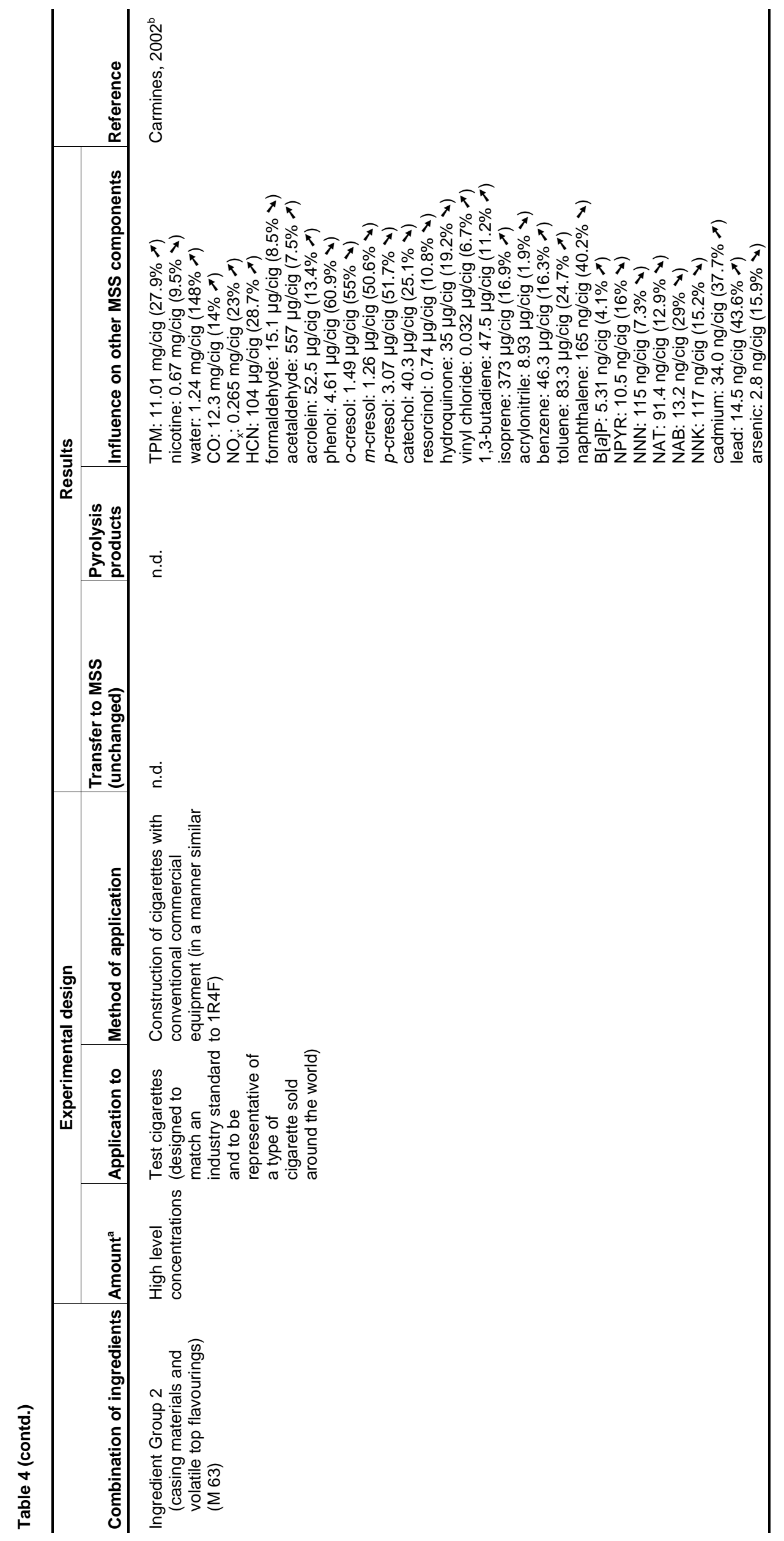




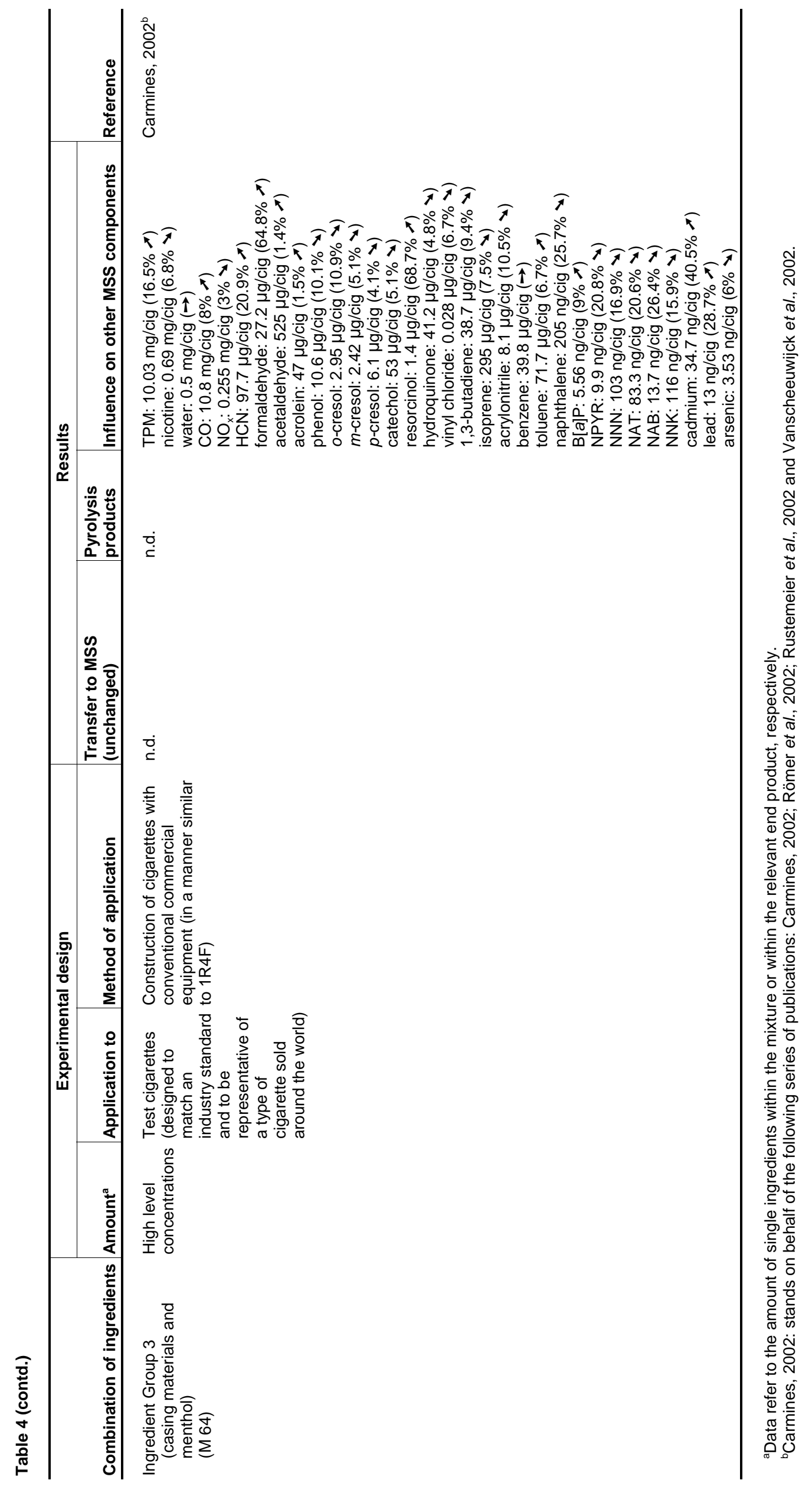


Table 5: Pyrolysis experiments with tobacco ingredients

\begin{tabular}{|c|c|c|c|c|}
\hline Ingredient(s) & Pyrolysis conditions & Transfer (\%) & Pyrolysis products & Reference(s) \\
\hline $\begin{array}{l}\text { Acetic acid (sodium } \\
\text { salt) }\end{array}$ & $\begin{array}{l}50 \mathrm{~g} \text { (in } 0.5 \mathrm{~g} \text { portions) of the } \\
\text { additive were heated at } \\
700{ }^{\circ} \mathrm{C} \text { (until the organic } \\
\text { material has disappeared) in } \\
\text { an air flow of } 1.5 \mathrm{~L} / \mathrm{min}\end{array}$ & Acetic acid (present) & $\begin{array}{l}\text { PAH: none } \\
\text { Quinones: none } \\
\text { Phenols: none } \\
\text { Others: acetic acid anhydride }\end{array}$ & Kröller, 1966b \\
\hline
\end{tabular}

Agar-agar

$30 \mathrm{~g}$ (in 0.5-1.0 g portions) of not applicable the additive were heated at (because a complex $700^{\circ} \mathrm{C}$ for about $30 \mathrm{~min}$ (until the organic material has mixture or a polymerized product disappeared) in an air flow of was investigated) $1.5 \mathrm{~L} / \mathrm{min}$

$P A H$ : pentacene, coronene, $\mathrm{B}[a] \mathrm{P}$ Kröller, 1965b

$47 \mu \mathrm{g} / 100 \mathrm{~g}$, fluoranthene, anthracene, tetrabenzonaphthalene, fluorene, acenaphthene

Quinones: toluolquinone, anthraquinone Phenols: o-cresol, pyrogallol Others: aliphatic hydrocarbons, water, $\mathrm{CO}_{2}$, (formic acid, acetic acid)

Agar-agar

$10-15 \mathrm{mg}$ of the additive were not applicable pyrolysed at $600{ }^{\circ} \mathrm{C}$ for $20 \mathrm{~s}$ (ramp $10{ }^{\circ} \mathrm{C} / \mathrm{ms}$ )

Volatile pyrolytic products: acetoin, methyl formate, 3-methylfurane, Pyysalo, 1985 2-methyl-2-cyclopentene-1-one, furfural, acetylacetone, 2-furylmethylketone, 2,4hexadienal, 5-methyl-2-furfural, isomaltol, 2-furanmethanol, cyclooctane, 3-methyl-2-hydroxycyclopentenone, hydroxyfuranone isomer, methyl-3furanecarboxylate, phenol, 4oxopentanoic acid, 4-methyl-4-hepten-3one, acetic acid, propionic acid, 2methylpropionic acid, butyric acid, 3methylbutyric acid, pentanoic acid, hexanoic acid, octanoic acid, nonanoic acid, decanoic acid

Alginic acid $\quad 30 \mathrm{~g}$ (in $0.5-1.0 \mathrm{~g}$ portions) of n.d. the additive were heated at $700{ }^{\circ} \mathrm{C}$ for about $10 \mathrm{~min}$ (until the organic material has disappeared) in an air flow of $1.5 \mathrm{~L} / \mathrm{min}$

$P A H: \mathrm{B}[a] \mathrm{P} 3 \mu \mathrm{g} / 100 \mathrm{~g}$, anthracene, chrysene, 4,5-methylenephenanthrene Quinones: anthraquinone

Phenols: 3,5-ethelmethylphenol, ethylphenol, carvacrol, 2,4,6trimethylphenol, $p$-cresol, $\beta$-naphthol, pyrogallol

Others: aliphatic and olefinic

hydrocarbons, water, $\mathrm{CO}_{2}$, formaldehyde, acetic acid

Alginic acid

10-15 mg of the additive were not applicable pyrolysed at $600{ }^{\circ} \mathrm{C}$ for $20 \mathrm{~s}$

Volatile pyrolytic products: methyl formate, 3-methylfurane, 2methyl-2-cyclopenten-1-one, furfural, acetylacetone, 2-furylmethylketone, 2,4hexadienal, 5-methyl-2-furfural, isomaltol, 2-furanmethanol, cyclooctane, 3-methyl-2-hydroxycyclopentenone, hydroxyfuranone isomer, methyl-3furanecarboxylate, phenol, benzyl alcohol derivative, 4-oxopentanoic acid, furanecarboxylic acid derivative, 4methyl-4-hepten-3-one, acetic acid, propionic acid, 2-methylpropionic acid, butyric acid, 3-methylbutyric acid, pentanoic acid, hexanoic acid, octanoic acid, nonanoic acid, decanoic acid

Anethole (as DielsAlder adduct with maleic anhydride)

Benzoic acid (sodium salt)
Adduct mixed with 3 times its weight of Celite and pyrolysed $1 \mathrm{~min}$ at $750{ }^{\circ} \mathrm{C}$ in a stream of nitrogen $(15-25 \mathrm{~mL} / \mathrm{min})$

\section{$30 \mathrm{~g}$ (in portions) of the} additive were heated at $700{ }^{\circ} \mathrm{C}$ until the organic material has disappeared in an air flow of $1.5 \mathrm{~L} / \mathrm{min}$ anethole $14 \%$ benzoic acid (present)

c

(n)

Kröller, 1965b

Sjöberg and

Pyysalo, 1985 n.d.

Robb et al., 1964

Kröller, 1970

$P A H: B[e] \mathrm{P}, \mathrm{B}[\mathrm{a}] \mathrm{P} 20 \mu \mathrm{g} / 100 \mathrm{~g}$ fluoranthene, 2,3-benzofluorene, acenaphthylene, 5,12-dihydrotetracene, dimethylbenzanthracene, terphenyl, 2methylphenanthrene Quinones: anthraquinone, acenaphthenequinone Phenols: $p$-benzylphenol, $p$-cresol, oethylphenol Others: aliphatic hydrocarbons, monocarboxylic acids 


\begin{tabular}{|c|c|c|c|c|}
\hline Ingredient(s) & Pyrolysis conditions & Transfer (\%) & Pyrolysis products & Reference(s) \\
\hline $\begin{array}{l}\text { Buckthorne berry } \\
\text { extract (from } \\
\text { Rhamnus } \\
\text { cartharticus) } \\
\text { major components: } \\
\text { rhamnetin } \\
\text { rhamnecin }\end{array}$ & $\begin{array}{l}3 \mathrm{~g} \text { of extract were heated at } \\
700^{\circ} \mathrm{C} \text { for } 1 \mathrm{~h} \text { in an air flow } \\
\text { of } 1.5 \mathrm{~L} / \mathrm{min}\end{array}$ & not applicable & $\begin{array}{l}\text { water, acetic acid, catechol, guajacol, } \\
m \text {-cresol, } \alpha \text {-naphthol, } \beta \text {-naphthol, } \\
\text { pyrogallol, pyrene, fluoranthene, } \mathrm{B}[a] \mathrm{P} \\
2 \mu \mathrm{g} / 100 \mathrm{~g} \text { extract. } \\
\mathrm{B}[\mathrm{a}] \mathrm{P} \text { content insignificant compared to } \\
\text { that in tobacco smoke }\end{array}$ & Kröller, 1963a \\
\hline 1,3-Butylene glycol & $\begin{array}{l}2 \mathrm{~mL} \text { of the glycol on silica } \\
\text { were heated at } 700{ }^{\circ} \mathrm{C} \text { for } \\
\text { about } 10 \mathrm{~min} \text { (until the glycol } \\
\text { has disappeared) in an air } \\
\text { flow of } 1.5 \mathrm{~L} / \mathrm{min}\end{array}$ & $36 \%$ & $\begin{array}{l}P A H: \mathrm{B}[a] \mathrm{P} \text { about } 13 \mu \mathrm{g} / 100 \mathrm{~g}, \\
\text { fluoranthene, } 2 \text {-methylphenanthrene } \\
\text { Quinones: anthraquinone } \\
\text { Phenols: } 0 \text { - and } p \text {-cresol } \\
\text { Others: hydrocarbons, } \mathrm{CO}_{2} \text {, water, } \\
\text { aldehydes }\end{array}$ & Kröller, 1964b \\
\hline 1,3-Butylene glycol & $\begin{array}{l}\text { Pyrolysis of } 100 \mathrm{~g} \text { of } \\
\text { polyalcohol was investigated } \\
\text { at various temperatures }\end{array}$ & not applicable & $\begin{array}{l}\text { Principal compounds at } 600{ }^{\circ} \mathrm{C} \text { : } \\
\text { formaldehyde, acetaldehyde } \\
10-15 \mathrm{~g} / 100 \mathrm{~g}\end{array}$ & $\begin{array}{l}\text { Doihara et al., } \\
1964\end{array}$ \\
\hline $\begin{array}{l}\text { Campeachy wood } \\
\text { extract (from } \\
\text { Haematoxylon } \\
\text { campe-chianum), } \\
\text { major components: } \\
\text { Haematein }\end{array}$ & $\begin{array}{l}3 \mathrm{~g} \text { of extract were heated at } \\
700^{\circ} \mathrm{C} \text { for } 40 \mathrm{~min} \text { in an air } \\
\text { flow of } 1.5 \mathrm{~L} / \mathrm{min}\end{array}$ & not applicable & $\begin{array}{l}\mathrm{CO}, \mathrm{CO}_{2} \text {, water, formaldehyde, acetic } \\
\text { acid, phenol, } m \text {-cresol, catechol, } \\
\text { anthraquinone, fluoranthene, } \\
\text { phenanthrene, } \mathrm{B}[\mathrm{a}] \mathrm{P}<1 \mu \mathrm{g} / 100 \mathrm{~g} \\
\text { extract, traces of: } 4,5- \\
\text { methylenephenanthrene, pyrene, } \\
\text { naphthacene, pyrenequinone } \\
\text { amounts of carcinogens insignificant } \\
\text { compared to those in tobacco smoke }\end{array}$ & Kröller, 1963b \\
\hline $\begin{array}{l}\text { Carboxymethyl- } \\
\text { cellulose } \\
\text { sodium salt }\end{array}$ & $\begin{array}{l}30 \mathrm{~g} \text { (in } 0.5 \mathrm{~g} \text { portions) of the } \\
\text { cellulose derivate were } \\
\text { heated at } 700{ }^{\circ} \mathrm{C} \text { for about } \\
30 \text { min (until the organic } \\
\text { material has disappeared) in } \\
\text { an air flow of } 1.5 \mathrm{~L} / \mathrm{min}\end{array}$ & not applicable & $\begin{array}{l}P A H: \text { perylene, phenanthrene, 1,2- } \\
\text { fluoranthene, B[a]P } 12 \mu \mathrm{g} / 100 \mathrm{~g}, \\
\text { benzanthracene } 2 \mu \mathrm{g} / 100 \mathrm{~g}, \\
\text { anthracene, } 20 \text {-methylcholanthrene } \\
1 \mu \mathrm{g} / 100 \mathrm{~g} \\
\text { Quinones: phenanthrenequinone, } \\
\text { anthraquinone } \\
\text { Phenols: phenol, o-cresol, carvacrol, } \\
\text { pyrogallol, gallic acid, catechol } \\
\text { Others: aliphatic hydrocarbons, } \\
\text { aldehydes, carboxylic acids, water }\end{array}$ & Kröller, 1964a \\
\hline $\begin{array}{l}\text { Carboxymethyl- } \\
\text { cellulose }\end{array}$ & $\begin{array}{l}10-15 \mathrm{mg} \text { of the additive } \\
\text { were pyrolysed at } 600^{\circ} \mathrm{C} \text { for } \\
20 \mathrm{~s}\left(\text { ramp } 10^{\circ} \mathrm{C} / \mathrm{ms}\right)\end{array}$ & not applicable & $\begin{array}{l}\text { Volatile pyrolytic products: } \\
\text { acetoin, methyl formate, 3-methylfurane, } \\
\text { 2-methyl-2-cyclopenten-1-one, furfural, } \\
\text { acetylacetone, 2-furylmethylketone, 2,4- } \\
\text { hexadienal, 5-methyl-2-furfural, } \\
\text { isomaltol, 2-furanmethanol, decanoic } \\
\text { acid, cyclooctane, 3-methyl-2- } \\
\text { hydroxycyclopentenone, } \\
\text { hydroxyfuranone isomer, methyl-3- } \\
\text { furanecarboxylate, phenol, benzyl } \\
\text { alcohol derivative, 4-oxopentanoic acid, } \\
\text { furanecarboxylic acid derivative, 4- } \\
\text { methyl-4-hepten-3-one, acetic acid, } \\
\text { propionic acid, 2-methylpropionic acid, } \\
\text { butyric acid, 3-methylbutyric acid, } \\
\text { pentanoic acid, hexanoic acid, octanoic } \\
\text { acid, nonanoic acid }\end{array}$ & $\begin{array}{l}\text { Sjöberg and } \\
\text { Pyysalo, } 1985 \\
\end{array}$ \\
\hline Carboxymethyl starch & $\begin{array}{l}30 \mathrm{~g} \text { (in } 0.5 \mathrm{~g} \text { portions) of the } \\
\text { additive were heated at } \\
700{ }^{\circ} \mathrm{C} \text { for up to } 30 \mathrm{~min} \text { (until } \\
\text { the organic material has } \\
\text { disappeared) in an air flow of } \\
1.5 \mathrm{~L} / \mathrm{min}\end{array}$ & n.d. & $\begin{array}{l}P A H: 1,2 \text {-benzanthracene, B[a]P } \\
30 \mu \mathrm{g} / 100 \mathrm{~g} \text {, fluoranthene, } \\
\text { phenanthrene, anthracene, 2- } \\
\text { methylphenanthrene } \\
\text { Quinones: phenanthrenequinone, } \\
\text { anthraquinone } \\
\text { Phenols: phenol, o-cresol, guajacol, o- } \\
\text { ethylphenol, pyrogallol, gallic acid, } \\
\text { catechol } \\
\text { Others: aliphatic hydrocarbons, } \\
\text { aldehydes, carboxylic acids, water }\end{array}$ & Kröller, 1966a \\
\hline 5-Carboxyvanillin & $\begin{array}{l}\text { Compound pyrolysed in } \\
\text { helium at } 300^{\circ} \mathrm{C}\end{array}$ & vanillin $92 . \%$ & $\begin{array}{l}\mathrm{CO}_{2}: 4.5 \% \\
\text { 5-carboxy-3,4-dimethoxybenzaldehyde: } \\
3.5 \%\end{array}$ & $\begin{array}{l}\text { Southwick, } \\
1992(P)\end{array}$ \\
\hline
\end{tabular}




\begin{tabular}{|c|c|c|c|c|}
\hline Ingredient(s) & Pyrolysis conditions & Transfer (\%) & Pyrolysis products & Reference(s) \\
\hline $\begin{array}{l}\text { Carob (locust bean } \\
\text { gum) }\end{array}$ & $\begin{array}{l}10-15 \mathrm{mg} \text { of the additive were } \\
\text { pyrolysed at } 600{ }^{\circ} \mathrm{C} \text { for } 20 \mathrm{~s} \\
\left.\text { (ramp } 10{ }^{\circ} \mathrm{C} / \mathrm{ms}\right)\end{array}$ & not applicable & $\begin{array}{l}\text { Volatile pyrolytic products: } \\
\text { acetoin, methyl formate, furfural, 3- } \\
\text { methylfurane, 2-furanmethanol, } \\
\text { acetylacetone, cyclooctane, 2-methyl-2- } \\
\text { cyclopenten-1-one, isomaltol, 2- } \\
\text { furylmethylketone, 2,4-hexadienal, 5- } \\
\text { methyl-2-furfural, phenol, 3-methyl-2- } \\
\text { hydroxycyclopentenone, methyl-3- } \\
\text { furanecarboxylate, hydroxyfuranone } \\
\text { isomer, benzyl alcohol derivative, 4- } \\
\text { oxopentanoic acid, furanecarboxylic acid } \\
\text { derivative, 4-methyl-4-hepten-3-one, } \\
\text { acetic acid, propionic acid, 2- } \\
\text { methylpropionic acid, butyric acid, 3- } \\
\text { methylbutyric acid, pentanoic acid, } \\
\text { hexanoic acid, octanoic acid, nonanoic } \\
\text { acid, decanoic acid }\end{array}$ & $\begin{array}{l}\text { Sjöberg and } \\
\text { Pyysalo, } 1985\end{array}$ \\
\hline
\end{tabular}

Carob seed powder (from Ceratonia siliqua $L$.)

Casein

Cellobiose

Cellubiose

Cellulose

Cellulose (from cotton)

Cellulose

Cellulose
$30 \mathrm{~g}$ (in 0.5-1.0 g portions) of not applicable the additive were heated at $700{ }^{\circ} \mathrm{C}$ for about $30 \mathrm{~min}$ (until the organic material has disappeared) in an air flow of $1.5 \mathrm{~L} / \mathrm{min}$

Pyrolysis of $0.5-2.0 \mathrm{~g}$ at $800-860{ }^{\circ} \mathrm{C}$ in an $\mathrm{N}_{2}$-flow

not applicable
About $1 \mathrm{~g}$ of material was heated to $840 \pm 10^{\circ} \mathrm{C}$ in a stream of nitrogen $(60 \mathrm{~mL} / \mathrm{min})$

Pyrolysis at $700{ }^{\circ} \mathrm{C}$ in an $\mathrm{N}_{2}-$ flow $(30 \mathrm{~mL} / \mathrm{min})$

15-30 mg of material was heated to $250,350,500^{\circ} \mathrm{C}$ for 5,1 and 1 min, respectively in a stream of helium

$(60 \mathrm{~mL} / \mathrm{min})$

Condition 1: air, $100 \mathrm{~mL} / \mathrm{min}$

$314{ }^{\circ} \mathrm{C}$ (furnace 1 )

$320{ }^{\circ} \mathrm{C}$ (furnace 2)

$685^{\circ} \mathrm{C}$ (mobile furnace)

Condition 3: air, $100 \mathrm{~mL} / \mathrm{min}$

$777{ }^{\circ} \mathrm{C}$ (furnace 1)

$562{ }^{\circ} \mathrm{C}$ (furnace 2)

$685{ }^{\circ} \mathrm{C}$ (mobile furnace)

Condition 4: $\mathrm{N}_{2}, 100 \mathrm{~mL} / \mathrm{min}$

$315{ }^{\circ} \mathrm{C}$ (furnace 1 )

$320^{\circ} \mathrm{C}$ (furnace 2)

$685^{\circ} \mathrm{C}$ (mobile furnace)

Pyrolysis at $700{ }^{\circ} \mathrm{C}$ in an $\mathrm{N}_{2}$ flow $(30 \mathrm{~mL} / \mathrm{min})$

0.2-0.5 mg cellulose (filter paper untreated and nitratetreated) were pyrolysed for $30 \mathrm{~s}$ at $400-800^{\circ} \mathrm{C}\left(50{ }^{\circ} \mathrm{C}\right.$ intervals) in nitrogen and air

not applicable

not applicable

$0.5 \mathrm{~g}$ of cellulose were heated not applicable at $700{ }^{\circ} \mathrm{C}$ for $5-6$ min (until the organic material has disappeared) in an air flow of $1.5 \mathrm{~L} / \mathrm{min}$

n.d.

not applicable

n.d.
$P A H$ : pentacene, coronene, $\mathrm{B}[\mathrm{a}] \mathrm{P}$

$6 \mu \mathrm{g} / 100 \mathrm{~g}$, fluoranthene, 2,3-

benzofluorene, anthracene

Quinones: anthraquinone.

benzoquinone

Phenols: phenol, o-cresol, pyrogallol

Others: aliphatic hydrocarbons, water, formaldehyde, formic acid

Principle products: pyridine, quinoline, pyrrole, toluene, phenol, $m$-, $p$-cresol Other products: 2-methylpyridine, 3-/4methylpyridine, 3-vinylpyridine, aniline, isoquinoline, benzene, styrene, xylene, benzonitrile, indene, $o$-tolunitrile, $m$ tolunitrile, naphthalene, indole, fluorene, o-cresol, ethylphenol, xylenol

Selected pyrolysis products:

benzene $9.0 \%$, indole $6.8 \%$, pyridine $23.0 \%$, quinone $13.4 \%$, phenol $35.3 \%$

Formation of phenols $(\mathrm{mg} / 100 \mathrm{~g})$ : phenol 31, o-cresol 9, m-, p-cresol 11

Relative amounts (cm peak height for $10 \mathrm{mg}$ ) of selected pyrolysis products at $500^{\circ} \mathrm{C}$ :

acetaldehyde 10.0, propionaldehyde 1.3, acrolein 2.6, furfural 4.8

Condition 1: $0.024 \%$ phenol

Condition 3: $0.008 \%$ phenol

Condition $4: 0.04 \%$ phenol

Bell et al., 1966

Higman, E.B. et al., 1970

Schlotzhauer et al., 1967

Kato, 1967

Schmeltz et al., 1972

Formation of phenols $(\mathrm{mg} / 100 \mathrm{~g})$ : phenol 6,o-cresol 2, $m$-, $p$-cresol 2

Schlotzhauer et al., 1967

Major pyrolysis products at $500{ }^{\circ} \mathrm{C}$ ( $\mathrm{mg} / \mathrm{g}$ cellulose):

In $N_{2}$ (neat) $-N_{2}+K_{N} O_{3}-$ air acetaldaldehyde: $4.7-3.0-15.7$ acrolein: $8.1-3.9-20.8$

3-buten-2-one: $4.0-1.5-3.7$

glucopyranose: $5.3-3.0-7.7$ 5-hydroxymethyl-2-furaldehyde: $10.0-2.0-7.8$

$P A H$ : picene, $\mathrm{B}[\mathrm{a}] \mathrm{P} \sim 8 \mu \mathrm{g} / 100 \mathrm{~g}$, fluoranthene, anthracene, 4,5methylenephenanthrene

Quinones: phenanthrenequinone, anthraquinone, pyrenequinone Phenols: pyrogallol, $m$-cresol

Others: hydrocarbons, water, $\mathrm{CO}_{2}$, formaldehyde, acetic acid
Sakuma et al., 1981

Kröller, 1964a 


\begin{tabular}{|c|c|c|c|c|}
\hline Ingredient(s) & Pyrolysis conditions & Transfer (\%) & Pyrolysis products & Reference(s) \\
\hline Cellulose & $\begin{array}{l}5-10 \mathrm{mg} \text { cellulose were } \\
\text { heated for } 10 \mathrm{~s} \text { at } 700^{\circ} \mathrm{C} \\
\text { under an } \mathrm{N}_{2} \text {-flow }(15 \mathrm{~mL} / \mathrm{min})\end{array}$ & n.d. & $\begin{array}{l}\text { 2-furaldehyde } 20.7 \% \text {, 3-hydroxy-2- } \\
\text { methylpyran-4-one } 10.0 \% \text {, 5-methyl-2- } \\
\text { furaldehyde } 2.1 \%, 3 \text {-methylfuran } 6.1 \% \text {, } \\
\text { furancarboxylic acid methyl ester } 6.9 \% \text {, } \\
\text { 3-methyl-2,4(3H,5H)-furandione } 5.1 \% \text {, } \\
\text { 2-furanmethanol } 2.0 \%, 1,3 \text { - } \\
\text { cyclopentanedione } 3.6 \% \text {, propionic acid } \\
\text { methyl ester } 1.1 \%\end{array}$ & $\begin{array}{l}\text { Schlotzhauer et } \\
\text { al., } 1985\end{array}$ \\
\hline Cellulose & $\begin{array}{l}\text { Cellulose was rapidly heated } \\
\text { (within } 2 \text { min) to } 300-550{ }^{\circ} \mathrm{C} \text { in } \\
\text { a stream of helium at flow } \\
\text { rates of } 100,200 \text { and } \\
300 \mathrm{~cm}^{3} / \mathrm{min}\end{array}$ & n.d. & $\begin{array}{l}\text { Condition with maximum yields }\left(450{ }^{\circ} \mathrm{C}\right. \\
\left.\text { and } 100 \mathrm{~cm}^{3} / \mathrm{min}\right) \text { : } \\
\text { hydrogen } 46.0 \mu \mathrm{mol} / \mathrm{L} \text {, methane } \\
42.6 \mu \mathrm{mol} / \mathrm{L} \text {, carbon monoxide } \\
660.0 \mu \mathrm{mol} / \mathrm{L} \text {, ethene } 15.4 \mu \mathrm{mol} / \mathrm{L} \text {, } \\
\text { ethane } 2.36 \mu \mathrm{mol} / \mathrm{L} \text {, propene } \\
4.36 \mu \mathrm{mol} / \mathrm{L} \text {, carbon dioxide } \\
168.0 \mu \mathrm{mol} / \mathrm{L} \text {, propine } 0.2 \mu \mathrm{mol} / \mathrm{L} \text {, } \\
\text { but- } 1 \text {-ene } 0.0 \mu \mathrm{mol} / \mathrm{L} \text {, } \\
\text { butane } 0.24 \mu \mathrm{mol} / \mathrm{L}\end{array}$ & $\begin{array}{l}\text { Cullis et al., } \\
1983 \mathrm{~b}\end{array}$ \\
\hline Cellulose & $\begin{array}{l}\text { Cellulose was rapidly heated } \\
\text { (within } 2 \mathrm{~min} \text { ) to } 300-550^{\circ} \mathrm{C} \text { in } \\
\text { a stream of nitrogen with } \\
\text { increasing amounts of oxygen } \\
(5-21 \mathrm{vol} . \% \text { ) at a flow rate of } \\
100 \mathrm{~cm}^{3} / \mathrm{min}\end{array}$ & n.d. & $\begin{array}{l}\text { Condition with almost maximum yields } \\
\left(450{ }^{\circ} \mathrm{C} \text { and } 100 \mathrm{~cm}^{3} / \text { min nitrogen with }\right. \\
21 \% \text { oxygen }) \text { : } \\
\text { hydrogen } 838 \mu \mathrm{mol} / \mathrm{L} \text {, methane } \\
1315 \mu \mathrm{mol} / \mathrm{L} \text {, carbon monoxide } \\
9483 \mu \mathrm{mol} / \mathrm{L} \text {, ethene } 648 \mu \mathrm{mol} / \mathrm{L}, \\
\text { propene } 141 \mu \mathrm{mol} / \mathrm{L}, \text { carbon dioxide } \\
4547 \mu \mathrm{mol} / \mathrm{L}, \text { oxygen } 676 \mu \mathrm{mol} / \mathrm{L}, \\
\text { nitrogen } 27397 \mu \mathrm{mol} / \mathrm{L}\end{array}$ & $\begin{array}{l}\text { Cullis et al., } \\
1983 a\end{array}$ \\
\hline Cellulose & $\begin{array}{l}5 \mathrm{~g} \text { of material was rapidly } \\
\text { heated to } 650^{\circ} \mathrm{C} \text { in a stream of } \\
\text { nitrogen for } 1 \mathrm{~h}\end{array}$ & n.d. & $\begin{array}{l}\text { PAHs (out of } 11 \text { investigated) }(\mu \mathrm{g} / 100 \mathrm{~g}) \text { : } \\
\text { pyrene } 219, \mathrm{~B}[\mathrm{a}] \mathrm{P} 78\end{array}$ & $\begin{array}{l}\text { Gilbert and } \\
\text { Lindsey, } 1957\end{array}$ \\
\hline Cellulose & $\begin{array}{l}\text { About } 1 \mathrm{~g} \text { of material was } \\
\text { heated to } 840 \pm 10^{\circ} \mathrm{C} \text { in a } \\
\text { stream of nitrogen }(60 \mathrm{~mL} / \mathrm{min})\end{array}$ & n.d. & $\begin{array}{l}\text { Selected pyrolysis products: } \\
\text { benzene } 25.7 \% \text {, furfural - } \text {, pyrene } \\
2.1 \% \text {, phenol } 67.5 \%, \mathrm{~B}[\mathrm{a}] \mathrm{P} 288.8 \mu \mathrm{g} / \mathrm{g}\end{array}$ & $\begin{array}{l}\text { Higman, E.B. et } \\
\text { al., } 1970\end{array}$ \\
\hline Cellulose & $\begin{array}{l}15-30 \mathrm{mg} \text { of material was } \\
\text { heated to } 250,350,500^{\circ} \mathrm{C} \text { for } \\
5,1 \text { and } 1 \mathrm{~min} \text {, respectively in } \\
\text { a stream of helium } \\
(60 \mathrm{~mL} / \mathrm{min})\end{array}$ & n.d. & $\begin{array}{l}\text { Relative amounts (cm peak height for } \\
10 \mathrm{mg} \text { ) of selected pyrolysis products } \\
\text { at } 500{ }^{\circ} \mathrm{C} \text { : } \\
\text { acetaldehyde } 11.4 \text {, propionaldehyde } 2.6 \text {, } \\
\text { acrolein } 1.9 \text {, furfural } 3.3\end{array}$ & Kato, 1967 \\
\hline Cellulose & $\begin{array}{l}5 \mathrm{~g} / 30 \text { min cellulose were } \\
\text { pyrolysed at various } \\
\text { temperatures }\left(350-880^{\circ} \mathrm{C}\right) \text { in } \\
\text { a stream of nitrogen } \\
(85-1050 \mathrm{~mL} / \mathrm{min})\end{array}$ & n.d. & $\begin{array}{l}\text { Influence on pyrolytic } B[a] P \text { formation: } \\
\text { Temperature: increase with temp., } \\
\text { sharp increase at } 650^{\circ} \mathrm{C} \\
\text { Oxygen: higher yield in the presence } \\
\text { of } \mathrm{O}_{2} \\
\text { Metals, salts: strong effect (decrease) of } \\
\text { iron, nickel, cobalt, ferric oxide, } \\
\text { ferrocene moderate effect of nitrate } \\
\text { Flow rate of carrier gas: increase with } \\
\text { flow } \\
\text { Atmosphere: nitric oxide inhibits, } \\
\text { propene increases } \mathrm{B}[\mathrm{a}] \mathrm{P} \text { yield }\end{array}$ & $\begin{array}{l}\text { Robb et al., } \\
1966\end{array}$ \\
\hline Cellulose & $\begin{array}{l}25 \mathrm{~g} \text { material were pyrolysed } \\
\text { at } 800^{\circ} \mathrm{C} \text { in the following way: } \\
12 \text { cycles consisting of an } \\
\text { "operative time" ( } 20 \mathrm{~s} \text { in a gas } \\
\text { flow of nitrogen and air } \\
{[1 \mathrm{~L} / \mathrm{min} \text { for each gas], }} \\
\text { simulating a puff) followed by } \\
\text { an "inoperative time" ( } 40 \mathrm{~s} \text { in a } \\
\text { flow of nitrogen, simulating the } \\
\text { puff interval) }\end{array}$ & n.d. & $\begin{array}{l}\text { Major pyrolysis products (catechols): } \\
\text { furfural } 5.4 \mathrm{mg} / \mathrm{g}, \\
\text { levoglucosan } 2.9 \mathrm{mg} / \mathrm{g}\end{array}$ & $\begin{array}{l}\text { Schlotzhauer et } \\
\text { al., } 1982\end{array}$ \\
\hline $\begin{array}{l}\text { Cellulose } \\
\text { monoacetate }\end{array}$ & $\begin{array}{l}30 \mathrm{~g} \text { (in portions) of the } \\
\text { cellulose derivate were heated } \\
\text { at } 700{ }^{\circ} \mathrm{C} \text { for about } 30 \text { min (un- } \\
\text { til the organic material has } \\
\text { disappeared) in an air flow of } \\
1.5 \mathrm{~L} / \mathrm{min}\end{array}$ & not applicable & $\begin{array}{l}\text { PAH: naphthacene, } \mathrm{B}[\mathrm{a}] \mathrm{P} \\
28.5 \mu \mathrm{\mu g} / 100 \mathrm{~g}, \text { fluoranthene, } \\
\text { anthracene, } 20 \text {-methylcholanthrene } \\
\text { Quinones: toluolquinone, } \\
\text { naphthoquinone, anthraquinone } \\
\text { Phenols: pyrogallol, o-cresol, 3,5-ethyl- } \\
\text { methyl-phenol } \\
\text { Others: acetic acid, aliphatic } \\
\text { hydrocarbons, water, aldehyde(s) }\end{array}$ & Kröller, 1964a \\
\hline
\end{tabular}


Table 5 (contd.)

\begin{tabular}{|c|c|c|c|c|}
\hline Ingredient(s) & Pyrolysis conditions & Transfer (\%) & Pyrolysis products & Reference(s) \\
\hline Chlorogenic acid & $\begin{array}{l}25 \mathrm{~g} \text { material were pyrolysed } \\
\text { at } 800{ }^{\circ} \mathrm{C} \text { in the following way: } \\
12 \text { cycles consisting of an } \\
\text { "operative time" ( } 20 \mathrm{~s} \text { in a gas } \\
\text { flow of nitrogen and air } \\
\text { [1 L/min for each gas], } \\
\text { simulating a puff) followed by } \\
\text { an "inoperative time" ( } 40 \mathrm{~s} \text { in a } \\
\text { flow of nitrogen, simulating the } \\
\text { puff interval) }\end{array}$ & n.d. & $\begin{array}{l}\text { Major pyrolysis products (catechols): } \\
\text { catechol: } 43.3 \mathrm{mg} / \mathrm{g}, 4 \text {-ethylcatechol } \\
40.2 \mathrm{mg} / \mathrm{g} \text {, phenol } 13.9 \mathrm{mg} / \mathrm{g}, \\
\text { 5-(hydroxymethyl)fufural } 13.2 \mathrm{mg} / \mathrm{g}\end{array}$ & $\begin{array}{l}\text { Schlotzhauer } \\
\text { et al., } 1982\end{array}$ \\
\hline Citric acid & $\begin{array}{l}5 \mathrm{~g} \text { of material was rapidly } \\
\text { heated to } 650{ }^{\circ} \mathrm{C} \text { in a stream of } \\
\text { nitrogen for } 1 \mathrm{~h}\end{array}$ & n.d. & $\begin{array}{l}\text { PAHs (out of } 11 \text { investigated): } \\
\text { pyrene } 24 \mu \mathrm{g} / 100 \mathrm{~g}, \mathrm{~B}[\mathrm{a}] \mathrm{P} 17 \mu \mathrm{g} / 100 \mathrm{~g}\end{array}$ & $\begin{array}{l}\text { Gilbert and } \\
\text { Lindsey, } 1957\end{array}$ \\
\hline $\begin{array}{l}\text { Citric acid (sodium } \\
\text { salt) }\end{array}$ & $\begin{array}{l}50 \mathrm{~g} \text { (in } 0.5 \mathrm{~g} \text { portions) of the } \\
\text { additive were heated at } 700{ }^{\circ} \mathrm{C} \\
\text { (until the organic material has } \\
\text { disappeared) in an air flow of } \\
1.5 \mathrm{~L} / \mathrm{min}\end{array}$ & n.d. & $\begin{array}{l}\text { PAH: 1,2,5,6-dibenzanthracene, } \\
\text { coronene, B[a]P } 5 \mu \mathrm{g} / 100 \mathrm{~g}, \\
\text { fluoranthene, } 20 \text {-methylcholanthrene } \\
\text { Quinones: anthraquinone } \\
\text { Phenols: phenol, pyrogallol } \\
\text { Others: aliphatic hydrocarbons, } \\
\text { carboxylic acids, } \mathrm{CO}, \mathrm{CO}_{2} \text {, water }\end{array}$ & Kröller, 1966b \\
\hline Cocoa & $\begin{array}{l}20 \mathrm{~g} \text { were pyrolysed at } 350 \text {, } \\
450,550,650 \text { and } 750{ }^{\circ} \mathrm{C}\end{array}$ & not applicable & $\begin{array}{l}\text { Formation of phenol, o-cresol, } m-, p \text { - } \\
\text { cresol, xylenols, catechol (between } \\
0.001 \text { and } 0.085 \% \text { at all temperatures } \\
\text { tested) } \\
\text { Palmitic acid: } \\
0.334 \%\left(350{ }^{\circ} \mathrm{C}\right), 0.355 \%\left(450{ }^{\circ} \mathrm{C}\right) \text {, } \\
0.184 \%\left(550{ }^{\circ} \mathrm{C}\right), 0.052 \%\left(650^{\circ} \mathrm{C}\right) \\
\text { Stearic acid: } \\
0.538 \%\left(350{ }^{\circ} \mathrm{C}\right), 0.593 \%\left(450{ }^{\circ} \mathrm{C}\right) \text {, } \\
0.309 \%\left(550^{\circ} \mathrm{C}\right), 0.086 \%\left(650^{\circ} \mathrm{C}\right)\end{array}$ & $\begin{array}{l}\text { Schlotzhauer, } \\
1978\end{array}$ \\
\hline Collagen & $\begin{array}{l}\text { Pyrolysis of } 0.5-2.0 \mathrm{~g} \text { at } \\
800-860{ }^{\circ} \mathrm{C} \text { in an } \mathrm{N}_{2} \text {-flow }\end{array}$ & not applicable & $\begin{array}{l}\text { Principle products: pyridine, 2- } \\
\text { methylpyridine, 3-/4-methylpyridine, } \\
\text { pyrrole, phenol } \\
\text { Other products: 3-vinylpyridine, aniline, } \\
\text { quinoline, isoquinoline, benzene, } \\
\text { toluene, styrene, xylene, benzonitrile, } \\
\text { indene, o-tolunitrile, } m \text {-tolunitrile, } \\
\text { naphthalene, indole, } m \text {-, } p \text {-cresol, } \\
\text { ethylphenol, xylenol }\end{array}$ & $\begin{array}{l}\text { Schmeltz et al., } \\
1972\end{array}$ \\
\hline Collagen & $\begin{array}{l}\text { About } 1 \mathrm{~g} \text { of material was } \\
\text { heated to } 840 \pm 10{ }^{\circ} \mathrm{C} \text { in a } \\
\text { stream of nitrogen }(60 \mathrm{~mL} / \mathrm{min})\end{array}$ & n.d. & $\begin{array}{l}\text { Selected pyrolysis products: } \\
\text { benzene } 0.6 \% \text {, indole } 7.2 \% \text {, pyridine } \\
26.5 \% \text {, quinone } 7.6 \% \text {, phenol } 19.6 \%\end{array}$ & $\begin{array}{l}\text { Higman et al., } \\
1970\end{array}$ \\
\hline Cyclodextrins & $\begin{array}{l}\text { Cyclodextrins mixed with } 3 \\
\text { times its weight of Celite and } \\
\text { pyrolysed at } 750{ }^{\circ} \mathrm{C} \text {, for } 1 \mathrm{~min} \\
\text { in a stream of nitrogen } \\
(15-25 \mathrm{~mL} / \mathrm{min})\end{array}$ & n.d. & $\begin{array}{l}\text { Identified: methanol, ethylene, } \\
\text { acetaldehyde, acetone, acrolein, 3- } \\
\text { methyl-1-butene, furan, 2-methylfuran } \\
\text { Provisionally identified: methane, } \\
\text { ethane, propane, propene, } \\
\text { propionaldehyde, 1-butene, 2- } \\
\text { methylbutene-1, n-butane, butadiene, } \\
\text { 2,3-butanedione, 2-butanone, pentane, } \\
\text { 1-hexane }\end{array}$ & $\begin{array}{l}\text { Robb et al., } \\
1964\end{array}$ \\
\hline $\begin{array}{l}\text { Cyclopentadiene (as } \\
\text { Diels-Alder adduct } \\
\text { with acetylene- } \\
\text { dicarboxylic acid) }\end{array}$ & $\begin{array}{l}\text { Adduct mixed with } 3 \text { times its } \\
\text { weight of Celite and pyrolysed } \\
1 \mathrm{~min} \text { at } 750^{\circ} \mathrm{C} \text { in a stream of } \\
\text { nitrogen }(15-25 \mathrm{~mL} / \mathrm{min})\end{array}$ & cyclopentadiene $26 \%$ & n.d. & $\begin{array}{l}\text { Robb et al., } \\
1964\end{array}$ \\
\hline $\begin{array}{l}\text { Deertongue leaf } \\
\text { powder }\end{array}$ & $\begin{array}{l}5.2 \mathrm{~g} \text { (in } 1 \mathrm{~g} \text { portions) were } \\
\text { pyrolysed at } 840 \pm 10^{\circ} \mathrm{C} \text { under } \\
\text { nitrogen }\end{array}$ & not applicable & $\begin{array}{l}\text { Neutrals }(0.22 \mathrm{~g}) \text { : benzene } 7.0 \% \text {, } \\
\text { toluene } 15.4 \% \text {, styrene } 1.0 \% \text {, } \\
\text { benzofuran } 8.7 \% \text {, indene } 6.1 \% \text {, } \\
\text { naphthalene } 4.4 \% \text {, methylnaphthalene } \\
13.5 \% \text {, coumarin/acenaphthene } 8.0 \% \text {, } \\
\text { phenanthrene/anthracene } 2.4 \% \text {, } \\
\text { methylphenanthrene/anthracene } 5.6 \% \\
\text { Nitrogen bases }(0.02 \mathrm{~g}) \text { : pyridine } 3.4 \% \text {, } \\
\text { picoline } 6.3 \% \text {, dimethylpyridine } 4.9 \% \text {, } \\
\text { vinylpyridine } 5.1 \% \text {, indole } 1.3 \% \text {, } \\
\text { quinoline } 8.1 \% \text {, isoquinoline } 3.5 \% \text {, } \\
\text { methylquinoline } 6.9 \% \text {, carbazole } 1.0 \% \text {, } \\
\text { benzoquinoline } 1.1 \% \text {, } \\
\text { methylbenzoquinoline } 2.1 \% \\
\text { Phenols }(0.005 \mathrm{~g}) \text { : phenol } 15.5 \% \text {, cresol } \\
20.2 \% \text {, xylenol } 3.6 \% \text {, coumarin } 1.3 \% \text {, } \\
\text { naphthol } 2.8 \%\end{array}$ & $\begin{array}{l}\text { Higman et al., } \\
1974\end{array}$ \\
\hline
\end{tabular}


Table 5 (contd.)

\begin{tabular}{|c|c|c|c|c|}
\hline Ingredient(s) & Pyrolysis conditions & Transfer (\%) & Pyrolysis products & Reference(s) \\
\hline $\begin{array}{l}\text { endo- } \\
\text { Dehydronorborneol }\end{array}$ & $\begin{array}{l}\text { Adduct mixed with } 3 \text { times its } \\
\text { weight of Celite and pyrolysed } \\
1 \mathrm{~min} \text { at } 750^{\circ} \mathrm{C} \text { in a stream of } \\
\text { nitrogen }(15-25 \mathrm{~mL} / \mathrm{min})\end{array}$ & cyclopentadiene $17 \%$ & acetaldehyde $12 \%$, benzene $1 \%$ & $\begin{array}{l}\text { Robb et al., } \\
1964\end{array}$ \\
\hline Dextrin & $\begin{array}{l}5-10 \mathrm{mg} \text { dextrin were heated } \\
\text { for } 10 \mathrm{~s} \text { at } 700{ }^{\circ} \mathrm{C} \text { under an } \mathrm{N}_{2}- \\
\text { flow }(15 \mathrm{~mL} / \mathrm{min})\end{array}$ & n.d. & $\begin{array}{l}\text { 3-methylfuran } 19.9 \% \text {, 2-furaldehyde } \\
16.7 \%, 1,3 \text { cyclopentanedione } 6.2 \% \text {, } \\
\text { 2-furanmethanol } 3.8 \% \text {, cyclopentanone } \\
2.8 \% \text {, propionic acid methyl ester } 2.5 \% \text {, } \\
\text { 2-hydroxy-3-methyl-2-cyclopenten-1-one } \\
2.1 \% \text {, 2-methyl-2-cyclopenten-1-one } \\
2.0 \%, 2,4 \text {-pentanedione } 1.8 \%, 5 \text {-methyl- } \\
\text { 2-furaldehyde } 1.7 \%\end{array}$ & $\begin{array}{l}\text { Schlotzhauer et } \\
\text { al., } 1985\end{array}$ \\
\hline $\begin{array}{l}\text { Dialdehyde starch } \\
\text { (Oxystarch) }\end{array}$ & $\begin{array}{l}30 \mathrm{~g} \text { (in } 0.5 \mathrm{~g} \text { portions) of the } \\
\text { additive were heated at } \\
700^{\circ} \mathrm{C} \text { for up to } 30 \text { min (until } \\
\text { the organic material has } \\
\text { disappeared) in an air flow of } \\
1.5 \mathrm{~L} / \mathrm{min}\end{array}$ & n.d. & $\begin{array}{l}P A H: \text { pentacene, } \mathrm{B}[\mathrm{a}] \mathrm{P} 23.5 \mu \mathrm{g} / 100 \mathrm{~g}, \\
\text { fluoranthene, phenanthrene, terphenyl } \\
\text { Quinones: anthraquinone } \\
\text { Phenols: } m \text {-cresol } \\
\text { Others: aliphatic hydrocarbons, } \\
\text { formaldehyde, acetic acid, water }\end{array}$ & Kröller, 1966a \\
\hline Dibutyl phthalate & $\begin{array}{l}30 \mathrm{~g} \text { (in portions) of the } \\
\text { additive were heated at } 700{ }^{\circ} \mathrm{C} \\
\text { until the organic material has } \\
\text { disappeared in an air flow of } \\
1.5 \mathrm{~L} / \mathrm{min}\end{array}$ & n.d. & $\begin{array}{l}P A H: 1,2,5,6 \text {-dibenzanthracene, } \\
\text { naphthacene, pyrene, anthracene, } \\
\text { B[a]P } 12 \mu \mathrm{\mu g} / 100 \mathrm{~g} \\
\text { Quinones: anthraquinone } \\
\text { Phenols: phenol, } m \text {-xylenol } \\
\text { Others: phthalic acid anhydride, } \\
\text { n-butanol, aliphatic hydrocarbons, } \mathrm{CO}_{2}\end{array}$ & Kröller, 1968 \\
\hline Diethylene glycol & $\begin{array}{l}2 \mathrm{~mL} \text { of the glycol on silica } \\
\text { were heated at } 700^{\circ} \mathrm{C} \text { for } \\
\text { about } 10 \mathrm{~min} \text { (until the glycol } \\
\text { has disappeared) in an air flow } \\
\text { of } 1.5 \mathrm{~L} / \mathrm{min}\end{array}$ & $77 \%$ & $\begin{array}{l}\text { PAH: fluoranthene, naphthacene, } \mathrm{B}[\mathrm{a}] \mathrm{P} \\
\sim 1.5 \mathrm{\mu g} / 100 \mathrm{~g} \\
\text { Quinones: anthraquinone } \\
\text { Phenols: none } \\
\text { Others: aldehydes }\end{array}$ & Kröller, 1964b \\
\hline \multirow[t]{2}{*}{ Docosane } & $\begin{array}{l}\text { Condition 3: air, } 100 \mathrm{~mL} / \mathrm{min} \\
777^{\circ} \mathrm{C} \text { (furnace 1) } \\
562^{\circ} \mathrm{C} \text { (furnace 2) } \\
685^{\circ} \mathrm{C} \text { (mobile furnace) }\end{array}$ & n.d. & $\begin{array}{l}\text { Condition 3: } 0.022 \% \text { phenol } \\
\text { Condition } 4: 0 \% \text { phenol }\end{array}$ & Bell et al., 1966 \\
\hline & $\begin{array}{l}\text { Condition 4: } \mathrm{N}_{2}, 100 \mathrm{~mL} / \mathrm{min} \\
315^{\circ} \mathrm{C} \text { (furnace 1) } \\
320{ }^{\circ} \mathrm{C} \text { (furnace 2) } \\
685{ }^{\circ} \mathrm{C} \text { (mobile furnace) }\end{array}$ & & & \\
\hline $\begin{array}{l}\text { Ethyl 2-(2-butyl)-3- } \\
\text { hydroxy-3-methyl-3- } \\
\text { phenylpropionate }\end{array}$ & $\begin{array}{l}10 \mathrm{mg} \text { of the ester were } \\
\text { pyrolysed in an open tube at } \\
250^{\circ} \mathrm{C} \text { for } 5 \mathrm{~min}\end{array}$ & n.d. & $\begin{array}{l}>90 \% \text { decomposition to a } 1: 1 \text { mixture of } \\
\text { acetophenone + ethyl valerate }\end{array}$ & $\begin{array}{l}\text { Grubbs and } \\
\text { Houminer, } 1982 \\
\text { (P) }\end{array}$ \\
\hline $\begin{array}{l}\text { Ethyl vanillyl-D- } \\
\text { glucoside }\end{array}$ & $\begin{array}{l}\text { Pyrolysis in a thermal analyzer } \\
\text { in the thermogravimetric mode } \\
\left(50-900^{\circ} \mathrm{C}\right)\end{array}$ & $\begin{array}{l}\text { mass loss of } 66.5 \% \text { at } \\
226{ }^{\circ} \mathrm{C} \text { is consistent } \\
\text { with levogclucosan } \\
\text { formation and ethyl } \\
\text { vanillin release }\end{array}$ & n.d. & $\begin{array}{l}\text { Herron, } 1988 \\
(P)\end{array}$ \\
\hline $\begin{array}{l}\text { Flavour mixture } \\
\text { (brown, aromatic } \\
\text { taste) }\end{array}$ & $\begin{array}{l}50 \mathrm{~g} \text { (in portions) of the flavour } \\
\text { material on silica were heated } \\
\text { at } 700^{\circ} \mathrm{C} \text { until the organic } \\
\text { material has disappeared in an } \\
\text { air flow of } 1.5 \mathrm{~L} / \mathrm{min}\end{array}$ & n.d. & $\begin{array}{l}P A H: \mathrm{B}[a] \mathrm{P} 1 \mu \mathrm{g} / 100 \mathrm{~g} \text {, fluoranthene, } \\
\text { phenanthrene } \\
\text { Quinones: anthraquinone } \\
\text { Phenols: o-cresol, pyrogallol } \\
\text { Others: aliphatic hydrocarbons, } \\
\text { formaldehyde, vanillin, essential oils }\end{array}$ & Kröller, 1967 \\
\hline Fructose & $\begin{array}{l}5 \mathrm{~g} \text { of material was rapidly } \\
\text { heated to } 650^{\circ} \mathrm{C} \text { in a stream } \\
\text { of nitrogen for } 1 \mathrm{~h}\end{array}$ & n.d. & $\begin{array}{l}\text { PAHs (out of } 11 \text { investigated): } \\
\text { pyrene } 35 \mu \mathrm{g} / 100 \mathrm{~g}, \mathrm{~B}[\mathrm{a}] \mathrm{P} 33 \mu \mathrm{g} / 100 \mathrm{~g}\end{array}$ & $\begin{array}{l}\text { Gilbert and } \\
\text { Lindsey, } 1957\end{array}$ \\
\hline Fructose & $\begin{array}{l}\text { About } 1 \mathrm{~g} \text { of material was } \\
\text { heated to } 840 \pm 10^{\circ} \mathrm{C} \text { in a } \\
\text { stream of nitrogen }(60 \mathrm{~mL} / \mathrm{min})\end{array}$ & n.d. & $\begin{array}{l}\text { Selected pyrolysis products: } \\
\text { benzene } 27.4 \% \text {, furfural } 12.5 \% \text {, pyrene } \\
0.13 \% \text {, phenol } 77.9 \% \text {, B[a]P } 98.4 \mu \mathrm{kg} / \mathrm{g}\end{array}$ & $\begin{array}{l}\text { Higman et al., } \\
1970\end{array}$ \\
\hline Fructose & $\begin{array}{l}25 \mathrm{~g} \text { material were pyrolysed } \\
\text { at } 800^{\circ} \mathrm{C} \text { in the following way: } \\
12 \text { cycles consisting of an } \\
\text { "operative time" ( } 20 \mathrm{~s} \text { in a gas } \\
\text { flow of nitrogen and air } \\
{[1 \mathrm{~L} / \mathrm{min} \text { for each gas], }} \\
\text { simulating a puff) followed by } \\
\text { an "inoperative time" ( } 40 \mathrm{~s} \text { in a } \\
\text { flow of nitrogen, simulating the } \\
\text { puff interval) }\end{array}$ & n.d. & $\begin{array}{l}\text { Major pyrolysis products (catechols): } \\
\text { furfural } 38.6 \mathrm{mg} / \mathrm{g}, \\
\text { 5-hydroxymethylfurfural } 19.5 \mathrm{mg} / \mathrm{g}\end{array}$ & $\begin{array}{l}\text { Schlotzhauer et } \\
\text { al., } 1982\end{array}$ \\
\hline $\begin{array}{l}\text { Furan (as Diels-Alder } \\
\text { adduct with } \\
\text { acetylene- } \\
\text { dicarboxylic acid) }\end{array}$ & $\begin{array}{l}\text { Adduct mixed with } 3 \text { times its } \\
\text { weight of Celite and pyrolysed } \\
1 \text { min at } 750^{\circ} \mathrm{C} \text { in a stream of } \\
\text { nitrogen }(15-25 \mathrm{~mL} / \mathrm{min})\end{array}$ & furan $33 \%$ & n.d. & $\begin{array}{l}\text { Robb et al., } \\
1964\end{array}$ \\
\hline
\end{tabular}


Table 5 (contd.)

\begin{tabular}{|c|c|c|c|c|}
\hline Ingredient(s) & Pyrolysis conditions & Transfer (\%) & Pyrolysis products & Reference(s) \\
\hline Glucose & $\begin{array}{l}\text { Pyrolysis at } 700{ }^{\circ} \mathrm{C} \text { in an } \mathrm{N}_{2}^{-} \\
\text {flow }(30 \mathrm{~mL} / \mathrm{min})\end{array}$ & n.d. & $\begin{array}{l}\text { Formation of phenols }(\mathrm{mg} / 100 \mathrm{~g}) \text { : } \\
\text { phenol } 27, o \text {-cresol } 7, m \text {-, } p \text {-cresol } 5\end{array}$ & $\begin{array}{l}\text { Schlotzhauer } \\
\text { et al., } 1967\end{array}$ \\
\hline \multirow[t]{4}{*}{ Glucose } & $\begin{array}{l}\text { Condition 1: air, } 100 \mathrm{~mL} / \mathrm{min} \\
314^{\circ} \mathrm{C} \text { (furnace 1) } \\
320^{\circ} \mathrm{C} \text { (furnace 2) } \\
685^{\circ} \mathrm{C} \text { (mobile furnace) }\end{array}$ & n.d. & $\begin{array}{l}\text { Condition } 1: 0.050 \% \text { phenol } \\
\text { Condition } 2: 0.061 \% \text { phenol } \\
\text { Condition } 3: 0.077 \% \text { phenol } \\
\text { Condition } 4: 0.090 \% \text { phenol }\end{array}$ & Bell et al., 1966 \\
\hline & $\begin{array}{l}\text { Condition 2: air, } 100 \mathrm{~mL} / \mathrm{min} \\
520^{\circ} \mathrm{C} \text { (furnace 1) } \\
530{ }^{\circ} \mathrm{C} \text { (furnace 2) } \\
685^{\circ} \mathrm{C} \text { (mobile furnace) }\end{array}$ & & & \\
\hline & $\begin{array}{l}\text { Condition 3: air, } 100 \mathrm{~mL} / \mathrm{min} \\
777^{\circ} \mathrm{C} \text { (furnace 1) } \\
562{ }^{\circ} \mathrm{C} \text { (furnace 2) } \\
685^{\circ} \mathrm{C} \text { (mobile furnace) }\end{array}$ & & & \\
\hline & $\begin{array}{l}\text { Condition 4: } \mathrm{N}_{2}, 100 \mathrm{~mL} / \mathrm{min} \\
315^{\circ} \mathrm{C} \text { (furnace 1) } \\
320^{\circ} \mathrm{C} \text { (furnace 2) } \\
685^{\circ} \mathrm{C} \text { (mobile furnace) }\end{array}$ & & & \\
\hline Glucose & $\begin{array}{l}\text { Pyrolysis of glucose at } \\
200-500{ }^{\circ} \mathrm{C} \text { (reported here are } \\
\text { only results obtained at } \\
450-500{ }^{\circ} \mathrm{C} \text { ) }\end{array}$ & n.d. & $\begin{array}{l}\text { Compostion of gases: } \\
\mathrm{CO}_{2}: 9.27 \%, \mathrm{CO}: 35.22 \%, \mathrm{C}_{\mathrm{n}} \mathrm{H}_{2 \mathrm{n}}: 0.73 \% \text {, } \\
\mathrm{CH}_{4}: 43.55 \%, \mathrm{H}_{2}: 11.91 \%\end{array}$ & Tomasik, 1989 \\
\hline Glucose & $\begin{array}{l}5 \mathrm{~g} \text { of material was rapidly } \\
\text { heated to } 650^{\circ} \mathrm{C} \text { in a stream of } \\
\text { nitrogen for } 1 \mathrm{~h}\end{array}$ & n.d. & $\begin{array}{l}\text { PAHs (out of } 11 \text { investigated): } \\
\text { pyrene: } 66 \mu \mathrm{g} / 100 \mathrm{~g}, \mathrm{~B}[\mathrm{a}] \mathrm{P}: 29 \mu \mathrm{g} / 100 \mathrm{~g}\end{array}$ & $\begin{array}{l}\text { Gilbert and } \\
\text { Lindsey, } 1957\end{array}$ \\
\hline Glucose & $\begin{array}{l}\text { About } 1 \mathrm{~g} \text { of material was } \\
\text { heated to } 840 \pm 10^{\circ} \mathrm{C} \text { in a } \\
\text { stream of nitrogen }(60 \mathrm{~mL} / \mathrm{min})\end{array}$ & n.d. & $\begin{array}{l}\text { Selected pyrolysis products: } \\
\text { benzene } 17.6 \% \text {, pyrene -, furfural } \\
7.4 \% \text {, phenol } 59.6 \% \text {, B[a]P } 47.5 \mu \mathrm{g} / \mathrm{g}\end{array}$ & $\begin{array}{l}\text { Higman et al., } \\
1970\end{array}$ \\
\hline Glucose & $\begin{array}{l}15-30 \mathrm{mg} \text { of material was } \\
\text { heated to } 250,350,500^{\circ} \mathrm{C} \text { for } \\
5,1 \text { and } 1 \mathrm{~min} \text {, respectively in } \\
\text { a stream of helium } \\
(60 \mathrm{~mL} / \mathrm{min})\end{array}$ & n.d. & $\begin{array}{l}\text { Relative amounts (cm peak height for } \\
10 \mathrm{mg} \text { ) of selected pyrolysis products at } \\
500^{\circ} \mathrm{C} \text { : } \\
\text { acetaldehyde } 5.6 \text {, propionaldehyde } 1.5 \text {, } \\
\text { acrolein } 4.3 \text {, furfural } 3.3\end{array}$ & Kato, 1967 \\
\hline Glucuronic acid & $\begin{array}{l}\text { Pyrolysis at } 700{ }^{\circ} \mathrm{C} \text { in an } \mathrm{N}_{2^{-}} \\
\text {flow }(30 \mathrm{~mL} / \mathrm{min})\end{array}$ & not applicable & $\begin{array}{l}\text { Formation of phenols }(\mathrm{mg} / 100 \mathrm{~g}) \\
\text { phenol } 18, \mathrm{o} \text {-cresol } 4, \mathrm{~m} \text {-, } p \text {-cresol } 5\end{array}$ & $\begin{array}{l}\text { Schlotzhauer } \\
\text { et al., } 1967\end{array}$ \\
\hline Glycerol & $\begin{array}{l}\text { Pyrolysis of glycerol in a steam } \\
\text { with argon as purge gas at } \\
650-700{ }^{\circ} \mathrm{C}\end{array}$ & $\begin{array}{l}650{ }^{\circ} \mathrm{C}: 82.4 \% \\
675{ }^{\circ} \mathrm{C}: 66 \% \\
700{ }^{\circ} \mathrm{C}: 75 \%\end{array}$ & $\begin{array}{l}\text { Mol- } \% \text { of converted glycerol at } \\
650 / 675 / 700{ }^{\circ} \mathrm{C} \\
\text { acrolein: } 52 / 39 / 34 \\
\text { acetaldehyde: } 48 / 38 / 42 \\
\mathrm{CO}-1 / 35 / 58 \\
\text { hydrogen: }-/ 29 / 44 \\
\text { ethylene: }-10 / 17 \\
\text { methane: }-/ 5 / 11 \\
\text { ethane: }-1 / 2 \\
\mathrm{CO}_{2}:-10.3 / 1\end{array}$ & $\begin{array}{l}\text { Stein and Antal, } \\
1983\end{array}$ \\
\hline Glycerol & $\begin{array}{l}\text { Pyrolysis of } 100 \mathrm{~g} \text { of the } \\
\text { polyalcohol was investigated at } \\
\text { various temperatures }\end{array}$ & not applicable & $\begin{array}{l}\text { Principal compounds at } 600{ }^{\circ} \mathrm{C} \\
\text { acetaldehyde } 10-15 \mathrm{~g} / 100 \mathrm{~g} \text {, acrolein } \\
<0.5 \mathrm{~g} / 100 \mathrm{~g}\end{array}$ & $\begin{array}{l}\text { Doihara et al., } \\
1964\end{array}$ \\
\hline Glycerol & $\begin{array}{l}30 \mathrm{~g} \text { (in portions) of the } \\
\text { humectant on silica were } \\
\text { heated at } 700{ }^{\circ} \mathrm{C} \text { until the } \\
\text { organic material has } \\
\text { disappeared in an air flow of } \\
1.5 \mathrm{~L} / \mathrm{min}\end{array}$ & $60 \%$ & $\begin{array}{l}\text { PAH: tribenzopyrene, pentacene, } \\
\text { coronene, } \mathrm{B}[\mathrm{a}] \mathrm{P} 6 \mu \mathrm{g} / 100 \mathrm{~g}, \\
\text { fluoranthene, anthracene } \\
\text { Quinones: anthraquinone } \\
\text { Phenols: phenol } \\
\text { Others: aldehyde(s), carboxylic acids, } \\
\text { aliphatic hydrocarbons, water, } \mathrm{CO}_{2}\end{array}$ & Kröller, 1965a \\
\hline Glycine & $\begin{array}{l}\text { Pyrolysis of } 0.5-2.0 \mathrm{~g} \text { at } \\
800-860^{\circ} \mathrm{C} \text { in an } \mathrm{N}_{2} \text {-flow }\end{array}$ & not applicable & $\begin{array}{l}\text { Pyridine, 2-methylpyridine, pyrrole, } \\
\text { toluene, indene }\end{array}$ & $\begin{array}{l}\text { Schmeltz et al., } \\
1972\end{array}$ \\
\hline Glycyrrhizic acid & $\begin{array}{l}2 \text { mg pyrolysed in a } \\
\text { Curie-point pyrolyser } 770{ }^{\circ} \mathrm{C} \\
\text { for } 12.5 \mathrm{~s} \text { under nitrogen } \\
(40 \mathrm{~mL} / \mathrm{min})\end{array}$ & n.d. & $\begin{array}{l}18 \text { Compounds identified, major } \\
\text { components: } \\
\text { 2,5-dimethylfuran, } 2(3 H) \text {-furanone, } \\
\text { 3,4-dimethyl-4-ethyl-2,5-cyclohexadien- } \\
\text { 1-ol, 3,4-dimethyl-4-ethyl-2,5-cyclo- } \\
\text { hexadien-1-one, pentamethyloctahydro- } \\
\text { naphthalene }\end{array}$ & $\begin{array}{l}\text { Yongkuan and } \\
\text { Wangyun, } 1995\end{array}$ \\
\hline
\end{tabular}


Table 5 (contd.)

\begin{tabular}{|c|c|c|c|c|}
\hline Ingredient(s) & Pyrolysis conditions & Transfer (\%) & Pyrolysis products & Reference(s) \\
\hline \multirow[t]{2}{*}{$\begin{array}{l}\text { Glycyrrhizic acid } \\
\text { disodium salt }\end{array}$} & $\begin{array}{l}2 \mathrm{mg} \text { pyrolysed in a } \\
\text { Curie-point pyrolyser } \\
770{ }^{\circ} \mathrm{C} \text { for } 12.5 \mathrm{~s} \text { under } \\
\text { nitrogen }(40 \mathrm{~mL} / \mathrm{min})\end{array}$ & n.d. & $\begin{array}{l}38 \text { Compounds identified, major } \\
\text { components: } \\
\text { 2,5-dimethylfuran, } 2(3 H) \text {-furanone, } \\
\text { pentamethyloctahydronaphthalene, } \\
\text { 3,4-dimethyl-4-ethyl-2,5-cyclohexadien- } \\
\text { 1-one, 3,4-dimethyl-4-ethyl-2,5- } \\
\text { cyclohexadien-1-ol }\end{array}$ & $\begin{array}{l}\text { Yongkuan and } \\
\text { Wangyun, } 1995\end{array}$ \\
\hline & & & $\begin{array}{l}\text { disodium glycyrrhetate is optimum } \\
\text { Asweetener@ }\end{array}$ & \\
\hline $\begin{array}{l}\text { Glycyrrhizic acid } \\
\text { monosodium salt }\end{array}$ & $\begin{array}{l}2 \mathrm{mg} \text { pyrolysed in a } \\
\text { Curie-point pyrolyser } \\
770{ }^{\circ} \mathrm{C} \text { for } 12.5 \mathrm{~s} \text { under } \\
\text { nitrogen }(40 \mathrm{~mL} / \mathrm{min})\end{array}$ & n.d. & $\begin{array}{l}18 \text { Compounds identified, major } \\
\text { components: } \\
\text { pentamethyldecahydronaphthalene, } \\
\text { 3,4-dimethyl-4-ethyl-2,5-cyclohexadien- } \\
\text { 1-one, 2,5-cylclohexadien-1-one, } 2(3 H) \text { - } \\
\text { furanone, 2,5-dimethylfuran, } \\
\text { tetramethylhexahydronaphthalene }\end{array}$ & $\begin{array}{l}\text { Yongkuan and } \\
\text { Wangyun, } 1995\end{array}$ \\
\hline $\begin{array}{l}\text { Glycyrrhizic acid } \\
\text { trisodium salt }\end{array}$ & $\begin{array}{l}2 \mathrm{mg} \text { pyrolysed in a } \\
\text { Curie-point pyrolyser } \\
770^{\circ} \mathrm{C} \text { for } 12.5 \mathrm{~s} \text { under } \\
\text { nitrogen }(40 \mathrm{~mL} / \mathrm{min})\end{array}$ & n.d. & $\begin{array}{l}36 \text { Compounds identified, major } \\
\text { components: } \\
\text { pentamethyloctahydronaphthalene, } \\
\text { 3,4-dimethyl-4-ethyl-2,5-cyclohexadien- } \\
\text { 1-one, 3,4-dimethyl-4-ethyl-2,5- } \\
\text { cyclohexadien-1-ol, 1,4,6- } \\
\text { trimethyldihydronaphthalene, } \\
\text { trimethyltetrahydronaphthalene }\end{array}$ & $\begin{array}{l}\text { Yongkuan and } \\
\text { Wangyun, } 1995\end{array}$ \\
\hline Glyoxal & $\begin{array}{l}30 \mathrm{~g} \text { (in portions) of the } \\
\text { additive on silica were } \\
\text { heated at } 700{ }^{\circ} \mathrm{C} \text { until the } \\
\text { organic material has } \\
\text { disappeared in an air flow of } \\
1.5 \mathrm{~L} / \mathrm{min}\end{array}$ & n.d. & $\begin{array}{l}P A H: B[a] P 3.4 \mu \mathrm{g} / 100 \mathrm{~g} \text {, fluoranthene, } \\
\text { 2,3-benzofluorene } \\
\text { Quinones: none } \\
\text { Phenols: o-cresol } \\
\text { Others: aliphatic hydrocarbons, } \\
\text { carboxylic acids }\end{array}$ & Kröller, 1970 \\
\hline Guar gum & $\begin{array}{l}30 \mathrm{~g} \text { (in } 0.5-1.0 \mathrm{~g} \text { portions) } \\
\text { of the additive were heated } \\
\text { at } 700{ }^{\circ} \mathrm{C} \text { for about } 30 \mathrm{~min} \\
\text { (until the organic material } \\
\text { has disappeared) in an air } \\
\text { flow of } 1.5 \mathrm{~L} / \mathrm{min}\end{array}$ & not applicable & $\begin{array}{l}\text { PAH: pentacene, phenanthrene, } \\
\text { fluoranthene, coronene, } 1,2,5,6- \\
\text { dibenzanthracene, } \mathrm{B}[\mathrm{a}] \mathrm{P} 30 \mu \mathrm{g} / 100 \mathrm{~g}, \\
\text { terphenyl } \\
\text { Quinones: acenaphthenequinone, } \\
\text { phenanthrenequinone, anthraquinone } \\
\text { Phenols: phenol, } m \text {-cresol, gallic acid, } \\
\text { catechol } \\
\text { Others: aliphatic hydrocarbons, water, } \\
\mathrm{CO}_{2} \text {, formic acid, acetic acid }\end{array}$ & Kröller, 1965b \\
\hline Guar gum & $\begin{array}{l}10-15 \mathrm{mg} \text { of the additive } \\
\text { were pyrolysed at } 600^{\circ} \mathrm{C} \\
\text { for } 20 \mathrm{~s} \text { (ramp } 10^{\circ} \mathrm{C} / \mathrm{ms} \text { ) }\end{array}$ & not applicable & $\begin{array}{l}\text { Volatile pyrolytic products: } \\
\text { acetoin, methyl formate, 2-methyl-2- } \\
\text { cyclopenten-1-one, 3-methylfurane, } \\
\text { furfural, acetylacetone, isomaltol, 2,4- } \\
\text { hexadienal, 5-methyl-2-furfural, 2- } \\
\text { furylmethylketone, 2-furanmethanol, } \\
\text { cyclooctane, furanecarboxylic acid } \\
\text { derivative, hydroxyfuranone isomer, } \\
\text { methyl-3-furanecarboxylate, 3-methyl-2- } \\
\text { hydroxycyclopentenone, phenol, benzyl } \\
\text { alcohol derivative, 4-methyl-4-hepten-3- } \\
\text { one, acetic acid, propionic acid, 2- } \\
\text { methylpropionic acid, butyric acid, 3- } \\
\text { methylbutyric acid, pentanoic acid, } \\
\text { hexanoic acid, octanoic acid, nonanoic } \\
\text { acid, decanoic acid }\end{array}$ & $\begin{array}{l}\text { Sjöberg and } \\
\text { Pyysalo, } 1985\end{array}$ \\
\hline Guar, oxygenated & $\begin{array}{l}30 \mathrm{~g} \text { (in portions) of the } \\
\text { additive were heated at } \\
700^{\circ} \mathrm{C} \text { until the organic } \\
\text { material has disappeared in an } \\
\text { air flow of } 1.5 \mathrm{~L} / \mathrm{min}\end{array}$ & n.d. & $\begin{array}{l}P A H: \mathrm{B}[\mathrm{a}] \mathrm{P} 15 \mu \mathrm{g} / 100 \mathrm{~g}, \\
\text { hexahydropyrene, fluoranthene } \\
\text { Quinones: none } \\
\text { Phenols: } m \text {-cresol, catechol, pyrogallol } \\
\text { Others: aldehydes, acetic acid, aliphatic } \\
\text { hydrocarbons, water }\end{array}$ & Kröller, 1968 \\
\hline Gummi arabicum & $\begin{array}{l}30 \mathrm{~g} \text { (in } 0.5-1.0 \mathrm{~g} \text { portions) of } \\
\text { the additive were heated at } \\
700{ }^{\circ} \mathrm{C} \text { for about } 30 \text { min (until } \\
\text { the organic material has } \\
\text { disappeared) in an air flow of } \\
1.5 \mathrm{~L} / \mathrm{min}\end{array}$ & not applicable & $\begin{array}{l}P A H \text { : pentacene, } 1,2,5,6 \text {-dibenz- } \\
\text { anthracene, coronene, B[a]P } \\
32 \mu \mathrm{g} / 100 \mathrm{~g} \text {, fluoranthene, terphenyl, } \\
\text { phenanthrene, dihydropyrene } \\
\text { Quinones: phenanthrenequinone, } \\
\text { anthraquinone } \\
\text { Phenols: phenol, } m \text {-cresol, gallic acid } \\
\text { Others: aliphatic hydrocarbons, water, } \\
\text { acetic acid }\end{array}$ & Kröller, 1965b \\
\hline
\end{tabular}




\begin{tabular}{|c|c|c|c|c|}
\hline Ingredient(s) & Pyrolysis conditions & Transfer (\%) & Pyrolysis products & Reference(s) \\
\hline Gummi arabicum & $\begin{array}{l}10-15 \mathrm{mg} \text { of the additive were } \\
\text { pyrolysed at } 600{ }^{\circ} \mathrm{C} \text { for } 20 \mathrm{~s} \\
\text { (ramp } 10^{\circ} \mathrm{C} / \mathrm{ms} \text { ) }\end{array}$ & not applicable & $\begin{array}{l}\text { Volatile pyrolytic products: } \\
\text { acetoin, methyl formate, furfural, 3- } \\
\text { methylfurane, isomaltol, 2-methyl-2- } \\
\text { cyclopenten-1-one, acetylacetone, 2- } \\
\text { furylmethylketone, 2,4-hexadienal, 5- } \\
\text { methyl-2-furfural, 2-furanmethanol, } \\
\text { cyclooctane, furanecarboxylic acid } \\
\text { derivative, 2-methylpropionic acid, 3- } \\
\text { methyl-2-hydroxycyclopentenone, } \\
\text { hydroxyfuranone isomer, phenol, benzyl } \\
\text { alcohol derivative, acetic acid, 4- } \\
\text { oxopentanoic acid, 4-methyl-4-hepten-3- } \\
\text { one, propionic acid, butyric acid, 3- } \\
\text { methylbutyric acid, pentanoic acid, } \\
\text { hexanoic acid, octanoic acid, nonanoic } \\
\text { acid, decanoic acid }\end{array}$ & $\begin{array}{l}\text { Sjöberg and } \\
\text { Pyysalo, } 1985\end{array}$ \\
\hline
\end{tabular}

$\begin{array}{ll}\begin{array}{l}\text { Humic acid, sodium } \\ \text { salt }\end{array} & 3 \mathrm{~g} \text { of Na-huminate were } \\ \text { heated at } 700{ }^{\circ} \mathrm{C} \text { for about } 1 \mathrm{~h} & \text { not applicable } \\ \text { in an air flow of } 1.5 \mathrm{~L} / \mathrm{min}\end{array}$

p-Hydroxybenzoic acid ethylester (PHB ester)

Hydroxyethyl cellulose $30 \mathrm{~g}$ (in $0.5 \mathrm{~g}$ portions) of the

Isoeugenol

Isoprene (as DielsAlder adduct with maleic anhydride)

Isoprene (as DielsAlder adduct with cinnamaldehyde)

Lactic acid (sodium salt)

Lactose

Lettuce leaves (from Lactuca virosa) cellulose derivate were heated at $700{ }^{\circ} \mathrm{C}$ for about $30 \mathrm{~min}$ (until the organic material has disappeared) in an air flow of $1.5 \mathrm{~L} / \mathrm{min}$
$30 \mathrm{~g}$ (in portions) of the until the organic material has disappeared in an air flow of $1.5 \mathrm{~L} / \mathrm{min}$ additive were heated at $700{ }^{\circ} \mathrm{C}$

n.d.

(n)

n.d.

Pyrolysis at $700{ }^{\circ} \mathrm{C}$ in an $\mathrm{N}_{2}-$ flow $(30 \mathrm{~mL} / \mathrm{min})$

not applicable

Adduct mixed with 3 times its weight of Celite and pyrolysed $1 \mathrm{~min}$ at $750{ }^{\circ} \mathrm{C}$ in a stream of nitrogen (15-25 mL/min)

Adduct mixed with 3 times its weight of Celite and pyrolysed $1 \mathrm{~min}$ at $750{ }^{\circ} \mathrm{C}$ in a stream of nitrogen (15-25 mL/min)

isoprene $18 \%$ cinnamaldehyde $13 \%$

$50 \mathrm{~g}$ (in 0.5 portions) of the n.d additive were heated at $700{ }^{\circ} \mathrm{C}$ (until the organic material has disappeared) in an air flow of $1.5 \mathrm{~L} / \mathrm{min}$

isoprene $37 \%$

Pyrolysis of lactose at n.d.

200-500 $\mathrm{C}$ (reported here are only results obtained at $450-500^{\circ} \mathrm{C}$ )

$30 \mathrm{~g}$ (in $2 \mathrm{~g}$ portions) of the additive were heated at $700{ }^{\circ} \mathrm{C}$ until the organic material has disappeared in an air flow of 1.5 L/min

not applicable
$\mathrm{CO}_{2}$, water, carboxylic acids, aliphatic hydrocarbons, phenols, coronene, anthraquinone, $\mathrm{B}[e] \mathrm{P}$, fluoranthene, perylene, B[a]P $27 \mu \mathrm{g} / 100 \mathrm{~g}$ salt,

1,2,5,6-dibenzanthracene $2 \mu \mathrm{g} / 100 \mathrm{~g}$, 20 -methylcholanthrene $2 \mu \mathrm{g} / 100 \mathrm{~g}, 2,3$ benzofluoranthene $2 \mu \mathrm{g} / 100 \mathrm{~g}$

$P A H:$ 1,2,5,6-dibenzanthracene, coronene, B[a]P $40 \mu \mathrm{g} / 100 \mathrm{~g}$,

fluoranthene, pyrene, 1,2,5,7-

tetrahydropyrene, anthracene

Quinones: anthraquinone

Phenols: catechol, $p$-benzylphenol, $p$ sec-butylphenol

Others: aliphatic hydrocarbons, benzoic acid, hydroxybenzoic acid, carbonyls

$P A H$ : tribenzopyrene, naphthacene, $\mathrm{B}[\mathrm{a}] \mathrm{P} 34 \mu \mathrm{g} / 100 \mathrm{~g}$, fluoranthene, anthracene

Quinones: anthraquinone

Phenols: $m$-cresol, gallic acid, guajacol Others: acetic acid, formaldehyde, water, aliphatic hydrocarbons

Formation of phenols (mg/100 g): phenol 305, o-cresol 415, $m$-, p-cresol 1450

dipentene $2 \%$

Kröller, 1963c

Kröller, 1970

Kröller, 1964a

benzene $2 \%$, toluene $1 \%$, styrene ca. Robb et al.,

$0.1 \%$, dipentene ca. 0.1\%, 2-phenyl-4- 1964 methylbenzaldehyde ca. $0.01 \%$

$P A H$ : fluoranthene, $\mathrm{B}[\mathrm{a}] \mathrm{P} 6 \mu \mathrm{g} / 100 \mathrm{~g}$, 4,5-methylenephenanthrene, coronene Quinones: none

Phenols: o-cresol

Others: aliphatic hydrocarbons,

formaldehyde, $\mathrm{CO}, \mathrm{CO}_{2}$, water

Compostion of gases:

Tomasik, 1989

carbon dioxide $6.66 \%$, carbon monoxide

$35.08 \%, \mathrm{C}_{n} \mathrm{H}_{2 \mathrm{n}} 0.85 \%$, methane $49.30 \%$, hydrogen $7.56 \%$

$P A H$ : B[a]P $5 \mu \mathrm{g} / 100 \mathrm{~g}$, fluoranthene,

Kröller, 1970

phenanthrene

Quinones: none

Phenols: $p$-cresol, pyrogallol

Others: aliphatic hydrocarbons,

carboxylic acids, carbonyls 


\begin{tabular}{|c|c|c|c|c|}
\hline Ingredient(s) & Pyrolysis conditions & Transfer (\%) & Pyrolysis products & Reference(s) \\
\hline Licorice & $\begin{array}{l}\text { Thermogravimetry/GC-MS } \\
\text { ambient to } 900^{\circ} \mathrm{C} \text { at } \\
20{ }^{\circ} \mathrm{C} / \mathrm{min}\end{array}$ & not applicable & $\begin{array}{l}\text { Decompositon, weight loss (\%): } \\
37-138{ }^{\circ} \mathrm{C}: 8 \% \\
138-380 \text { C: } 44 \% \\
382-529 \text { C: } 42 \% \\
\text { About } 60 \text { degraded compounds: acids, } \\
\text { aldehydes, esters, ethers, hydrocarbons, } \\
\text { ketones, alcohols, hydrocarbons, N- } \\
\text { containing compounds }\end{array}$ & $\begin{array}{l}\text { Chung and } \\
\text { Aldridge, } 1999 \\
\text { (A) }\end{array}$ \\
\hline Licorice & $\begin{array}{l}30 \mathrm{~g} \text { (in portions) of the } \\
\text { additive were heated at } \\
700^{\circ} \mathrm{C} \text { until the organic } \\
\text { material has disappeared } \\
\text { in an air flow of } 1.5 \mathrm{~L} / \mathrm{min}\end{array}$ & n.d. & $\begin{array}{l}\text { PAH: 1,2,5,6-dibenzanthracene, 1,2- } \\
\text { dihydropyrene, } p \text {-terphenyl, 20- } \\
\text { methylcholantrene, B[a]P } 3 \mu \mathrm{g} / 100 \mathrm{~g} \\
\text { Quinones: anthraquinone } \\
\text { Phenols: cresol, (pyrogallol) } \\
\text { Others: aliphatic hydrocarbons, } \\
\text { carboxylic acids, (furfurol) }\end{array}$ & Kröller, 1967 \\
\hline Licorice & $\begin{array}{l}\text { Dichloromethane extract of } \\
\text { licorice was water suspended } \\
\text { and steam distilled }\end{array}$ & n.d. & $\begin{array}{l}\text { Most abundant volatile components } \\
\text { were: acetol, propionic acid, } 2 \text { - } \\
\text { acetylpyrrole, 2-acetylfuran, furfuryl } \\
\text { alcohol }\end{array}$ & $\begin{array}{l}\text { Frattini et al., } \\
1977\end{array}$ \\
\hline Lignin (from wood) & $\begin{array}{l}\text { Pyrolysis at } 700{ }^{\circ} \mathrm{C} \text { in an } \mathrm{N}_{2}- \\
\text { flow }(30 \mathrm{~mL} / \mathrm{min})\end{array}$ & not applicable & $\begin{array}{l}\text { Formation of phenols }(\mathrm{mg} / 100 \mathrm{~g}) \text { : } \\
\text { phenol } 61, o \text {-cresol } 30, m \text {-, } p \text {-cresol } 114\end{array}$ & $\begin{array}{l}\text { Schlotzhauer et } \\
\text { al., } 1967\end{array}$ \\
\hline Lignin & $\begin{array}{l}5-10 \mathrm{mg} \text { lignin were heated } \\
\text { for } 10 \mathrm{~s} \text { at } 700{ }^{\circ} \mathrm{C} \text { under an } \\
\mathrm{N}_{2} \text {-flow }(15 \mathrm{~mL} / \mathrm{min})\end{array}$ & n.d. & $\begin{array}{l}m \text {-, } p \text {-cresol } 16.6 \% \text {, phenol +o-cresol } \\
12.3 \% \text {, 4-ethylphenol } 2.6 \% \text {, 2-hydroxy- } \\
\text { 3-methyl-2-cyclopenten-1-one 1.8\%, } 2 \text { - } \\
\text { ethyl-5-methylphenol } 1.3 \%, 1,4- \\
\text { dimethoxybenzene } 1.3 \%\end{array}$ & $\begin{array}{l}\text { Schlotzhauer et } \\
\text { al., } 1985\end{array}$ \\
\hline Lignin & $\begin{array}{l}5 \mathrm{~g} \text { of material was rapidly } \\
\text { heated to } 650{ }^{\circ} \mathrm{C} \text { in a stream } \\
\text { of nitrogen for } 1 \mathrm{~h}\end{array}$ & n.d. & $\begin{array}{l}\text { PAHs (out of } 11 \text { investigated): } \\
\text { pyrene } 33 \mu \mathrm{g} / 100 \mathrm{~g}, \mathrm{~B}[\mathrm{a}] \mathrm{P}: 47 \mu \mathrm{g} / 100 \mathrm{~g}\end{array}$ & $\begin{array}{l}\text { Gilbert and } \\
\text { Lindsey, } 1957\end{array}$ \\
\hline Lignin & $\begin{array}{l}25 \mathrm{~g} \text { material were pyrolysed } \\
\text { at } 800{ }^{\circ} \mathrm{C} \text { in the following way: } \\
12 \text { cycles consisting of an } \\
\text { "operative time" ( } 20 \mathrm{~s} \text { in a gas } \\
\text { flow of nitrogen and air } \\
\text { [1 L/min for each gas], } \\
\text { simulating a puff) followed by } \\
\text { an "inoperative time" ( } 40 \mathrm{~s} \text { in a } \\
\text { flow of nitrogen, simulating the } \\
\text { puff interval) }\end{array}$ & n.d. & $\begin{array}{l}\text { Major pyrolysis products (catechols): } \\
\text { catechol } 9.5 \mathrm{mg} / \mathrm{g} \text {, guaiacol } 5.2 \mathrm{mg} / \mathrm{g} \text {, } \\
\text { 4-methylcatechol } 4.3 \mathrm{mg} / \mathrm{g} \text {, } \\
\text { phenol } 2.3 \mathrm{mg} / \mathrm{g} \text {, isoeugenol } 1.1 \mathrm{mg} / \mathrm{g}\end{array}$ & $\begin{array}{l}\text { Schlotzhauer et } \\
\text { al., } 1982\end{array}$ \\
\hline $\begin{array}{l}\text { Madder lake (from } \\
\text { Rubia tinctorum), } \\
\text { major component: } \\
\text { 1,2-dioxyanthra- } \\
\text { quinone }\end{array}$ & $\begin{array}{l}3 \mathrm{~g} \text { of madder lake were } \\
\text { heated at } 700{ }^{\circ} \mathrm{C} \text { for } 1 \mathrm{~h} \text { in } \\
\text { an air flow of } 1.5 \mathrm{~L} / \mathrm{min}\end{array}$ & not applicable & $\begin{array}{l}\text { anthracene, flouranthene, } 1,4- \\
\text { dioxyanthraquinone, anthraquinone (as } \\
\text { intermediate), B[a]P } 12 \mu \mathrm{g} / 100 \mathrm{~g}\end{array}$ & Kröller, 1963d \\
\hline Malic acid & $\begin{array}{l}30 \mathrm{~g} \text { (in } 0.5 \mathrm{~g} \text { portions) of the } \\
\text { additive were heated at } \\
700{ }^{\circ} \mathrm{C} \text { (until the organic } \\
\text { material has disappeared) in } \\
\text { an air flow of } 1.5 \mathrm{~L} / \mathrm{min}\end{array}$ & n.d. & $\begin{array}{l}\text { PAH: B[a]P } 3 \mu \mathrm{g} / 100 \mathrm{~g} \text {, fluoranthene, } \\
\text { 20-methylcholanthrene } \\
\text { Quinones: anthraquinone } \\
\text { Phenols: phenol, m-cresol } \\
\text { Others: aliphatic hydrocarbons, } \\
\text { carboxylic acids, } \mathrm{CO}, \mathrm{CO}_{2} \text {, water }\end{array}$ & Kröller, 1966b \\
\hline Malic acid & $\begin{array}{l}5 \mathrm{~g} \text { of material was rapidly } \\
\text { heated at } 650^{\circ} \mathrm{C} \text { in a stream of } \\
\text { nitrogen for } 1 \mathrm{~h}\end{array}$ & n.d. & $\begin{array}{l}\text { PAHs (out of } 11 \text { investigated): } \\
\text { pyrene: } 166 \mu \mathrm{g} / 100 \mathrm{~g} \\
\mathrm{~B}[\mathrm{a}] \mathrm{P}: 35 \mu \mathrm{g} / 100 \mathrm{~g}\end{array}$ & $\begin{array}{l}\text { Gilbert and } \\
\text { Lindsey, } 1957\end{array}$ \\
\hline $\begin{array}{l}\text { Melamine- } \\
\text { formaldehyde resin }\end{array}$ & $\begin{array}{l}30 \mathrm{~g} \text { (in portions) of the } \\
\text { additive were heated at } 700{ }^{\circ} \mathrm{C} \\
\text { until the organic material has } \\
\text { disappeared in an air flow of } \\
1.5 \mathrm{~L} / \mathrm{min}\end{array}$ & n.d. & $\begin{array}{l}\text { PAH: B[a]P } 3 \mu \mathrm{g} / 100 \mathrm{~g} \text {, fluoranthene, } \\
\text { 2-methylphenanthrene } \\
\text { Quinones: none } \\
\text { Phenols: phenol, o-cresol } \\
\text { Others: carbonyls, carboxylic acids, } \\
\text { aliphatic hydrocarbons, (pyridines, } \\
\text { ammonia) }\end{array}$ & Kröller, 1968 \\
\hline $\begin{array}{l}\text { Melilot (from } \\
\text { Melilotus officinalis) }\end{array}$ & $\begin{array}{l}30 \mathrm{~g} \text { (in portions) of the } \\
\text { additive were heated at } 700{ }^{\circ} \mathrm{C} \\
\text { until the organic material has } \\
\text { disappeared in an air flow of } \\
1.5 \mathrm{~L} / \mathrm{min}\end{array}$ & not applicable & $\begin{array}{l}\text { PAH: coronene, B[a]P } 2 \mu \mathrm{g} / 100 \mathrm{~g}, \\
\text { anthracene, fluoranthene, } \\
\text { 4,5-methylenephenanthrene } \\
\text { Quinones: anthraquinone } \\
\text { Phenols: o-cresol, catechol, pyrogallol } \\
\text { Others: aliphatic hydrocarbons, } \\
\text { carboxylic acids, aldehydes }\end{array}$ & Kröller, 1967 \\
\hline Menthol & $\begin{array}{l}1 \mathrm{~g} \text { was pyrolysed for } 5 \mathrm{~min} \text { at } \\
200-700 \mathrm{C}\end{array}$ & $\begin{array}{l}200-500{ }^{\circ} \mathrm{C}: \text { no } \\
\text { degradation } \\
500-700{ }^{\circ} \mathrm{C}:>98 \% \\
\text { unchanged }\end{array}$ & n.d. & $\begin{array}{l}\text { Van Duuren et } \\
\text { al., } 1968\end{array}$ \\
\hline
\end{tabular}


Table 5 (contd.)

\begin{tabular}{|c|c|c|c|c|}
\hline Ingredient(s) & Pyrolysis conditions & Transfer (\%) & Pyrolysis products & Reference(s) \\
\hline Menthol & $\begin{array}{l}\text { Menthol was pyrolysed in a } \\
\text { stream of nitrogen }(30 \mathrm{~mL} / \mathrm{min}) \\
\text { at } 600 \text { and } 860^{\circ} \mathrm{C}\end{array}$ & $\begin{array}{l}78 \% \text { in neutral fraction } \\
\text { at } 600^{\circ} \mathrm{C} \text {, which is } 9 \\
\text { times as much } \\
\text { menthol compared to } \\
860^{\circ} \mathrm{C}\end{array}$ & $\begin{array}{l}\text { Selected pyrolysis products } \\
(600 / 860 \mathrm{C}): \\
\text { phenol } 29 / 192 \mathrm{mg} / 100 \mathrm{~g} \\
\text { benzene } 11.9 / 17.5 \% \\
\text { styrene }-112.0 \% \\
\text { naphthalene }-/ 3.7 \%\end{array}$ & $\begin{array}{l}\text { Schmeltz and } \\
\text { Schlotzhauer, } \\
1968\end{array}$ \\
\hline $\begin{array}{l}\text { Methofuran (as Diels- } \\
\text { Alder adduct with } \\
\text { maleic anhydride) }\end{array}$ & $\begin{array}{l}\text { Adduct mixed with } 3 \text { times its } \\
\text { weight of Celite and pyrolysed } \\
1 \mathrm{~min} \text { at } 750{ }^{\circ} \mathrm{C} \text { in a stream of } \\
\text { nitrogen }(15-25 \mathrm{~mL} / \mathrm{min})\end{array}$ & methofuran $30 \%$ & n.d. & $\begin{array}{l}\text { Robb et al., } \\
1964\end{array}$ \\
\hline Methyl cellulose & $\begin{array}{l}30 \mathrm{~g} \text { (in portions) of the } \\
\text { cellulose derivate were heated } \\
\text { at } 700{ }^{\circ} \mathrm{C} \text { for about } 30 \text { min } \\
\text { (until the organic material has } \\
\text { disappeared) in an air flow of } \\
1.5 \mathrm{~L} / \mathrm{min}\end{array}$ & not applicable & $\begin{array}{l}P A H: \text { picene, } \mathrm{B}[\mathrm{a}] \mathrm{P} 18 \mu \mathrm{g} / 100 \mathrm{~g}, \\
\text { fluoranthene, anthracene, } 9,10-\text { or } \\
\text { 7,12-dimethyl-1,2-benzoanthracene } \\
\text { Quinones: phenanthrenequinone, } \\
\text { anthraquinone } \\
\text { Phenols: } m \text {-cresol, pyrogallol } \\
\text { Others: aliphatic hydrocarbons, acetic } \\
\text { acid, formaldehyde, water, } \mathrm{CO}_{2}\end{array}$ & Kröller, 1964a \\
\hline Methyl starch & $\begin{array}{l}30 \mathrm{~g} \text { (in } 0.5 \mathrm{~g} \text { portions) of the } \\
\text { additive were heated at } 700{ }^{\circ} \mathrm{C} \\
\text { for up to } 30 \text { min (until the } \\
\text { organic material has } \\
\text { disappeared) in an air flow of } \\
1.5 \mathrm{~L} / \mathrm{min}\end{array}$ & not applicable & $\begin{array}{l}P A H \text { : picene, B[a]P } 16 \mu \mathrm{g} / 100 \mathrm{~g}, \\
\text { fluoranthene, anthracene } \\
\text { Quinones: phenanthrenequinone, } \\
\text { toluolquinone, anthraquinone } \\
\text { Phenols: phenol, } m \text {-cresol, pyrogallol } \\
\text { Others: aliphatic hydrocarbons, } \\
\text { formaldehyde, acetic acid, formic acid, } \\
\text { water }\end{array}$ & Kröller, 1966a \\
\hline Monoacetin & $\begin{array}{l}30 \mathrm{~g} \text { (in portions) of the } \\
\text { additive were heated at } 700{ }^{\circ} \mathrm{C} \\
\text { until the organic material has } \\
\text { disappeared in an air flow of } \\
1.5 \mathrm{~L} / \mathrm{min}\end{array}$ & n.d. & $\begin{array}{l}P A H \text { : coronene, } \mathrm{B}[a] \mathrm{P} 6 \mu \mathrm{g} / 100 \mathrm{~g}, \\
\text { fluoranthene, anthracene } \\
\text { Quinones: anthraquinone, phenanthren- } \\
\text { quinone } \\
\text { Phenols: phenol, o-ethylphenol, } \\
\text { pyrogallol } \\
\text { Others: glycerol, acetic acid, } \\
\text { acetaldehyde, aliphatic hydrocarbons, } \\
\mathrm{CO}_{2} \text {, water }\end{array}$ & Kröller, 1968 \\
\hline $\begin{array}{l}\text { Myrcene (as Diels- } \\
\text { Alder adduct with } \\
\text { maleic acid) }\end{array}$ & $\begin{array}{l}\text { Adduct mixed with } 3 \text { times its } \\
\text { weight of Celite and pyrolysed } \\
1 \mathrm{~min} \text { at } 750{ }^{\circ} \mathrm{C} \text { in a stream of } \\
\text { nitrogen }(15-25 \mathrm{~mL} / \mathrm{min})\end{array}$ & myrcene $32 \%$ & n.d. & $\begin{array}{l}\text { Robb et al., } \\
1964\end{array}$ \\
\hline \multirow[t]{3}{*}{ Pectin } & $\begin{array}{l}\text { Condition 1: air, } 100 \mathrm{~mL} / \mathrm{min} \\
\left.314^{\circ} \mathrm{C} \text { (furnace } 1\right) \\
\left.320{ }^{\circ} \mathrm{C} \text { (furnace } 2\right) \\
685{ }^{\circ} \mathrm{C} \text { (mobile furnace) }\end{array}$ & not applicable & $\begin{array}{l}\text { Condition } 1: 0.026 \% \text { phenol } \\
\text { Condition } 3: 0.017 \% \text { phenol } \\
\text { Condition } 4: 0.039 \% \text { phenol }\end{array}$ & Bell et al., 1966 \\
\hline & $\begin{array}{l}\text { Condition 3: air, } 100 \mathrm{~mL} / \mathrm{min} \\
777^{\circ} \mathrm{C} \text { (furnace 1) } \\
562{ }^{\circ} \mathrm{C} \text { (furnace 2) } \\
685{ }^{\circ} \mathrm{C} \text { (mobile furnace) }\end{array}$ & & & \\
\hline & $\begin{array}{l}\text { Condition } 4: \mathrm{N}_{2}, 100 \mathrm{~mL} / \mathrm{min} \\
\left.315^{\circ} \mathrm{C} \text { (furnace } 1\right) \\
\left.320{ }^{\circ} \mathrm{C} \text { (furnace } 2\right) \\
685{ }^{\circ} \mathrm{C} \text { (mobile furnace) }\end{array}$ & & & \\
\hline Pectin (citrus) & $\begin{array}{l}\text { Pyrolysis at } 700{ }^{\circ} \mathrm{C} \text { in an } \\
\mathrm{N}_{2} \text {-flow }(30 \mathrm{~mL} / \mathrm{min})\end{array}$ & not applicable & $\begin{array}{l}\text { Formation of phenols }(\mathrm{mg} / 100 \mathrm{~g}) \text { : } \\
\text { phenol } 12, o \text {-cresol } 6, m \text {-, } p \text {-cresol } 8\end{array}$ & $\begin{array}{l}\text { Schlotzhauer et } \\
\text { al., } 1967\end{array}$ \\
\hline Pectin & $\begin{array}{l}5 \mathrm{~g} \text { of material was rapidly } \\
\text { heated at } 6500^{\circ} \mathrm{C} \text { in a stream } \\
\text { of nitrogen for } 1 \mathrm{~h}\end{array}$ & n.d. & $\begin{array}{l}P A H \mathrm{~s} \text { (out of } 11 \text { investigated): } \\
\text { pyrene } 133 \mu \mathrm{g} / 100 \mathrm{~g} \\
\mathrm{~B}[\mathrm{a}] \mathrm{P} 45 \mu \mathrm{g} / 100 \mathrm{~g}\end{array}$ & $\begin{array}{l}\text { Gilbert and } \\
\text { Lindsey, } 1957\end{array}$ \\
\hline Pectin & $\begin{array}{l}10-15 \mathrm{mg} \text { of the additive were } \\
\text { pyrolysed at } 600{ }^{\circ} \mathrm{C} \text { for } 20 \mathrm{~s} \\
\left.\text { (ramp } 10{ }^{\circ} \mathrm{C} / \mathrm{ms}\right)\end{array}$ & not applicable & $\begin{array}{l}\text { Volatile pyrolytic products: } \\
\text { acetic anhydride, acetoin, methyl } \\
\text { formate, 3-methylfurane, 2-methyl-2- } \\
\text { cyclopenten-1-one, furfural, } \\
\text { acetylacetone, 2-furylmethylketone, 2,4- } \\
\text { hexadienal, 5-methyl-2-furfural, } \\
\text { isomaltol, 2-furanmethanol, methyl-3- } \\
\text { furanecarboxylate, cyclooctane, 3- } \\
\text { methyl-2-hydroxycyclopentenone, } \\
\text { hydroxyfuranone isomer, phenol, benzyl } \\
\text { alcohol derivative, 4-oxopentanoic acid, } \\
\text { furanecarboxylic acid derivative, 4- } \\
\text { methyl-4-hepten-3-one, acetic acid, } \\
\text { propionic acid, 2-methylpropionic acid, } \\
\text { butyric acid, 3-methylbutyric acid, } \\
\text { pentanoic acid, hexanoic acid, octanoic } \\
\text { acid, nonanoic acid, decanoic acid }\end{array}$ & $\begin{array}{l}\text { Sjöberg and } \\
\text { Pyysalo, } 1985\end{array}$ \\
\hline
\end{tabular}




\begin{tabular}{|c|c|c|c|c|}
\hline Ingredient(s) & Pyrolysis conditions & Transfer (\%) & Pyrolysis products & Reference(s) \\
\hline $\begin{array}{l}\text { Peppermint leaves } \\
\text { (from Mentha } \\
\text { piperita L.) }\end{array}$ & $\begin{array}{l}30 \mathrm{~g} \text { (in } 2 \mathrm{~g} \text { portions) of the } \\
\text { additive were heated at } \\
700^{\circ} \mathrm{C} \text { until the organic } \\
\text { material has disappeared } \\
\text { in an air flow of } 1.5 \mathrm{~L} / \mathrm{min}\end{array}$ & not applicable & $\begin{array}{l}P A H: \mathrm{B}[a] \mathrm{P} 5 \mu \mathrm{g} / 100 \mathrm{~g} \text {, fluoranthene, } \\
\text { pyrene, anthracene, } 2 \text {-methyl- } \\
\text { phenanthrene } \\
\text { Quinones: anthraquinone } \\
\text { Phenols: phenol, } \beta \text {-naphthol, } m \text {-cresol } \\
\text { Others: menthol, aliphatic hydrocarbons, } \\
\text { carboxylic acids }\end{array}$ & Kröller, 1970 \\
\hline $\begin{array}{l}\alpha \text {-Phellandrene (as } \\
\text { Diels-Alder adduct } \\
\text { with maleic } \\
\text { anhydride) }\end{array}$ & $\begin{array}{l}\text { Adduct mixed with } 3 \text { times its } \\
\text { weight of Celite and pyrolysed } \\
1 \mathrm{~min} \text { at } 750^{\circ} \mathrm{C} \text { in a stream of } \\
\text { nitrogen }(15-25 \mathrm{~mL} / \mathrm{min})\end{array}$ & $\alpha$-phellandrene 8\% & n.d. & $\begin{array}{l}\text { Robb et al., } \\
1964\end{array}$ \\
\hline Polyethylenglycol 400 & $\begin{array}{l}30 \mathrm{~g} \text { (in portions) of the } \\
\text { humectant on silica were } \\
\text { heated at } 700{ }^{\circ} \mathrm{C} \text { until the } \\
\text { organic material has } \\
\text { disappeared in an air flow of } \\
1.5 \mathrm{~L} / \mathrm{min}\end{array}$ & $\begin{array}{l}49 \% \text { destillate with } \\
\text { condensed and } \\
\text { monoglycols }\end{array}$ & $\begin{array}{l}\text { PAH: tribenzopyrene, pentacene, } \\
\text { fluoranthene, } 2,3 \text {-benzofluorene, } \mathrm{B}[\mathrm{a}] \mathrm{P} \\
10.5 \mu \mathrm{g} / 100 \mathrm{~g}, \text { anthracene } \\
\text { Quinones: anthraquinone } \\
\text { Phenols: none } \\
\text { Others: olefinic and aliphatic } \\
\text { hydrocarbons, } \mathrm{CO}, \mathrm{CO}_{2} \text {, water, } \\
\text { carboxylic acid(s), aldehyde(s) }\end{array}$ & Kröller, 1965a \\
\hline Polyethylenglycol 600 & $\begin{array}{l}30 \mathrm{~g} \text { (in portions) of the } \\
\text { humectant on silica were } \\
\text { heated at } 700{ }^{\circ} \mathrm{C} \text { until the } \\
\text { organic material has } \\
\text { disappeared in an air flow of } \\
1.5 \mathrm{~L} / \mathrm{min}\end{array}$ & $\begin{array}{l}22 \% \text { destillate with } \\
\text { triethylene glycol and } \\
\text { other glycols }\end{array}$ & $\begin{array}{l}\text { PAH: pentacene, B[a]P } 29 \mu \mathrm{g} / 100 \mathrm{~g} \text {, } \\
\text { coronene, fluoranthene } \\
\text { Quinones: anthraquinone, } 2 \text { unidentified } \\
\text { Phenols: none } \\
\text { Others: aldehyde(s), aliphatic } \\
\text { hydrocarbons, water, carboxylic acid(s) }\end{array}$ & Kröller, 1965a \\
\hline $\begin{array}{l}\text { Polyethylenglycol } \\
1000\end{array}$ & $\begin{array}{l}30 \mathrm{~g} \text { (in portions) of the } \\
\text { humectant on silica were } \\
\text { heated at } 700{ }^{\circ} \mathrm{C} \text { until the } \\
\text { organic material has } \\
\text { disappeared in an air flow of } \\
1.5 \mathrm{~L} / \mathrm{min}\end{array}$ & $\begin{array}{l}16 \% \text { destillate with } \\
\text { triethylen glycol and } \\
\text { other glycols }\end{array}$ & $\begin{array}{l}P A H: \text { fluoranthene, anthracene, } \\
\text { pentacene, coronene, B[a]P } 42 \mu \mathrm{g} / 100 \mathrm{~g} \\
\text { Quinones: anthraquinone } \\
\text { Phenols: polyphenol(s) } \\
\text { Others: aldehyde(s), water, aliphatic } \\
\text { hydrocarbons, carboxylic acid(s) }\end{array}$ & Kröller, 1965a \\
\hline Polygalacturonic acid & $\begin{array}{l}\text { Pyrolysis at } 700^{\circ} \mathrm{C} \text { in an } \\
\mathrm{N}_{2} \text {-flow }(30 \mathrm{~mL} / \mathrm{min})\end{array}$ & not applicable & $\begin{array}{l}\text { Formation of phenols }(\mathrm{mg} / 100 \mathrm{~g}) \text { : } \\
\text { phenol } 14, o \text {-cresol } 7, m \text {-, } p \text {-cresol } 8\end{array}$ & $\begin{array}{l}\text { Schlotzhauer et } \\
\text { al., } 1967\end{array}$ \\
\hline Potassium sorbate & $\begin{array}{l}30 \mathrm{~g} \text { (in portions) of the } \\
\text { additive were heated at } \\
700^{\circ} \mathrm{C} \text { until the organic } \\
\text { material has disappeared } \\
\text { in an air flow of } 1.5 \mathrm{~L} / \mathrm{min}\end{array}$ & (present) & $\begin{array}{l}P A H: \text { coronene, } \mathrm{B}[e] \mathrm{P}, \text { fluoranthene, } \\
\mathrm{B}[\mathrm{a}] \mathrm{P} 14 \mu \mathrm{g} / 100 \mathrm{~g}, \text { phenanthrene, } \\
\text { anthracene, acenaphthene } \\
\text { Quinones: anthraquinone, } \\
\text { phenanthrenequinone } \\
\text { Phenols: } \beta \text {-naphthol, o-cresol, } \\
\text { o-ethylphenol } \\
\text { Others: aliphatic hydrocarbons, } \mathrm{K}_{2} \mathrm{CO}_{3} \\
\text { (residue), carboxylic acids, aldehydes }\end{array}$ & Kröller, 1970 \\
\hline Proline & $\begin{array}{l}\text { About } 1 \mathrm{~g} \text { of material was } \\
\text { heated at } 840 \pm 10^{\circ} \mathrm{C} \text { in a } \\
\text { stream of nitrogen }(60 \mathrm{~mL} / \mathrm{min})\end{array}$ & n.d. & $\begin{array}{l}\text { Selected pyrolysis products: } \\
\text { benzene } 2.8 \% \text {, indole } 36.6 \% \text {, pyridine } \\
10.1 \% \text {, quinone } 2.0 \% \text {, phenol } 19.6 \%\end{array}$ & $\begin{array}{l}\text { Higman, E.B. et } \\
\text { al., } 1970\end{array}$ \\
\hline Proline & $\begin{array}{l}\text { Pyrolysis of } 0.5-2.0 \mathrm{~g} \text { at } \\
800-860{ }^{\circ} \mathrm{C} \text { in an } \mathrm{N}_{2} \text {-flow }\end{array}$ & not applicable & $\begin{array}{l}\text { Principle products: pyridine, } \\
\text { isoquinoline, pyrrole, toluene, indole } \\
\text { Other products: } 2 \text {-methylpyridine, 3-/4- } \\
\text { methylpyridine, aniline, quinoline, } \\
\text { benzene, benzonitrile, o-tolunitrile, } \\
m \text {-tolunitrile }\end{array}$ & $\begin{array}{l}\text { Schmeltz et al., } \\
1972\end{array}$ \\
\hline Propylene glycol & $\begin{array}{l}\text { Pyrolysis of } 100 \mathrm{~g} \text { of the } \\
\text { polyalcohol was investigated at } \\
\text { various temperatures }\end{array}$ & not applicable & $\begin{array}{l}\text { Principal compounds at } 600{ }^{\circ} \mathrm{C} \text { : } \\
\text { acetaldehyde } 10-15 \mathrm{~g} / 100 \mathrm{~g} \\
\text { acetone }\end{array}$ & $\begin{array}{l}\text { Doihara et al., } \\
1964\end{array}$ \\
\hline 1,2-Propylene glycol & $\begin{array}{l}2 \mathrm{~mL} \text { of the glycol on silica } \\
\text { were heated at } 700^{\circ} \mathrm{C} \text { for } \\
\text { about } 10 \text { min (until the glycol } \\
\text { has disappeared) in an air flow } \\
\text { of } 1.5 \mathrm{~L} / \mathrm{min}\end{array}$ & $50 \%$ & $\begin{array}{l}\text { PAH: tribenzopyrene, coronene, } \\
\text { fluoranthene, phenanthrene, } \mathrm{B}[\mathrm{a}] \mathrm{P} \\
6 \mu \mathrm{g} / 100 \mathrm{~g} \\
\text { Quinones: pyrenequinone, } \\
\text { anthraquinone } \\
\text { Phenols: none } \\
\text { Others: aldehydes }\end{array}$ & Kröller, 1964b \\
\hline o-n-Propylphenol & $\begin{array}{l}\text { Pyrolysis at } 700^{\circ} \mathrm{C} \text { in an } \\
\mathrm{N}_{2} \text {-flow }(30 \mathrm{~mL} / \mathrm{min})\end{array}$ & n.d. & $\begin{array}{l}\text { Formation of phenols }(\mathrm{mg} / 100 \mathrm{~g}) \text { : } \\
\text { phenol } 1600, o \text {-cresol } 13400, \\
m-, p \text {-cresol }-\end{array}$ & $\begin{array}{l}\text { Schlotzhauer et } \\
\text { al., } 1967\end{array}$ \\
\hline Prune extract & $\begin{array}{l}50 \mathrm{~g} \text { (in portions) of the dried } \\
\text { extract were heated at } 700^{\circ} \mathrm{C} \\
\text { until the organic material has } \\
\text { disappeared in an air flow of } \\
1.5 \mathrm{~L} / \mathrm{min}\end{array}$ & not applicable & $\begin{array}{l}P A H: B[a] P 3 \mu \mathrm{g} / 100 \mathrm{~g} \text {, phenanthrene, } \\
\text { fluoranthene, } 20 \text {-methylcholanthrene } \\
\text { Quinones: none } \\
\text { Phenols: pyrogallol } \\
\text { Others: aliphatic hydrocarbons, furfurol, } \\
\text { acetic acid, (aldehydes) }\end{array}$ & Kröller, 1967 \\
\hline
\end{tabular}


Table 5 (contd.)

\begin{tabular}{|c|c|c|c|c|}
\hline Ingredient(s) & Pyrolysis conditions & Transfer (\%) & Pyrolysis products & Reference(s) \\
\hline Rose leaves & $\begin{array}{l}30 \mathrm{~g} \text { (in portions) of the } \\
\text { additive were heated at } \\
700^{\circ} \mathrm{C} \text { until the organic } \\
\text { material has disappeared } \\
\text { in an air flow of } 1.5 \mathrm{~L} / \mathrm{min}\end{array}$ & not applicable & $\begin{array}{l}\text { PAH: 1,2,5,6-dibenzanthracene, B[a]P } \\
2 \mu \mathrm{g} / 100 \mathrm{~g} \text {, fluoranthene, anthracene, } \\
7,12 \text { - or } 9,10 \text {-dimethyl-1,2- } \\
\text { benzanthracene } \\
\text { Quinones: anthraquinone } \\
\text { Phenols: phenol, } p \text {-cresol, } \beta \text {-naphthol, } \\
\text { pyro-gallol } \\
\text { Others: aliphatic hydrocarbons, } \\
\text { carboxylic acids, aldehydes }\end{array}$ & Kröller, 1967 \\
\hline \multirow[t]{3}{*}{ Rutin } & $\begin{array}{l}\text { Condition 1: air, } 100 \mathrm{~mL} / \mathrm{min} \\
314^{\circ} \mathrm{C} \text { (furnace 1) } \\
320^{\circ} \mathrm{C} \text { (furnace 2) } \\
685^{\circ} \mathrm{C} \text { (mobile furnace) }\end{array}$ & n.d. & $\begin{array}{l}\text { Condition } 1: 0.008 \% \text { phenol } \\
\text { Condition } 3: 0.004 \% \text { phenol } \\
\text { Condition } 4: 0.028 \% \text { phenol }\end{array}$ & Bell et al., 1966 \\
\hline & $\begin{array}{l}\text { Condition 3: air, } 100 \mathrm{~mL} / \mathrm{min} \\
777^{\circ} \mathrm{C} \text { (furnace 1) } \\
562{ }^{\circ} \mathrm{C} \text { (furnace 2) } \\
685^{\circ} \mathrm{C} \text { (mobile furnace) }\end{array}$ & & & \\
\hline & $\begin{array}{l}\text { Condition } 4: \mathrm{N}_{2}, 100 \mathrm{~mL} / \mathrm{min} \\
315^{\circ} \mathrm{C} \text { (furnace 1) } \\
320{ }^{\circ} \mathrm{C} \text { (furnace 2) } \\
685{ }^{\circ} \mathrm{C} \text { (mobile furnace) }\end{array}$ & & & \\
\hline Rutin (trihydrate) & $\begin{array}{l}25 \mathrm{~g} \text { material were pyrolysed } \\
\text { at } 800^{\circ} \mathrm{C} \text { in the following way: } \\
12 \text { cycles consisting of an } \\
\text { "operative time" ( } 20 \mathrm{~s} \text { in a gas } \\
\text { flow of nitrogen and air } \\
\text { [ } 1 \text { L/min for each gas], } \\
\text { simulating a puff) followed by } \\
\text { an "inoperative time" ( } 40 \mathrm{~s} \text { in a } \\
\text { flow of nitrogen, simulating the } \\
\text { puff interval) }\end{array}$ & n.d. & $\begin{array}{l}\text { Major pyrolysis products (catechols): } \\
\text { catechol: } 7.8 \mathrm{mg} / \mathrm{g} \\
\text { 4-methylcatechol: } 5.5 \mathrm{mg} / \mathrm{g} \\
\text { 4-ethylcatechol: } 4.6 \mathrm{mg} / \mathrm{g} \\
\text { 4-propylcatechol: } 1.2 \mathrm{mg} / \mathrm{g}\end{array}$ & $\begin{array}{l}\text { Schlotzhauer et } \\
\text { al., } 1982\end{array}$ \\
\hline $\begin{array}{l}\text { Shellac (resin } \\
\text { excreted by } \\
\text { Lakshadia indica) }\end{array}$ & $\begin{array}{l}30 \mathrm{~g} \text { (in portions) of the } \\
\text { additive were heated at } \\
700^{\circ} \mathrm{C} \text { (until the organic } \\
\text { material has disappeared) in } \\
\text { an air flow of } 1.5 \mathrm{~L} / \mathrm{min}\end{array}$ & not applicable & $\begin{array}{l}\text { PAH: pentacene, coronene, } 1,2,5,6- \\
\text { dibenzanthracene, B[a]P } 28 \mu \mathrm{g} / 100 \mathrm{~g} \text {, } \\
\text { fluoranthene, phenanthrene, anthracene } \\
\text { Quinones: anthraquinone } \\
\text { Phenols: o-cresol, pyrogallol } \\
\text { Others: acetic acid, aliphatic } \\
\text { hydrocarbons, water }\end{array}$ & Kröller, 1966d \\
\hline $\begin{array}{l}\text { Sodium } \\
\quad \text { glycerophosphate }\end{array}$ & $\begin{array}{l}30 \mathrm{~g} \text { (in portions) of the } \\
\text { additive were heated at } \\
700^{\circ} \mathrm{C} \text { (until the organic } \\
\text { material has disappeared) in } \\
\text { an air flow of } 1.5 \mathrm{~L} / \mathrm{min}\end{array}$ & not applicable & $\begin{array}{l}P A H: \mathrm{B}[a] \mathrm{P} 3 \mu \mathrm{g} / 100 \mathrm{~g} \text {, fluoranthene, } \\
\text { anthracene } \\
\text { Quinones: anthraquinone } \\
\text { Phenols: phenol } \\
\text { Others: formaldehyde, aliphatic } \\
\text { hydrocarbons, water }\end{array}$ & Kröller, 1966d \\
\hline Sorbitol & $\begin{array}{l}30 \mathrm{~g} \text { (in portions) of the } \\
\text { humectant were heated at } \\
700^{\circ} \mathrm{C} \text { until the organic } \\
\text { material has disappeared in an } \\
\text { air flow of } 1.5 \mathrm{~L} / \mathrm{min}\end{array}$ & n.d. & $\begin{array}{l}\text { PAH: tribenzopyrene, coronene, } \mathrm{B}[\mathrm{a}] \mathrm{P} \\
13 \mu \mathrm{g} / 100 \mathrm{~g} \text {, fluoranthene, } \\
4,5 \text {-methylenephenanthrene } \\
\text { Quinones: anthraquinone } \\
\text { Phenols: m-cresol } \\
\text { Others: formaldehyde, acetic acid, } \\
\text { aliphatic hydrocarbons, water }\end{array}$ & Kröller, 1966d \\
\hline \multirow[t]{3}{*}{ Starch } & $\begin{array}{l}\text { Condition 1: air, } 100 \mathrm{~mL} / \mathrm{min} \\
314^{\circ} \mathrm{C} \text { (furnace 1) } \\
320^{\circ} \mathrm{C} \text { (furnace 2) } \\
685{ }^{\circ} \mathrm{C} \text { (mobile furnace) }\end{array}$ & not applicable & $\begin{array}{l}\text { Condition } 1: 0.002 \% \text { phenol } \\
\text { Condition } 3: 0.030 \% \text { phenol } \\
\text { Condition } 4: 0.10 \% \text { phenol }\end{array}$ & Bell et al., 1966 \\
\hline & $\begin{array}{l}\text { Condition 3: air, } 100 \mathrm{~mL} / \mathrm{min} \\
777^{\circ} \mathrm{C} \text { (furnace 1) } \\
562{ }^{\circ} \mathrm{C} \text { (furnace 2) } \\
685{ }^{\circ} \mathrm{C} \text { (mobile furnace) }\end{array}$ & & & \\
\hline & $\begin{array}{l}\text { Condition } 4: \mathrm{N}_{2}, 100 \mathrm{~mL} / \mathrm{min} \\
315^{\circ} \mathrm{C} \text { (furnace 1) } \\
320{ }^{\circ} \mathrm{C} \text { (furnace 2) } \\
685{ }^{\circ} \mathrm{C} \text { (mobile furnace) }\end{array}$ & & & \\
\hline Starch & $\begin{array}{l}30 \mathrm{~g} \text { (in } 0.5 \mathrm{~g} \text { portions) of the } \\
\text { additive were heated at } \\
700^{\circ} \mathrm{C} \text { for about } 10 \mathrm{~min} \\
\text { (until the organic material has } \\
\text { disappeared) in an air flow of } \\
1.5 \mathrm{~L} / \mathrm{min}\end{array}$ & not applicable & $\begin{array}{l}P A H: \text { picene, B }[a] \mathrm{P} 7 \mu \mathrm{g} / 100 \mathrm{~g}, \\
\text { fluoranthene, anthracene, } \\
\text { 4,5-methylenephenanthrene } \\
\text { Quinones: phenanthrenequinone, } \\
\text { anthraquinone } \\
\text { Phenols: pyrogallol, gallic acid, } m \text {-cresol } \\
\text { Others: aliphatic and olefinic } \\
\text { hydrocarbons, water, furfurol, acetic acid } \\
\text { (formaldehyde) }\end{array}$ & Kröller, 1966a \\
\hline
\end{tabular}


Table 5 (contd.)

\begin{tabular}{|c|c|c|c|c|}
\hline Ingredient(s) & Pyrolysis conditions & Transfer (\%) & Pyrolysis products & Reference(s) \\
\hline Starch & $\begin{array}{l}5 \mathrm{~g} \text { of material was rapidly } \\
\text { heated to } 650^{\circ} \mathrm{C} \text { in a stream } \\
\text { of nitrogen for } 1 \mathrm{~h}\end{array}$ & n.d. & $\begin{array}{l}\text { PAHs (out of } 11 \text { investigated): } \\
\text { pyrene } 35 \mu \mathrm{g} / 100 \mathrm{~g}, \mathrm{~B}[\mathrm{a}] \mathrm{P} 17 \mu \mathrm{g} / 100 \mathrm{~g}\end{array}$ & $\begin{array}{l}\text { Gilbert and } \\
\text { Lindsey, } 1957\end{array}$ \\
\hline $\begin{array}{l}\text { Sucrose (invert } \\
\text { sugar, e.g. } \\
\text { honey) }\end{array}$ & $\begin{array}{l}30 \mathrm{~g} \text { (in portions) of the sugar } \\
\text { were heated at } 700{ }^{\circ} \mathrm{C} \text { until } \\
\text { the organic material has } \\
\text { disappeared in an air flow of } \\
1.5 \mathrm{~L} / \mathrm{min}\end{array}$ & n.d. & $\begin{array}{l}P A H: \text { fluoranthene, anthracene, } \mathrm{B}[\mathrm{a}] \mathrm{P} \\
1 \mathrm{\mu g} / 100 \mathrm{~g} \\
\text { Quinones: anthraquinone } \\
\text { Phenols: phenol } \\
\text { Others: aliphatic hydrocarbons, furfurol, } \\
\text { carboxylic acids }\end{array}$ & Kröller, 1967 \\
\hline \multirow[t]{3}{*}{ Sucrose } & $\begin{array}{l}\text { Condition 1: air, } 100 \mathrm{~mL} / \mathrm{min} \\
314^{\circ} \mathrm{C} \text { (furnace 1) } \\
320^{\circ} \mathrm{C} \text { (furnace 2) } \\
685{ }^{\circ} \mathrm{C} \text { (mobile furnace) }\end{array}$ & n.d. & $\begin{array}{l}\text { Condition } 1: 0.067 \% \text { phenol } \\
\text { Condition 3: } 0.062 \% \text { phenol } \\
\text { Condition } 4: 0.082 \% \text { phenol }\end{array}$ & Bell et al., 1966 \\
\hline & $\begin{array}{l}\text { Condition 3: air, } 100 \mathrm{~mL} / \mathrm{min} \\
777^{\circ} \mathrm{C} \text { (furnace 1) } \\
562{ }^{\circ} \mathrm{C} \text { (furnace 2) } \\
685{ }^{\circ} \mathrm{C} \text { (mobile furnace) }\end{array}$ & & & \\
\hline & $\begin{array}{l}\text { Condition } 4: \mathrm{N}_{2}, 100 \mathrm{~mL} / \mathrm{min} \\
315^{\circ} \mathrm{C} \text { (furnace 1) } \\
320{ }^{\circ} \mathrm{C} \text { (furnace 2) } \\
685{ }^{\circ} \mathrm{C} \text { (mobile furnace) }\end{array}$ & & & \\
\hline Sucrose & $\begin{array}{l}\text { 5-10 } \mathrm{mg} \text { sucrose were heated } \\
\text { for } 10 \mathrm{~s} \text { at } 700{ }^{\circ} \mathrm{C} \text { under an } \mathrm{N}_{2}- \\
\text { flow }(15 \mathrm{~mL} / \mathrm{min})\end{array}$ & n.d. & $\begin{array}{l}\text { 2-furaldehyde } 67.1 \% \text {, 5-methyl-2- } \\
\text { furaldehyde } 4.2 \%, 3 \text {-methylfuran } 3.0 \% \text {, } \\
2 \text {-furanmethanol } 2.4 \% \text {, furancarboxylic } \\
\text { acid methyl ester } 2.0 \%, 1,3- \\
\text { cyclopentanedione } 1.6 \%\end{array}$ & $\begin{array}{l}\text { Schlotzhauer } \\
\text { et al., } 1985\end{array}$ \\
\hline Sucrose & $\begin{array}{l}\text { Pyrolysis of sucrose at } \\
200-500{ }^{\circ} \mathrm{C} \text { (reported here are } \\
\text { only results obtained at } \\
450-500{ }^{\circ} \mathrm{C} \text { ) }\end{array}$ & n.d. & $\begin{array}{l}\text { Compostion of gases: } \\
\mathrm{CO}_{2} 6.08 \% \text {, CO } 36.15 \%, \mathrm{C}_{\mathrm{n}} \mathrm{H}_{2 \mathrm{n}} 0.73 \% \text {, } \\
\mathrm{CH}_{4} 47.40 \%, \mathrm{H}_{2} 9.64 \%\end{array}$ & Tomasik, 1989 \\
\hline Sucrose & $\begin{array}{l}5 \mathrm{~g} \text { of material was rapidly } \\
\text { heated at } 650^{\circ} \mathrm{C} \text { in a stream of } \\
\text { nitrogen for } 1 \mathrm{~h}\end{array}$ & n.d. & $\begin{array}{l}\text { PAHs (out of } 11 \text { investigated): } \\
\text { pyrene: } 24 \mu \mathrm{g} / 100 \mathrm{~g}, \mathrm{~B}[\mathrm{a}] \mathrm{P}: 10 \mu \mathrm{g} / 100 \mathrm{~g}\end{array}$ & $\begin{array}{l}\text { Gilbert and } \\
\text { Lindsey, } 1957\end{array}$ \\
\hline Sucrose & $\begin{array}{l}200 \mathrm{~g} \text { of sucrose (in } 10-20 \mathrm{~g} \\
\text { portions) were heated with a } \\
\text { gas burner under atmospheric } \\
\text { pressure until evolution of } \\
\text { aerosol ceased }\end{array}$ & n.d. & $\begin{array}{l}7.8 \% \text { of volatile products } \\
\text { Major products: } \\
\text { 5-hydroxymethylfurfural and furfural }\end{array}$ & $\begin{array}{l}\text { Gilbert and } \\
\text { Lindsey, } 1957\end{array}$ \\
\hline Sucrose & $\begin{array}{l}25 \mathrm{~g} \text { material were pyrolysed } \\
\text { at } 800^{\circ} \mathrm{C} \text { in the following way: } \\
12 \text { cycles consisting of an } \\
\text { "operative time" ( } 20 \mathrm{~s} \text { in a gas } \\
\text { flow of nitrogen and air } \\
\text { [ } 1 \mathrm{~L} / \text { min for each gas], } \\
\text { simulating a puff) followed by } \\
\text { an "inoperative time" ( } 40 \mathrm{~s} \text { in a } \\
\text { flow of nitrogen, simulating the } \\
\text { puff interval) }\end{array}$ & n.d. & $\begin{array}{l}\text { Major pyrolysis products (catechols): } \\
\text { furfural } 27.7 \mathrm{mg} / \mathrm{g} \text {, } \\
\text { 5-hydroxymethylfurfural } 19.5 \mathrm{mg} / \mathrm{g}\end{array}$ & $\begin{array}{l}\text { Schlotzhauer } \\
\text { et al., } 1982\end{array}$ \\
\hline Sucrose & $\begin{array}{l}5 \mathrm{mg} \text { sucrose were heated for } \\
10 \mathrm{~s} \text { at } 350-850^{\circ} \mathrm{C} \text { under an } \\
\mathrm{N}_{2} \text {-flow }(15 \mathrm{~mL} / \mathrm{min})\end{array}$ & n.d. & $\begin{array}{l}\text { Formation of } 5 \text {-hydroxymethylfurfural: } \\
350^{\circ} \mathrm{C}: 60.0 \mu \mathrm{g} / \mathrm{mg} \text { sucrose } \\
450{ }^{\circ} \mathrm{C}: 82.9 \mu \mathrm{g} / \mathrm{mg} \text { sucrose } \\
550^{\circ} \mathrm{C}: 76.0 \mu \mathrm{g} / \mathrm{mg} \text { sucrose } \\
650^{\circ} \mathrm{C}: 65.9 \mu \mathrm{g} / \mathrm{mg} \text { sucrose } \\
750^{\circ} \mathrm{C}: 47.4 \mu \mathrm{g} / \mathrm{mg} \text { sucrose } \\
850^{\circ} \mathrm{C}: 37.3 \mu \mathrm{g} / \mathrm{mg} \text { sucrose }\end{array}$ & $\begin{array}{l}\text { Schlotzhauer } \\
\text { et al., } 1986\end{array}$ \\
\hline $\begin{array}{l}\text { Sucrose ester (with 3- } \\
\text { methylvaleric acid) }\end{array}$ & $\begin{array}{l}5 \mathrm{mg} \text { sucrose ester was } \\
\text { heated for } 10 \mathrm{~s} \text { at } 250-850{ }^{\circ} \mathrm{C} \\
\text { under an } \mathrm{N}_{2} \text {-flow }(15 \mathrm{~mL} / \mathrm{min})\end{array}$ & n.d. & $\begin{array}{l}\text { Temperature-dependent formation of: } \\
\text { 3-methylvaleric acid: } 60.7-67.3 \% \\
\text { 3-methylbutyric acid: } 11.2-12.7 \% \\
\text { 5-hydroxy-methylfurfural: } 8.9-14.6 \% \\
\text { 2-methylbutyric acid: } 5.8-7.2 \% \\
\text { 4-methylvaleric acid: } 1.3-2.6 \% \\
\text { isobutyric acid: } 0.6-1.6 \%\end{array}$ & $\begin{array}{l}\text { Schlotzhauer } \\
\text { et al., } 1986\end{array}$ \\
\hline $\begin{array}{l}\text { Tartric acid (disodium } \\
\text { salt) }\end{array}$ & $\begin{array}{l}50 \mathrm{~g} \text { (in } 0.5 \text { portions) of the } \\
\text { additive were heated at } 700{ }^{\circ} \mathrm{C} \\
\text { (until the organic material has } \\
\text { disappeared) in an air flow of } \\
1.5 \mathrm{~L} / \mathrm{min}\end{array}$ & n.d. & $\begin{array}{l}P A H: \mathrm{B}[e] \mathrm{P}, \mathrm{B}[\mathrm{a}] \mathrm{P} 4 \mu \mathrm{g} / 100 \mathrm{~g}, \\
\text { fluoranthene, } 20 \text {-methylcholanthrene } \\
\text { Quinones: anthraquinone } \\
\text { Phenols: phenol, o-cresol } \\
\text { Others: aliphatic hydrocarbons, } \\
\text { aldehyde(s), pyruvic acid, } \mathrm{CO}, \mathrm{CO}_{2} \text {, } \\
\text { water }\end{array}$ & Kröller, 1966b \\
\hline
\end{tabular}


Table 5 (contd.)

\begin{tabular}{|c|c|c|c|c|}
\hline Ingredient(s) & Pyrolysis conditions & Transfer (\%) & Pyrolysis products & Reference(s) \\
\hline \multirow[t]{2}{*}{ Tetracosane } & $\begin{array}{l}\text { Condition 3: air, } 100 \mathrm{~mL} / \mathrm{min} \\
777^{\circ} \mathrm{C} \text { (furnace 1) } \\
562{ }^{\circ} \mathrm{C} \text { (furnace 2) } \\
685^{\circ} \mathrm{C} \text { (mobile furnace) }\end{array}$ & n.d. & $\begin{array}{l}\text { Condition 3: } 0.024 \% \text { phenol } \\
\text { Condition } 4: 0 \% \text { phenol }\end{array}$ & Bell et al., 1966 \\
\hline & $\begin{array}{l}\text { Condition } 4: \mathrm{N}_{2}, 100 \mathrm{~mL} / \mathrm{min} \\
\left.315{ }^{\circ} \mathrm{C} \text { (furnace } 1\right) \\
\left.320{ }^{\circ} \mathrm{C} \text { (furnace } 2\right) \\
685{ }^{\circ} \mathrm{C} \text { (mobile furnace) }\end{array}$ & & & \\
\hline $\begin{array}{l}\text { Thiabendazole } \\
\text { (2-(4'-thiazolyl)- } \\
\text { benzimidazole) }\end{array}$ & $\begin{array}{l}30 \mathrm{~g} \text { (in portions) of the } \\
\text { additive were heated at } \\
700{ }^{\circ} \mathrm{C} \text { until the organic } \\
\text { material has disappeared } \\
\text { in an air flow of } 1.5 \mathrm{~L} / \mathrm{min}\end{array}$ & $75 \%$ & $\begin{array}{l}\text { PAH: anthracene, } \mathrm{B}[\mathrm{a}] \mathrm{P}<1 \mu \mathrm{g} / 100 \mathrm{~g} \text {, } \\
\text { fluoranthene } \\
\text { Quinones: none } \\
\text { Phenols: none } \\
\text { Others: thiophene, mercaptanes, } \mathrm{H}_{2} \mathrm{~S} \text {, } \\
\text { sulfur }\end{array}$ & Kröller, 1968 \\
\hline Tonka bean powder & $\begin{array}{l}5.7 \mathrm{~g} \text { (in } 1 \mathrm{~g} \text { portions) were } \\
\text { pyrolysed at } 840 \pm 10^{\circ} \mathrm{C} \\
\text { under nitrogen }\end{array}$ & not applicable & $\begin{array}{l}\text { Neutrals }(0.22 \mathrm{~g}) \text { : benzene } 14.1 \% \text {, } \\
\text { toluene } 9.5 \% \text {, styrene } 15.9 \% \text {, } \\
\text { benzofuran } 9.7 \% \text {, indene } 3.0 \% \text {, } \\
\text { naphthalene } 13.7 \% \text {, methylnaphthalene } \\
3.2 \% \text {, coumarin/acenaphthene } 2.1 \% \text {, } \\
\text { phenanthrene/anthracene } 4.5 \% \text {, } \\
\text { methylphenanthrene/anthracene } 1.3 \% \\
\text { Nitrogen bases }(0.03 \mathrm{~g}) \text { : pyridine } 13.4 \% \text {, } \\
\text { picoline } 4.3 \% \text {, dimethylpyridine } 3.2 \% \text {, } \\
\text { vinylpyridine } 4.4 \% \text {, indole } 1.0 \% \text {, } \\
\text { quinoline } 9.5 \% \text {, isoquinoline } 2.5 \% \text {, } \\
\text { methylquinoline } 5.5 \% \text {, carbazole } 1.2 \% \text {, } \\
\text { benzoquinoline } 2.9 \% \text {, } \\
\text { methylbenzoquinoline } 1.6 \% \\
\text { Phenols }(0.04 \mathrm{~g}): \text { phenol } 14.5 \% \text {, cresol } \\
8.1 \% \text {, xylenol } 1.1 \% \text {, coumarin } 2.3 \% \text {, } \\
\text { naphthol } 9.2 \%\end{array}$ & $\begin{array}{l}\text { Higman et al., } \\
1974\end{array}$ \\
\hline
\end{tabular}

Tragacanth $\quad 30 \mathrm{~g}$ (in $0.5-1.0 \mathrm{~g}$ portions) of not applicable the additive were heated at $700{ }^{\circ} \mathrm{C}$ for about $30 \mathrm{~min}$ (until the organic material has disappeared) in an air flow of $1.5 \mathrm{~L} / \mathrm{min}$

Tragacanth

Triacetin

Triethylene glycol
$10-15 \mathrm{mg}$ of the additive were not applicable pyrolysed at $600{ }^{\circ} \mathrm{C}$ for $20 \mathrm{~s}$ (ramp $10{ }^{\circ} \mathrm{C} / \mathrm{ms}$ ) disappeared in an air flow of $1.5 \mathrm{~L} / \mathrm{min}$

$2 \mathrm{~mL}$ of the glycol on silica

$80 \%$
$\mathrm{PAH}$ : pentacene, coronene, $\mathrm{B}[\mathrm{a}] \mathrm{P}$ were heated at $700{ }^{\circ} \mathrm{C}$ for about 10 min (until the glycol has disappeared) in an air flow of $1.5 \mathrm{~L} / \mathrm{min}$ $23 \mu \mathrm{g} / 100 \mathrm{~g}$, fluoranthene, anthracene, 20-methylcholanthrene

Quinones: anthraquinone, phenanthrenequinone

Phenols: phenol, o-cresol, carvacrol, (pyrogallol)

Others: aliphatic hydrocarbons, water, formic acid, acetic acid

Volatile pyrolytic products: acetic anhydride, acetoin, methyl formate, 3-methylfurane, 2-methyl-2-cyclopenten-

1-one, furfural, acetylacetone,

2-furylmethylketone, 2,4-hexadienal,

5-methyl-2-furfural, isomaltol,

2-furanmethanol, cyclooctane,

hydroxyfuranone isomer, benzyl alcohol derivative, 3-methyl-2-

hydroxycyclopentenone, methyl-3-

furanecarboxylate, phenol,

4-oxopentanoic acid, propionic acid, furanecarboxylic acid derivative,

4-methyl-4-hepten-3-one, acetic acid,

2-methylpropionic acid, butyric acid,

3-methylbutyric acid, pentanoic acid, hexanoic acid, octanoic acid, nonanoic acid, decanoic acid

PAH: $\mathrm{B}[\mathrm{a}] \mathrm{P} 4 \mu \mathrm{g} / 100 \mathrm{~g}$, fluoranthene, anthracene

Quinones: anthraquinone

Phenols: phenol

Others: acetic acid, glycerol, aliphatic hydrocarbons

Kröller, 1965b

Pyysalo, 1985

$P A H$ : fluoranthene, 2,3-benzofluorene $\mathrm{B}[\mathrm{a}] \mathrm{P} \sim 15 \mu \mathrm{g} / 100 \mathrm{~g}$, tribenzopyrene Quinones: anthraquinone

Phenols: none

Others: aldehydes 
Table 5 (contd.)

\begin{tabular}{|c|c|c|c|c|}
\hline Ingredient(s) & Pyrolysis conditions & Transfer (\%) & Pyrolysis products & Reference(s) \\
\hline Triglycerol & $\begin{array}{l}30 \mathrm{~g} \text { (in portions) of the } \\
\text { humectant were heated at } \\
700^{\circ} \mathrm{C} \text { until the organic } \\
\text { material has disappeared } \\
\text { in an air flow of } 1.5 \mathrm{~L} / \mathrm{min}\end{array}$ & n.d. & $\begin{array}{l}\text { PAH: 4,5-methylenephenanthrene, } \\
\text { tribenzopyrene, fluoranthene, } \\
\text { pentacene, coronene, anthracene } \\
\mathrm{B}[a] \mathrm{P} 10 \mathrm{\mu g} / 100 \mathrm{~g} \\
\text { Quinones: anthraquinone, } \\
\text { phenanthrenequinone } \\
\text { Phenols: phenol, o-ethylphenol, } \\
\text { pyrogallol } \\
\text { Others: glycerol } 15 \% \text {, acetaldehyde, } \\
\text { acetic acid, aliphatic hydrocarbons, } \\
\mathrm{CO}_{2} \text {, water }\end{array}$ & Kröller, 1966d \\
\hline Vanilla extract & $\begin{array}{l}17.8 \mathrm{~g} \text { (in } 5 \mathrm{~g} \text { portions) were } \\
\text { pyrolysed at } 840 \pm 10^{\circ} \mathrm{C} \\
\text { under nitrogen }\end{array}$ & not applicable & $\begin{array}{l}\text { Neutrals }(0.28 \mathrm{~g}) \text { : benzene } 12.3 \% \text {, } \\
\text { toluene } 11.6 \% \text {, furfural } 5.5 \% \text {, styrene } \\
6.6 \% \text {, benzofuran } 4.8 \% \text {, indene } 6.2 \% \text {, } \\
\text { naphthalene } 8.1 \% \text {, methylnaphthalene } \\
3.8 \% \text {, acenaphthylene } 2.3 \% \text {, } \\
\text { phenanthrene } / \text { anthracene } 1.7 \% \text {, } \\
\text { methylphenanthrene } / \text { anthracene } 1.6 \% \\
\text { Nitrogen bases }(0.12 \mathrm{~g}) \text { : pyridine } 18.8 \% \text {, } \\
\text { picoline } 8.0 \% \text {, dimethylpyridine } 5.7 \% \text {, } \\
\text { vinylpyridine } 5.6 \% \text {, quinoline } 2.8 \% \text {, } \\
\text { methylquinoline } 0.6 \% \\
\text { Phenols }(0.39 \mathrm{~g}) \text { : phenol } 39.1 \% \text {, cresol } \\
26.5 \% \text {, xylenol } 4.8 \%\end{array}$ & $\begin{array}{l}\text { Higman, H.C. } \\
\text { et al., } 1974\end{array}$ \\
\hline $\begin{array}{l}\text { Vanilla roots (from } \\
\text { Trilisa } \\
\text { odoratissima) }\end{array}$ & $\begin{array}{l}30 \mathrm{~g} \text { (in portions) of the } \\
\text { additive were heated at } \\
700^{\circ} \mathrm{C} \text { until the organic } \\
\text { material has disappeared } \\
\text { in an air flow of } 1.5 \mathrm{~L} / \mathrm{min}\end{array}$ & not applicable & $\begin{array}{l}P A H: \text { 2,3-benzofluorene, } \mathrm{B}[a] \mathrm{P} \\
3 \mu \mathrm{g} / 100 \mathrm{~g} \text {, fluoranthene, } \\
\text { 1,2-dihydropyrene, } p \text {-terphenyl } \\
\text { Quinones: anthraquinone } \\
\text { Phenols: pyrogallol, phenol, o-cresol, } \\
\text { ethylphenol } \\
\text { Others: coumarine, carboxylic acids, } \\
\text { aliphatic hydrocarbons, aldehydes }\end{array}$ & Kröller, 1967 \\
\hline $\begin{array}{l}\text { Woodruff (from } \\
\text { Asperula odorata) }\end{array}$ & $\begin{array}{l}30 \mathrm{~g} \text { (in portions) of the } \\
\text { additive were heated at } \\
700^{\circ} \mathrm{C} \text { until the organic } \\
\text { material has disappeared } \\
\text { in an air flow of } 1.5 \mathrm{~L} / \mathrm{min}\end{array}$ & coumarin (present) & $\begin{array}{l}P A H: \text { tribenzopyrene, fluoranthene, } \\
\text { B[a]P } 4 \mu \mathrm{g} / 100 \mathrm{~g} \text {, phenanthrene, } p \text { - } \\
\text { terphenyl } \\
\text { Quinones: anthraquinone, } \\
\text { phenanthrenequinone } \\
\text { Phenols: catechol, pyrogallol } \\
\text { Others: aliphatic hydrocarbons, } \\
\text { carboxylic acids, aldehydes }\end{array}$ & Kröller, 1967 \\
\hline $\begin{array}{l}\text { Yellow wood extract } \\
\text { (from Morus } \\
\text { tinctoria) }\end{array}$ & $\begin{array}{l}30 \mathrm{~g} \text { (in } 1 \mathrm{~g} \text { portions) of the } \\
\text { additive were heated at } \\
700^{\circ} \mathrm{C} \text { (until the organic } \\
\text { material has disappeared) } \\
\text { in an air flow of } 1.5 \mathrm{~L} / \mathrm{min}\end{array}$ & not applicable & $\begin{array}{l}\text { PAH: fluoranthene, anthracene, } \\
\text { 9,10-dihydroanthracene } \\
\text { Quinones: anthraquinone } \\
\text { Phenols: o- and } m \text {-cresol, pyrogallol, } \\
\text { catechol } \\
\text { Others: acetic acid, olefinic } \\
\text { hydrocarbons, } \mathrm{CO}, \mathrm{CO}_{2} \text {, water }\end{array}$ & Kröller, 1966c \\
\hline $\begin{array}{l}\text { Yellow wood extract } \\
\text { (in a mixture with } \\
\text { diethylene glycol) }\end{array}$ & $\begin{array}{l}30 \mathrm{~g} \text { (in portions) of the } \\
\text { additive were heated at } \\
700^{\circ} \mathrm{C} \text { until the organic } \\
\text { material has disappeared } \\
\text { in an air flow of } 1.5 \mathrm{~L} / \mathrm{min}\end{array}$ & Glycol (present) & $\begin{array}{l}\text { PAH: } \mathrm{B}[\mathrm{a}] \mathrm{P} 1 \mu \mathrm{g} / 100 \mathrm{~g} \text {, fluoranthene, } \\
4,5 \text { methylenephenanthrene, } \\
\text { anthracene } \\
\text { Quinones: anthraquinone } \\
\text { Phenols: pyrogallol, catechol } \\
\text { Others: formaldehyde, acetic acid, } \\
\text { aliphatic hydrocarbons }\end{array}$ & Kröller, 1968 \\
\hline
\end{tabular}




\begin{tabular}{|c|c|c|c|c|}
\hline Ingredient(s) & Experimental design & Biol & logical effect/biological assay & Reference(s) \\
\hline $\begin{array}{l}2 \text { Ingredients: } \\
\text { 1-octanol } \\
\text { 1-decanol } \\
\text { (M 58) }\end{array}$ & CSC of cigarettes $\pm 480 \mathrm{ppm}$ alcohol mixture & $\rightarrow$ & $\begin{array}{l}\text { Tumorigenicity in the mouse skin } \\
\text { painting assay }\end{array}$ & Tso, $1975(P)$ \\
\hline $\begin{array}{l}2 \text { Ingredients: } \\
\text { glycerol } \\
\text { propylene glycol } \\
\text { (M 59) }\end{array}$ & $\begin{array}{l}\text { MSS of cigarettes } \pm \text { glycerol/propylene glycol, } \\
\text { which were added in different combinations and } \\
\text { concentrations; the mixtures used contained } \\
12000 / 7000,24000 / 14000 \text { or } 72000 / 42000 \text { ppm } \\
\text { glycerol/propylene glycol }\end{array}$ & $\rightarrow$ & $\begin{array}{l}\text { Respiratory tract changes in a } \\
\text { 13-week nose-only smoke inhalation } \\
\text { study in Fischer } 344 \text { rats }\end{array}$ & $\begin{array}{l}\text { Gaworski et al., } \\
\text { 1999b (A) }\end{array}$ \\
\hline $\begin{array}{l}150 \text { Flavor ingredients } \\
\text { in } 4 \text { unique } \\
\text { combinations } \\
\text { (M 60) }\end{array}$ & $\begin{array}{l}\text { Cigarette smoke condensate of cigarettes treated } \\
\text { with } 150 \text { flavour ingredients (exaggerated } \\
\text { concentrations if possible) in } 4 \text { unique flavour } \\
\text { combinations vs. reference cigarettes without } \\
\text { additives }\end{array}$ & $\rightarrow$ & $\begin{array}{l}\text { Tumor promotion in a two stage } \\
\text { mouse skin painting assay with } \\
\text { SENCAR mice }\end{array}$ & $\begin{array}{l}\text { Gaworski et al., } \\
\text { 1999a }\end{array}$ \\
\hline $\begin{array}{l}172 \text { Ingredients in } 4 \\
\text { typical mixtures } \\
\text { (M 61) }\end{array}$ & $\begin{array}{l}\text { Mainstream smoke of cigarettes containing } 172 \\
\text { ingredients in } 4 \text { typical mixtures (exaggerated } \\
\text { concentrations if possible) vs. reference } \\
\text { cigarettes without additives }\end{array}$ & $\rightarrow$ & $\begin{array}{l}\text { Biological effects in a } 13 \text {-week } \\
\text { nose-only smoke inhalation study } \\
\text { using Fischer } 344 \text { rats }\end{array}$ & $\begin{array}{l}\text { Gaworski et al., } \\
1998\end{array}$ \\
\hline $\begin{array}{l}333 \text { Ingredients in } 3 \\
\text { different groups } \\
\text { (M 62: Ingredient } \\
\text { Group 1, M 63: } \\
\text { Ingredient Group 2, } \\
\text { M 64: Ingredient } \\
\text { Group 3) }\end{array}$ & $\begin{array}{l}\text { MSS and CSC of cigarettes } \pm 333 \text { ingredients in } \\
3 \text { groups typically found in commercial cigarettes }\end{array}$ & $\rightarrow$ & $\begin{array}{l}\text { Overall toxicity of cigarette smoke in } \\
\text { the following biological assays: } \\
\text { Ames Assay (according to OECD } \\
\text { guideline 471), Neutral Red Assay } \\
\text { (with BALB/c 3T3 cells), subchronic } \\
\text { inhalation in Sprague-Dawley rats } \\
\text { (according to OECD guideline 413) } \\
\text { and chemical analysis of smoke } \\
\text { composition and determination of risk } \\
\text { indices }\end{array}$ & Carmines, $2002^{\mathrm{a}}$ \\
\hline Cellulose & Tobacco smoke of cigarettes $\pm 10 \%$ cellulose & $\begin{array}{l}\rightarrow \\
\rightarrow \\
\rightarrow\end{array}$ & $\begin{array}{l}\text { Tumorigenicity in the mouse skin } \\
\text { painting assay with female ICR Swiss } \\
\text { mice } \\
\text { Cytotoxicity in a growth inhibition assay } \\
\text { using the human KB tumor cell line } \\
\text { ciliatoxicity using an in vitro and in vivo } \\
\text { Chicken tracheal assay measuring } \\
\text { particle clearance }\end{array}$ & $\begin{array}{l}\text { NCl, Report No. } \\
4,1980\end{array}$ \\
\hline Citric acid & $\begin{array}{l}\text { Tobacco smoke of experimental cigarettes } \\
\pm 1.25 \% \text { citric acid }\end{array}$ & $\rightarrow$ & $\begin{array}{l}\text { Ciliostasis in the trachea of cats } \\
\text { exposed in vivo to the smoke of } \\
\text { treated and control cigarettes }\end{array}$ & $\begin{array}{l}\text { Dalhamn and } \\
\text { Rylander, } 1971\end{array}$ \\
\hline Cocoa & Tobacco smoke of cigarettes $\pm 1 \%$ cocoa & $\begin{array}{l}\pi \\
\\
\end{array}$ & $\begin{array}{l}\text { Tumorigenicity in the mouse skin } \\
\text { painting assay with female ICR Swiss } \\
\text { mice } \\
\text { Cytotoxicity in a growth inhibition assay } \\
\text { using the human KB tumor cell line } \\
\text { ciliatoxicity using an in vitro and in vivo } \\
\text { chicken tracheal assay measuring } \\
\text { Particle clearance }\end{array}$ & $\begin{array}{l}\text { NCI, Report No. } \\
3,1977\end{array}$ \\
\hline Cocoa & CSC of cigarettes \pm 1 or $3 \%$ cocoa & $\rightarrow$ & $\begin{array}{l}\text { Tumorous and non-tumorous lesions } \\
\text { in the mouse skin painting assay } \\
\text { with female ICR Swiss mice }\end{array}$ & $\begin{array}{l}\text { Römer and } \\
\text { Hackenberg, } \\
1990\end{array}$ \\
\hline $\begin{array}{l}\text { Diammonium } \\
\text { phosphate }\end{array}$ & $\begin{array}{l}\text { Tobacco smoke of different cigarettes (tobacco, } \\
\text { reconstituted leaf tobacco and a mixture of both) } \\
\pm \text { DAP }(3000-14200 \mathrm{ppm})\end{array}$ & $\rightarrow$ & $\begin{array}{l}\text { Histopathologic lesions, decreases in } \\
\text { body weight gain, increases in blood } \\
\text { COHb and serum nicotine and cotinine } \\
\text { in a } 13 \text {-week sub-chronic inhalation } \\
\text { study in Fischer-344 rats }\end{array}$ & Misra et al., 2001 \\
\hline Glycerol & MSS of cigarettes \pm 72000 ppm glycerol & $\rightarrow$ & $\begin{array}{l}\text { Respiratory tract changes in a } \\
\text { 13-week nose-only smoke inhalation } \\
\text { study in Fischer } 344 \text { rats }\end{array}$ & $\begin{array}{l}\text { Gaworski et al., } \\
\text { 1999b (A) }\end{array}$ \\
\hline Glycerol & Tobacco smoke of cigarettes $\pm 2.8 \%$ glycerol & $\begin{array}{l}\rightarrow \\
y \\
y\end{array}$ & $\begin{array}{l}\text { Tumorigenicity in the mouse skin } \\
\text { painting assay with female ICR Swiss } \\
\text { mice } \\
\text { Cytotoxicity in a growth inhibition assay } \\
\text { using the human KB tumor cell line } \\
\text { ciliatoxicity using an in vitro and in vivo } \\
\text { Chicken tracheal assay measuring } \\
\text { particle clearance }\end{array}$ & $\begin{array}{l}\text { NCl, Report No. } \\
3,1977\end{array}$ \\
\hline Menthol & $\begin{array}{l}\text { Tobacco smoke of experimental cigarettes } \pm \\
\text { menthol }\end{array}$ & $\rightarrow$ & $\begin{array}{l}\text { Ciliostasis using human, rabbit or rat } \\
\text { respiratory epithelium in in vitro } \\
\text { experiments }\end{array}$ & $\begin{array}{l}\text { Rakieten et al., } \\
1952\end{array}$ \\
\hline
\end{tabular}


Table 6 (contd.)

\begin{tabular}{|c|c|c|c|}
\hline Ingredient(s) & Experimental design & Biological effect/biological assay & Reference(s) \\
\hline Menthol & $\begin{array}{l}\text { Mainstream smoke (MSS) of cigarettes } \pm \\
\text { synthetic } l \text {-menthol }[5000 \mathrm{ppm}(w / w)]\end{array}$ & $\begin{array}{l}\text { Toxicity in a 13-week nose-only smoke } \\
\text { inhalation study using Fischer } 344 \text { rats }\end{array}$ & $\begin{array}{l}\text { Gaworski et al., } \\
1997\end{array}$ \\
\hline Menthol & $\begin{array}{l}\text { Mainstream smoke CSC of different cigarettes } \\
\text { (Eclipse and an ultralight brand) }\end{array}$ & $\begin{array}{l}\text { In vitro toxicology test batterie } \\
\text { including sister chromatide exchanges } \\
\text { and neutral red cytotoxicity in } \mathrm{CHO} \\
\text { cells and the Ames assay }\end{array}$ & $\begin{array}{l}\text { Bombick et al., } \\
2001\end{array}$ \\
\hline Propylene glycol & MSS of cigarettes \pm 42000 ppm propylene glycol & $\begin{array}{l}\text { Respiratory tract changes in a } 13 \text {-week } \\
\text { nose-only smoke inhalation study in } \\
\text { Fischer } 344 \text { rats }\end{array}$ & $\begin{array}{l}\text { Gaworski et al., } \\
\text { 1999b (A) }\end{array}$ \\
\hline Sugar & Tobacco smoke of cigarettes $\pm 5.3 \%$ invert sugar & $\begin{array}{l}\rightarrow \quad \begin{array}{l}\text { Tumorigenicity in mouse skin painting } \\
\text { assay with female ICR Swiss mice }\end{array} \\
\text { cytotoxicity in a growth inhibition assay } \\
\text { using the human KB tumor cell line } \\
\text { ciliatoxicity using an in vitro and in vivo } \\
\rightarrow \quad \begin{array}{l}\text { chicken tracheal assay measuring } \\
\text { particle clearance }\end{array}\end{array}$ & $\begin{array}{l}\mathrm{NCl}, \text { Report No. } \\
3,1977\end{array}$ \\
\hline Sugar & $\begin{array}{l}\text { CSC of high and low-"tar" cigarettes + different } \\
\text { sugars (glucose, fructose, galactose, sorbitol, } \\
\text { sucrose, lactose in concentrations from } 0.2 \text { to } \\
1.18 \mathrm{~g} / \mathrm{cig} \text { ) vs. reference cigarettes without the } \\
\text { addition of sugar }\end{array}$ & $\begin{array}{l}\text { Mutagenicity in the Ames assay using } \\
\text { strains TA98 and TA } 100 \text { with } \\
\text { metabolic activation (no reduction } \\
\text { without metabolic activation); } \\
\text { the lowest mutagenicities were } 37 \% \\
\text { (high-"tar" cigarettes) and } 22 \% \text { (low- } \\
\text { "tar" cigarettes) in comparison to } \\
\text { control cigarettes without addition of } \\
\text { sugars }\end{array}$ & Sato et al., 1979 \\
\hline
\end{tabular}

${ }^{a}$ Carmines, 2002: stands on behalf of the following series of publications: Carmines, 2002; Römer et al., 2002; Rustemeier et al., 2002 and Vanscheeuwijck et al., 2002. 


\begin{tabular}{|c|c|c|c|c|}
\hline Ingredient(s) & Experimental design & Bio & logical effect/biological assay & Reference(s) \\
\hline \multirow[t]{2}{*}{$\begin{array}{l}3 \text { Ingredients: } \\
\text { titanyl chloride } \\
\text { sodium hydroxide } \\
\text { wood pulp } \\
\text { (M 39) }\end{array}$} & $\begin{array}{l}\text { CSC of experimental cigarettes } \pm 7 \% \text { titanyl } \\
\text { chloride, sodium hydroxide (for } \mathrm{pH} \text { adjust- } \\
\text { ment to } \mathrm{pH} 5.5 \text { ) and } 7.5 \% \text { wood pulp }\end{array}$ & $\rightarrow$ & $\begin{array}{l}\text { Tumorigenicity in skin painting assays using } \\
\text { female Swiss ICR mice } \\
\text { Cytotoxicity in a growth inhibition assay using } \\
\text { the human KB tumor cell line: no ranking } \\
\text { possible }\end{array}$ & $\begin{array}{l}\text { NCl, Report } \\
\text { No. 1, } 1976\end{array}$ \\
\hline & $\begin{array}{l}\text { Tobacco smoke of experimental cigarettes } \\
\pm 7 \% \text { titanyl chloride and sodium hydroxide } \\
\text { (for } \mathrm{pH} \text { adjustment to } \mathrm{pH} 5.5 \text { ) and } 7.5 \% \text { wood } \\
\text { pulp }\end{array}$ & & $\begin{array}{l}\text { Ciliatoxicity using an in vitro and in vivo } \\
\text { chicken tracheal assay measuring particle } \\
\text { clearance } \\
\text { Biological activity using an in vitro macropha- } \\
\text { ges inhibition assay }\end{array}$ & \\
\hline \multirow[t]{2}{*}{$\begin{array}{l}3 \text { Ingredients: } \\
\text { ethylhydroxyethyl } \\
\text { cellulose } \\
\text { methocel } \\
\text { sulfite pulp } \\
\text { (M 40) }\end{array}$} & $\begin{array}{l}\text { CSC of experimental cigarettes } \pm \text { a mixture of } \\
1.84 \% \text { ethylhydroxyethyl cellulose } \\
7.35 \% \text { methocel and } \\
4.59 \% \text { refined, unbleached sulfite pulp }\end{array}$ & $\rightarrow$ & $\begin{array}{l}\text { Tumorigenicity in skin painting assays using } \\
\text { female Swiss ICR mice } \\
\text { Cytotoxicity in a growth inhibition assay using } \\
\text { the human KB tumor cell line: no ranking } \\
\text { possible }\end{array}$ & $\begin{array}{l}\text { NCl, Report } \\
\text { No. 1, } 1976\end{array}$ \\
\hline & $\begin{array}{l}\text { Tobacco smoke of experimental cigarettes } \\
\pm \text { a mixture of } \\
1.84 \% \text { ethylhydroxyethyl cellulose } \\
7.35 \% \text { methocel and } \\
4.59 \% \text { refined, unbleached sulfite pulp }\end{array}$ & 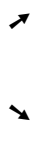 & $\begin{array}{l}\text { Ciliatoxicity using an in vitro and in vivo } \\
\text { chicken tracheal assay measuring particle } \\
\text { clearance } \\
\text { Biological activity using an in vitro macropha- } \\
\text { ges inhibition assay }\end{array}$ & \\
\hline \multirow[t]{2}{*}{$\begin{array}{l}2 \text { Ingredients: } \\
\text { magnesium nitrate } \\
\text { zinc oxide } \\
\text { (M 45) }\end{array}$} & $\begin{array}{l}\text { CSC of cigarettes } \pm 5.61 \% \text { magnesium } \\
\text { nitrate and } 6.96 \% \text { zinc oxide }\end{array}$ & & $\begin{array}{l}\text { Tumorigenicity in the mouse skin painting } \\
\text { assay with female ICR Swiss mice } \\
\text { Cytotoxicity in a growth inhibition assay using } \\
\text { the human KB tumor cell line }\end{array}$ & $\begin{array}{l}\text { NCl, Report } \\
\text { No. 3, } 1977\end{array}$ \\
\hline & $\begin{array}{l}\text { Tobacco smoke of cigarettes } \pm 5.61 \% \\
\text { magnesium nitrate and } 6.96 \% \text { zinc oxide }\end{array}$ & & $\begin{array}{l}\text { Ciliatoxicity using an in vitro and in vivo } \\
\text { chicken tracheal assay measuring particle } \\
\text { clearance }\end{array}$ & \\
\hline \multirow{2}{*}{$\begin{array}{l}4 \text { Ingredients: } \\
\text { cellulose ether gums } \\
\text { dialdehyde cross- } \\
\text { linker } \\
\text { galacto-mannan } \\
\text { gums } \\
\text { sulfite pulp } \\
\text { (M 46) }\end{array}$} & $\begin{array}{l}\text { CSC of experimental cigarettes } \pm \text { a mixture of } \\
0.52 \% \text { cellulose ether gums } \\
0.58 \% \text { dialdehyde crosslinker } \\
5.85 \% \text { galacto-mannan gums and } \\
6.05 \% \text { refined unbleached sulfite pulp }\end{array}$ & $\rightarrow$ & $\begin{array}{l}\text { Tumorigenicity in skin painting assays in fe- } \\
\text { male ICR Swiss mice } \\
\text { Cytotoxicity in a growth inhibition assay using } \\
\text { the human KB tumor cell line }\end{array}$ & $\begin{array}{l}\text { NCI, Report } \\
\text { No. } 4,1980\end{array}$ \\
\hline & $\begin{array}{l}\text { Tobacco smoke of experimental cigarettes } \\
\pm \text { a mixture of } \\
0.52 \% \text { cellulose ether gums } \\
0.58 \% \text { dialdehyde crosslinker } \\
5.85 \% \text { galacto-mannan gums and } \\
6.05 \% \text { refined unbleached sulfite pulp }\end{array}$ & $\rightarrow$ & $\begin{array}{l}\text { Ciliatoxicity using an in vitro and in vivo } \\
\text { chicken tracheal assay measuring particle } \\
\text { clearance }\end{array}$ & \\
\hline \multirow{2}{*}{$\begin{array}{l}6 \text { Ingredients in a } \\
\text { mixture: } \\
\text { cellulose ether gums } \\
\text { dialdehyde cross- } \\
\text { linker } \\
\text { galacto-mannan } \\
\text { gums } \\
\text { sulfite pulp } \\
\text { sodium hydroxide } \\
\text { citric acid } \\
\text { (M 47) }\end{array}$} & $\begin{array}{l}\text { CSC of experimental cigarettes } \pm \text { a mixture of } \\
0.52 \% \text { cellulose ether gums } \\
0.58 \% \text { dialdehyde crosslinker } \\
5.85 \% \text { galacto-mannan gums } \\
6.05 \% \text { refined, unbleached sulfite pulp } \\
3.2 \% \text { sodium hydroxide and } \\
2.8 \% \text { citric acid }\end{array}$ & $\rightarrow$ & $\begin{array}{l}\text { Tumorigenicity in skin painting assays using } \\
\text { female ICR Swiss mice } \\
\text { Cytotoxicity in a growth inhibition assay using } \\
\text { the human KB tumor cell line }\end{array}$ & $\begin{array}{l}\text { NCl, Report } \\
\text { No. } 4,1980\end{array}$ \\
\hline & $\begin{array}{l}\text { Tobacco smoke of experimental cigarettes } \\
\pm \text { a mixture of } \\
0.52 \% \text { cellulose ether gums } \\
0.58 \% \text { dialdehyde crosslinker } \\
5.85 \% \text { galacto-mannan gums } \\
6.05 \% \text { refined, unbleached sulfite pulp } \\
3.2 \% \text { sodium hydroxide and } \\
2.8 \% \text { citric acid }\end{array}$ & $\rightarrow$ & $\begin{array}{l}\text { Ciliatoxicity using an in vitro and in vivo } \\
\text { chicken tracheal assay measuring particle } \\
\text { clearance }\end{array}$ & \\
\hline $\begin{array}{l}\text { Chemosol } \\
\text { (M 65) }\end{array}$ & $\begin{array}{l}\text { CSC of cigarettes with and without } \\
\text { "Chemosol" (citric acid and deuterium oxide } \\
\text { in distilled water) }\end{array}$ & $\rightarrow$ & $\begin{array}{l}\text { Tumorigenicity in mouse skin painting } \\
\text { assays with Swiss ICR mice }\end{array}$ & $\begin{array}{l}\text { Gargus et al., } \\
1975\end{array}$ \\
\hline Aluminium oxide & $\begin{array}{l}\text { CSC of experimental cigarettes } \pm \text { aluminium } \\
\text { oxide }(4-5 \%)\end{array}$ & $x$ & $\begin{array}{l}\text { Tumorigenicity in mouse skin painting } \\
\text { assays using female Swiss ICR mice }\end{array}$ & $\begin{array}{l}\text { Wynder and } \\
\text { Hoffmann, } \\
1961\end{array}$ \\
\hline $\begin{array}{l}\text { Aluminium oxide } \\
\text { (activated) }\end{array}$ & $\begin{array}{l}\text { CSC of experimental cigarettes } \pm \text { aluminium } \\
\text { oxide (activated) }(4-5 \%)\end{array}$ & $y$ & $\begin{array}{l}\text { Tumorigenicity in mouse skin painting } \\
\text { assays using female Swiss ICR mice }\end{array}$ & $\begin{array}{l}\text { Wynder and } \\
\text { Hoffmann, } \\
1961\end{array}$ \\
\hline $\begin{array}{l}\text { Aluminium oxide } \\
\text { (aereted) }\end{array}$ & $\begin{array}{l}\text { CSC of experimental cigarettes } \pm \text { aluminium } \\
\text { oxide (aereted, } 4-5 \% \text { ) }\end{array}$ & $\pi$ & $\begin{array}{l}\text { Tumorigenicity in mouse skin painting } \\
\text { assays using female Swiss ICR mice }\end{array}$ & $\begin{array}{l}\text { Wynder and } \\
\text { Hoffmann, } \\
1961\end{array}$ \\
\hline $\begin{array}{l}\text { Aluminium oxide } \\
\text { trihydrate }\end{array}$ & $\begin{array}{l}\text { CSC of experimental cigarettes } \pm \text { aluminium } \\
\text { oxide trihydrate }(4-5 \%)\end{array}$ & & $\begin{array}{l}\text { Tumorigenicity in mouse skin painting } \\
\text { assays using female Swiss ICR mice }\end{array}$ & $\begin{array}{l}\text { Wynder and } \\
\text { Hoffmann, } \\
1961\end{array}$ \\
\hline
\end{tabular}




\begin{tabular}{|c|c|c|c|c|}
\hline \multirow{2}{*}{$\begin{array}{l}\text { Ingredient(s) } \\
\begin{array}{c}\text { Aluminium oxide } \\
\text { trihydrate }\end{array}\end{array}$} & \multirow{2}{*}{$\begin{array}{l}\text { Experimental design } \\
\text { CSC of experimental cigarettes } \pm \text { aluminium } \\
\text { trihydrate } \times 3 \mathrm{H}_{2} \mathrm{O}\end{array}$} & \multicolumn{2}{|c|}{ Biological effect/biological assay } & \multirow{2}{*}{$\begin{array}{l}\text { Reference(s) } \\
\text { Hoffmann and } \\
\text { Wynder, } 1968\end{array}$} \\
\hline & & $\nearrow$ & $\begin{array}{l}\text { Tumorigenicity in mouse skin painting } \\
\text { assays }\end{array}$ & \\
\hline Aluminium silicate & $\begin{array}{l}\text { CSC of experimental cigarettes } \pm \text { aluminium } \\
\text { silicate ( } 1 \text { and } 4 \% \text { ) }\end{array}$ & $y$ & $\begin{array}{l}\text { Tumorigenicity in mouse skin painting } \\
\text { assays using female Swiss ICR mice }\end{array}$ & $\begin{array}{l}\text { Wynder and } \\
\text { Hoffmann, } \\
1961\end{array}$ \\
\hline Ammonium sulfamate & $\begin{array}{l}\text { CSC of cigarettes with ammonium sulfamate } \\
(5,6 \text { and } 7.5 \mathrm{mg} / \mathrm{cig}) \text { treated paper in compa- } \\
\text { rison to untreated control cigarettes }\end{array}$ & $\rightarrow$ & $\begin{array}{l}\text { No statistically significant differences in } \\
\text { final tumor incidence, but significantly } \\
\text { lower tumor incidence during earlier test } \\
\text { periods in mouse skin painting assays with } \\
\text { female ICR Swiss mice was caused by the } \\
\text { addition of ammonium sulfamate }\end{array}$ & $\begin{array}{l}\text { Bock et al., } \\
1974\end{array}$ \\
\hline Boric acid & $\begin{array}{l}\text { CSC of experimental cigarettes } \pm \text { boric acid } \\
(4-5 \%)\end{array}$ & $y$ & $\begin{array}{l}\text { Tumorigenicity in mouse skin painting } \\
\text { assays using female Swiss ICR mice }\end{array}$ & $\begin{array}{l}\text { Wynder and } \\
\text { Hoffmann, } \\
1961\end{array}$ \\
\hline Calcium carbonate & $\begin{array}{l}\text { CSC of experimental cigarettes } \pm \text { calcium } \\
\text { carbonate }(4-5 \%)\end{array}$ & $x$ & $\begin{array}{l}\text { Tumorigenicity in mouse skin painting } \\
\text { assays using female Swiss ICR mice }\end{array}$ & $\begin{array}{l}\text { Wynder and } \\
\text { Hoffmann, } \\
1961\end{array}$ \\
\hline Cobalt (III) oxide & $\begin{array}{l}\text { CSC of experimental cigarettes } \pm \text { cobalt (III) } \\
\text { oxide }(4-5 \%)\end{array}$ & $\rightarrow$ & $\begin{array}{l}\text { Tumorigenicity in mouse skin painting } \\
\text { assays using female Swiss ICR mice }\end{array}$ & $\begin{array}{l}\text { Wynder and } \\
\text { Hoffmann, } \\
1961\end{array}$ \\
\hline Copper nitrate & $\begin{array}{l}\text { CSC of experimental cigarettes } \pm 5 \% \text { copper } \\
\text { nitrate }\end{array}$ & $y$ & $\begin{array}{l}\text { Tumorigenicity in mouse skin painting } \\
\text { assays }\end{array}$ & $\begin{array}{l}\text { Hoffmann and } \\
\text { Wynder, } 1968\end{array}$ \\
\hline Copper nitrate & $\begin{array}{l}\text { CSC of experimental cigarettes } \pm \text { copper (II) } \\
\text { nitrate }(4-5 \%)\end{array}$ & $x$ & $\begin{array}{l}\text { Tumorigenicity in mouse skin painting } \\
\text { assays using female Swiss ICR mice }\end{array}$ & $\begin{array}{l}\text { Wynder and } \\
\text { Hoffmann, } \\
1961\end{array}$ \\
\hline Copper nitrate & $\begin{array}{l}\text { CSC of experimental cigarettes } \pm 5 \% \text { copper } \\
\text { nitrate }\end{array}$ & $y$ & $\begin{array}{l}\text { Tumor multiplicity in mouse skin painting } \\
\text { assays using HA/ICR/Mil (Swiss Albino) } \\
\text { female mice }\end{array}$ & $\begin{array}{l}\text { Wynder and } \\
\text { Hoffmann, } \\
1969\end{array}$ \\
\hline Diethylamine citrate & $\begin{array}{l}\text { Tobacco smoke of experimental cigarettes } \\
\pm 3.12 \% \text { diethylamine citrate }\end{array}$ & $\rightarrow$ & $\begin{array}{l}\text { Ciliostasis in the trachea of cats exposed } \\
\text { in vivo to the smoke of treated cigarettes }\end{array}$ & $\begin{array}{l}\text { Dalhamn and } \\
\text { Rylander, } \\
1971\end{array}$ \\
\hline Magnesium nitrate & $\begin{array}{l}\text { CSC of experimental cigarettes } \pm 10 \% \\
\text { magnesium nitrate }\end{array}$ & $\rightarrow$ & $\begin{array}{l}\text { Mutagenicity in Ames test strains TA } 1538 \\
\text { liver and lung S9 mix and TA } 1535 \pm \text { liver } \\
\text { S9 mix; } \\
\text { no activity could be measured using the fra- } \\
\text { meshift mutant strains TA } 1536 \text { and TA } 1537\end{array}$ & $\begin{array}{l}\text { Kier et al., } \\
1974\end{array}$ \\
\hline \multirow[t]{2}{*}{ Magnesium nitrate } & $\begin{array}{l}\text { CSC of cigarettes } \pm 5.72 \% \text { magnesium } \\
\text { nitrate }\end{array}$ & 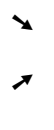 & $\begin{array}{l}\text { Tumorigenicity in the mouse skin painting } \\
\text { assay with female ICR Swiss mice } \\
\text { Cytotoxicity in a growth inhibition assay } \\
\text { using the human KB tumor cell line }\end{array}$ & $\begin{array}{l}\mathrm{NCl}, \text { Report } \\
\text { No.3, } 1977\end{array}$ \\
\hline & $\begin{array}{l}\text { Tobacco smoke of cigarettes } \pm 5.72 \% \\
\text { magnesium nitrate }\end{array}$ & $\rightarrow$ & $\begin{array}{l}\text { Ciliatoxicity using an in vitro and in vivo } \\
\text { chicken tracheal assay measuring particle } \\
\text { clearance }\end{array}$ & \\
\hline Magnesium oxide & $\begin{array}{l}\text { CSC of experimental cigarettes } \pm \\
\text { magnesium oxide }(4-5 \%)\end{array}$ & $x$ & $\begin{array}{l}\text { Tumorigenicity in mouse skin painting } \\
\text { assays using female Swiss ICR mice }\end{array}$ & $\begin{array}{l}\text { Wynder and } \\
\text { Hoffmann, } \\
1961\end{array}$ \\
\hline Methyl caprate & CSC of cigarettes \pm 480 ppm methyl caprate & $\rightarrow$ & $\begin{array}{l}\text { Tumorigenicity in the mouse skin painting } \\
\text { assay }\end{array}$ & Tso, $1975(P)$ \\
\hline Nickel acetate & $\begin{array}{l}\text { CSC of experimental cigarettes } \pm \text { nickel } \\
\text { acetate }\end{array}$ & $y$ & $\begin{array}{l}\text { Tumorigenicity in mouse skin painting } \\
\text { assays using female Swiss ICR mice }\end{array}$ & $\begin{array}{l}\text { Hoffmann and } \\
\text { Wynder, } 1968\end{array}$ \\
\hline Nitrate & $\begin{array}{l}\text { CSC of experimental cigarettes } \pm \text { nitrate } \\
\text { (total nitrate content from } 0.22-0.59 \% \text { ) }\end{array}$ & 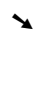 & $\begin{array}{l}\text { Tumorigenicity in mouse skin painting } \\
\text { assays when the amount of total nitrate is } \\
\text { greater than about } 0.4 \%\end{array}$ & $\begin{array}{l}\text { Collins et al., } \\
1981\end{array}$ \\
\hline Nitrate & $\begin{array}{l}\text { CSC of experimental cigarettes containing } \\
1.8 \% \text { nitrate vs. untreated reference } \\
\text { cigarettes (nitrate was adjusted to } 1.8 \% \text { in } \\
\text { experimental cigarettes) }\end{array}$ & $y$ & $\begin{array}{l}\text { Tumorigenicity in mouse skin painting } \\
\text { assays using female CFLP mice (genetically } \\
\text { identical with ICI mice) for about } 5-10 \% \\
\text { (application of } 33 \text { and } 66 \text { mg condensate } \\
\text { per painting) }\end{array}$ & $\begin{array}{l}\text { Dontenwill } \\
\text { et al., } 1976\end{array}$ \\
\hline Oxolamine citrate & $\begin{array}{l}\text { Tobacco smoke of experimental cigarettes } \\
\pm 5 \% \text { oxolamine citrate }\end{array}$ & $y$ & $\begin{array}{l}\text { Ciliostasis in the trachea of cats exposed } \\
\text { in vivo to the smoke of treated cigarettes }\end{array}$ & $\begin{array}{l}\text { Dalhamn, } \\
1969\end{array}$ \\
\hline Palladium & $\begin{array}{l}\text { CSC of experimental cigarettes } \pm \text { palladium } \\
\text { (total palladium content from } 0-580 \mathrm{ppm} \text { ) }\end{array}$ & $y$ & $\begin{array}{l}\text { Tumorigenicity in mouse skin painting } \\
\text { assays when the amount of non-extractable } \\
\text { palladium is greater than about } 100 \text { ppm }\end{array}$ & $\begin{array}{l}\text { Collins et al., } \\
1981\end{array}$ \\
\hline $\begin{array}{l}\text { Phenylmethyl-oxadia- } \\
\text { zole (PMO) }\end{array}$ & $\begin{array}{l}\text { Tobacco smoke of experimental cigarettes } \\
\pm 0.5-10 \% \text { phenylmethyloxadiazole }\end{array}$ & $x$ & $\begin{array}{l}\text { Ciliostasis in the trachea of cats exposed } \\
\text { in vivo to the smoke of cigarettes } \\
\text { containing } 2 \% \text { PMO }\end{array}$ & $\begin{array}{l}\text { Dalhamn and } \\
\text { Rylander, } \\
1971\end{array}$ \\
\hline
\end{tabular}




\begin{tabular}{|c|c|}
\hline Ingredient(s) & Experimental design \\
\hline $\begin{array}{l}\text { Phenylmethyl-oxadia- } \\
\text { zole (PMO) }\end{array}$ & $\begin{array}{l}\text { Tobacco smoke of experimental cigarettes } \\
\pm 2 \% \text { phenylmethyloxadiazole }\end{array}$ \\
\hline $\begin{array}{l}\text { Phenylmethyl-oxadia- } \\
\text { zole (PMO) }\end{array}$ & $\begin{array}{l}\text { Tobacco smoke of experimental cigarettes } \\
\pm 2 \% \text { phenylmethyloxadiazole }\end{array}$ \\
\hline $\begin{array}{l}\text { Phenylmethyl-oxadia- } \\
\text { zole (PMO) }\end{array}$ & $\begin{array}{l}\text { Tobacco smoke of experimental cigarettes } \\
\pm 2 \% \text { phenylmethyloxadiazole }\end{array}$ \\
\hline $\begin{array}{l}\text { Phenylmethyl-oxadia- } \\
\text { zole (PMO) }\end{array}$ & $\begin{array}{l}\text { Tobacco smoke of experimental cigarettes } \\
\pm 2 \% \text { phenylmethyloxadiazole }\end{array}$ \\
\hline
\end{tabular}

Phenylvinyloxadiazole Tobacco smoke of experimental cigarettes $\pm 2.02 \%$ phenylvinyloxadiazole

Potassium nitrate

Potassium nitrate

Potassium nitrate potassium nitrate in comparison to cigarettes

Potassium nitrate

Sodium nitrate

Sodium nitrate
CSC of reconstituted tobacco $(\mathrm{RT}) \pm 5 \%$ po tassium nitrate in comparison to normal tobacco

CSC of reconstituted tobacco (RT) \pm made from original tobacco

CSC of experimental cigarettes containing $2.2 \%$ nitrate (partially added as potassium nitrate) in comparison to control cigarettes with $1.1 \%$ nitrate

Tobacco smoke of experimental cigarettes containing $2.2 \%$ nitrate (partially added as potassium nitrate) in comparison to control cigarettes with $1.1 \%$ nitrate

CSC of experimental cigarettes $\pm 3 \%$ potassium nitrate ${ }_{3}$

CSC of experimental cigarettes soaked in $10^{-2} \mathrm{M}$ sodium nitrate was prepared smoking the cigarettes in the presence of vapors of $\mathrm{HNO}_{3}$ or acetic acid to enable the development of nitroarenes

CSC of experimental cigarettes $\pm 8.3 \%$ sodium nitrate

\section{Biological effect/biological assay}

Reference(s)

\ Inhibition of pulmonary particle clearance (mucus transport and phagocytic activity of the lung) using guinea pigs exposed to smoke and to a mixed aerosol of killed radioactive and viable Escherichia coli bacteria (complete protection)

\ Inhibition of pulmonary clearance in guinea pigs exposed to smoke and to a mixed aerosol of killed radioactive and viable Escherichia coli bacteria (complete protection)

\ Increase in macrophages in long-term exposures in guinea pigs (complete protection)

\ Irritation in respiratory epithelium of guinea pigs (partial protection)

$\rightarrow$ Decrease in weight gain in Sprague-Dawley rats exposed to tobacco smoke (no protection)

y Increase in goblet cell count in the trachea of exposed Sprague-Dawley rats (complete protection)

y Increase in epithelial thickness and cell number in the trachea of exposed Sprague-Dawley rats (partial protection)

\ Increasing number of cells in mitosis in the trachea, bronchial pathways, alveoli and oesophagus of Sprague-Dawley rats exposed to tobacco smoke (partial protection)

\ Increase in goblet cell number in the tracheal Jones et al., epithelium of exposed Sprague-Dawley rats 1973

$\rightarrow \quad$ Shift from neutral to acid glycoproteins within goblet cells and increase in secretory mass within goblet cells in exposed Sprague-Dawley rats

$\quad$ Increase in cell size in the tracheal gland and increase in the thickness of the gland in exposed Sprague-Dawley rats

\ Ciliostasis in the trachea of cats exposed in vivo to the smoke of treated cigarettes

Dalhamn and Rylander 1971

$\rightarrow$ Tumorigenicity in skin painting assays using female Swiss ICR mice

$\rightarrow$ Cytotoxicity in a growth inhibition assay using the human KB tumor cell line: no ranking possible

> Ciliatoxicity using an in vitro chicken tracheal assay measuring particle clearance

$\rightarrow \quad$ Ciliatoxicity using an in vivo chicken tracheal assay measuring particle clearance

$\quad$ Biological activity using an in vitro macrophages inhibition assay

$\rightarrow$ Only slight differences in tumor promotion in Halter and Ito, mouse skin painting assays were found com- 1972 paring RT with and without potassium nitrate; RT ( \pm potassium nitrate) led to a significant reduction of the tumorigenicity $(39 \%$ of the biological activity of natural tobacco)

\ CSC of RT caused a decrease in tumorigeni- Hoffmann and city for more than $50 \%$ and addition of $5 \%$ $\mathrm{KNO}_{3}$ to RT caused a slight reduction of tumorigenicity in mouse skin painting assays using female Swiss ICR mice

v Toxicity and tumorigenicity in mouse skin painting assays with female Swiss ICR mice

Wynder, 1972

$\mathrm{NCl}$, Report

No.1, 1976

Direct acting mutagenicity in the Ames test strains TA 98, TA 98NR and TA 98/1,8-DNP 6 Ros were used) which was reduced by about 70\% 1982 using a strain deficient in the "classical" nitroreductase (TA 98NR)

> Toxicity and tumorigenicity in mouse skin painting assays with female Swiss ICR mice
Hoffmann and Wynder, 1968

McCoy and

Rosenkranz,

Hoffmann and Wynder, 1968 
Table 7 (contd.)

\begin{tabular}{|c|c|c|c|}
\hline Ingredient(s) & Experimental design & Biological effect/biological assay & Reference(s) \\
\hline Sodium nitrate & $\begin{array}{l}\text { CSC of experimental cigarettes }+8 \% \\
\text { sodium nitrate vs. untreated reference } \\
\text { cigarettes }\end{array}$ & $\begin{array}{l}\text { Laryngeal tumorigenicity in long-term inhala- } \\
\text { tion studies using Syrian Golden hamsters; } \\
\text { leucoplakia was reduced for about } 50 \% \text { and } \\
\text { early invasive carcinomas were reduced for } \\
\text { about } 75 \%\end{array}$ & $\begin{array}{l}\text { Dontenwill, } \\
1974\end{array}$ \\
\hline Sodium nitrate & $\begin{array}{l}\text { CSC of experimental cigarettes with different } \\
\text { tobacco mixtures } \pm 8.3 \% \text { sodium nitrate }\end{array}$ & $\begin{array}{l}\text { Toxicity and tumorigenicity in mouse skin } \\
\text { painting assays with female } \mathrm{Ha} / \mathrm{ICR} / \mathrm{Mil} \\
\text { (Swiss Albino) mice }\end{array}$ & $\begin{array}{l}\text { Hoffmann and } \\
\text { Wynder, } 1967\end{array}$ \\
\hline Sodium nitrate & $\begin{array}{l}\text { CSC of experimental cigarettes } \pm 8.3 \% \\
\text { sodium nitrate }\end{array}$ & $\begin{array}{l}\text { Tumor multiplicity in mouse skin painting } \\
\text { assays using HA/ICR/Mil (Swiss Albino) } \\
\text { female mice }\end{array}$ & $\begin{array}{l}\text { Wynder and } \\
\text { Hoffmann, } \\
1969\end{array}$ \\
\hline Sodium nitrate & $\begin{array}{l}\text { CSC of experimental cigarettes with different } \\
\text { tobacco mixtures } \pm 8 \% \text { sodium nitrate }\end{array}$ & $\begin{array}{l}\text { Tumorigenicity in mouse skin painting assay } \\
\text { with female ICI mice }\end{array}$ & $\begin{array}{l}\text { Dontenwill } \\
\text { et al., } 1972\end{array}$ \\
\hline \multirow[t]{2}{*}{ Zinc oxide } & CSC of cigarettes $\pm 7.09 \%$ zinc oxide & $\begin{array}{l}\rightarrow \quad \text { Tumorigenicity the mouse skin painting assay } \\
\text { with female ICR Swiss mice } \\
\text { Cytotoxicity in a growth inhibition assay using } \\
\text { the human KB tumor cell line }\end{array}$ & $\begin{array}{l}\mathrm{NCl}, \text { Report } \\
\text { No.3, } 1977\end{array}$ \\
\hline & $\begin{array}{l}\text { Tobacco smoke of cigarettes } \pm 7.09 \% \text { zinc } \\
\text { oxide }\end{array}$ & $\begin{array}{l}\text { Ciliatoxicity using an in vitro and in vivo } \\
\text { chicken tracheal assay measuring particle } \\
\text { clearance }\end{array}$ & \\
\hline
\end{tabular}

